\title{
CONNECTING POLICY AND PRACTICE
}

This volume brings together a selection of papers presented at an international conference on issues related to teachers and teaching and how they understand and act on matters of theory and practice. Topics are of interest to novice and veteran teachers as well as those involved in policy making, curriculum development and teachers' professional development.

The book contains five sections which address, amongst others, the following themes:

1. Teacher education - professional identity, professional research, and quality of teacher education.

2. Teacher practice - basic values, tacitly implies ethics and cultural scaffolding.

3. Higher education - academic motivation, discourse dissonance concerning intellectual property, self-studies of teacher education practice.

4. Teacher development - the challenge to be the best teacher, the link between policy and practice, personal theory and practice in tertiary development.

5. Research and theory - reflective practice, shared democratic values, teachers and researchers.

This volume derives from the work of experienced researchers, most of whom are themselves practising teachers. It is international in scope and context, demonstrating differences and similarities between and within countries. Educational practitioners and policy makers will benefit from reading this thought-provoking book.

Pam M. Denicolo is Director of the Graduate School for Social Sciences at the University of Reading, UK. Michael Kompf is Professor in the Faculty of Education at Brock University, Canada. 



\title{
Connecting Policy and Practice:
}

\section{Challenges for Teaching and Learning}

\section{in Schools and Universities}

\author{
EDITED BY
}

Pam M. Denicolo

and

Michael Kompf 
First published 2005 by Routledge

Published 2017 by Routledge

2 Park Square, Milton Park, Abingdon, Oxon OX14 4RN

711 Third Avenue, New York, NY 10017, USA

Routledge is an imprint of the Taylor \& Francis Group, an informa business

Copyright $\odot 2005$ Pam M. Denicolo and Michael Kompf for selection and editorial material. Individual chapters $\mathbb{C}$ the contributors

Typeset in Times by

HWA Text and Data Management, Tunbridge Wells

The Open Access version of this book, available at www.tandfebooks. com, has been made available under a Creative Commons AttributionNon Commercial-No Derivatives 4.0 license.

British Library Cataloguing in Publication Data

A catalogue record for this book is available from the British Library

Library of Congress Cataloging in Publication Data

A catalog record for this book has been requested

ISBN 978-0-415-36224-5 (hbk) 
This book is dedicated to the members of ISATT - the International Study Association on Teachers and Teaching. For more than two decades the ISATT community has willingly travelled around Europe and the UK, to Canada, and soon to Australia (July, 2005). To new members of ISATT: the works expressed in this volume are markers of thought - use them, as you will, and share with us how you craft your own.

We also dedicate this volume to Sigrun Gudmundsdottir, a long-time ISATT member and valued colleague who passed away during the time ISATT was meeting in Leiden, The Netherlands, in July 2003. We dedicate this volume to her memory and the excellence she demonstrated and fostered in students and colleagues. 



\section{Contents}

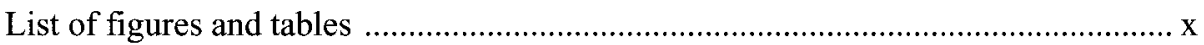



Acknowledgements ....................................................................................... xii

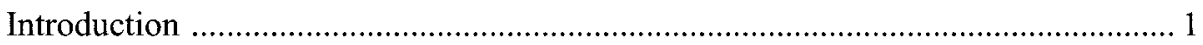

Section A Teacher Education ........................................................................... 3

Chapter 1 Teacher Education and the Development of Professional Identity:

Learning to be a Teacher

Judyth Sachs

Chapter 2 Teacher Learning and the Theory of Variation

Silwa Claesson

Chapter 3 Areas of Professional Research: A Proposal for Organising the Content of Teacher Education Ana Rivero Garcia and Rafael Porlán Ariza

Chapter 4 How to Affect the Quality of Teacher Education: A Four-Year Policy-Driven Project Implemented at University Level

Beatrice Avalos

Chapter 5 Learning from the Conversation of New Teachers Frances $O^{\prime}$ Connell Rust.....

Section B Teacher Practice

Chapter 6 Inside Teacher Community: Representations of Classroom Practice Judith Warren Little

Chapter 7 The Contemporary Basic Values of School: “The Emperor's new Clothes"? Kennert Orlenius

Chapter 8 Exploring the Landscape of Teachers' Tacitly Implied Ethics: An Aristotelian Uncovering

Jukka Husu

Chapter 9 Cultural Scaffolding: The Arts and Crafts Teacher's Mediation with Her Students with Behavioural Problems

Tove Pettersson, May Britt Postholm, Annlaug Flem, Sigrun Gudmundsdottir and "Tina"

Chapter 10 What is Actually Happening in Secondary Classrooms? The Rhetoric and Reality of Curricular Reform Barbara Šteh and Barica Marentič Požarnik 
Chapter 11 Students' Voices at a Portuguese University: Academic Motivation and its Relationship with Academic Success

Fernando Ribeiro Gonçalves, Sandra Valadas, Luis Faísca and Carla Vilhena.

Chapter 12 Discourse Dissonance in University Policy Concerning Intellectual Property Andrew Short

Chapter 13 When Angels Dance With Devils: What is Sacred and Profane in the University?

Michael Kompf

Chapter 14 Listening to Students' Voices: Self Study of Teacher Education Practice

Ruth G. Kane

Chapter 15 Doctoral Degree Assessment Criteria: Towards Transparency through Exploring Teacher Thinking

Pam M. Denicolo

Section D Teacher Development

Chapter 16 The Challenge to be the Best: Research and the Teacher

Christopher Day

Chapter 17 Tertiary Teacher Development: Connecting Policy, Personal

Theory and Practice

Neil Haigh

Chapter 18 Collaboration in Cross-National Networks for Teacher

Professional Development

Manfred Lang, Bernadette Charlier, Murray Saunders, Joël Bonamy, Thérèse Laferrière and Alain Breuleux

Chapter 19 Dilemmas of Democratic Education

Frank M. Flanagan.

Chapter 20 When the Best Maps Cannot Guide Us: Exploring and

Understanding Teacher Vulnerability

Susan Lasky 
Section $E$ The Theory and Practice of Educational Research

Chapter 21 Teacher and Student Identities as Situated Cognitions Anneli Lauriala and Maria Kukkonen

Chapter 22 On a Pedagogy of Research Problems

Heinze Oost

Chapter 23 Shared Fundamental Democratic Values by Means of Education?

A Deweyan Perspective on Some Democratic Illusions and

Necessities

Niclas Rönnström

Chapter 24 Confronting the Person in Biographical Interviews

Raija Erkkilä and Maarit Mäkelä

Chapter 25 Teachers Becoming Researchers: Reflections on Professional

Development

Helen E. Hayes

References

Index 266 


\section{Figures}

Figure 3.1 The role of the areas of professional research in articulating practical professional knowledge ............................................ 34

Figure 3.2 The progession of the development of professional knowledge ............ 35

Figure 6.1 The optimistic premise of professional community ............................ 51

Figure 6.2 Teachers' written accounts of goals for student feedback ................... 59

Figure 7.1 Different educational-philosophical points of view .......................... 81

Figure 10.1 Profile of mean ratings of various classroom activities by the students and the teachers ............................................................. 102

Figure 11.1 Responses for each academic year ............................................. 113

Figure 11.2 Percentage of students choosing possible different meanings of academic failure ............................................................................ 114

Figure 11.3 Multidimensional scaling for co-occurence of meaning attribution to academic failure .................................................................. 114

Figure 11.4 Response profiles for each academic year ....................................... 115

Figure 11.5 Evaluation of academic performance for each academic year ............. 116

Figure 11.6 Explanation of a weak or very weak academic performance ...............116

Figure 11.7 Multidimensional scale for preferences among the explanations ......... 117

Figure 11.8 Response profiles for 1st versus 5th academic year .......................... 117

Figure 16.1 A conceptual map of factors affecting teacher effectiveness ................ 165

Figure 16.2 Relationship between diffuser and user ......................................... 168

Figure 18.1 A system for cross-national collaborative networks with three units ... 183

Figure 21.1 The dimensions and dynamics of self-conception formation of teachers and students ........................................................... 201

Figure 22.1 Structure model of the central research problem ............................. 211

\section{Tables}

Table 4.1 Curriculum ............................................................................ 41

Table 4.2 Teaching and learning strategies ................................................. 42

Table 4.3 Learning to teach - the practicum experiences ................................ 42

Table 4.4 Quality control processes ........................................................... 43

Table 11.1 Distribution of the participants according to academic year ............... 111

Table 11.2 Pertinence evaluation for each symptom: descriptive statistics for the global sample ...................................................................... 113

Table 11.3 Distribution of students according to the estimated level of academic performance ............................................................... 115

Table 18.1 Answers by teachers on co-operation and use of computers and the Internet 


\section{Contributors}

Beatrice Avalos, Ministry of Education, Chile.

Joël Bonamy, Centre national de la recherche scientifique, Ecully, France.

Alain Breuleux, Department of Educational and Counselling Psychology, McGill University, Montreal, Canada.

Bernadette Charlier, Namur University, Namur, Belgium.

Silwa Claesson, Department of Education, Göteburg University, Göteburg, Sweden.

Christopher Day, School of Education, University of Nottingham, Nottingham, United Kingdom.

Pam M. Denicolo, School of Pharmacy, University of Reading, Reading, United Kingdom.

Raija Erkkilä, Department of Educational Science and Teacher Education, University of Oulu, Oulu, Finland.

Luís Faísca, Permanent Observatory for Teaching and Learning Quality, University of Algarve, Faro, Portugal.

Frank M. Flanagan, Department of Education, University of Limerick, Limerick, Ireland.

Annlaug Flem, Department of Education, Norwegian University of Science and Technology, Trondheim, Norway.

Sigrun Gudmundsdottir, Department of Education, Norwegian University of Science and Technology, Trondheim, Norway.

Neil Haigh, Teaching and Learning Development Unit, Waikato University, Hamilton, New Zealand.

Helen E. Hayes, School of Education, University of Ballarat, Ballarat, Victoria, Australia.

Jukka Husu, Department of Applied Sciences of Education, University of Helsinki, Helsinki, Finland.

Ruth G. Kane, Department of Technology, Science and Mathematics Education, Massey University, Palmerston North, New Zealand.

Michael Kompf, Faculty of Education, Brock University, St Catharines, Ontario, Canada.

Thérèse Laferrière, Département d'études sur l'enseignement et l'apprentissage, Laval University, Quebec, Canada.

Manfred Lang, Institut für Pädagogik der Naturwissenschaften, Kiel, Germany.

Susan Lasky, Centre for Social Organization of Schools, Johns Hopkins University, Baltimore, MD, USA.

Anneli Lauriala, Department of Educational Sciences and Teacher Education, University of Oulu, Oulu, Finland. 
Maarit Mäkelä, Department of Educational Science and Teacher Education, University of Oulu, Oulu, Finland.

Barica Marentið̌ Požarnik, Department of Education, University of Ljubljana, Lubljana, Slovenia.

Frances O'Connell Rust, Department of Teaching and Learning, Steinhardt School of Education, New York University, New York, USA.

Heinze Oost, IVLOS, University of Utrecht, Utrecht, The Netherlands.

Kennert Orlenius, School of Humanities and Informatics, University of Skövde, Skövde, Sweden.

Tove Pettersson, Department of Education, Norwegian University of Science and Technology, Trondheim, Norway.

Rafael Porlán Ariza, Department of Didáctica de las Ciencias, University of Seville, Seville, Spain.

May Britt Postholm, Department of Education, Norwegian University of Science and Technology, Trondheim, Norway.

Fernando Ribeiro Gonçalves, Centre for Educational Research, University of Algarve, Faro, Portugal.

Ana Rivero García, Department of Didáctica de las Ciencias, University of Seville, Seville, Spain.

Niclas Rönnström, Institute of Education, University of Stockholm, Sweden.

Judyth Sachs, Faculty of Education and Social Work, The University of Sydney, Sydney, Australia.

Murray Saunders, Deparment of Educational Research, Lancaster University, Lancaster, United Kingdom.

Andrew Short, Faculty of Education, Brock University, St Catharines, Ontario, Canada.

Barbara Šteh, Department of Education, University of Ljubljana, Ljubljana, Slovenia.

"Tina", teacher participating in the research, Norway.

Sandra Valadas, Permanent Observatory for Teaching and Learning Quality, University of Algarve, Faro, Portugal.

Carla Vilhena, Permanent Observatory for Teaching and Learning Quality, University of Algarve, Faro, Portugal.

Judith Warren Little, Graduate School of Education, University of California, Berkeley, CA, USA. 


\section{Acknowledgements}

This volume would not have been possible without the good will, cooperation and patience of the contributors - we thank you. Acknowledgement and thanks are owed to Daniela Brewis for coordinating the flow of paper, to Lesa Mansfield and Marie Harris for manuscript preparation, to Ken Kehl for preparation of the index, and special thanks are owed to Rahul Kumar for his exceptional service in preparation of all of the figures and tables. We acknowledge Teachers College Press for allowing us to include Judith Warren Little's paper without charge.

To our families near and far the forgiven debts of time and attention are appreciated. To the students whose travel to ISATT meetings will be assisted through all proceeds of this volume - welcome.

Pam M. Denicolo PhD

University of Reading, UK
Michael Kompf PhD Brock University, Canada

June 2004 



\section{Introduction}

ISATT (first known as the International Study Association on Teacher Thinking) began in Tilburg, The Netherlands in October 1983 and was initiated by Rob Halkes, John Olson, Alan Brown, Christopher Clark, Erik De Corte and William Reid. In 1985 ISATT met again, this time with representatives from 12 countries. Since that time ISATT has become the International Study Association on Teachers and Teaching. ISATT is: responsible for the journal Teachers and Teaching; Theory and Practice published by Carfax; the producer of some 13 volumes of academic writing, research and theory; and mentor to several generations of scholars.

The 9th biennial meeting of ISATT "Connecting Policy and Practice: challenges for teaching and learning in schools and universities" took place at the University of the Algarve in Faro, Portugal. Professor Fernando Ribero Gonçalves, Sandra Valadas, Carla Vilhena and Helen Quintas graciously and effectively hosted this meeting. A companion CD-ROM of the full texts of papers was produced with the assistance of the Faculty of Human and Social Sciences, The University of Algarve, Permanent Observatory for Teaching and Learning Quality, ISATT, Fundação para a Ciênca e Tecnologia, Instituto de Inovação Educacional and Câmara Municipal de Faro (Portugal). This CD-ROM was produced in a limited quantity and was not widely available. Interest in the work and activities of ISATT, specifically the papers presented in Portugal, has led to the publication of this volume.

The conference in Faro was memorable for the spirit of Portugal that prevailed and the marvels of a historic and beautiful country unfolded more every day. Excellent surroundings were provided at or near the university and much-appreciated time for personal interaction was included in the program. The relaxed atmosphere and casual manner of the conference showed a different face of ISATT that was by chance most welcome and necessary.

While ISATT is an apolitical body comprised of voices from all over the world, all of us shared the impact of the 9/11/2001 tragedy that marked the world only a few days before our gathering began. For many colleagues travel was difficult, long, and nerve-wracking; for some travel was impossible. Carrying out meaningful scholarly interactions in the aftermath of such a crisis, while thought unlikely by many, turned out to be a tonic for world-weary souls in a safe haven of hospitality and caring.

The ISATT meeting in Faro signalled a turning point that forced many nations and individuals to come of age and acknowledge the advantages, and perhaps naiveté, that had previously characterized life in a rapidly changing world. Absent colleagues were acknowledged, as was the pain that touched many who lost loved ones. As seems to only occur at ISATT, the collegial spirit of support, challenge, and critical observation, transformed subtly with more warm embraces, deeper care and concern, and passionate wishes expressed for peacefulness and understanding of the concerns that bring drastic actions to the world stage. In spite of the clouds of uncertainty, participants at this meeting filled all available space in the schedule with an interesting and insightful array of papers and discussions.

Included are papers presented by keynote speakers Judith Warren Little, Judyth Sachs and Christopher Day (the inaugural Michael Huberman Lecture). Further selections were made with the criteria of representing the global spread of interesting and important ideas and writing that has characterized the work of ISATT throughout 
its existence. This volume is divided into five sections that reflect the diversity of interests presented under the conference theme "Connecting Policy and Practice: challenges for teaching and learning in schools and universities".

Each section is preceded by an overview that summarizes that section and provides issues that might critically guide the reader though the contents. 


\section{Section A}

\section{Teacher Education}

The chapters in this section lead us through reflections on and research concerned with the theory and practice of teacher education, beginning with a keynote chapter by Judyth Sachs: "Teacher Education and the Development of Professional Identity: Learning to be a Teacher". As a prelude to her ensuing discussion, Prof. Sachs draws our attention to the "war stories" told in the media by or about harried and harassed teachers and introduces an illustrative section from a narrative provided by a trainee teacher. She poses the following questions: what can such stories contribute to our understanding of the experience of learning to be a teacher; what meaning can we make of these to inform the development of teacher education programmes; what kind of teacher do these recounted experiences suggest is dominating professional and policy discourse?

Summarising the emergent issues derived from these stimulating questions, Prof. Sachs focuses on the pervasive underpinning theme of the professional identity of teachers. She notes the multiple influences on identity formation, those that are external - imposed by society - which yet are mediated and negotiated over time by the individual's own experiences, values, beliefs and aspirations. In so doing, she focuses on two prevalent emergent identities, that of the entrepreneurial teacher and that of the activist teacher. The former she links with the efficient, responsible and accountable version of service promulgated by the state, which leads to a competitive rather than collaborative professional ethos. In contrast, she describes the activist as motivated by improving student learning and the conditions in which this can occur, and as aiming for the development of emancipatory practice, equity and social justice. Further, she suggests that, since the "market" is failing as an appropriate metaphor for education, a balancing strategy is needed in tertiary teacher education so that teachers are prepared to teach a mandated curriculum yet are encouraged to recognise the important intellectual, political and social aspects of their work.

Prof. Sachs advocates a social re-constructionist approach as a way of providing a strong intellectual foundation for teacher education programmes so that novice teachers can learn to deal with the complexities of continuous change, developing new identities in a proactive professional way as they do so. In the course of her argument, she refers to the value of attending to and sharing narratives as one mechanism that would be congruent with and contribute to such an approach.

In the second chapter, "Teacher Learning and the Theory of Variation" by Silwa Claesson, again the stories of novice teachers are told to illustrate a research study in which teachers, selected for their declared adherence to particular theoretical perspectives, were observed to enact those perspectives in practice. An overview of three theoretical perspectives dominating Swedish Teacher Education provides a preface to a description of the research study and the presentation of some of its results. While noting that the teachers may not always be able to articulate well the theories that inform their practice, a particular point emerges that knowledge of a limited number of theories constrains teaching methods. The author recommends a phenomenological 
life-world approach as a potentially useful overarching holistic philosophy for teacher education.

Professional knowledge also forms the focus of the next chapter by Rivero García and Porlán Ariza, entitled "Areas of Professional Research: A Proposal for Organising the Content of Teacher Education". The authors contend that it is important to harness the teacher's own agency in attempting educational improvement. While recognising that both explicit theoretical knowledge and implicit experiential knowledge are necessary for developing educational practice, the authors suggest, through a description of their own work using "Areas of Professional Research", that an integration and amalgamation of the two would benefit teacher education.

In contrast to the two preceding chapters based on local studies, Avalos' chapter: "How to affect the Quality of Teacher Education: A Four-Year Policy-Driven Project Implemented at University Level", addresses the substantial reform of Initial Teacher Education across the whole of Chile. In this initiative several large-scale projects conducted over a period of four years were combined to address an identified need for development in the system. As in the previous chapter, it was found that addressing perceived needs results in greater commitment to change. Although the Ministry of Education provided no blueprint, resources were provided for the projects, which shared a philosophical basis in many ways like those described in the previous chapters. The results are discussed in terms of shifts in practice implemented and those more resistant to change - the latter tending to be long-standing habits of practice. The chapter does demonstrate the effectiveness of collaborative effort expended on recognised practical problems.

The final chapter by O'Connell Rust, "Learning from the Conversation of New Teachers", returns to the issue of the developing identity of student and novice teachers as the author highlights the value of both narrative autobiography and conversation with other teachers as a method to incorporate into ITE programmes and during the difficult transition years between formal education and engagement with practice, when identity formation is critical.

In sum, the chapters in this section convey similar philosophical approaches to teacher education yet provide details of different ways and means of implementing issues from the research and experiences of teacher educators. 


\title{
Chapter 1
}

\section{Teacher Education and the} Development of Professional Identity: Learning to be a Teacher $^{1}$

\author{
Judyth Sachs
}

\section{Introduction}

Stories of teachers, especially "war stories" in the media, make for good press. There would be few weeks when there is not a story in the media about education or of teachers. Many of these reports paint a picture of a harried or harassed teacher - overburdened by marking, rude and difficult students and working in conditions that could almost be Dickensian. As a teacher educator these stories catch my eye. An attention-grabbing headline in the Education section of the Independent newspaper titled "The worst six weeks of my life: the diary of a trainee teacher" written by Stephen McCormack, a former BBC news correspondent, certainly grabbed my attention. With such a provocative title I was of course intrigued to read on. My imagination was put into overdrive, what had happened to this student teacher for him to make such a strong statement? Let me present some extracts of what McCormack wrote. ${ }^{2}$

\section{Monday morning}

The alarm goes off at six and I haul myself out of bed at the start of another week. I try to do half an hour's work before setting of to school. I am still managing to get a decent night's sleep most nights, but the cumulative effect of the work load is taking its toll. I constantly feel the dull weight of deep fatigue. I am now six weeks into my second and final teaching practice, and I can honestly say that they have been the hardest six weeks' work of my life.

When I make this observation to friends outside the profession they say: "Surely journalism was more arduous?" Well, I certainly remember stints of intense pressure as a reporter, covering industrial disputes, the aftermath of bad accidents or terrorist incidents, and wars and revolutions. There were days and nights on end with little 
sleep in uncomfortable and sometimes dangerous environments at home and abroad.

But these periods would not last too long, and they would usually be punctuated by lulls when the news moved on. That would allow a day or two's relative relaxation, with a long lunch hour or an afternoon reading the chapter before the next range of activity.

School teaching is different. As least it is for me. The pressure of work is unremitting. For days and weeks on end, lessons have to be prepared and taught, homework and tests marked, miscreant pupils dealt with. All of this I find rewarding, yes, but energy sapping and draining too. The thought of a long lunch or an hour or two reading the chapter is unimaginable. And the key additional factor for me is the weight of social responsibility that teachers bear. ...

\section{Tuesday morning}

Today I'm being observed. Not in the Big Brother sense, although some teachers see Orwellian parallels in much of the inspection system. No, the scrutiny will last just an hour and I will see, and know, the person doing the observing. He's my tutor from college, and this is one of the three or four official visits he will make during my training year to assess me in the environment that really matters: standing in front of a class.

Although my lessons are prepared, with plans of varying detail, observed lessons are planned just a little bit more thoroughly. ...

An hour and a half later, and I'm sharing a coffee with my tutor over the debrief. One of his greatest skills is in accentuating the positive. He will always start any post mortem like this with a discussion of what went well, and lavish praise for the good bits. This softens the blow when he comes to the mistakes and wrong turnings, and the criticism is always constructive. Trainee teachers need this approach, because confidence and morale can often be finely balanced.

Everyday I get masses of helpful advice, support and reassurance from the other maths teachers at my school. I believe I could not get by without it. The observation was OK-ish, and I move on to my next class.

\section{Friday}

... The bureaucratic load on teachers is well known and no one could complain that we, as trainees, are not being adequately prepared for that part of our future careers. From the very outset of my course, I have been swamped with paper and loaded with form-filling and report-writing exercises. Only tenuously linked to the aim (which can be lost in the fog) of teaching maths to teenagers.

Much of this paper work is driven by the obligation of all trainee teachers to achieve what are called the Standards Necessary to become a Qualified Teacher, set out in a Government circular known affectionately as 4/98. 
These standards (68 of them) range from the sensible and constructive to the mind-numbingly obvious, via the familiar verbal contortions of the politically correct.

\section{Thursday 8:30 pm}

More than 12 hours after most of the teachers arrived at school, they're nearly all still here. It's a Year 10 parents' evening and my colleagues are sitting behind desks in the school halls talking to parents in fiveminute slots ...

What strikes me is how little slack there is in the system. Every teacher seems to be working flat out all of the time; so much so that when for one reason or another a teacher is absent for any prolonged period, the strain is felt immediately...

I've seen it happen in one department in this school recently and, were it not for the selfless and voluntary effort by all members of the department and the large amount of time and extra organisation by the faculty head, there would have been numerous times in which pupils were little more than baby-sat. And this is a very popular comprehensive, with a stable and experienced teaching staff in a comfortable teaching area with largely well-motivated pupils and parents. I shudder to think how things are in less fortunate schools, like the one a maths colleague of mine is teaching in, where a third of the staff are leaving at the end of the school year, and where it is not unusual for the police to be called to sort out unruly incidents. All this is creating a tension within the profession and between the unions and the Government. The demand is out for a 35-hour week. I personally don't think this hour counting, clocking on and off mentality is compatible with the professional approach required of being a teacher. But it is clear to me that the pressure must be relieved somewhere and somehow, probably by reducing the number of classcontact hours of each teacher. That would be a long-term task but without a commitment to it soon, I think that burnout and early retirements will only increase, and retention of new recruits will remain difficult ...

While this is an example of the experiences of a trainee teacher in England, similar stories could be written by my students in Sydney or students elsewhere. What then is this narrative telling us about the experience of learning to be a teacher? Can we make some generalisations from McCormack's experience of his teacher education program in general and his experience of practice in particular? To this end we need to ask what are these extracts telling us about how a trainee teacher is experiencing teaching and what meanings can we make out of that experience in terms of developing new teacher education programs. Also, what kind of teacher (an autonomous and independent professional or a compliant technician) do these experiences suggest is dominating professional and policy discourses? It is not my intention to provide answers for all of these questions, but rather for them to provide some foreground regarding current issues of becoming a teacher. Let me make some observations regarding the extracts.

- The work of teachers is difficult intellectually, emotionally and physically; 
- The work of teachers is becoming highly accountable and bureaucratic, especially through the application of standards regimes;

- The work of teachers is intensified and unrelenting;

- Teaching is a highly socially responsible occupation;

- Among teachers there is a blurred differentiation between the industrial and professional aspects of their work;

- Teachers work in the best interests of their students, even if the system appears to let them down;

- People are entering the profession after having worked in other professions while others are leaving the profession.

In this chapter, I want to look behind some of these issues about becoming a teacher, in particular those that relate to the professional identity of teachers. This means examining the types of identity that are circulating in policy discourses and the practices of teachers in schools who may be supervising students. I argue that learning to be a teacher not only requires skill acquisition but also the development of an understanding of what it means to be a teacher, in one's own eyes but also in the eyes of others, what I refer to as professional identity. I identify two kinds of teacher professional identity that I have observed as emerging out of current educational policies in Australia and elsewhere; these are the entrepreneurial and the activist identity. I conclude the chapter by identifying a set of assumptions that would provide the conceptual scaffolding to support the development of a different kind of teacher professional, namely activist teacher professionals.

\section{Professional Identity}

Identity is the way that people understand their own individual experience and how they act and identify with various groups. For Hall (1996: 17) "identities are constructed within, not outside discourse, our need to understand them as produced in specific historical and institutional sites within specific discursive formations and practices". That identity is complex seems clearly obvious, as does the view that it emerges from the relationship between individuals, institutions and organizations in its construction. The construction of identities uses building materials from history, from geography, from biology, from productive and reproductive institutions, from collective memory and from personal fantasies, from power apparatuses and religious revelations (Castells, 1997: 7). As Castells goes on to argue, "individuals, social groups, and societies process all these materials, and rearrange their meaning, according to social determinations and cultural projects that are rooted in their social structure and their in space/time framework" (p. 7). In the development of professional identity, teachers draw on their own experiences as a student and as a teacher, their personal and professional histories inside and outside of schools, as well as the images of teachers presented in the popular media, films, fiction and so on.

In terms of its orthodox uses, the idea of teacher professional identity is rarely taken as problematic. It is used to refer to a set of externally ascribed attributes that are used to differentiate one group from another. Professional identity thus is a set of attributes that are imposed upon the teaching profession either by outsiders or members of the teaching fraternity itself. It provides a shared set of attributes, values and so on 
that enable the differentiation of one group from another. From this perspective it is an exclusive rather than inclusive ideal and is conservative rather than radical in its intent. Following Epstein, identity is essentially a concept of synthesis, integration and action:

It represents the process by which the person seeks to integrate his (sic) various statuses and roles, as well as his diverse experiences, into a coherent image of self. (Epstein, 1978: 101)

In times of rapid change identity cannot be seen to be a fixed "thing"; it is negotiated, open, shifting, ambiguous, the result of culturally available meanings and the open-ended power-laden enactment of those meanings in everyday situations (Kondo, 1990: 24). For teachers this is mediated by their own experience in schools and outside of schools as well as their own beliefs and values about what it means to be a teacher and the type of teacher they aspire to be.

Within the context of uncertainty and multiple educational restructurings teachers' professional identity is not straightforward. There would be incongruities between the defined identity of teachers as proposed by systems, unions and individual teachers themselves and these will change at various times according to contextual and individual factors and exigencies. Identity must be forever re-established and negotiated. It defines our capacity to speak and act autonomously and allows for the differentiation of ourselves from those of others while continuing to be the same person (Melucci, 1996). For teachers this is a challenge given that governments do not see it to be in their best interests to have a vocal and autonomous teaching service. When teachers do act autonomously their behaviour is often not sanctioned by their employing authorities, but rather chastised. Nevertheless the development and sustaining of a strong professional identity is what distinguishes the expertise of teachers from other workers.

While any idea of a fixed teacher professional identity is unproductive nevertheless, it can serve the needs of the State by providing a framework for externally initiated controls. These controls set the limits for what can be said about teacher professional identity and at the same time define what must remain unsaid on pain of censure. In such situations teacher professional identity serves bureaucratic purposes, in so far as control of debates about its meaning are taken away from the people who "live" it on a daily basis, namely teachers themselves.

Wenger's (1998: 149) five dimensions of identity speak to the complexity of identity. For him it circulates around the idea of "who we are". First, identity must be seen as negotiated experiences where we define who we are by the ways we experience our selves through participation as well as the way we and others reify ourselves. For teachers this is how we are seen by our peers and also by members of the community at large. Second, is community membership, which defines who we are by the familiar and the unfamiliar. The third dimension posits identity as a learning trajectory where the focus is to define who we are by where we have been and where are going. Fourth is identity as nexus of multi-membership where we define who we are by the ways we reconcile our various forms of identity into one identity. Finally, identity as a relation between the local and the global is achieved by negotiating local ways of belonging to broader constellations and manifesting broader styles and discourses. Identity here is about how teachers define themselves through their experience and the factors that mediate that experience and how meaning is attributed to these experiences. Identity 
then works on a number of levels but its project is to help individuals and others understand who they are in particular contexts and circumstances.

\section{Teacher professional identity}

Examination of recent education policy documents, government policies and teacher professional development initiatives in Australia and elsewhere suggests that two forms of teacher professional identity are currently evident in the discourses of schooling and the debates about teacher professionalism. These are the entrepreneurial identity and the activist identity. ${ }^{3}$ While these forms of teacher identity are quite different in terms of their view of what it means to be a teacher, they do not stand in opposition to one another, nor can it be said that teachers are polarised in their identifying with one and disregarding the other. Rather it might be more accurate to say that at various times teachers shift from one to the other, depending on the context and the circumstances. This again reinforces the earlier argument of identity not being fixed.

\section{The entrepreneurial identity}

The development of the entrepreneurial identity has emerged in response to recent educational reforms in Australia, the UK and New Zealand, which have been based on the logic of the new public sector reform agenda. These reforms have sought to make educational bureaucracies not only more accountable but also to engage in practices derived from the business world. Here, management serves two purposes in the reform process, means and end. In other words

... management (as synonym for efficiency) is taken to be "the one best way" to organize and run schools, and to the extent that management culture embraces enterprise and commercialism it shifts schools away from a "culture of welfare" to a "culture of profit and production" - that is management does profound ideological work in relation to the conception and conduct of schooling. (Ball, 1994: 71)

Accordingly, new forms of control have been mandated in policy decisions and educational practices. One significant outcome of these initiatives is the credo of "doing more with less" in a context of a competitive educational market. Schools are expected to compete for additional resources and to meet the needs of "consumers". Corporate managerial control is the modus operandi. This form of control involves a complex mix of control through the invisible hand of the market, centralized prescriptive curriculum control, an ideology informed by such values as enterprise, competition and choice ... (Smyth et al., 2000: 43).

A new teacher professional with an aligned identity is thus emerging, what Menter, Muschamp, Nicholls, Ozga and Pollard (1997) refer to as the "entrepreneurial professional" who will identify with the efficient, responsible and accountable version of service that is currently being promulgated by the state. Du Gay (1996: 181) observes "because previously distinct forms of life or modes of conduct are now classified primarily, if not exclusively, as 'enterprise forms' the conceptions and practices of personhood they give rise to are remarkably consistent". Thus, there is the emergence of what Catherine Casey (1995) refers to as "designer employees" who are responding to a broad crisis in industrial production, work organisation and culture. Education 
bureaucracies too would encourage "designer teachers" who consistently demonstrate compliance to policy imperatives and perform at high levels of efficiency and effectiveness. They must also demonstrate consistent high-quality teaching, measured by externally set performance indicators. The logic is that these teachers must be compliant employees who accept standards regimes while ensuring at the same time the learning outcomes of all students are improved.

The rise of managerialism has significant implication for the teaching profession, especially as they relate to issues of professional identity. As Fergusson (1994) observes:

The potential impact on the constitution, standing, identity, autonomy and authority of the profession is enormous. The socialisation of intending teachers into the mores, values, understandings of what it means to be a teacher will switch from being developed in a collective setting of debate informed by theory, research and evidence, to one in which socialisation is entirely dependent on two or three teachers. New teachers' capacities to act autonomously work independently and most of all mount well-grounded challenges to managerial diktat are likely to diminish, and their sense of membership and solidarity of a larger body to be diluted. (pp. 106-7)

Menter et al. (1997: 57) maintain “judgement about priorities, appropriateness and efficacy, once the preserve of the expert, guided by rules and precedent, is ignored or excluded". The preferred version of teacher professionalism imbued in public sector reform agendas has very significant consequences for both teachers' work and teacher professional identity.

Under managerialist discourses, the market plays an important part in how teachers constitute their professional identity collectively and individually. Competition for reduced resources between schools fosters the development of a competitive ethos, rather than a collaborative one. The efficient operation of the market is fostered through the combination of legislative controls and internal, institutional mechanisms, notably performance indicators and inspections, which ostensibly provide consumers with a basis for selection but more importantly provide managerial imperatives (Menter et al., 1997: 64).

Standardised measures of performance enable schools to be ranked by their customers; market competition-penalised non-conformity in teaching and learning and the national curriculum function as a system of cultural control, "a standardised language, a narrative history of national destiny, so a normative, monocultural definition of community claiming the legitimacy of familiar values and an external identity" (Marginson, 1997: 190). Putting education into the market place means making education appear more like a commodity so that parents are given access to a range of products from which they can select. In this framework, schools become more efficient in response to competition (Menter et al., 1997:26). Teachers are placed at the centre of these discussions, having to balance the pressures of competition, within and outside of the school, with the demands of quality education provision and improved student learning outcomes.

In the UK, the New Right policies in education are aimed at removing costs and responsibilities as a means of raising standards from the state and thus improving efficiency and responsiveness as a means of raising standards of performance. What 
the state fails to acknowledge is the agency of teachers collectively and individually in such an enterprise.

Under managerialist conditions, a cult of individualism has the possibility to re-infect the occupational culture of teachers. This individualism developed in response to teachers' working conditions is characterised by isolation and privacy. As Andy Hargreaves (1992) observes: "individualism is primarily a shortcoming, not a strength, not a possibility; something to be removed rather than something to be respected" ( $\mathrm{p}$. 171). In many cases the history, structure and architecture of schools helps to reinforce such an individualistic culture. Such cultures certainly work towards the maintenance of conservative, even reactionary, practice and stand in opposition to a generative or change-embracing culture. Individualism is in stark contrast to collaboration and collegiality that are the cornerstones of democratic discourses and the development of an activist professional identity. The entrepreneurial identity is summarised as:

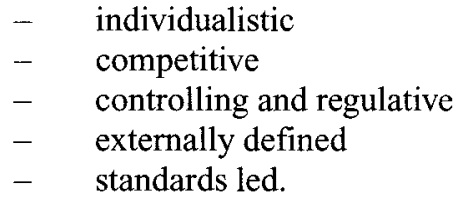

Having indicated some of the characteristics of the entrepreneurial identity, I now turn to elaborate the activist identity. This teacher identity provides the possibility for a new kind of teacher professionalism - one that requires rethinking what it means to be a teacher, both by teachers themselves but also by members of the community.

\section{The activist identity}

The activist identity is emerging in response to and perhaps in reaction against managerialism. It draws its inspiration and momentum from the work of people in the broad teaching profession. Furthermore, its motivation is situated in a belief of the importance of mobilising teachers in the best interests of improving student learning and improving the conditions in which this can occur.

Theoretically, this identity draws its strength from a long-standing tradition in democratic schooling. Much of the basis of democratic schooling is premised on the framework developed by John Dewey (1916) in Democracy in Education. It is worth noting Dewey's position:

In order to have large numbers of values in common, all the members of the group must have an equitable opportunity to receive and take from others. There must be a large variety of shared undertakings and experiences. Otherwise, the influences, which educate some into masters, educate others into slaves. And the experiences of each party loses in meaning when the free interchange of varying modes of life experiences is arrested. (p. 84)

Schools in which democratic discourses inform all aspects of school life do not happen by chance; they require strategy and commitment. They result from explicit attempts by educators to put in place arrangements and opportunities that will bring democracy to life (Apple and Beane, 1999). They require two forms of activity: putting into place democratic structures and processes and creating a curriculum that will give students democratic experiences (Apple and Beane, 1999). It is the former that is the 
focus of attention here. The focus is on participation and inclusion of all involved in the educational enterprise. The complexity of this is captured by Apple and Beane (1999: 10) who suggest that:

... all of those directly involved in the school, including young children, have the right to participate in the process of decisionmaking. For this reason, democratic schools are marked by widespread participation in issues of governance and policy making. Committees, councils and other school wide decision-making groups include not only professional educators, but also young people, their parents and other members of the school community.

Clearly, an activist identity emerging from democratic discourses has clear emancipatory aims. Beane and Apple (1995) capture the conditions for democratic schools informed by democratic discourses. These conditions enable an activist identity to emerge and flourish. They include:

- The open flow of ideas, regardless of their popularity, that enables people to be as fully informed as possible.

- Faith in the individual and collective capacity of people to create possibilities for resolving problems.

- The use of critical reflection and analysis to evaluate ideas, problems and policies.

- Concern for the welfare of others and "the common good".

- Concern for the dignity and rights of individuals and minorities.

- An understanding that democracy is not so much an "ideal" to be pursued as an "idealised" set of values that we must live and that must guide our life as people.

- The organization of social institutions to promote and extend the democratic way of life. (Beane and Apple, 1995, pp. 6-7)

First and foremost, an activist identity found in democratic schools is concerned to reduce or eliminate exploitation, inequality and oppression. Accordingly, the development of this identity is deeply rooted in principles of equity and social justice. These are not only for the teaching profession but also for a broader education constituency of parents and students.

Democratic discourses provide the conditions for the development of communities of learning or practice. They are primarily concerned with engaging with some enterprise but also in figuring out how this engagement fits in the broader scheme of things (Wenger, 1998). These communities of practice are collegial, negotiated and they form and reform around specific issues. Notwithstanding this, there is a need to defend some of the older identities. Sometimes the call for the "new" can act in ways that support managerialism as it sees itself as "new". Hence the creation of professional identities builds on, rather than rejects, previous notions. Accordingly, it requires a form of reflexivity when what has come previously is used a resource to build upon.

Earlier I suggested that a revised professional identity requires a new form of professionalism and engagement. Redefining teacher professional identity along activist lines involves two main elements: the effort to shed the shackles of the past, thereby permitting a transformative attitude towards the future; and second, overcoming the 
legitimate or the illegitimate domination of some individuals or groups over others. To do this a strategy needs to be developed in order to have teachers think and talk about what it means for them to be a teacher, and how others see them.

First, Gergen and Gergen's (1988) use of professional self-narratives provides a useful starting point. These are culturally provided stories about selves and their passage through lives that provide resources drawn upon by teachers in their interactions with one another and with themselves. Stories provide a compelling basis for change or for affirmations. For Gergen and Gergen

narratives are, in effect, social constructions, undergoing continuous alteration as interaction progresses. ... the self-narrative is a linguistic implement constructed by people in relationships to sustain, enhance or impede various actions. Self-narratives are symbolic systems used for such social purposes as justification, criticism and social solidification. (1988: 20-1)

For teachers these self-narratives are developed as they relate to their social, political and professional agendas. They are stories of stories, and are reflexive in that they are understood both by the individual whose stories they are and by others who may have similar experiences. These are often tacit insofar as they operate at the level of the taken-for-granted. They are developed during their own schooling and initial teacher education and are then embedded and reinforced in the course of their professional lives in schools and so on.

These self-narratives provide the glue for a collective professional identity and provide a provocation for renewing teacher professionalism. It is important that stories are made public, not necessarily in a written sense but at least shared so they are communicated in a way that can be shared, debated and contested by others. I suggest that making these narratives public is a source for lively professional development. It provides opportunities for teachers to communicate with each other about what they think schooling, education, subject-knowledge, pedagogy and so on is about. Furthermore it acts as a provocation to institute a more active, spirited debate about policy and practice. Critical self-narratives about professional identity at the individual and collective level have clear emancipatory objectives. These objectives, I suggest, are towards an activist stance and the development of an activist identity.

The challenge for those of us involved in the broader political project of revitalising issues of teacher professionalism and professional identity is how to facilitate public debate among teachers, the teaching profession collectively and the wider community about the nature of teaching. Issues to be addressed include dealing with the challenges of working under conditions of rapid change, ambiguity and uncertainty, in order to have a clear and articulated sense of what it means to be a teacher in contemporary society.

In summary then an activist identity is:

- based on democratic principles

- negotiated

- collaborative

- socially critical

- future oriented

- strategic and tactical. 
Teachers' professional identities are rich and complex because they are produced in a rich and complex set of relations of practice (Wenger, 1998: 162). This richness and complexity needs to be nurtured and developed in conditions where there is respect, mutuality and communication for teachers individually and the teaching profession collectively. It is done under the conditions described by Beane and Apple (1995). An activist teacher professional identity is not something that will come naturally to all teachers. It has to be negotiated, lived and practised. The development of such an identity will be a challenge for many, and will be challenged by others, but once its elements are learned and communicated across the teaching fraternity it will make a significant contribution to teachers' work and how they experience and make sense of that work and how outsiders view it as well.

Teacher professional identity then stands at the core of the teaching profession. It provides a framework for teachers to construct their own ideas of "how to be", "how to act" and "how to understand" their work and their place in society. Importantly, teacher identity is not something that is fixed nor is it imposed; rather it is negotiated through experience and the sense that is made of that experience.

The search for a new identity sometimes assumes such an identity already exists and wants to be discovered. This may be correct only if the new identity is to be written by someone else (Czarniawska, 1997). If the teaching profession wants to be the author of its own identity or professional narrative then now is possibly the time for this to occur. There is now some evidence suggesting that the market is no longer the appropriate metaphor or structure in which education policies and practices develop. Under more democratic conditions, where teacher knowledge and expertise is recognised and rewarded, an activist teacher professional identity fosters new forms of public and professional engagement by teachers themselves and the broader population. Activist teacher professional identity encourages new forms of association of teachers among themselves and with others. It promotes new work practices and more flexible ways of thinking about practice.

Let me return to the extracts I began the chapter with and ask: what is the professional identity emerging in this teacher? While I acknowledge that we are provided with a somewhat one-dimensional personal narrative, we can see some emerging trends. Given what we know about education in the UK, with its emphasis on the compliance to standards regimes and the strong managerialist tendencies of government policy as it relates to initial teacher training, it would not be surprising to suggest that the entrepreneurial identity seems to have dominance. Indeed it would be difficult to see how an activist teacher identity could emerge and survive. In what follows I would like to sketch out some of the features of a teacher education program that would enable an alternative form of teacher professional identity to emerge. While I acknowledge that government policies may encourage the development of one kind of teacher over another; the technician over the professional, the entrepreneurial over the activist identity, I believe that there are possibilities for tertiary institutions to act in socially and professionally responsible ways to produce different kinds of teachers, who do have the skills, knowledge and competence to work effectively in schools. Teacher education institutions need to act independently and autonomously to balance their role in preparing students to teach the mandated curriculum, but at the same time recognise the important intellectual, social and political work that teaching involves. Let me also emphasise that what I put forward is not a utopian ideal, but is evident in many teacher education programs in various parts of the world. My own experience in 
working in three teacher education programs in two Australian states has been directed towards these ideals.

\section{Teacher Education for an Activist Teaching Profession}

Having argued for an activist teacher professional identity I now turn my attention to outlining the assumptions and structures for a teacher education program to achieve these ends. A teacher education program to prepare an activist teaching profession would have many of the characteristics that Liston and Zeichner (1991) identified a decade ago under the rubric of their social-reconstructionist approach. It is disappointing that many of the ideas presented a decade ago are yet to find their way into many teacher education programs. It is worth revisiting some of the elements of a social-reconstructionist approach to teacher education.

A social-reconstructionist teacher education program or one to produce activist teacher professionals requires a strong articulation between the structure, organisation and delivery of the programs, course content, and the pedagogy and social relations that are integral in its delivery. In many instances to ensure that the whole program is an aggregate of all of its parts will require substantial changes in the philosophy and structure of the teacher education program. Those teaching in programs will also be required to rethink their role and their pedagogical strategies.

The development of a common set of assumptions, which will advise the form and content of the program is equally important. My own work, as part of a team teaching in the Master of Teaching program at the University of Sydney has provided me with a variety of experiences that have provoked my thinking and practices about a new kind of teacher education program. In what follows I outline four assumptions drawn from my own experience, which provide the conceptual and operational scaffolding underpinning an activist teacher education program.

\section{Education is Political}

It seems obvious to say that education is political. What counts as curriculum knowledge, how schools and education programs are resourced, who has influence in the development of policy agendas, are all dimensions of the political nature of education policy and practices. The development of education policy and how these policies are enacted in schools are all sites of struggle, with various interest groups vying for the control of meaning and practice. Schools are, as Mahony and Hextall (2000) argue, political institutions.

They both reflect and reconstitute (or challenge) social inequalities organised around the axes of "race", gender, class, sexuality and disability. What Connell (1993) has called the "political order" of the school is mediated through patterns of teaching and non-teaching staff employment; the messages conveyed in curriculum materials; the organisation of option choices; the basis on which students are grouped; teaching and assessment practices; the assumptions embedded in school discipline; the organisation of the pastoral system; the kinds of language used and the ways interpersonal relations are handled. (p. 123) 
Similarly teacher education is political, both internally and externally. Its place and status in universities is variable. In some universities there are large and relatively well-resourced faculties, while in others teacher education is located in small departments which are vying with other departments in the faculty not only for resources but also for visibility. Given this, it is necessary for students to gain skills so that they may operate in political environments. For Reid et al. (1998: 252) such programs will have to develop political sensibilities that will enable teachers:

to struggle in the various arenas where policy is determined, to wrest back and then maintain some greater degree of autonomy in their curriculum work. This will require the capacity to recognise the way curriculum operates, the critical skills to uncover hegemonic constructions of teaching as an apolitical activity, and the will to work collectively, through union and professional associations, to do something about it. It requires political understandings including knowledge about how and where educational policy is shaped, who to target in political campaigns, and how education unions and political parties work. And it demands a significant array of political skills, including the capacity to negotiate, advocate, lobby communicate and organize in the wider political arena.

The challenge then is to provide teachers with the knowledge and skills that will enable them to operate effectively in political environments. These environments may be the schools in which they are working but are more likely in the communities in which these schools are located. Effective communication, problem solving and advocacy are some of the skills that will enable teachers to be activists in their own professional lives.

\section{Inquiry into Practice}

Inquiry stands at the centre of all activities in developing an activist teacher. As Liston and Zeichner (1991) argue, teaching itself can be seen as a form of inquiry. In a program to develop the activist teacher, professional teachers are viewed as researchers of their own practices, capable of producing worthwhile knowledge about teaching, which can contribute to their own, and others', professional development. Developing the skills to help teachers inquire into their own and others' practice is fundamental to an activistoriented teacher education program. Inquiry must be seen to be a fundamental aspect of any teacher education program, and the opportunity to communicate the results of such inquiry to a wide range of peer, practitioner and academic audiences must be encouraged. This can be done in systematic ways as in internship of the Master of Teaching program where students undertake an action research project in their school. Students develop skills to undertake this "formal" type of research, which is presented, both in written form and orally, to their peers. On other occasions students may be encouraged to capture incidents that occur during the times they spend in classrooms, which can be returned to later to trigger discussion with their peers or as the basis for self-reflection about their own practice. These snapshots of practice contribute to the compilation of a public body of professional knowledge. Atkinson (2000: 328) captures the spirit of inquiry into practice by arguing "the purpose is ... to inform discussion among practitioners, 
researchers, policy-makers about the nature, purpose and content of the educational enterprise".

\section{Learning-centred Programs}

Learning rather than teaching and content should be the focus of an activist teacher education program. By making learning rather than teaching the focus, the social relations of on-campus learning are fundamentally changed. Both students and teacher educators see that the interactions that occur in classrooms become part of a body of intellectual and experiential knowledge that can be interrogated and debated.

The Master of Teaching program in my own faculty at the University of Sydney is an example of a program that is attempting to develop teachers who are change agents. This is two-year postgraduate program, which uses an interdisciplinary inquirybased approach using cases from practice. Many of the cases have been written by teachers working in schools and provide the main framework for the course rather than one segment (Ewing and Smith, 1999). The use of the case-based framework implies that every student teacher's experience on entering the course and during it will be unique. In each phase of the course student teachers are encouraged to adopt a socially critical and reflective approach to teaching. Questions of equity and the effects of different pedagogies on student learning are examined through the lenses of race, ethnicity, class, gender and sexuality. The use of information technology as a tool for student learning and as a means for students to communicate with one another is an important feature of the course. Course materials are available on the website as are other resources. Students are also encouraged to engage in online, virtual discussions. A virtual classroom is also under development as a learning resource for students.

Students are encouraged to keep a journal of their learning over the two years of the program of both campus-based and school-based reflections and professional development. This forms part of their learning portfolio, one of the forms of assessment used in the program. While the journals are private, journal entries form the basis of some assessment tasks.

The program concludes with a ten-week internship. As part of this internship, student teachers are expected to engage in an action research project. The research projects are wide ranging - from specific classroom issues that have risen during the course of the internship such as managing collaborative groups, student questioning strategies, to broader areas across the whole school (revising merit awards at the invitation of the principal, student welfare, bullying, gender issues and other social issues relating to school/classroom practice). The findings of these projects are shared with the M. Teach cohort at a Student Forum. Students who have undertaken their internship at an overseas site and are not on campus for the research forum are expected to present their research and engage in discussion with their peers over the internet.

\section{Collaboration and Partnership}

Partnerships and collaboration between various stakeholders provide a central platform in the project of an activist teacher education. Furlong et al. (2000: 77-78) identify what they describe as ideal typical models of partnership. The continuum they present 
ranges from collaborative partnership at one end of the continuum to complementary partnership at the other. These two types of partnership represent two very different strategies for linking work in schools with those of teacher education and other interested parties. According to Furlong et al. (2000), in a complementary partnership the school and the university are seen as having separate and complementary responsibilities but there is no attempt to bring these two dimensions into dialogue. Alternatively, a collaborative partnership

... requires the commitment by teacher educators and school-based practitioners to develop a program where students are exposed to different forms of educational knowledge, some of which come from the school, some of which come from higher education or elsewhere. Teachers are seen as having an equally legitimate but perhaps different body of professional knowledge from those in higher education. Students are expected and encouraged to build up their own body of professional knowledge. (Furlong et al. 2000: 80)

The institutionalisation of collaborative partnerships embedded into the culture and practices of schools and teacher education faculties requires the development of what Nias, Southworth and Yeomans (1989) refer to as cultures of collaboration. These are informal as well as formal, intermingle personal and professional life, and are often constructed in the interstices of school life through conversation, shared glances and many kinds of joint work. Not surprisingly, many of the outcomes of partnerships emerge, not from the planned or intended expectations, but rather by happenstance and serendipity.

The list below is indicative of some possible outcomes facilitated by partnerships and collaborative relationships between teacher educators and other educational stakeholders.

- Negotiated expectations - making sure that all parties are working towards to same goals.

- Collaborative planning - working together and building on the expertise of both parties.

- Sharing of expertise - recognition that both groups have areas of expertise and that when these come together new insights, practices and research can be achieved.

- Diversity of perspectives and view points - the opportunity to see another's point of view and in so doing looking at the taken for granted anew.

- Knowledge generation - the interaction and engagement of practitioners and academics can lead to new understandings about the nature of practice and the conditions that shape, influence or improve that practice.

- Development of trust - stands at the core of any relationship or partnership between the various parties or stakeholders involved in education.

Importantly, though, in order to develop collaborative partnerships we must not underestimate the high level of trust and mutual respect that this entails. Without trust and respect partnerships are on very shaky ground.

With the rapid rate and extent of social change now occurring we have reached a historical moment where it is imperative to radically revise how teachers are educated. This will demand that we fundamentally rethink the types of programs that will provide 
new teachers with the requisite intellectual and professional skills. By giving them a strong intellectual foundation, teacher education programs will enable beginning teachers to deal with the complexities of change and enable them to work in schools that are likely to be different from their current formations. New times and conditions require alternative forms of teacher professionalism and teacher identities to develop. Furlong et al. (2000: 175) suggest

that we need to ask some fundamental questions about who does have a legitimate right to be involved in defining teacher professionalism. Are state control and market forces or professional self-governance really the only models of accountability available to us - or can we develop new approaches to teacher professionalism, based upon more participatory relationships with diverse communities?

\section{Conclusion}

In this chapter I have used a newspaper article as a prompt to examine teacher education programs and practices, in particular the types of professional identities embedded in these programs. I present some ideas that will move us beyond what Smith (2000) refers to as the conventional model. Importantly, I see that teacher education and teacher educators have a central role in the development of new kinds of teacher professionalism and professional identity. Through a socially critical form of teacher education that is predicated on learning, partnerships, collaboration and risk taking, the rise of an activist teacher professional is possible. This will not occur overnight but, if there are exemplars of an activist form of teacher professionalism in place and teacher education faculties provide the intellectual leadership, then an activist teacher professionalism led by teacher educators, with the support of a variety of stakeholders, is a strong possibility. It is my hope that this will be profession led, with multiple constituencies that become recognised as the norm rather than as a social experiment. For a strong teaching force we need strong teacher education programs. To achieve this we need a teacher education that is contemporary, rigorous and intellectually demanding. In practice, this may mean that some will be left by the wayside and that new staff members enter into teacher education faculties. It is a future to be excited about, but one in which we as individual and collective teacher educators must take intellectual and moral leadership. In other words, we must create the agenda and opportunities for the professional future of teaching. The onus lies on us to create an alternative agenda regarding debates and policies for teacher education and to identify opportunities for a future for the teaching profession that is activist in its orientation. This is certainly something that can be our legacy for future generations of teachers and students.

\section{Notes}

1 This chapter preceded the publication of Judyth Sachs (2003) The Activist Teaching Profession, Open University Press. Ideas presented here are elaborated in this publication.

2 Stephen McCormack, Teachers seem to work flat out all the time, The Independent, 19 April 2001, pp. 6-7. 
3 Elsewhere (Sachs, 2000, Teacher professional identity: Competing discourses, competing outcomes. Journal of Education Policy 16 (2)), I have developed the argument regarding the conditions in which these two forms of teacher professional identity have emerged. I argue that they have developed in response to what I refer to as the managerial and democratic discourses of education policy and practice. 


\section{Chapter 2}

\section{Teacher Learning and the Theory of Variation}

\section{Silwa Claesson}

In many countries, universities no longer conduct teacher training. However, this tendency seems to be going in the opposite direction in Sweden, where, as a result of the university reform of 1977, the training of teachers is supposed to be more theoretical than it was before.

As an educator of teachers at a university I have been teaching students the theoretical perspectives of Piaget, Vygotsky and others. I have found the students to be interested in and inspired by these theories, but I wondered what the inspiration meant in action and in actual teaching situations. I also wondered if this inspiration makes any difference. In recent years, pupils' conceptions have been on the agenda of pedagogical empirical research, and research methods. Results of this research have been presented in courses to teachers and trainees. In a previous study I investigated whether the inspiration teachers get from the results of research on pupils' conception influence the way they teach and described the ways in which they are influenced (Claesson, 1999). There follows a short description of what I mean by "research on pupils' conception".

\section{Research on Pupils' Conception}

Piaget can be regarded as the founder of constructivism. Constructivist research has very much focused on the learning of science in school. Pfundt and Duit (1991) and von Glasersfeld (1995) focus on pupils' conception as a contrast to the conception of research knowledge. According to them, the teacher is supposed to be familiar with the different conceptions his or her pupils have about the phenomena being taught, as well as having the necessary scientific knowledge. In the constructivist classroom the pupils are supposed to be active, and they can work on different subject content in order to construct new knowledge or reconstruct old knowledge. The pupils' own initiatives are encouraged by the teacher, the teacher lets the pupils take command, they don't use textbooks, and they experiment. In dialogue with the pupils, the teacher tries to understand how they conceptualize what they are working on, and the teacher encourages them to reflect upon what they have learned.

If Piaget is the important man behind constructivism, Vygotsky is the man behind socio-cultural studies. Vygotsky argues that you can't separate development 
from learning, which means that humans in a learning situation successively integrate into a context. Lave and Wenger (1991) have had a dominating influence on the debate on socio-cultural studies. They describe how beginners are successively brought into different contexts. All trainees are initially in "the periphery", and they successively move toward "the middle" as they get more and more used to the context, becoming transformed into practitioners in the zone of proximal development. The focus is on the process of learning and on social interaction in the learning situation. The difference between socio-cultural studies and constructivism is that socio-cultural studies do not focus on pupils' conception but rather on the context and the communication between humans. When teachers use this approach when teaching, for example, the process of writing, they will focus on pupils' ways of understanding. In school, teachers who are working in this tradition see themselves as "coaches" and primarily try to create a good learning environment.

Marton and his colleagues at the department of pedagogy at the University of Gothenburg introduced phenomenography. For many years, phenomenographical research there used more or less the same methodology: the researcher made semistructured interviews with persons relevant to the study. The results of the interviews were written down and interpreted in order to find categories of conception. These categories were called "second-order perspective" as opposed to "first-order perspective". First-order perspective means that it does not matter by whom the phenomenon is experienced. Second-order perspective emphasises that there is a somebody who experiences the phenomenon. Phenomenographic research has a secondorder perspective.

In the book Learning and Awareness (1997), Marton and Booth try to describe phenomenography as a theory rather than as a research method. They stress variation as a fundamental aspect of learning. Awareness, as the use of the word in the title of the book shows, is another central term in the formation of their theory. Marton and Booth claim that when humans direct their attention towards a phenomenon, it is possible and, indeed, meaningful for them to discern simultaneously more than one aspect of that phenomenon. One of the implications for teaching and learning is that the conceptions of individual students are not so unique that the teacher must teach one pupil at a time. The teacher can teach the class as a whole if he or she is aware of the different conceptions on a collective level. The teacher can open the pupils' minds to variation by stressing the possibility of simultaneously experiencing a phenomenon in many different ways. This has been called "theory of variation" by for example Runesson (1999) and Rovie-Johansson (1999). Pramling (1994) has implemented phenomenography in a pre-school context. Her main points are that the teacher should be aware of how the children are thinking, should create situations which make the children think, should be aware that children can teach other children, should accept children's different ways of thinking, and should turn that into a learning experience.

The question in this article is whether the knowledge of pupils' conception means anything to schoolteachers in the practice of their work. In a questionnaire, Robertsson Hörberg (1997) asked Swedish teachers what they thought was the most important knowledge to possess as a teacher. Her conclusion, after summing up their answers, is that they considered knowledge of how their pupils think as the most essential. Korthagen et al. (1997) remark that trainee teachers have their intellectual focus on pupils' thinking, but that they do not possess a profound knowledge of it they just rhetorically ask the pupils: "How do you think?" and that is all. The trainee 
teachers do not follow it up by taking the pupil's point of view into consideration. I will now briefly present a study that takes its departures in three different theoretical perspectives: constructivism, socio-cultural studies and phenomenography.

\section{An Observation Study}

What follows is an observation-study (Claesson, 1999) with theoretical grounding in phenomenological life-world theory (Husserl, 1970; Merleau-Ponty, 1962; Schutz, 1967; Van Manen, 1990; Bengtsson, 1988) influenced by the phenomenographical approach.

The teachers in the case studies were chosen from a questionnaire in which 396 teachers answered questions about their influences from constructivism, sociocultural studies, and phenomenography. The teachers chosen were all strongly committed to these theories. First, each teacher was interviewed; then, at a later stage, they were observed. The focus of the interviews was on the teachers' theoretical inspiration and their thoughts on what influences theories had on their teaching. These are "observer-participant studies", which means that I have been in classrooms without trying to hide myself (Merriam, 1994). I introduced myself to everybody I met and told them why I was there. On the other hand, I did not emphasise my presence. During my stay in the classrooms, I continuously wrote down my observations on what the teachers were directing their attention towards. My notes mirrored dialogues and events in the classroom. Sometimes, I wrote down what I concluded and what I thought. At the end, I interviewed the observed teachers' colleagues and pupils. Each observation period lasted for two weeks. At the end of each day I rewrote my notes, and the next day the teachers read them before we discussed them. This meant that $I$ had the opportunity to check what I had seen and, not least important, I could instantly discuss any moral or ethical dilemmas that this kind of situation can turn up.

\section{Adam}

Adam, who is in his early 40s, works in a suburban secondary school. He is a math and science teacher, although for the moment he teaches only science. In the interview he tells how, during his training, he got acquainted with a great number of constructivist ideas but that somewhat later he also came in contact with Ference Marton and phenomenography. He mentions the good feeling he had when he read a paper in which Marton disclaims the dualism between the subject and the object (Marton, 1995). It legitimated Adam's view that every single person is unique. When I ask him during the interview what phenomenography means to his teaching, he is uncertain, he cannot tell.

Adam's pupils mostly work alone or in pairs. They are allowed to choose their own subjects, and subsequently some pupils cultivate plants, some study chemistry, while others carry out scientific experiments, all at the same time. Mostly, to start with, they don't know themselves what to do, and for inspiration they study different reading materials. This provides them with open-ended questions about scientific issues. Adam mostly walks around in the class talking to one pupil at a time. He usually stays with each pupil for quite a long time. Some of the pupils, though, are not studying science or doing any school work at all. They chat, wander about, or are in one way or another busy doing non-science things. This does not seem to disturb Adam.

What does Adam talk to his pupils about? Now Adam is standing by a girl's desk. He goes down on his hunkers so that he is able to look her in the eye when they 
are talking. The girl is interested in cells. It all started, Adam told me later, when she looked at fossils in a microscope. She discovered the cells and started to wonder about their significance for everything that is alive. She wondered about the mystery of life. Then she wrote about "the Cromosolls" and distributed the text to her class. She was so astonished that they believed her. She had in fact made it up in order to see how easy it is to make people believe in things that are false. It was easy! She is now studying heredity and environment. Adam looks her in the eyes and confronts her with questions. His questions are open-ended. He goes on, putting new questions to her, and that makes her think further. He never states how things "really are", she has to figure that out on her own. This way of teaching is of great importance to Adam.

Is this constructivism in practice? It seems that the strong constructivist influence Adam got during his education shows itself like this in practice. When reading my protocols and discussing them he admits that this must be the case. My next question is where I could find the phenomenographical influence. Adam can't answer that question.

Adam is a teacher who has read a lot about different theoretical orientations and during interviews he talks a lot about them. When I ask him about the connection between constructivism/phenomenography and what he is actually doing, he is unable to give a specific answer. In his classroom he is a master at putting open-ended questions to pupils and showing an interest in each one of them. This interest includes a social interest, which in his classes, with many immigrants and children with social problems, is a great part of the daily contact with the young. One can say that he intertwines his interest in their learning with social commitment. He focuses his attention on how the pupils conceive different phenomena. He acts as if each pupil is constructing his or her own picture of the world, and he challenges that picture. When I ask him about the phenomenographical influence, he says that he realises that it is a theoretical interest of his, which hasn't, so far, had any influence upon his teaching. When I return half a year later, he is trying, off and on, to change his teaching, and he uses the idea of phenomenography. This means that he tries to make the pupils talk to each other about what they are doing, in order to make them realize that the way they are thinking might not always be the best way.

\section{Cecilia}

Cecilia works in a newly built school in a suburb. She is about 25 years old and has been trained in a new education programme for primary teachers. She has a class of her own with twelve-year-old children. Her theoretical inspiration stems from her teacher training. As she was trained in Gothenburg, where phenomenography was developed, she has been strongly influenced by that. She tells me that what fascinates her is that pupils conceive phenomena in so many different ways. Sometimes, she says, she revisits her old school of education in order to read new essays written by trainees. Those essays often focus, in a phenomenographical manner, on how pupils conceive different phenomena.

Cecilia often starts the lessons by asking an open-ended question. One of the pupils answers, another pupil has something else to add, another child says something, Cecilia makes a comment, a child is again given the floor, and so on. During this interaction, everyone is interested, which you can tell by their body language. After a while Cecilia writes on the whiteboard what they have said and asks them if that is correct. Cecilia directs her attention towards different ways of conceiving a 
phenomenon. After a while, the pupils start to work on their own. Sometimes they work on different subjects and sometimes they work on themes.

I ask Cecilia why she teaches the way she does. She does not know, she says, it just comes naturally. I ask if she has learnt to do so during her training and she says that she thinks so. But when I talk about phenomenography, she says that she doesn't remember what the word phenomenography means. She has asked many of her colleagues, mostly young people, but they don't know either. I tell her what it means and then she says that of course that must have been the inspiration.

Cecilia was influenced by phenomenography during her teacher training, and although she has forgotten the word itself she directs her attention towards the different conceptions that her pupils have.

\section{Dagny}

In the countryside, in a very small village with a church, a shop, a school and a pizzeria we find Dagny. Dagny, who is a little over 60 years old, has been working in this school for many years. She was trained to teach small children in the 1950 s and has been teaching ever since. Her theoretical influences have, of course, differed through the years. She is still extremely interested in theoretical ideas, which makes her sign up for different courses and read pedagogical literature. In recent years she has heard a lot about Vygotsky's ideas at courses on "the process of writing". Dagny thinks that those ideas are extremely good. She has also come upon phenomenographical ideas. Those have been mixed with different kinds of experience, for example she finds it extremely important to make all children feel that they are able to succeed in their schoolwork.

Most of the time the pupils work on their own with different things, and Dagny talks to those of the pupils who need her help. When talking to the children she directs her attention towards the contents of the matter. She is consistently encouraging the pupils, making them feel that they have succeeded in doing whatever they have done. One aspect of socio-cultural learning stands out here: Dagny is the coach and the pupils are the apprentices. She makes them feel confident in the environment of writing and reading, confident enough to believe that they will succeed. The older children often teach the younger. A small boy asks an older one about a math problem and the older says: "How do you think?" imitating his teacher.

To come back to Dagny's classroom after some time is to come back to the same kind of environment. It doesn't change. It is stable. Through the years Dagny has found her own way of teaching. She thoroughly plans for each day. She directs her attention primarily towards the contents of the issue at hand. Even if a child has read just a few lines, she makes him focus on the content of what he has been reading, trying to connect it with his fantasy. In Dagny's coaching of the writing process, there are elements that point to the influence of socio-cultural studies. The context of the learning situation is very important to Dagny.

\section{Theories in Practice}

Research on pupils' conception has influenced education in a general way, but is it possible to differentiate between constructivism, socio-cultural studies and phenomenography in classroom teaching? In my study of the cases mentioned, which focuses on where teachers direct their awareness, you can discern certain things. 
Adam is consistent when he, to start with, uses one single way of teaching. He allows the pupils to make different experiments on their own, and in the classroom, he talks to the pupils one at a time. He has a special way of talking, never stating what things are, and always asking open-ended questions. His own training was strongly influenced by constructivist ideas. Still, I wouldn't call Adam a constructivist teacher. $\mathrm{He}$ is inspired by constructivism, but he has also been exposed to a lot of other influences. In the interview, Adam says that he has also been inspired by phenomenography. After our discussion he has realised that he does not use phenomenography in his teaching. He says that his phenomenographical inspiration is on an intellectual level. Six months later he tries to use his phenomenographical knowledge in teaching. When doing so he does not address one pupil at a time, he addresses the group. He tries to make the pupils aware that they can listen to each other in order to find new directions in their thinking.

Cecilia came in touch with phenomenography during her training. She is not acquainted with the term phenomenography, but her way of teaching is interacting with the group, letting the children listen to each other, and writing down what they are saying. Still, she isn't able to keep on working this way when in a stressful situation. Dagny has been inspired by socio-cultural studies. She plans her work so that all the pupils feel confident that they will, in due time, achieve the skills of reading and writing. Dagny is the coach and the children are the apprentices. Of course it is important to mention that each theoretical perspective is richer than I can present here. It is also important to stress that theories, as they are presented in scientific books, are rarely the same as they turn out in practice. The reason why it is possible to discern anything at all in these studies is probably because the three teachers presented here are chosen out of 396 who answered the questionnaire and these three teachers maintained that they are especially committed to these theories. (There is an ongoing study that is focusing upon some teachers in the questionnaire who write that they are not committed to any theories at all.)

My study shows how teachers who know about phenomenography, for example, still don't have access to an adequate terminology. They don't know that they have been studying constructivism, socio-cultural studies or phenomenography. When they communicate with each other they say that they work in the spirit of Piaget, Vygotsky, Säljö, Marton, Pramling, or they will name a researcher. It seems that the theory of teaching is a business of "name-dropping". If teachers knew the names of the different theoretical perspectives, they would be able to communicate more easily with each other, and could then understand the main ideas of each perspective.

I think that an adequate terminology would help teachers in their professional development. Instead of merely discussing research on pupil conception or asking, "How did you figure that out?", teachers would do well to discuss different theoretical orientations. Teachers have been accused of only asking for ready-made teaching models, having been pampered by educators throughout the years. But instead of these ready-made models, what might perhaps be more useful is a combination of research theories and examples of what teachers can do as a result of their inspiration, as suggested by, for example, Joyce et al. (1992). 


\section{An Analysis in Which the Theory of Variation is Used}

What can we learn from this study? Let us use one of the theories described earlier in order to analyse the data. The theory I will use is developed from phenomenography and called the "theory of variation" (Runesson, 1999; Rovie-Johansson, 1999). Marton and Booth (1997) argue that some learning is more fundamental than others:

In order for an aspect of a phenomenon to be present in awareness it has to be discerned as an aspect, which implies awareness of potential variation, and has to be seen as being simultaneous with other aspects of the phenomenon. (p. 209)

This means that they stress variation as a fundamental aspect of learning. This also means that when humans direct their attention towards a phenomenon, it is possible and meaningful for them to discern simultaneously more than one aspect of that phenomenon. Teachers who base their work on the phenomenographical tradition seem to try to bring out various aspects of the phenomenon being taught. Cecilia is one of those teachers. The pupils are asked by Cecilia to describe how they experience a certain phenomenon, and the variety of answers received will make each pupil aware that their personal experience is not the only possible answer. In that way it can be possible for them to discern simultaneously more than one aspect. According to Marton and Booth and Marton and Tsui (2004), this is the moment when learning takes place. The pupil has received access to a variation of experiences related to one phenomenon and consequently can choose between them. In addition, according to the theory of variation, there is always one choice that is better than the others. Let's make an analysis based on the theory of variation and relate it to my study.

If Marton and Booth are right, these aspects of learning must be valid for teachers as well as for pupils. It means that teachers should be able to discern simultaneously different aspects of their teaching. A relevant question is what "teaching" means here. If you look at teaching in a narrow sense, the variation can focus on the subject being taught. Consequently, as a teacher you have to be aware of pupils' different conceptions related to a subject. As far as I can see this is what Marton and Booth want to show.

But if a teacher just focuses on the subject, he or she has access to only one way of teaching. It is, however, possible to consider teaching in a broader sense. For example, Englund (1991) claims that teachers should have a variation of knowledge about different philosophical traditions and ways of handling different situations. The present study, which focuses on constructivism, socio-cultural studies, and phenomenography, can be regarded as teaching and learning in a broader sense. Here I will consider teaching in a broader sense; consequently, still using the theory of variation, a conclusion I can draw from the observation study is that teachers ought to know about constructivism, socio-cultural studies as well as phenomenography in order to have access to variations and to be able to discern them simultaneously.

Let us have a look at Adam, who is familiar with two ways of teaching (the constructivistic and the phenomenographical) but still only uses one of them. How come? He is not able to review his own teaching and reflect on it from the point of view of different theoretical perspectives. But when I observed his teaching in the classroom and discussed this with him, he realised that he was, in fact, not teaching in more than one way. 
Cecilia, with her teacher training in recent memory, still has access to no more then one theoretical perspective. Basically that is what she was taught, so her teacher training has been normative. It seems that, at any one time, teacher training is influenced only by the theory that is in fashion. How come? To answer that question, it is of value to compare teachers and researchers. The researcher's goal is to define and deepen theoretical knowledge. The teacher's goal is to have as many theoretical and practical angles as possible in order to handle different situations in the classroom. These are two completely opposite perspectives. So if a particular researcher's theory is the fashion of the day, it will have a powerful influence on teacher training, and will possibly dominate teacher training, to the exclusion of other theories that are also of value to the teacher. Dagny has many different influences and perspectives, although she does not know about constructivism and phenomenography. Nevertheless, she has plenty of perspectives, and these give her a freedom of choice.

The theory of variation emphasises the importance of discerning different aspects simultaneously. Consequently, the analysis leads to the conclusion that it is important for teachers to have knowledge of many different theories of teaching and learning. That in turn leads to the conclusion that teachers, besides knowing about phenomenography, should also know about other theoretical perspectives. So this analysis concludes that teachers should study many different theoretical perspectives, where phenomenography is just one. This means that phenomenography or the theory of variation partly is pointing away from itself.

Researchers using the theory of variation usually present their results in a similar way. Qualitatively distinct outcome-spaces are presented hierarchically, the first being the simplest and the following progressively more complex. This means that the final outcome-space of a research study, being the most complex, will contain all the others. In other words, they are constructed in the same way as taxonomies (Biggs and Collins, 1989; Bloom et al., 1960). That means that the broader and more complex the outcome-space, the higher up it is in the hierarchy. My study focuses on the three perspectives: constructivism, socio-cultural studies and phenomenography in teaching. However, none of these three can be said to be highly complex, they are simply theoretical perspectives. So, if, in the spirit of theory of variation, we should search for a theory to cover the complexity of teaching and learning it will neither be constructivism, socio-cultural studies nor phenomenography that can help us. In order to develop teachers' learning, following the theory of variation, we have to find a theory or a philosophy that can go beyond reductionism. The phenomenological lifeworld approach might perhaps have those qualities. Van Manen writes:

And phenomenology differs from other disciplines in that it does not aim to explicate meanings specific to particular cultures, to certain social groups, to historical periods, to mental types, or to an individual's personal life history. Rather, phenomenology attempts to explicate the meanings as we live them in our everyday existence, our life-world. (van Manen, 1990: 11)

When Adam is teaching, he interacts with his pupils by asking open-ended questions. These questions not only focus on cognitive aspects but also on social aspects. In practice, these things are intertwined. The life-world approach enables us to understand teaching situations holistically, where, for instance, cognitive and social aspects are inseparable. 
So, my analysis, in the spirit of theory of variation, concludes that if teachers want to become good at teaching they should deepen their knowledge of as many different theories as possible that cover the complexity of teaching and learning. One of the most holistic theoretical perspectives is the life-world approach 


\section{Chapter 3}

\section{Areas of Professional Research:}

\section{A Proposal for Organising the Content of Teacher Education}

\section{Ana Rivero García and Rafael Porlán Ariza}

Many studies have shown that it is indispensable to involve teachers as agents in any process of educational improvement. In the awareness of this, it is of great interest to us to try to better understand the knowledge that we, as teachers, use in performing our work and the processes that might favour its further evolution. Having a clearer picture of our professional knowledge should hopefully help not only to improve our own teaching but also be a small contribution to educational improvement in the school in general.

Such an epistemological outlook focused on characterising professional knowledge, both that which we propose as being ideally desirable and that which really exists in most cases, would seem to us to favour the understanding and orientation of the processes of professional development. We are fundamentally concerned with the practical nature of this knowledge, the most relevant sources of information that feed it, and the organisation that might allow it to shape itself into a body of knowledge that is specific and valid for the teaching profession.

With respect to its nature, we would emphasise that there has to be resolved a major dichotomy that revolves around a "formal knowledge - experiential knowledge" axis. In teachers' professional knowledge, the tension set up by this dichotomy may become very strong, so that there may coexist in the teacher two subsystems of quite different ideas. On the one hand, there is the more formal knowledge, which mainly comes from the academic education that we have received, and which is usually fairly explicit - the theory. On the other hand, there is the body of experiential knowledge, which has been built up from personal experience, not only teaching, but also as a school student, and which is usually implicit - the action (Porlán, Rivero and Martin, 1997).

The characterisation of each of these types of knowledge has been abundantly treated in educational research, and there has been a fair degree of agreement that, despite the diversity, which does indeed exist, in most cases the formal knowledge is somewhat sparse, fragmented, and encyclopaedic, while experiential knowledge is mostly routine and with little or no reflection involved. Evidently, neither type of knowledge as such is useful on its own in furthering the appropriate development of 
our profession, although they are both fundamental and necessary. There is a need for the emergence of another type of knowledge that would come from both the enrichment of and the conscious interaction between these two basic sources, and whose sense would be to resolve the numerous practical problems that arise in the profession (professional practical knowledge, Porlán and Rivero, 1998).

There clearly exist very many sources of information that can contribute relevant meanings and experiences to this process:

- The disciplines related to the subjects being taught (Biology, Geology, Physics, Chemistry, Mathematics, Language, History, Geography, etc.) and to Education Science (Psychology, General and Specific Didactics, Sociology, Philosophy, etc.).

- Metadiscipline knowledge, and ideologies with a greater or lesser degree of organisation.

- One's own experiences and those of one's colleagues.

But of course the question immediately arises as how to encourage the contribution of each of these sources without once more falling back into a fragmented and additive organisation of practical knowledge. And how can we guarantee that it will be genuinely meaningful for the teachers themselves? Our response would be the "Areas of Professional Research". These areas are linked to the immediate functional interests of the teaching community, to professional problems, which are relevant to that community, and to the construction of a desirable body of professional knowledge. Investigation in these areas represents a step towards the organisation, construction, and development of this integrating knowledge.

\section{The Areas of Professional Research}

Some of these areas of research and the related professional problems are:

- School-level subject matter (Porlán et al., 1997): What do we know about certain parts of the content of the school curriculum? What types of information are involved, and what are the relationships between them? What different formulations are there of this content? What is our idea of the characteristics of scientific knowledge? What is science? How is it constructed and why does it change? What do we know about other forms of knowledge that are relevant to the school context? What types of knowledge are involved in that context and how are they related?

- The students' ideas (García Díaz, 1999): What is the nature of the students' ideas? Are they incoherent, arbitrary, and not very consistent? Do they follow general models, or are they always specific ideas relating to particular situations and content? Are they common to many students or are they widely diverse? How do the students' ideas change? How can one question the ideas without falling back into a model of error substitution? What learning strategy should be encouraged in each situation and for each particular content? Which are the useful techniques and strategies for exploring and analysing the students' ideas?

- The formulation of school content (Porlán, 1999): What should be, and what actually is, the social function of obligatory schooling? What model of human and social development is the referent for our professional activity? What is 
the role of academic subjects in the basic education of a citizen? Which sources should we use, and which do we actually use, in preparing school content? What is the legislation in this regard? What of the textbooks? Who should be responsible for formulating which is the desirable body of knowledge for our students? How should we formulate, organise, and present school-level knowledge? How extensive should it be, and how deeply should we go into it? What types of knowledge should we consider?

- The methodology of teaching (Azcárate, 1999): What should a sequence of activities be, and how should it be oriented? How can one formulate a realistic hypothesis of desirable school-level knowledge that takes into account the point the students start out from, and their expectations and potential interests? What hypothesis of progression should be established in order to overcome potential learning difficulties, and how can this be put into practice? Which activities, and in what sequence, might favour the change and significant evolution of the students' ideas? What methodological moments exist and on what are they founded? How are the dynamics of the classroom to be managed and regulated? How are spaces and times to be organised? In the management of the class, what role does the teacher play, and what role do the pupils play? etc.

- Evaluation (Martín del Pozo and Rivero, 2001): What models of evaluation exist, and on what are they based? What conception of evaluation is compatible with the research approach to teaching? To what degree does evaluation allow our curricular hypotheses and, in the long term, our practical professional knowledge to be subjected to empirical tests? How can the pupils' learning be evaluated rigorously? What data should be collected and how should they be collected in order to obtain suitable information about the curriculum in action? What roles are pupils and teachers to play in the evaluation and decisionmaking process? etc.

- The planning and development of teaching units (Martín del Pozo and Rivero, 2001): How can meaningful and coherent relationships be established between the what, the how, and the evaluation? What models of planning teaching units exist, and on what are they based? How can one guarantee that the development of the teaching unit has meaning and coherence for both the teacher and the pupils? etc.

- The planning of a complete course (Martín del Pozo and Rivero, 2001): What general progression hypothesis could be established and on the basis of which criteria? How does one select and organise the different objects of study coherently with the general progression hypothesis at the same time as being attentive to classroom dynamics? What models of course organisation exist, and on what are they based? What distinct moments or phases can we distinguish during a course, and on the basis of which criteria? etc.

Definition of the personal pedagogical model (Martín del Pozo and Rivero, 2001): What are my general pedagogical principles? What is the knowledge that forms the foundations of these principles? What degree of coherence is there between my principles and those foundations? What norms for action are deduced from them? What types of relationship should exist between a pedagogical model and specific professional actions? etc. 
The resolution of these practical problems requires input from other kinds of knowledge different from one's own experience. They thus endow the set of sources of information described above with a particular significance (see Figure 3.1).

Research into these problems allows one to:

- Organise networks of sub-problems, which are appropriate to the characteristics of a specific context.

- Organise schemes of professional knowledge to serve as referents for intervention (chosen and organised in accordance with the resolution of the specific professional problems being dealt with), in the form of authentic practical theories.

- Set up a hypothesis of the progression from the knowledge at the start of the process to what has been regarded as the desirable (also the referent) knowledge, with especial attention paid to the obstacles against constructing the required degree of complexity and improvement of the teachers' knowledge (see Figure 3.2 ).

- Organise a set of teaching resources and activities that we consider particularly appropriate (readings, videos about real classroom situations, Peterson and Treagust, 1998; instruments to detect the students' conceptions and examples of their analysis, Jones, Carter and Rua, 1999; the more frequent obstacles and patterns of action, Joram and Gabriele, 1998; Porlán, Rivero and Martín del Pozo, 1998; plans and sequences of activities that aid in overcoming obstacles, specific case histories, Zuckerman, 1999; etc.), and which must serve as support for the process of reconstructing a teachers' knowledge and performance.

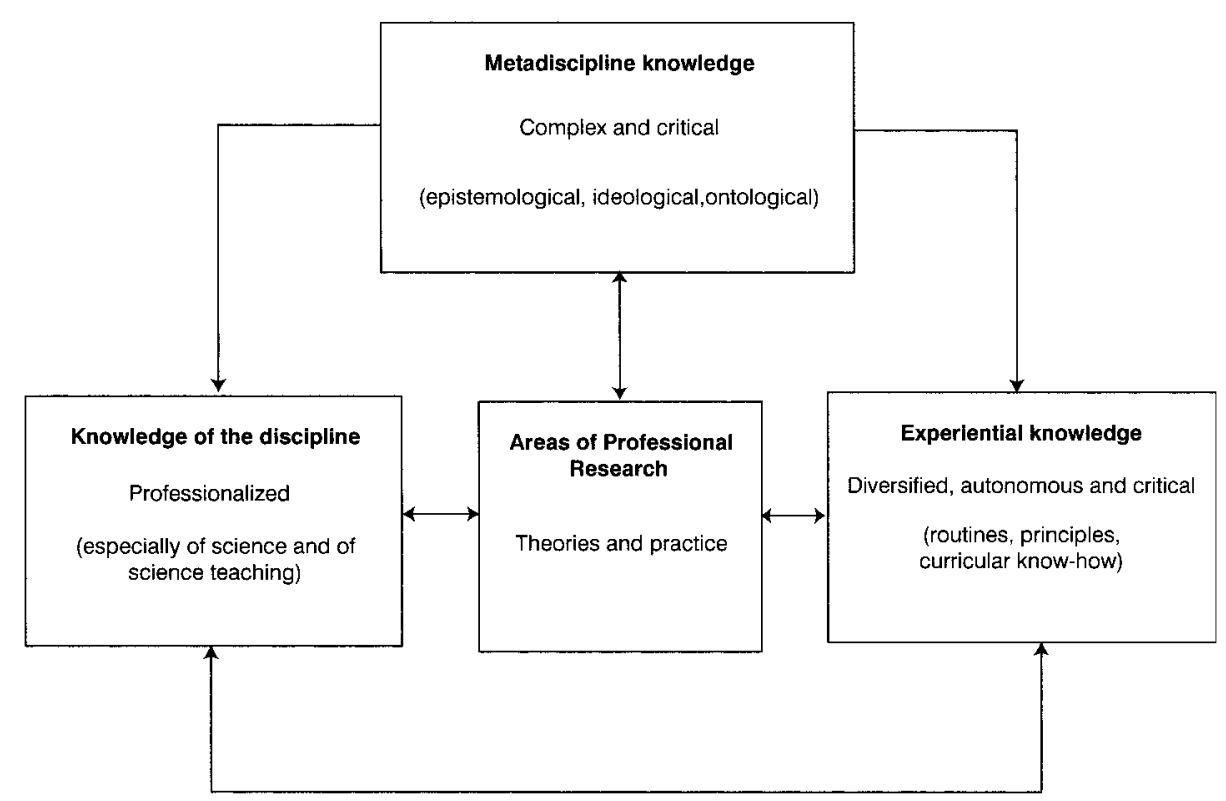

Figure 3.1 The role of the areas of professional research in articulating praqctical professional knowledge 


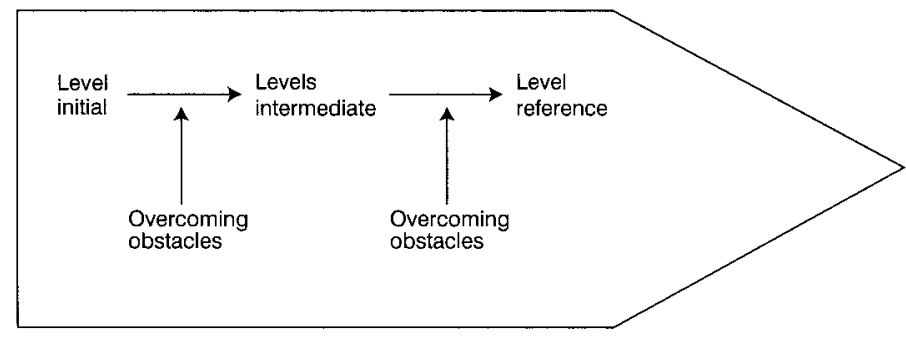

Figure 3.2 The progession of the development of professional knowledge

\section{Scientific Knowledge in Initial Teacher Education}

During the 1999/2000 academic year, we worked in our class on two inter-related blocks of issues. The first was oriented towards encouraging reflection on the various kinds of argument that we should take into account when designing a proposal for intervention, and which constitute the foundations of our curricular proposal. We hence included in this block work corresponding to two different areas: one related to school subject matter and the other related to the pupils' ideas. A period of negotiation with the students led to settling on the following problems as the specific content of this first block of the course:

- Problem 1: What utility does the curricular area "Knowledge of the Environment" have for the citizen in general? How is this knowledge appropriately taught?

- Problem 2: What are the characteristics of the scientific knowledge related to "Knowledge of the Environment"?

- Problem 3: What ideas do the pupils already have about the content of the area of "Knowledge of the Environment", and how much do these ideas influence learning?

The answers that were elaborated to these problems were used later as elements against which to test the curricular proposals that the students designed.

The second programmed block was directly focused on curricular design in the aspects of what and how to teach. The particular problems worked on in class were:

Problem 4: What knowledge should be taught in the area of "Knowledge of the Environment?

- Problem 5: What is the appropriate way to teach this knowledge?

We next present, by way of an extract from our "teacher's diary", an example of how we develop our classes in the Initial Teacher Education of prospective primary school teachers with respect to the areas of professional research.

\section{Context}

Class with student teachers in the speciality of Infant Education. We describe the activities performed within each problem situation, and the students' difficulties or obstacles that we detected. 


\section{Problem worked up with the students}

Problem 2 of the course: What are the characteristics of the scientific knowledge related to "Knowledge of the Environment"? Our intention was to call into question ideas, which are usually held by a majority - this is true, superior, objective knowledge, etc. so that they can construct an idea of school-level knowledge that is different from a simple reduction of science.

\section{Activities carried out}

\section{Activity 1. Reflection on the nature of science}

The students respond individually to an anonymous questionnaire on science. The majority ideas detected were:

Science as a set of items of knowledge (an accumulative and encyclopaedic view).

They emphasise observation and experimentation as basic procedures in scientific method. Very occasionally, reference is also made to study.

- Scientific knowledge is a superior form of knowledge because it is true, objective, and neutral, since the scientific method allows it to be unequivocally checked against reality.

- The changes that scientific knowledge undergoes are accumulative, basically due to technological advances.

\section{Activity 2. Analysis of some relevant documents}

The students have to read six short simple texts, of a popularising nature, which attempt specifically to deal with the aforementioned ideas, but give certain information which contradicts them. They must then note down in their class books what they do not understand, the most significant phrases that they agree with, the most significant phrases that they disagree with, and a final synthesis (in a short paragraph) of what they think the authors are trying to tell us.

In class, we discuss and clarify what was not understood, as well as some of the students' syntheses. It is particularly interesting to compare the latter, because two things usually occur. One is that the synthesis is a more or less long, more or less detailed summary of what was said in the text, without managing to detect the central theme that was the object of discussion in the text. The other is that different students may have completely opposite interpretations, some of them being very far removed from the intentions of the text that they read. For instance, one of the texts that they read is The Inductivist Turkey by Bertrand Russell. This text describes and criticises ironically the inductivist method in the production of scientific knowledge. Various groups reach the conclusion that "to do science", one has to act in the same way as the turkey: make repeated observations of a phenomenon, and from them enunciate a law or, according to these groups, even a theory. The last part of the text, in which the turkey's head is cut off on Christmas Day, is considered by some groups to be a sort of final gag, without any relevant meaning.

A similar case occurs with another text (The Science of Umbrellas) which attempts to show that the more or less strict following of the "scientific method" is no guarantee that the problem being investigated and the resulting knowledge will be relevant to science, and far less with the product attained being considered as scientific. Some groups' conclusions, however, are in the line that scientific knowledge can be 
elaborated, "from everything that surrounds us", i.e., that "science is everywhere, all around us". It is even possible, as is described in the text, to make a scientific theory that relates the colour of the umbrella to the gender of the person carrying it: "Women carry coloured umbrellas, men black ones".

In our opinion, there may be two basic reasons behind these facts. The first difficulty or obstacle that strikes one is that the students seem to have only a poorly developed ability to analyse texts and extract from them the most relevant information. The second, of equal or even greater importance, is that they seem to believe that any information which is in a written form, and more so if it has been given them by their teacher, must be true information and taken as such.

\section{Activity 3. Small group and whole-class debate about the previous questionnaire}

The students subsequently return to the initial questionnaire, this time in groups, and take into account the information that came from the discussion of the texts. They mostly now found the group work "hard" (their words), and very tiring. We do not know if the problem was that the topic (after all, it is the epistemology of scientific knowledge) is a little dry, or not of their interest.

The conclusions they reached at this stage were:

- Science is an organised set of items of knowledge at different levels (data, concepts, laws, and theories), which attempts to explain reality, which is compartmentalised into different disciplines, and which is elaborated by specialists. It took us nearly a whole class session to reach this consensus, because after three or four groups had given their definition of science, a doctoral student who was attending the class as a guest posed a very interesting question for debate: the information that had been given up to that time would equally do to define science as the knowledge, for example, of a baker. Then, either one has to admit that the knowledge bakers have with respect to their profession and to the elaboration of their products is scientific knowledge, or one has to improve the definition. We believe that the resulting discussion was only really followed by a few students in the class. Although it could perhaps have been more fruitful, we were only able to reach the more or less shared idea that science is an attempt to explain reality, while bakers attempt to be more effective in their work (better tasting and therefore more competitive products, or cheaper ingredients that achieve the same effect, etc.). The groups should perhaps have considered this issue more calmly, with time to discuss it, to look for information, and so on, instead of taking it on directly in a debate which could only be followed by a few.

- Science is also a process (research), which is fundamentally characterised by the posing of interesting problems and by the researchers' hypotheses being subjected to rigorous testing (whether logical or empirical, direct or indirect). The reading and discussion of some of the texts (The Inductivist Turkey, for instance, seeing is not always believing) had already called into question the students' prior conceptions on the importance of observation and experimentation in the production of scientific knowledge. Thus, although in the consensus there again appeared in some groups the idea that it is observation that initiates a line of research, other groups argued against this idea, holding that what one observes depends on one's knowledge, or interests, or whether or not a problem has already been posed and one is making observations in that context, etc. 
With respect to the importance of direct comparative testing with reality, the groups' interventions were more homogeneous. We had to propose counterexamples to provoke any questioning of their ideas. It was also necessary to establish new relationships with the readings to question the direct passage that most of the students proposed between the positive test of a hypothesis and the elaboration of a theory, since they had given no special relevance to the role of the scientific community itself in mediating this step.

- It is a valid (not necessarily true) and intersubjective type of knowledge, which may undergo different types of changes: extension, substitution, and modification.

During the course of this debate there arose some problems that we decided to resolve later, when we define what to teach. Examples were:

- The ultimate goal of scientific knowledge is to seek general explanations about the world, while that of bakers is to allow them to try to do their work as efficiently as possible. So what is the ultimate goal of school-level knowledge?

- What type of information should be worked up with the students? Concepts, theories? At what level?

- Is scientific research translatable to a classroom? To what degree?

- Who must endow school-level knowledge with validity? The teacher, the pupil, the class as a whole?

- Scientific knowledge is unique. Must school-level knowledge also be unique?

\section{Conclusions}

In this work, we have tried to offer a brief overview of how one can facilitate the construction of professional knowledge with regard to the areas of professional research.

It is our hope that the epistemological perspective adopted to analyse the teachers' knowledge, together with other possible perspectives, might contribute to a real transformation of our own practice in teacher education, improving our professional know-how and that of the teachers we are educating. Thus, although our students generally showed satisfaction with our classes, we are aware that these classes are clearly improvable with respect to teaching and potentially profitable with respect to our own research. Some of our current concerns constituting the lines along which this work will proceed are:

- To improve the education given to our students with respect to the procedures and strategies they will need in order to be more self-sufficient in learning: analysing, designing, drawing conclusions, etc.

- To perform a far more detailed and rapid follow-up of the evolution of our students' conceptions, in order to apply appropriate educational strategies and resources that match their needs as closely as possible.

- To somehow foster a far more direct connection between initial and ongoing teacher education, in the sense of endowing our students with tools that will allow them to subsequently continue their professional development and not in isolation. 


\section{Chapter 4}

\section{How to Affect the Quality of Teacher Education:}

\section{A Four-Year Policy-Driven}

Project Implemented at University Level

\section{Beatrice Avalos}

\section{Introduction}

This short paper analyses results of a large-scale project to reform initial teacher education in Chile. Countries with similar or lower levels of development as Chile also shared the project that finished its implementation in 2002, targeting problems in the field of teacher education. The information base, besides my own experience as Project Co-ordinator, comes from mid-term evaluations in all institutions in the years 1999-2000 and the final assessment made in 2002 (Avalos, 2000). ${ }^{1}$

There was a need for teacher education reform because what had been one of the best systems in Latin America in the first part of the twentieth century had largely deteriorated. Amongst the reasons for the situation was the downgrading of teachers, teaching and teacher education institutions that occurred as a result of economic policies and political forces in the 1970s and 1980s (cf. Avalos, 1996; Reimers, 1994). Both the teacher education institutions and the schools and parents judged the quality of teacher preparation by the mid-1990s as being of low quality. The Ministry of Education had been engaged in reforms to the educational system, especially a new curriculum, and considered that it was essential to intervene within the limits of its authority on programmes that were largely part of universities. To address the situation about US $\$ 30$ million was set aside to fund teacher education projects presented on a competitive basis by university institutions, both public and private. To influence the quality of applicants for teacher education another fund was allocated for scholarships to be given to able high-school leavers entering teacher education programmes. 
No blueprint was provided on how or what the changes should look like, but there was guidance about where change should be focused: curriculum, practical experiences, and quality of teacher educators and relationships with the school system. The implementation of the idea was handed over to a small team at the Ministry of Education, and their task was to turn the idea into practice. What happened in the course of time, not so much in its successive events, but in the mode in which change took place, follows in the rest of this paper.

\section{The Initial Kick}

With a diagnosis that showed: curricula to be outdated; a diminishing number of students entering teacher education programmes (with low qualifications); teacher educators and academics who had remained isolated from intellectual and professional ideas elsewhere; teaching that was mostly theoretical and a practicum placed at the end of the four to five year programmes; with libraries that lacked up-to-date books and journals and with almost no computer infrastructure - there was a gigantic task ahead. The institutions that responded to the Ministry's call for improvement projects considered that all components of teacher education had to be looked into. After a year-long preparation and two external evaluations per project, seventeen university programmes were awarded funds to implement their projects over a period of four years. They covered 80 percent of the student teachers and the institutions extended all over the country.

\section{The Key Change Concepts}

The change areas in the projects reflected emerging re-conceptualisations of what had been until then the dominant theoretical perspectives in teacher education in Chile. ${ }^{2}$ These new concepts were found in one way or another in all of the projects, but really began to make greater sense in their implications as the implementation phase proceeded.

- A gradual shift towards a constructivist view of learning.

- Recognition of reflective teaching, action-research, learning by doing, as targets according to which teaching strategies might be reoriented.

- Learning to teach through collaboration.

- Learning to teach as a growth process embedded in the whole programme of studies.

In what follows, the main change areas are sketched considering summarily what was achieved (what innovations), and what is still pending and why (permanencies).

\section{Change Areas - Innovations and Permanencies}

These occurred at two levels: (a) the teacher education institutional level, and (b) emergent areas. The areas of curriculum, practicum and teaching and learning strategies are selected to illustrate the first category, while networking and quality control illustrate the second set. In each case, we look at innovations and permanencies (situations resistant to change and factors affecting this). 


\section{Teacher education processes at institutional level}

Curriculum changes have occurred in all institutions. From a structural perspective the main targets were to reduce the number of fragmented and disconnected courses, to reduce the number of hours of face-to-face instruction, and to watch for both vertical and horizontal integration among curricular subjects. It involved revising contents and bibliography as well as learning strategies required from students. What happened in relation to this reform is presented in Table 4.1.

The second change area refers to the process of preparing teachers and specifically to altering teaching and learning strategies in the direction of constructivist and reflective-learning outlooks. Changes and permanencies are presented in Table 4.2.

The third, and perhaps most important, change area has been the field experiences or practicum, that has been reformulated so that practical learning to teach is gradual and progresses from the first or second year of teacher education towards full teaching responsibility in the fourth or fifth year. Changes and permanencies are illustrated in Table 4.3.

\section{Emerging change areas}

As the project developed over time in all seventeen institutions, issues emerged that had not been specific targets for action at the beginning of the programme. Also, activities that were barely sketched as desirable initially took a much more specific focus. They are grouped in two categories: quality control and networking, and are outlined in Table 4.4.

The move from cultures of competitiveness and closure towards communication and networking has been one of the important emergent areas. Table 4.4 illustrates how this has been achieved.

\section{Table 4.1 Curriculum}

\section{Changes - Innovations}

- Less face-to-face instruction (all institutions).

- Specification of time allocated for student independent learning (most, but not all institutions).

- New frameworks for organising the curriculum - e.g. integrative themes instead of courses or contents (two institutions).

- Introduction of integrative activities Problem-Based Learning and Workshops (two institutions).

- Revision of curriculum contents for all courses and activities (all institutions gradually - not all completed).

- Introduction of cross-sectional themes or courses dealing with broad value issues (curriculum of about four institutions).
Permanencies

1. Insufficient reduction of face-to-face instruction as judged by evaluators of almost all projects. This is due to academics' resistance and job related concerns. Also, to concerns about content knowledge and professional knowledge time allocations.

2. Vertical and horizontal integration still precarious - especially in secondary teacher education programmes that are managed by several Faculties.

3. Partial updating of curricula and bibliography. Unwillingness to explore new avenues by some academic staff, time factors, and not enough knowledge of languages other than Spanish.

4. Variation in the time and proportion allocated to content, professional knowledge, general knowledge and practicum.

5. Student resistance to curricular change. 
Table 4.2 Teaching and learning strategies

\begin{tabular}{ll}
\hline Changes - Innovations & Permanencies \\
\hline - Open or implicit focus on constructivist & More active learning is observed in \\
learning. & $\begin{array}{l}\text { classrooms of all institutions, but too } \\
\text { much reliance on more or less }\end{array}$ \\
- Introduction of active delivery & stereotyped forms of group work. \\
strategies, especially group-work or & Fear of academics of altering their \\
workshops along with the classic & habitual and longstanding way of \\
lecture mode. & doing things, and, insufficient \\
- Introduction of ICT as a course (in all & knowledge base about alternative \\
institutions) but linked to teaching & active learning strategies explains \\
activities in only a few. & permanencies. \\
& Insufficient bibliographic resources to \\
& support active learning in all \\
institutions despite the resource & allocation for such purchases.
\end{tabular}

Table 4.3 Learning to teach - the practicum experiences

\begin{tabular}{|c|c|}
\hline Changes - Innovations & Permanencies \\
\hline $\begin{array}{l}\text { New progressive structure of practicum } \\
\text { experiences (all institutions). } \\
\text { Diversity of activities of early contact } \\
\text { with schools and classrooms moving } \\
\text { from the ability to recognise problem } \\
\text { situations to engagement in independent } \\
\text { teaching. } \\
\text { - Mentor preparation programmes (four } \\
\text { institutions). } \\
\text { Incentives for schoolteacher } \\
\text { collaboration (5 or } 6 \text { institutions). }\end{array}$ & $\begin{array}{l}\text { - Not all academics participate in the } \\
\text { preparation and implementation of } \\
\text { practical activities. } \\
\text { - Lack of a system of incentives for } \\
\text { mentor teachers. } \\
\text { - Traditional segmentation between } \\
\text { content and practice, affects curricular } \\
\text { integration and the representation of } \\
\text { content knowledge areas in the } \\
\text { practicum activities. }\end{array}$ \\
\hline
\end{tabular}

\section{The Beginning of a Conclusion}

Four years to revamp all major components of teacher education programmes are, clearly, insufficient. There are cultures, ways of thinking and of doing embedded in historical circumstances that slow the pace of change, however important or valuable it may be judged by those involved.

However, after completion of the projects, it was clear that unwittingly a very powerful model of change became operant. This model consists in linking institutional change actions with support and monitoring from the ministerial co-ordinating body. As such it clearly represents Fullan's principle $(1993,1999,2000)$ of change without an initial detailed blueprint, and change that combines pressure and support. There were no specific targets set out initially (although now this is considered a shortcoming), but rather what Elliott (2000) defines as a "pedagogically driven perspective on educational change". The need to refocus initial plans was always accepted and cooperatively discussed. On the other hand, as the project progressed the need for standards 
Table 4.4 Quality control processes

\begin{tabular}{ll}
\hline Changes - Innovations & Permanencies \\
\hline - New progressive structure of practicum & - $\begin{array}{l}\text { Study visits initially seen as a } \\
\text { "reward" and therefore a degree of } \\
\text { criticism regarding the criteria to }\end{array}$ \\
- Gradual focussing of activities directed & $\begin{array}{l}\text { award these "study visits". } \\
\text { to improvement of teacher educators }\end{array}$ \\
such as study visits abroad. & $\begin{array}{l}\text { Those who benefited from the study } \\
\text { visits did not always convey to others } \\
\text { the result of their work - or there was }\end{array}$ \\
- Institution-initiated evaluations to deal & little to show of its effect on teaching. \\
Awareness of the need for common & This, however, is now under greater \\
standards, discussion, production and & control. \\
experimental implementation in four & Standards are feared as an element of \\
institutions. & control or as a form of imposing a \\
- Improvement of quality of student & learning. Therefore some level of \\
intake - search for instruments to & resistance to evaluating student \\
diagnose basic skills difficulties - & teachers using the National Standards. \\
preparation of basic skills diagnostic & However, widespread discussion has \\
test that was tried out in 5 institutions. & changed this perception. \\
Acknowledgement of the need for a & \\
system of accreditation - participation & \\
in the national committee that discussed & \\
and agreed on an accreditation system & \\
for teacher education. &
\end{tabular}

and a system of accreditation was recognised. Fullan's concept of "mediations" was important in this respect. There were mediations of ideas, stimulus, and information about possible change directions offered by the National Co-ordination team, but also mediations from project co-ordinators to their local constituencies as well as among project co-ordinators. To some extent, these mediators helped to produce changes in language and a "tacit conversion of knowledge", as Fullan puts it, among their peers within and among institutions. Some institutions feel that they are now ready for a next step of focalised projects, and also for writing the story of their change efforts, with its highs and lows.

\section{Notes}

1 The evaluations covered the areas of (a) Curriculum, Teaching and Learning Processes; (b) the preparation of Science and English Secondary Teachers; (c) Information and Communication Technologies in the Teacher Education Programmes; and (d) the Management of the Projects.

2 Behaviourism and competency-based teacher education. 


\section{Chapter 5}

\section{Learning from the Conversation of New Teachers}

\section{Frances O’Connell Rust}

Over four years of monthly meetings, I have listened to the talk of pre-service and beginning teachers in Friday evening conversations. As I have analysed my notes from our conversations, I have seen a variety of patterns emerge. The most obvious of these is that there is a qualitative difference in the ways pre-service teachers talk about themselves and the work of teaching compared with the talk of beginning and more experienced teachers, and these differences hold important lessons about learning to teach and about teacher education itself. Less obvious, but equally important for their implications for teachers' professional development, are the ways in which both pre-service and new teachers' conversation work as exemplars of autobiographically situated reflection and insight. Finally, consideration of who speaks, when, and about what has provided me with insight about what is important to these new teachers and has helped me to think critically about what works in preservice and in-service teacher education.

\section{Pre-service/In-service}

In the New Teachers' Conversation Group, participants talk about themselves, their students, their teaching, and their schools in ways that speak of their lived experience as learners and as new teachers who are learning about teaching. Members of the group who are pre-service students use their autobiographies, lived experience, and life as pre-service students as referents. They talk in general terms and of abstract concepts. James' introduction of himself is an example.

James is a junior. A thirty-year-old undergraduate, he's had a lot of time to think about teaching and to study it. Having tried college several times, James has strong opinions about good teaching. He says that he can't remember a time when he didn't want to teach. Growing up in the suburbs of Chicago, he was keenly aware of racism and the power of teachers as leaders. He wants to teach in emancipatory ways to empower students.

Members of the group who are in their first years of teaching situate themselves as teachers and talk in specifics about life in classrooms. Take, for example, this excerpt 
from the introduction made by Sara, a first year teacher, during our very first conversation group meeting in April 1996.

Sara tells us how she has reached out to a child who does not shower and smells quite bad. She moved the child up to the front of the room right near her desk. She took to spraying air freshener around herself and the child. She talked with the child and arranged for him to bathe in the morning in the sink at school before the other children came. Simultaneously, she talked with the child's mother. She discovered that there was always laundry in the bathtub of their home. Sara, the child, and the mother developed a schedule that went on the fridge at home that enabled the child (and other family members) to use the tub twice a week.

As the years go on, the pattern remains. Pre-service students simply do not have access to the complexities and subtle textures of life in classrooms and schools that is the milieu of the teachers in the group; nor do they have opportunity to shape the life of classrooms in the ways that are available to their teaching colleagues. Thus, the conversation of pre-service students situates them on a different experiential plane from that of classroom teachers in the group, even from teachers who have only been teaching for a few months.

\section{The Role of Autobiography}

Autobiography plays a major role in our conversation; however, it appears in different ways depending on who is talking and where the speakers are in their professional journeys. For those in the group who are pre-service students, autobiography emerges frequently in introductions and is cited as the experiential foundation for their theories and actions. They tell of their backgrounds and how these have played into their decisions to become teachers and their visions of who they will be and what they will do. Among first year teachers, autobiography rarely emerges. When it does it is something that we, as a group, call for, or it is something that is prompted by the conversation and works to situate the speaker as a teacher in a particular setting. In this way, autobiographical stories help to provide critical insights into teachers' thinking that work to enable the group not only to understand the speaker's actions but also to provide professional support.

Two examples might help:

1. On her first night with the conversation group, Anita, a senior who came from a comfortable home in the mid-west, told her story of coming to NYC as a teenager and deciding then and there that she wanted to make a difference. As part of her narrative, she incorporated the story of the starfish thrower - a boy who upon encountering hundreds of starfish on a seashore returns one to the water; when asked what difference throwing back one starfish would make given the huge number on the beach, he responded that it would make a difference to this one. By the middle of her first year in a school serving very poor children, Anita was questioning her idealism. She seemed distanced from her students. She was telling stories of her school but they were not from her classroom. They were stories told by other teachers. Despite the strong support 
that she was getting from a caring staff developer, she made the decision at the end of the year to leave teaching in the public schools.

2. Like Anita, Mari began with the conversation group as a senior. She was confident, secure in her knowledge of teaching and completely opaque when it came to discussing her own background. Her first year of teaching was in a very difficult school serving low-income families in one of the outer boroughs of New York City. Unlike Anita's, it was not a school that any of us were familiar with, thus, there were no familiar sources of support available to her.

From her first week of teaching, Mari was critical of the children. She talked about them as "delinquents" and was reluctant to do things that the other new teachers were doing such as share her own library of books with them. She seemed to have forgotten all that she had been taught about guided reading, hands-on math and science, and social studies made relevant to their lives. Instead, according to Mari, her time with her fourth graders was devoted completely to keeping them in their seats and keeping them quiet. In a matter of days, some of the children began to challenge her authority. They refused to do things that she told them to do. At least one called her "bitch". In response to our questions, Mari said that her response was "to ignore those kids". She said that she was following the advice of other teachers in the school who told her this was the way to handle such behaviour. She held to this response until May when, in a conversation about helping children to deal with anger, Mari asked Christie, a second year teacher, "What should I say?" Christie responded with, "You've really hurt my feelings. I'm not talking to you." Mari then said, "I don't know how to do that. All my life, I've been taught to ignore stuff like this. When I was a little girl and got teased about the way I looked (she was the only Asian student in her school), my mom would tell me, 'Just ignore them.' The teachers all tell me to do the same thing."

Mari's description of a life-long pattern had unlocked the door on her resistance, enabling us to negotiate a solution with her that would fit her and her students. In subsequent meetings, the conversation continued with descriptions of the lives of children in other teachers' classrooms and of the conditions in their schools and where the sources of support were for them. With these situated narratives, Mari was being told in many ways and at many levels that she was not alone. She is now in her sixth year of teaching.

For me, both stories are noteworthy. Anita's because the story that she chose to tell about who she was and why she chose teaching spoke to the idealised image of the teacher that she and so many others carry with them and to the distance that they must maintain in order to hold onto that idealism. Mari's story is noteworthy not only for what it tells about the power of autobiography in shaping teachers' understandings and practice but also for what it tells me about ways of knowing our students that are possible in teacher education. I had advised Mari when she transferred into the program and continued to do so through her remaining two years. I had worked with her in classes. But I did not know her; nor did her peers in the program and the conversation group. Formal interactions between professor and student were not sufficient for Mari's story to emerge. Over time, all of us have learned that there have to be ways for the type of authentic conversation around real classroom issues that is the substance of the conversation group's discourse to emerge in pre-service teacher education. We have also learned that groups like this are essential in the continuing professional development of teachers. 


\section{Topics of Conversation}

As I have studied our four years of conversation, I have identified six topics that occur with enough regularity to be considered critical foci for beginning teachers. These are assessment; classroom management; contexts and norms of schools; curriculum; getting, changing, and keeping a job; and kids. Each of these is addressed within a framework of providing professional support and enabling self-knowledge that seems to characterise the interaction of the group. There is a cycle to these topics over a year that has to do with who initiates them and with the cycle of activity in schools. Getting a job, for example, is a topic raised most often by pre-service students in anticipation of December or May graduations. Discussion of the contexts and norms of schools are interwoven with discussions of jobs in ways that suggest that the conditions of the workplace have a definite impact on new teachers' perceptions of teaching and on experienced teachers' considerations about their workplace. When teachers in the group find themselves in settings where there is virtually no support, the issue of finding a new job arises. This is as true of a first year teacher as it is of teachers in their second and third years. Decisions about moving from one school to another seem to peak at points when teachers are most free to move: January and summer months.

Discussions of classroom management originate with new teachers, particularly those who are struggling; the pre-service teachers in the group never initiate them. Conversations about classroom management are often interwoven with discussions of problem children and are generally initiated by teachers who are concerned about a child's progress and fit in the community of the classroom. Like discussions of classroom management, pre-service teachers rarely initiate these conversations.

Discussions of curriculum weave through discussions of assessment. Both are, in fact, central foci of the group's conversation occupying approximately 50 percent of our discussions. Curriculum surfaces in a variety of ways that relate to the cycle of activity in schools as well as to the group's interests and expertise.

Over time, it has become clear that this predictable set of topics appears and disappears at regular points across the year in a conversational spiral. Each time a topic appears it is handled with greater depth and sophistication, mirroring the experiential growth of the various members of the group. Thus, there is a development and rounding out of a topic across time and relative to experience. Pre-service students address a topic in one way, first year teachers in another, and second year teachers in still another way.

This pattern has held throughout our four years of conversation to the extent that I now know that it will be: first year teachers who raise the issue of classroom management and experienced teachers in the group who will address it; pre-service teachers who worry about finding jobs and the experienced teachers who push one another to move to schools where they will have support to teach as they were taught to teach; experienced teachers who will raise the issues of curriculum and assessment and pre-service teachers who will take notes and probe for further information.

\section{Conclusion}

Over these four years, we have learned that professional development in teaching might best be accomplished as a peer-mediated experience. The development of our conversation over time has involved us as a group in breaking down the barriers between 
pre-service and in-service teaching. My students now work with recent program graduates who are their cooperating teachers, and our graduates return each month to share their stories and draw on the wisdom of the group. And while we continually have new members join the group, our talk has moved from a general survey of the conditions of teaching and schools to a genuinely interactive discussion in which members draw on one another's knowledge and expertise. This is due in large measure to the continued participation of several members of the group since its inception; but it also relates to the development of our understandings about what the first years of teaching entail and what works in teacher preparation to support new teachers' transition to the real world of schools.

There is a complex interplay of individual and collective storytelling in our on-going conversation that resides in trust and confidence in one another. This interplay, it seems to me, has worked in ways that promote the development of the various participants as well as the whole group. The conversation group is, we have concluded, a form of sustainable professional development for teachers and by teachers that is not a substitute for teacher education. Rather, it enables a contextualised and selective revisitation of ideas and activities first encountered as student teachers. And beyond the re-visitation of ideas and concepts from pre-service days, the more experienced teachers' stories and advice breaks new ground and constitutes a credible curriculum of professional development for new teachers in challenging circumstances. In our conversation group meetings, we gather around the table and talk with one another in ways that blur the distinctions between pre-service and in-service teaching and that move us forward in pursuit of teaching well. 


\section{Section B}

\section{Teacher Practice}

This section presents a variety of perspectives on teachers' practices. Judith Warren Little's keynote address "Inside Teacher Community: Representations of Classroom Practice" continues her interest in teachers' professional relationships and examines the significance such relationships have for teacher development, teachers' careers and commitments and the implications for school reform. Her research responds to claims that the idea of "professional community constitutes an important contributor to teacher development, the collective capacity of schools, and improvements in the practices of teaching and schooling". She speculates on a "black box" of plausible but unexplored and unspecified relationships" that has yet to be fully opened. Teacher activities inside and outside of the classroom are discussed as possible interactive supports for instructional improvements. She critically explores the idea of teachers' community by using case studies and by drawing on a variety of research and theory that assist explaining current understandings of teachers' practices.

Kennert Orlenius' chapter entitled "The Contemporary Basic Values of School: 'The Emperors' New Clothes'?", uses H.C. Andersen's story as a metaphorical bridge to discuss the potential fraud of how values ought to be represented in schooling contrasted with what actually happens. He uses the concepts of universalism and communitarianism to understand the differences by focusing on curriculum from Denmark, Norway and Sweden. The "empty code" values often represent in practice is elaborated by describing basic values as espoused in the Scandinavian countries. His conclusions include an admonition for readers to be critical and reflective and to take advice from children who are often more clear-headed than adults.

Jukka Husu's contribution, "Exploring the Landscape of Teachers' Tacitly Implied Ethics", examines philosophical, ethical and pedagogical justifications that contribute content and meaning when teachers claim to be acting in the best interests of students. The everyday work of teachers and how the tasks and duties expected of them represent an empirical perspective is not often contrasted with more philosophical forms of inquiry and dialogue. Professional and institutional obligations are illustrated through a case study and described as a series of codes: rational, situational and moral character. Plural understandings are argued to provide a more comprehensive basis for understanding situations and how to deal with them.

Tove Pettersson, May Britt Postholm, Annlaug Flem and Sigrun Gudmundsdottir's chapter, entitled "Cultural Scaffolding: The Arts and Crafts Teacher's Mediation with her Students with Behavioural Problems", examines the socio-cultural nature of classrooms and the forms of instruction that capitalise on that interest. The authors demonstrate how arts and crafts, because of their roots in traditions and solid cultural footing, represent a viable entry point for understanding and dealing with behaviour problems. From activation of the "living word" through conversations with more experienced others, skills are developed in both academic and social domains that pertain to cultural knowledge, skills and attitudes. The experiences of "Tina", a teacher, 
are used to illustrate "considered risks" cultural scaffolding took acknowledging the co-creation of understanding through culture and cognition.

Barbara Šteh and Barica Marentič Požarnik's chapter, "What is Actually Happening in Secondary Classrooms? The Rhetoric and Reality of Curricular Reform", considers the differences between the plans and hopes for school reform and the perceptions held by students and teachers in classrooms. Qualitative and quantitative measures can be used to create a portrait of teacher thinking during times of great change and shifting expectations. A more bottom-up view of school reform is evident and elaborated by including the student voice about needs not considered. Discrepancies likely to lead to problems were identified and activities proposed to address them in meaningful ways. 


\section{Chapter 6}

\section{Inside Teacher Community: Representations of Classroom Practice}

\section{Judith Warren Little}

For more than two decades, I have pursued interests in teachers' professional relationships and their significance for teacher development, teachers' careers and commitments, and school reform. In this paper, I continue a set of investigations into professional community as a locus for teachers' work and teacher development. More specifically, I take up the problem of how classroom teaching practice comes to be known, shared, and developed among teachers through their out-of-classroom interactions.

This analysis responds to steadily expanding claims that professional community constitutes an important contributor to teacher development, the collective capacity of schools, and improvements in the practices of teaching and schooling. These claims amount to a certain optimistic premise (see Figure 6.1). Researchers posit that conditions for improving teaching and learning are strengthened when teachers collectively question ineffective teaching routines, examine new conceptions of teaching and learning, find generative means to acknowledge and respond to difference and conflict, and engage actively in supporting one another's professional growth (Achinstein, in press; Grossman et al., 2001; Gutierrez, 1996; Little, 1990, 1999; Louis

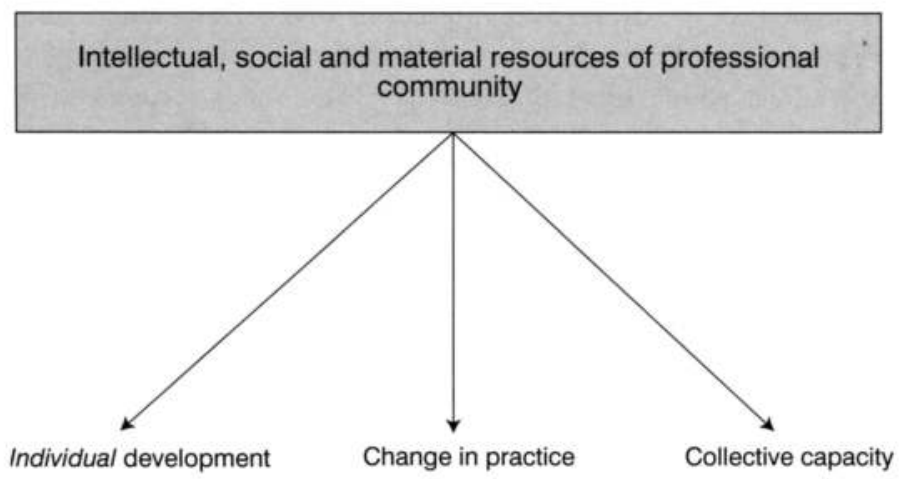

Figure 6.1 The optimistic premise of professional community 
and Kruse, 1995; McLaughlin and Talbert, 2001; Stokes, 2001; Talbert, 1995; Westheimer, 1998). Taken together, this body of work marks considerable progress in the conceptualisation and measurement of collegial interaction, and in specifying the attributes of professional communities.

Yet relatively little research examines the specific interactions and dynamics by which professional community constitutes a resource for teacher learning and innovations in teaching practice (Little, 2001; Wilson and Berne, 1999). In particular, few studies focus closely on the teacher development opportunities and possibilities that reside within ordinary daily work. Anne DiPardo's (1999) detailed ethnographic portraits of four teacher collaborations suggest that sorting out teachers' learning opportunities and trajectories in the course of their everyday work will be a complicated undertaking (see also Willman, 2001; Aguirre, 2001; Little, 2001). Nonetheless, if professional community operates to enable and create teacher learning, it ought to be evident in the ongoing encounters that teachers have with one another.

In a paper published in 1987, I speculated about what resources teachers might supply one another as colleagues, and how time spent together might plausibly translate into benefit to students:

Is it that lesson planning improves as people press each other to say not only what they do with students, but why? Is it that the toughest, most persistent problems of curriculum, instruction, and classroom management get the benefit of the group's experience? Is it the combined sense of confidence and obligation that teachers carry into the classroom? Is it the peer pressure to live up to agreements made and ideas offered? Is it that in making teaching principles and practices more public, the best practices are promoted more widely and the weakest ones are abandoned? Is it simply that close work with colleagues affords a kind of stimulation and solidarity that reflects itself in energetic classroom performance and holds talented teachers longer in the profession? (Little, 1987, p. 494)

At the time, I was speculating about a black box - a set of plausible but unexplored and unspecified relationships. Elsewhere at about the same time, I argued for investigations that would map the configuration and boundaries of teachers' professional ties within and beyond schools ("meaningful reference groups"), and would examine the content of collegial interchange. Regarding the latter, I sought "... a more close-grained account of the moral and intellectual dispositions that teachers bring to or develop in the course of their relations with one another" that would be informed by "careful scrutiny of the actual talk among teachers, the choices teachers make in concert, or the ways in which individual actions follow from the deliberations of the group" (Little, 1990, p. 524).

More than a decade later, this particular black box still remains largely to be opened. The fact that we have yet to do so places some serious limitations on the optimistic premise. So, suspending that optimism for the moment, I want to delve more fully into the questions of what constitutes the intellectual, social and material resources of professional community. Among these resources, I am particularly interested in what is afforded - or not - by accounts of classroom events, circumstances, relations, possibilities, and dilemmas that teachers put forward in work that transpires largely outside the classroom. 
In taking up this problem, I am acknowledging the arguments put forward by researchers and professional developers about the likely value of learning from and in practice (for example, Ball and Cohen, 1999). I am also responding to a likely policy interest in whether and how investments in teachers' time together outside the classroom might actually produce or support instructional improvement inside the classroom.

To pursue this curiosity, I am drawing primarily on intensive case studies of teacher knowledge, practice, and learning among teachers of mathematics and English in two high schools. My focus is on teacher groups that (1) have some clear collective identity (the teachers describe and name themselves in collective terms, sometimes in relation to a formal unit such as a department and sometimes with respect to more informal affiliations such as the "Algebra Group" or "Academic Literacy Group") and (2) profess a clear task orientation (the teachers see themselves as engaged in improvement-oriented professional work together). That is, this design is not organised to inquire into other kinds of informal groupings that may have personal or organisational significance but are formed around interests quite ancillary to teaching tasks (the "smokers") nor does it take into account routine exchanges in the informal settings of the school workplace, including staff room talk of the sort that Hammersley (1984), Woods (1984), or Ben-Peretz and Schonmann (2000) have analysed. Rather, the study takes up the question of what teacher learning opportunities and dynamics of professional practice are evident in teacher groups that consider themselves collaborative and innovative. ${ }^{1}$ The research team ${ }^{2}$ employed a range of conventional data sources and methods - observation, interviews, pen-and-paper instruments, and school documents - but the most central of these data, for my purposes, are the audio- and video-taped records of situated interaction among teachers.

\section{Useful Precedents in the Investigation of Teacher Community}

Certain useful precedents are particularly evident in the analysis I am developing. By useful precedents, I mean those theoretical frames and empirical bodies of work that I believe offer a foundation for emerging investigations of teachers' situated workplace practices. Evolving conceptions of occupational community and communities of practice offer a broad conceptual frame and set of organising problems.

Consistent with this broad frame are two bodies of empirical research-studies of workplace practices in diverse fields, and studies of teacher discourse in the context of formal professional development activity - that suggest ways of parsing the practice of teacher community and establishing its relationship to outcomes of interest. Finally, the heuristic notion of "affordances", joined to traditions of discourse analysis, supplies an analytic device for specifying the nature of teachers' collective practice and tracing trajectories of learning and change.

\section{Conceptions of Occupational Community and Workplace Communities of Practice}

I have framed this analysis most directly in relation to the sociological conception of occupational community, with its emphasis on work practices, identities, social relations, and socialisation processes (Van Maanen and Barley, 1984), and the related but broader 
community of practice literature with its orientation toward persons' mutual engagement in practice, the centrality of participation and its resources, and the notion of trajectories of learning (Wenger, 1998; Lave, 1996; Lave and Wenger, 1991). This framing permits a close focus on the nature of collective professional practice without falling prey to any assumptions about its virtues. Just as Popkewitz (1991) questions the premise of progress so routinely associated with discussions of reform, I question the premise of improvement in teaching knowledge, practice, and commitments associated with participation in professional communities. On this point, Wenger (1998) cautions:

Because the term "community" is usually a very positive one. I cannot emphasize enough that these interrelations [of mutual engagement, joint enterprise, and shared repertoire] arise out of engagement in practice and not out of an idealized view of what a community should be like. (pp. 76-7; see also Gusfield, 1975)

And further:

Claiming that communities of practice are a crucial locus of learning is not to imply that the process is intrinsically benevolent. In this regard, it is worth repeating that communities of practice should not be romanticized; they can reproduce counter-productive patterns, injustices, prejudices, racism, sexism, and abuses of all kinds. In fact, I would argue they are the very locus of such reproduction. (p. 132)

I have been consistently concerned about tendencies to romanticise collaborative or cohesive professional relationships (for example, Little, 1990). However, I do admit to a personal and professional interest in whether and how teacher communities turn out to be contributors to educational improvement. Educational scholars have a legitimate interest in questions of the public good associated with teacher communities; it matters whether those communities cultivate the capacity and the disposition to provide a high quality education for all children. We require a clear and accessible way to name communities that embody those qualities. For example, McLaughlin and Talbert (2001) employ three years of interview, survey, and observational data from 16 American high schools to differentiate "teacher learning communities" from strong "traditional communities" and further to distinguish both of these cohesive groupings from more individualistic, atomistic workplace environments. They have made an important contribution in decoupling the "strong" community from the "good" community; that is, they demonstrate that cohesive workplace communities need not necessarily be organised for wider benefit, and begin to specify the attributes of those communities whose strength is rooted in broader commitments to the public good.

At the same time, I find it problematic on both theoretical and practical grounds to reserve the designation of "learning community" to a subset of teacher communities whose dispositions we may admire. Theoretically, it becomes difficult to explain the emergence of "traditional" orientations without accounting at the level of practice for teacher learning and socialisation. Absent data on actual practice, it also becomes difficult to understand why teacher groups whose members are united by their expressed commitments to improvements in student learning and in classroom practice sometimes fail to achieve much of either. ${ }^{3}$ With some significant exceptions, prior work on the construct of "professional community" tends to rely primarily on interviews and surveys 
(sometimes supplemented with observations recorded in field notes) to differentiate varieties of professional community. If we are to theorise about the significance of professional community, we must be able to demonstrate how communities achieve their effects. This will require examining the specific interactions and dynamics by which professional communities constitute a resource for teacher learning and the formation of teaching practice.

\section{Empirical Investigations of Workplace Practice}

Mid-level concepts emerging from studies of workplace practice in fields outside education, together with the research methods employed in these studies, provide a rich and under-utilised resource for the study of teachers' workplace practice and professional community. Researchers have exploited advances in video and audio technology to uncover the practices by which people at work learn, construct, coordinate, and transform their practice (Barley and Orr, 1997; Drew and Heritage, 1992; Engestrom and Middleton, 1998; Hindmarsh and Heath, 1998; Middleton, 1998; Schegloff, 1992). Three examples serve to illustrate the potential utility of these studies for investigations of teacher community:

Access to practice and the "horizon of observation". One issue in understanding the nature and significance of communities of practice is how the practice comes to be known, shared, and changed through participation (Wenger, 1998). In their volume on situated learning, Lave and Wenger (1991) introduced the idea of "legitimate peripheral participation" to account for learning in communities of practice. The cases of apprenticeship briefly summarised in that volume suggested how participation might be quite differently organised to create or limit opportunities for learning and competent membership. In his studies of novice marine navigators, Hutchins (1996, p. 52) employs the term "horizon of observation" to define the extent to which elements of a work environment are available as a learning context. This horizon of observation structures how completely novices or newcomers are able to see, hear, and participate in the work in question: its central tasks, tools and instruments, relevant categories and terms, and lines of communication. As in the cases of apprenticeship summarised by Lave and Wenger (1991), these horizons vary in the degree to which they create broad or narrow opportunities for observing others, their interactions, and their tools. Of interest in studies of teaching and teacher community is the relative insularity of the classroom - its restricted horizon of observation.

Transparency of practice, or "publicly available features". More specifically, then, one might wonder about what specific aspects of work come to be visible through teachers' participation with one another, and with what fullness and specificity - what I have elsewhere termed the "face" and "transparency" of practice (Little, 2001). In their transcript records of veterinary surgeons working together, Pinch, Collins and Carbone (1997) show how assessments of a task's difficulty become a "publicly available feature of skill". 
Through their analysis of one feature of practice - the difficulty of specific tasks - the researchers introduce the more general concept of publicly available features of practice. This notion of publicly available features might profitably be applied and extended in studies of teachers' communities of practice. That is, Pinch and his colleagues focus on issues of a task's difficulty; they anticipate but do not actually investigate possible distinctions between what is difficult to learn and what is difficult to do. Other aspects of work practice might also be more or less publicly available, including the socio-emotional aspects of classroom life, the centrality or importance of certain tasks, or the consequences attached to doing something well, poorly or not at all.

Categories and classifications. A related body of research, not limited to workplace studies, focuses attention on the system of categories and classifications by which members of a community organise and communicate practice. Writing about "classification and its consequences", Bowker and Star (1999) employ examples as disparate as the history of the International Classification of Diseases (ICD), race classification in apartheid South Africa, trajectories of tuberculosis treatment, and shifts in the nature and codification of nurses' work to show how the creation and maintenance of classificatory schemes constitute fundamental kinds of social practice. Classification schemes operate in part to render the ambiguities of the world as if they possessed the "clarity of social facts" (Mehan, 1996, p. 243). Because they are inevitably (and continuously) historical, political, moral, and cultural constructions, and because they tend to form a taken-for-granted, invisible infrastructure of working practice, classifications supply both resources for and impediments to learning and change. ${ }^{4}$ In one analysis of data from our current study, Ilana Horn (2001) shows how routine ways of classifying students are taken up differently by the mathematics teachers in two high schools as they justify curricular decisions and explain students' difficulties or failures in mathematics; the result is to create quite different opportunities to examine and problematise practices of mathematics teaching and learning.

\section{Studies of Teacher Interaction in Professional Development Activity}

The most well-developed body of research on situated interactions among teachers has emerged from studies of teachers engaged in formal occasions of professional development. The occasions and groups that form the context for these studies differ from those of our own study in certain significant ways: the occasions entail a more explicit, formal, and sustained focus on teacher learning; they reserve time and space for purposes of professional development; they sometimes involve designated facilitators or experts who are researchers or professional development specialists; and the teacher participants may come together for professional development while not working together on a daily basis in the same school. Among the specialised 
programs of professional development that have yielded this promising body of research are: programs grounded in teachers' investigation of children's mathematics learning (Fennema et al., 1996; Franke et al., 1998; Stein et al., 1998); a "book club" of high school English and Social Studies teachers in which teachers grappled with the nature of text and text interpretation in English and History (Grossman et al., 2001); networks of teachers focused on the study of literacy practices (Greenleaf and Schoenbach, 1998; Florio-Ruane and Raphael, 2001; Lieberman and Wood, 2001) or teaching and learning practices in other disciplines (Brandes and Seixas, 1996; Pfeiffer and Featherstone, 1996; Rosebery and Warren, 1998; Seixas, 1993); teachers' deliberations on problems of student assessment (Gearhart and Wolf, 1994; Wilson, 1994); and a range of other teacher study groups (for example, Clark, 2001; Stokes, 2001).

Despite differences in research context, this line of investigation provides an important source of issues and guidance for investigations of teacher development in everyday work. Methodologically, these studies underscore the challenges in specifying the resources of professional community and teacher learning in the ordinary, mundane interactions of teachers at work together. Substantively, these studies point to the difficulty that teachers encounter in achieving sustained and deep consideration of teaching problems and possibilities, even in conditions formally structured for that purpose, and to related difficulties in contending with difference and disagreement on matters of practice. However, the few available longitudinal studies document participants' shifts over time in the focus and depth of conversation and in a group's capacity for airing, acknowledging and responding to differences and conflicts. Such studies have implications for studies of ongoing teacher work groups, calling attention to the composition and stability of the group over time, to its (enacted) conception of the work in which it is engaged, and to the role played by various participation structures and norms in creating and sustaining explicit attention to problems of practice. In what ways do all of these features permit teachers to make visible their understanding and practice of classroom teaching, and to learn, interrupt, problematise or re-invent those practices?

\section{Heuristic notion of "affordance"}

Finally, to locate and specify the resources of professional community, I have borrowed the notion of "affordance", which has its origins in studies of animal perception (Gibson, 1977) and is consistent with organising concepts in ecological psychology and in sociocultural analyses of cognition (see Greeno, 1998). ${ }^{5}$ For my purposes, which focus on the construction of professional practice, identity, and relationship, the heuristic notion of affordance calls attention to the multiple possibilities made available in and through talk, gestures and material artefacts. Used as a frame for fine-grained discourse analysis, it helps specify and locate the available resources for learning while acknowledging the inherent ambiguity, open-endedness, and indeterminacy of social practice and learning (Mehan, 1996; also Little, 2001; Wenger, 1998). As I use it here, the term affordance also owes a debt to Stokes' (2001) strategy of describing selected professional development activities in terms of what they enable or do not enable by way of teachers' collective inquiry into practice.

In examining these records of teacher interaction, I translate the notion of affordances into two broad questions: 
- What facets of classroom practice are made visible in out-of-classroom talk and with what degree of transparency? By the facets or "face" of practice, I mean those categories and aspects of practice that are made available for consideration in the topics taken up in conversation and through any material artefacts that teachers bring with them, create in the moment, or otherwise have available. By transparency, I mean the degree of specificity, completeness, depth and nuance of practice apparent in the talk and the associated artefacts.

- How does interaction open up or close down teachers' opportunity to learn? Embedded in this second question, and its image of "opening up" and "closing down", are two organising problems or concerns. One is for the orientation toward classroom practice and collegial practice conveyed by teachers' interactions, and specifically for how the teachers orient to problems of "improvement". The second organising concern centres on the structures and processes of participation, and specifically on whether and how teachers are enabled or constrained in taking up the problems and possibilities of classroom practice.

\section{Representations of Classroom Practice in Out-of-classroom Talk}

Using those organising questions or problems as entry points, I turn now to the data to examine three selected occasions on which portrayals of classroom practice come up in the routine out-of-classroom interaction of teacher groups. Although the instances that follow do not exhaust the ways that classroom practice is made manifest in our data, they do serve to demonstrate some of the analytic possibilities and dilemmas. My view is that these representations, taken together, greatly complicate the expectations we might have about what makes a "teacher learning community" and what differentiates such a community from a "traditional community" - and further, about what it will mean to investigate teacher learning in the context of ongoing teacher work.

\section{\#1: English Department meeting - portraying students' problems as problems of teaching}

Members of the English Department at East High School have repeatedly mentioned in passing to one another that their students have difficulty with various aspects of writing and specifically with conventions of grammar. As the school year begins in fall 1999 , they propose to devote part of their regularly scheduled department meeting times to talking about this problem. At the first monthly department meeting on September 20, two teachers have taken the lead in organising a discussion of how students respond (or not) to teachers' feedback on their writing. Miyuki has written a prompt on the board in the classroom where they are meeting, inviting the other teachers to write their responses underneath. The resulting display is reproduced in Figure 6.2.

In constructing the prompt in this way, Miyuki and Lynne convey certain assumptions about the participants' practice as English teachers, i.e. that teachers do make comments on student papers, and that they have goals in doing so. In crafting their responses, the teachers construct an artefact (albeit a transient one, erased when the meeting ends) that accords with those assumptions, one that positions each of them publicly in relationship to instructional goals. Miyuki observes that it "looks like everyone is sort of in some way on the same page as far as what our goals are". She 


\section{When I make comments on my students' papers, my goal is ...}

$>$ to reinforce their strengths and draw attention to major weaknesses (usually one or two)

$>$ to try to let them know that they did something right/well; let them know what to do differently next time (sometimes scold, I will admit)

> to be clear and specific and to improve drafts or future writing; to explain why

$>$ to encourage students and at the same time give them focus on how to make the most of their words

$>$ to let them know that I actually do read their papers

$>$ to be clear and encouraging while at the same time pointing out what needs to be done

$>$ to be clear and thoughtful and suggest improvements in a forceful way

Figure 6.2 Teachers' written accounts of goals for student feedback

continues in a vein that portrays this as a conversation about departmental consistency or uniformity in practice, and is subsequently echoed by the department chair (Patrick):

MIYUKI: So what I wanted us to see, what we're sort of on the same page about. And then try to see um, what we actually do when we get a paper in our hands, I guess. Our goal is to try to come up with some norms about common department preferences on paper and so there can be some consistencies. Not that we have to follow the exact same phrase every time, but some consistencies in terms of our understanding what our goals are and trying to help these students.

PATRICK: We said before that we were really interested in trying to come up with regular comments, both discussing comments that work and didn't work and comments that caused change, in sharing those. We are also interested in coming up with comments they [students] would $<$ see $>$ from the time they entered this school until the time they left.

However, others' comments suggest that their interest in this conversation may be driven less by a shared commitment to departmental consistency than by an interest in expanding individual instructional options:

UNIDENTIFIED: I'm also - <like > to [know?] what other people say because I find myself getting in a rut of running "Good!". Good, it was like a little vocabulary of comments. Yeah, I'd love to expand my glossary. 
CARLENE: I did these paragraphs this weekend and half of them start out with "good" and the other half start out with "not bad." I just realised ... I went "Oh God, okay, that needs to be more creative."

In effect, two different purposes that are potentially in tension - consistency or uniformity on the one hand, and individual "creativity" on the other have now framed the group's discussion. It is at this point that Lynne enters the conversation in a way that further complicates the group's focus and broadens the purposes the teachers might have in discussing their written feedback to students:

LYNNE: Well Patrick, Patrick I'd like to speak on this topic as well and what I did in somewhat of a hurry was to copy a couple of pages in two different students' papers. One is a paper I thought that was an above average interpretive in-class essay. And I just copied two pages of it. Above average in its thought format and its structure but too much summary, which is often the problem for me when teaching interpretive essays. They just summarise the quote. And then I copied an excellent couple of pages of an eleventh grade AP essay just to same thought, it was a good example of interpretive writing at its best at this level. So what I actually - Patrick [department chair] had asked me to talk about - or had asked us to talk about how to norm the comments that we make.

And I thought of something over the weekend that I thought is actually important to talk about before we even talk about the comments we make because I have a really hard time teaching interpretive essay, getting them to look different. And so I wanted to share these few thoughts ... on some sort of revelations I had about getting them to interpret.

She continues:

One of the things that I realised that I think we were talking about at our tenth grade meeting too is that when they are-there's a difference between showing quotes and telling quotes, just like there is a difference between telling statements - "She is really pretty" - and showing statements - "Her eyes are (.) whatever." ... But what we do want them to do is quote passages that show, through imagery, new language, something that needs to be interpreted. And something relating to you know making a connection between an image and a character's conflict or discussing the motivation for a character's actions ...

So the reason for my talk about this is that I realised that the comments that I write that are probably the most problematic both for me and the kids are things like "push" or "deeper" or "so what?" and maybe a few others. And I write this all the time because they are always so shallow in their commentary, either summarising what the quote already says and they say "Well, I can already see that. I've already read the story. You don't need to tell me that", or just not being effective, not being very deep. So I'm constantly writing things like this and what I realised was if I could get them to 
understand the difference between a showing quote and a telling quote, I probably don't even have to write so many of these comments.

Without purporting to analyse this excerpt fully here, I point to a few of its distinguishing features. Lynne supplies the group with actual samples of student work from her classes, one of which exemplifies a probiem in student performance. She identifies the problem as a recurrent one (and thus presumably worthy of attention) and interprets the shortcomings of student performance as a recurrent problem of teaching: "often the problem for me when teaching interpretive essays". Adding that "I have a really hard time teaching interpretive essay", Lynne (a) speculates about a reason that her students may continue to have difficulty - they don't understand what is called for in demonstrating the basis for an interpretation ("showing"); (b) concludes that her written feedback is inadequate to help students recognise or remedy the problem; and in effect (c) argues that discussing "how to norm the comments that we make" may not go far enough to remedy students' writing difficulties, especially if that discussion is de-coupled from a discussion of what students find difficult ("if I could get them to understand the difference between a showing quote and a telling quote"). Throughout, Lynne operates on the premise that the teachers share a certain language for talking about teaching writing (for example, a distinction between "telling" and "showing"). She also acts as if disclosing problems of practice and reasoning publicly about those problems are expected features of departmental practice; similarly, she acts as if the group's ordinary practice permits teachers other than the department chair to take initiative in opening up discussions of classroom practice.

In several respects, this is an instance that could be thought to embody the "optimistic premise" of teacher learning community. A group of teachers reserves time to engage in mutual problem-solving; a teacher discloses a problem of teaching practice and publicly accepts responsibility for helping students by revising her instruction; and evidence of student learning is on the table for the group's consideration. At the same time, the glimpse of Lynne's classroom is limited - two samples of student work chosen "in somewhat of a hurry" are handed out as Lynne is talking, with no provision for more than a cursory skim by the teachers present. Lynne's verbal account of her own usual feedback to students and that of others ("push", "deeper", "so what?", "good", "not bad") suggests that it may not be uniformly as encouraging nor as specific as one might anticipate from the list generated on the board, but neither Lynne nor any of the others calls attention to the teacher feedback actually written on the two writing samples.

In the 30 minutes or so reserved for this discussion in a 90-minute department meeting, ${ }^{6}$ teachers carve out an opportunity for concentrated attention to issues and practices of classroom teaching but its affordances prove complicated to unpack. The portrayals of classroom dilemmas and performances go well beyond a quick anecdote to include samples of student work and some detailed exegesis of the problem of teaching and learning the interpretive essay. Yet this representation of teaching, the face of teaching it makes visible, is both fleeting and incomplete, insufficient to grasp fully what Lynne's own practice encompasses in "teaching interpretive essay" or "making comments" on student papers.

As a display of the group's own collective practice as the "English Department" - the way its members elicit and treat accounts of classroom life - this episode is also both revealing and ambiguous. The teachers have publicly agreed they want to devote 
blocks of meeting time to the problems of teaching writing, but the dynamics of this episode suggest they may have no established practice for doing so. They do, however, have established routines and norms by which individual teachers take leadership in designing and presenting curriculum ideas. It may be this collective precedent for individual initiative in curriculum that Miyuki relies on when she structures an activity that focuses the conversation on consistency or "norming" of teachers' feedback on writing, and that Lynne embodies when she makes her move to redefine the focus of discussion. No one challenges Lynne's move at the time. Indeed, the teachers engage avidly in the discussion that follows Lynne's "revelation" and are still deep in conversation at 5:00, when their meeting typically ends. The department chair then intercedes, saying:

PATRICK: Can I ask a process question? It's 5:00. What do you guys want to do? This is such a valuable discussion. ... Can we, I just found what you guys did really helpful. And I think maybe if we all came with our thoughts about the effective ways to teach and comments that we're using that we might be able to do the same thing with a broader $<<$ ? $>>$ in another words. Um, can we plan to do that?

However, there is some evidence that Lynne's shift from a conversation about consistency of practice to a conversation about its effectiveness was not entirely unproblematic. As Lynne acknowledges, the department chair had established the original charge ("Patrick had asked me to talk about - or had asked us to talk about how to norm the comments that we make"). At 5:00 p.m., when Patrick subsequently turns the group's attention to plans for a follow-up discussion, he credits this discussion with having been "valuable" and "helpful", but adds, "I also want to come back to the idea of us norming." Lynne promptly apologises for taking the conversation in another direction, but a colleague counters, "No, that was brilliant." Another teacher concurs: "Maybe we can't have a norming discussion until we've dwelled a little bit deeper ... into how we communicate interpretive writing."

In this first department meeting of the year, then, members of the group display a disposition both to coordinate certain instructional practices (issues of consistency) and to engage in reflection or inquiry regarding their practice (issues of worth or effectiveness). Further, and crucially, these twin dispositions are shown to co-exist in a certain tension. To coordinate practice, in this case by aiming for consistency in teachers' feedback on student writing, is to embrace a collective responsibility for instruction but also to grant selected practices the imprimatur of certainty. To question practice is to delay agreements on more uniform practice, while making issues of purpose, worth, and effectiveness available as matters of collective concern. Representations of classroom practice surface in ways that advance both of these interests, while also showing how those interests are co-constructed, negotiated, and reconciled through participation in the group's routine work together.

\section{\#2: The Algebra Group's "check-in" routine and an intern's teaching problem}

A day later, in a classroom nearby, the Algebra Group is holding its weekly meeting. These mathematics teachers have committed collectively to increasing students' access to and success with college preparatory mathematics. Their classes are a heterogeneous mix of students, including both those who have succeeded with 
mathematics and those who have accumulated a record of struggle and failure. The teachers also share certain values and ideas about curriculum and pedagogy, including the use of small problem-solving groups and a curriculum built around what they term "group-worthy problems". On this occasion, they have devoted slightly more than an hour to discussing various mathematics problems, how they have approached teaching them, and how their students have responded. Having completed that work, they turn to the routine the group calls "check-in", in which each participant takes a turn to report how things are going in the classroom or to raise an issue or problem related to teaching and learning.

As each of the teachers takes a turn, seven teachers cast their contributions primarily as descriptive reports of their classroom activities and progress. The remaining four participants (two teachers and two interns) explicitly introduce some issue or problem with which they are struggling; these problem statements and the related discussions account for more than 75 percent of the time spent in checking in, 20 of 26 minutes.

The problem posed by Tina (an intern or novice teacher) consumes the group's attention for fully 10 minutes. Tina begins by expressing pleasure in what her students are able to accomplish, but then introduces a dilemma that she has been unable to resolve:

TINA: But the thing about my students is that there's kids that know a lot and then there's kids that you know, feel like they're slow learners. And I'm trying to find group-worthy activities where the kids who are fast learners and the kids who are slow learners, that it can close the gap. So that the kids that are slow learners can contribute and can you know feel smart, but I don't know if I can find activities that are group-worthy, activities like that. Because I can feel the "um" frustration of the fast learners, like, this is easy! I already know the answer! And then there's kids that are slow learners that are like give me a chance to find the answer and it's almost like they kind of give up because they feel like it's a speed competition, like who can get the answer the fastest kind of thing. And I'm trying to close the gap between that and that's been one of my frustrations I think. [Algebra Group Meeting, 9-21-99]

Tina frames the problem as one in which "fast" students constrain the opportunities and erode the motivation of "slow" learners to work through a problem, while the "fast" students express impatience with the pace of activity required to accommodate their "slower" peers. She also frames a solution with which she seeks the group's assistance or advice - finding activities that could somehow satisfy both groups and "close the gap". Rather than advising Tina directly about activities, others in the group take up Tina's framing of the problem as centring on the capacities of "fast" and "slow" students and how they relate to one another and the tasks of the classroom. Carrie, a relatively new teacher, speculates that what Tina is experiencing is a dilemma of well-established status relationships in the classroom:

CARRIE: I wonder if it's not just the activities you're doing but also just status. You know? I mean even if you did give them a groupworthy task, those kids who feel like they have low status will just continue to play that role... 
Guillermo, an experienced teacher and co-chair of the department, expands on Carrie's argument by tackling the very definition of what it means to be "fast" or "slow".

GUILLERMO: ... what I find is that when I have mindsets like that that they get in $m y$ way in terms of thinking about the curriculum. ... Um ... But that - I think that's from - from thinking about a group of kids as slow learners and that's, that's how we're, we're acclimatised to - to think about learning. Um. One thing I'm - I'm thinking about is the ones that are moving through things really quickly, often they're not stopping to think about what they're doing, what there is to learn from this activity. So ... um. I'm making stuff up because I don't know your kids. But, but - like find - think of the ones that you think of as fast learners and figure out what they're slow at. [abridged excerpt]

As the conversation unfolds, the teachers turn back to the possibilities that reside in specific classroom activities (like the "problem of the week"), but now with an eye toward how Tina might interrupt students' own assumptions about what it means to be "smart" or "fast".

This, too, strikes me as an instance that could be thought to embody the optimistic premise of teacher learning community. The routine of "check-in" organises opportunities for everyone to participate and invites the public airing of teaching issues, problems, and uncertainties. It illuminates the way in which systems of classification or categorisation organise ways of talking and thinking about students, subject, and teaching. It also suggests how those systems of classification may also be problematised ("fast kids, slow kids") in ways that open up spaces for learning and for the transformation of practice. Carrie and Guillermo might have responded with suggestions for activities as Tina requested, but focus instead on the way that Tina is talking about the students. ${ }^{7}$

At the same time, this excerpt suggests the kind of risk and strain to which individuals and groups become vulnerable when teachers put problems of teaching on the table. Tina could well have experienced Carrie's and Guillermo's responses as both unresponsive to her plight (her felt need for activities) and as a criticism of her as a teacher (having an inappropriate "mindset"). Perhaps sensitive to those possibilities, Guillermo makes it a point to continue the conversation one-on-one with Tina after the meeting; in conversations with the research team, he underscores the importance of establishing a sense of trust and safety within the group.

The teacher learning potential of this episode is complicated in other ways as well. The full 26-minute "check-in" segment reveals that not all problems and issues elicit the same kind of attention and participation. The moments for extended consideration of practice are co-constructed in ways whose meaning and significance are not immediately apparent. Of the four problems put forward by teachers and interns on this occasion, two get taken up at length (Jill's for 6 minutes early in the segment and Tina's for 10 minutes near the end of the segment). The remaining two are deflected in some manner - one by a joking response from teachers and the other by the presenter's own rapid change in topic. What might explain the group's selective attention to problems and issues, or to the participants who raise them? And finally, what about the classroom accounts rendered by seven of the participants as apparently straightforward descriptions of classroom activity and progress? Consider these excerpts: 
JILL: I am introducing guess and check in my warm-ups this week.

JILL: My focus this week is perimeter and surface area.

HOWARD: Mine too is perimeter and surface area this week.

LANI: Um, we're just trying to get off the ground with lab gear ...

TINA: I'm going over perimeters and I'm introducing a little bit of surface area ...

CARRIE: My goals in warm-ups are getting a geometrical idea of what fraction is and being able to translate something numerical into geometric ...

ANNIE: I've been doing a lot of geometric representations with the T-tables ...

GUILLERMO: Um, so I started a problem of the week today ...

Compared with the discussion of Tina's problem, these declarative statements of activity and progress seem almost mundane ("I've been doing ...", "I'm going over ...", "I started ...", "My focus this week ..."). The teachers make use of certain expected topical categories of high school mathematics (surface area and perimeter, geometric representations). Yet the group's language is also remarkably dense, specialised, and localised in ways that could not be predicted simply by knowing the subject domain. In the full transcript, two teachers speak of how they are using "warm-ups", three teachers refer to "guess and check" and five teachers speak of "lab gear" in ways that suggest that others in the room do and should share an understanding of what those terms mean. It seems likely that this local pedagogical talk serves to animate the standard mathematical topics that participants have listed in marking pace and progress, leading teachers to envision, for example, what it would look like in practice to "introduce" surface area.

These localised terms mark what it means to become a knowledgeable and competent member of this group, and further how each teacher is positioned to others with regard to issues of mathematics teaching and learning. That is, they establish not only the basis on which the group constitutes a group in the first place, but also the basis on which differences among the participants might surface. How might each of these routinised accounts be heard and evaluated by others as an indication of curriculum choices and pace, instructional strategy and its rationales or purposes, views of mathematics, and conceptions of students? However unremarkable the contributions may appear, any one of them could conceivably mark problematic issues in the group or in a given teacher's relationship to the group. How are the participants thereby positioned in relation to each other by how they describe what they are up to in the classroom? What interpretive resources would be needed to understand that positioning?

Both the time reserved to talk about writing in the English Department meeting and the check-in routine among the Algebra Group teachers stand out as bounded moments in the teachers' ongoing work when problems of practice appear to have heightened 
visibility. Both of the highlighted instances - Lynne's reported insight into the limitations of her written feedback to students and Tina's difficulty in teaching "fast kids" and "slow kids" together - entail an explicit move by one or more teachers to disclose a problem of teaching practice and to invite commentary from others as part of ongoing, ordinary group work. These are perhaps the kinds of moments most clearly anticipated by such terms as "teacher learning community", and one concern for this analysis is to look more carefully at when and how such moments arise and unfold.

However, such explicit and focused considerations of teaching problems are not the only occasions for invoking classroom events, circumstances or dilemmas as the teachers pursue their ongoing work. I cannot map out a full array in this short paper, but a final excerpt will introduce the problem of how representations of classroom practice come to be situated and embedded within ongoing work and discourse.

\section{\#3: Weekly meeting of the Academic Literacy Group - the challenge of being "on track"}

The Academic Literacy Group consists of five English teachers who have agreed to develop a new $9^{\text {th }}$ grade course titled Academic Literacy. The course focuses on helping students develop strategies for improving their reading comprehension in high school. The teachers' aim is to develop a curriculum together and to all teach from the same lesson plans and materials. In subsequently describing their collaboration to a group of fellow teachers, a spokesperson recalled their intent to really take a stance of inquiry in this process, and really learn from our work, and do our work by asking questions about what our roles were as teachers, and what we thought our students might need to know, and what we would want them to be able to do. And we've gone through this process really through questioning ourselves about how everything's going ... [Leigh Jacobs, team presentation at the monthly $9^{\text {th }}$ Grade meeting, March 13, 2000]

Weekly meetings serve principally as a means of coordinating their work and talking about "how it's going". When the teachers meet on September 15, school has been underway for a little more than one week. Karen Olsen has taken the lead in planning the group's first curriculum unit, and this is the teachers' first opportunity to confer about their progress. From informal conversations prior to the meeting, Karen has become aware that other teachers have not been able to maintain the schedule she anticipated in designing the first curriculum unit. As the meeting opens, she says, "I think that what we should maybe talk about for a minute is what does that mean, that we're all at different places."

Karen's statement becomes an occasion for talking from and about the classroom. Teachers first offer explanations for being "off track" or "behind", all of them resting on certain imperatives and dilemmas of classroom practice. At the same time, the teachers orient to their shared expectation of closely coordinated teaching, joining Karen in seeing "off track" or "being behind" as a legitimate problem. As they try to calibrate how far "off track" is acceptable, Patrick says:

PATRICK: I would go for 2-3 [days]. But I also think that $1-2$ is realistic. What I'm saying right now is that I think that what's important for me with my class, especially with these kids who are 
silent the first 2 days, 3 days, 4 days of school, is setting norms. And I think that my class is actually going to go much faster because of the norms that - not faster than yours, I'm saying much faster than it would have because of what we're doing now than it would have gone had I not stopped to do some of this stuff. ... And they also this whole - I mean I spent a lot longer setting up the [independent reading] logs than I would have thought I needed to do, but it was clear to me from what they were doing that they weren't doing what I wanted them to do.

Two other teachers (Lora and Leigh) concur that some of the activities that Karen has planned are taking longer to complete than they anticipated, and Leigh adds her observation that individual classes present different challenges and are moving at a different pace from one another:

LORA: And I took a good half an hour going around and helping kids one-on-one with their notebooks because they were a mess and they weren't getting how to organise them. I mean, I'm behind too.

LEIGH: I'm about the same place that Lora is, but I should also add that I've yet to feel in either of my classes that I've had a successful lesson. Um, my fourth block class is starting to come together, and so I let this - a little project go a little bit further today because I saw them begin to work together...

Among them, the three teachers (Patrick, Lora and Leigh) construct this set of explanations for being behind:

Explanation 1: (Patrick) Unaccustomed to teaching lessons planned by someone else. Explanation 2: (Patrick) "Setting norms" for participation in my class takes precedence over lesson pace and curriculum coverage right now, and will make it possible to move faster later.

Explanation 3: (Patrick) The process of "setting up" the materials and routines for a particular activity (weekly student reading logs) took longer than anticipated by the plan.

Explanation 4: (Lora, extending Patrick \#3) Everything has taken longer than anticipated by the plan.

Explanation 5: (Leigh, extending Patrick \#2) Have had to adjust pace and approach differently in each of two classes.

Explanation 6: (Lora, extending Patrick \#2 and Leigh \#5) Time-consuming one-onone trust-building necessary with some "challenging" students who have "roadblocks" to participation and learning.

Through their explanations for being behind or "off track", the teachers appeal to "realistic" vs. unrealistic expectations for coordinating curriculum. They invoke individual priorities that centre on responsiveness to particular students and classroom dynamics, and suggest that those independent responsibilities take precedence over collective agreements about curriculum content and pacing. In effect, the three teachers' successive explanations position them as a coalition with the potential to shift the direction of the group's coordinated activity. 
The significance of the "on track" issue becomes apparent as the meeting continues: in a meeting nominally organised to pursue planning and coordination for the next curriculum unit, 51 percent of transcript lines focus on whether or how the group will stay on track together. Teachers invoke classroom scenarios and considerations in ways that achieve their primary situational relevance in relation to the coordination work they are attempting to manage.

Further, the teachers' shared concern for resolving this problem of coordination subordinates or reorients other discussions centring on classroom dilemmas. In the following transcript excerpt, the group is discussing Patrick's suggestion that those who are behind could eliminate the independent reading projects scheduled for Fridays. Patrick and Margaret both admit to ambivalence about such an arrangement, arguing that "something's got to give", but anticipating students" disappointment:

PATRICK: I'm worried about telling them that we're not going to read on Fridays, because right now [independent reading] is something they absolutely crave.

MARGARET: I know, me too.

Their comments take Lora by surprise, and an exchange ensues. In some respects, this exchange parallels those moments illustrated by the two examples outlined above, in which a teacher discloses a problem of classroom practice and explicitly invites commentary or assistance:

LORA: What am I doing wrong? Mine are just like, they're all like whew ...

PATRICK: Oh, really?

LORA: Yeah, they can stop reading.

MARGARET: I think it just depends on the class. I tried it last year and it didn't work as well as it's going this year.

PATRICK: It's a classroom culture thing.

LORA: Okay.

PATRICK: Whole groups of kids can get into each other's mind set in just a little bit, and be happy if that's what they got.

MARGARET: And the kids who talk are, like they're readers, the ones in my class, which rarely happens in the past. You know, like they'll put (?) reading, like the people reading (?) are going, yeah, this happened, this happened.

LORA: I heard some of that in your class. Third block?

MARGARET: Maybe. 
LORA: "I read this and this is going on and" and then I thought ...

MARGARET: That rarely happens.

LORA: ... why can't I elicit this kind of comment?

PATRICK: You can.

MARGARET: I totally agree with you, it's a class culture, and I have a lot of readers in my class.

PATRICK: I don't have a lot of readers in my class, but I have sort of like, they were really frustrated with [independent reading] the first day, they hated me.

LORA: No, and the reading stuff, they did better today than yesterday. They were at least quiet and reading, but when you guys did your reading survey, did a chunk of them say that they hated to read and they didn't read, and ...

MARGARET: I find those really contradictory, I mean with (?) one person they contradict, on the first page, I don't like to read, I mean I love to read ... I didn't really find ...

PATRICK: It was a strange response.

LORA: I'm concerned about with the solution Patrick, in that, I'm afraid that my students will never get to do [independent reading] projects ...

On this occasion, Lora's questions fail to elicit any response centring on what she might do or think about as a teacher in the face of her students' apparent indifference to reading for pleasure. Unlike Lynne's reasoned explanation of how her teaching might contribute to her students' problems in writing an interpretive essay, or Guillermo's focus on how Tina might redefine her response to "fast" and "slow" students, Patrick and Margaret attribute Lora's difficulty to a "classroom culture" that exists independent of a teacher's action. Patrick subsequently implies that his students have gone from hating independent reading to craving it in the space of one week, but offers no indication of what he might have done to account for such a dramatic shift. Indeed, what Lora could conceivably conclude from this exchange is that teachers can expect to remain relatively helpless in the face of students' own predilections and the classroom culture prevailing among them.

Given the increasing specificity of Lora's questions (from "what am I doing wrong?" to "why can't I elicit this kind of comment?") and her inclination to probe into Patrick's and Margaret's assertions about their students (questioning what they found in their survey of reading attitudes and habits), it is possible that this conversation might have progressed to a more thorough examination of the teachers' assumptions, arguments, and practices. However, Karen and Leigh remain noticeably silent 
throughout this exchange, while the group's discussion of the coordination problem is left hanging. Perhaps sensitive to Karen's sense of urgency, Lora turns the conversation back to the issue at hand - how to keep the group on track. ${ }^{8}$

Acknowledging that this analysis is still in its early stages, I draw on these three episodes of teacher interaction to ground some provisional observations about representations of classroom practice as resources for professional community and teacher learning.

\section{Decontextualised ... and Recontextualising}

Teachers introduce classroom considerations and evoke classroom details in ways that illuminate selected aspects of classroom realities, sometimes vividly - students who are silent, intimidated or dominating and activities that go slowly or quickly, and the like. Yet these are decontextualised, disembodied accounts of the classroom. We might reasonably ask what one could expect of them as resources for professional community and for teachers' learning about classroom practice. By comparison to the tailors' shops investigated by Lave (Lave and Wenger, 1991), in which the ongoing practice of constructing garments and engaging in the social relations of the tailor's shop are available to the apprentice's eye and ear (if only gradually accessible to direct participation), the situated practices of the classroom arise in out-of-classroom talk as discrete, condensed and de-situated. Neither we nor the participants can grasp the full meaning of what Karen refers to by "settling in" activities, or what "setting norms" amounts to in Patrick's classroom, or what Tina interprets as the attributes of "fast kids, slow kids".

And yet these decontextualised accounts form pervasive and meaningful elements of the talk among the teachers in these out-of-classroom exchanges. To describe these classroom accounts as brief, condensed and disembodied is not to suggest that they are meaningless or unimportant. Making sense of one another's stories, speculations, explanations, comments, jokes, complaints and observations - treating them as situationally meaningful and adequate for some purpose - is a central and constitutive feature of teachers' collective practice. ${ }^{9}$ And it is in this sense that these decontextualised representations of the classroom are also recontextualising, supplying substantive resources for the group's joint work, conveying its dominant orientation toward teaching practice, and negotiating what it means to be a teacher in this group. What shows up as an account of classroom practice, and how it is taken up or not, is significant in that regard.

\section{The Many Layers of Meaning in Ordinary Interaction}

Even in these brief episodes, much happens and it seems all to happen at once, in complex and nuanced ways. Teachers not only engage in conversation about substantive work ("norming" comments, finding "group-worthy activities", staying "on track" in teaching a new course), but also continuously define and redefine the nature and meaning of that work as they talk. What it means to "norm" comments, for example, is under negotiation as the English teachers talk: "Not that we have to follow the exact same phrase every time, but ...". 
As in any stream of naturally occurring discourse, ${ }^{10}$ the teachers' talk serves as a principal resource in getting on with their work, while simultaneously reflecting and constructing the identities and social relations of among the teachers. The ongoing talk both conveys and constructs what it means to teach and to be a teacher, and to do so in this school, with these students and among these colleagues. Representations of classroom practice occupy a central place in that talk, and thus in the public construction of teaching practice and professional relationships. In the Academic Literacy Group, three teachers turn to classroom experiences and priorities to explain why they are "behind" or "off track". In doing so, they portray themselves as thinking and acting differently from their colleagues regarding curriculum pacing. In this and other occasions throughout our data, the teachers employ talk about classrooms to justify themselves and their choices to one another, and to rehearse how they will justify their choices to their colleagues outside the group, to parents, and to students. Their explanations and their subsequent "solutions" play a part in revealing (and either reconciling or intensifying) the tensions between their collective obligations and their individual priorities, preferences and intentions.

\section{Unpacking Professional Community}

Because they are at one and the same time decontextualised and significant, pervasive but often ambiguous, these portrayals of classroom practice present both participants and researchers with problems of interpretation (see also Little, 2001). Among them, three have surfaced prominently in this analysis.

First, accounts of classroom practice are generally opaque by comparison to lived or observed classroom practice. A central interest of this analysis has been the degree of transparency with which classroom practice comes to be portrayed in outof-classroom interactions. Yet the classroom accounts that surface in these interactions tend to rely heavily on a certain shorthand terminology, and on condensed narratives that convey something of the press of classroom life without fully elaborating its circumstances or dynamics (as when Patrick justifies taking the time for "setting norms"). ${ }^{11}$

Second, classroom accounts are partial, selective, and situationally relevant in time and space, making the face of practice differentially available both across individuals or groups, and when considered against the range of classroom practice. Classroom representations arise not necessarily with regard to their relevance in the classroom, but in relation to some immediate topic or some work immediately at hand; they cannot be interpreted independently of the whole enterprise that constitutes the joint work or practice of the group. What particular representations prove situationally relevant to the group's work at the moment? Whose representations matter and how?

Finally, accounts of classroom practice are time-compressed, fleeting moments commonly interspersed in a dense trajectory of dialogue. The Algebra Group's regular "check-in" routine offers one means to sustain opportunity for talk about practice, but the opportunities for extended talk remain short (on this occasion, 26 minutes to accommodate 11 people) and differentially distributed, from less than one minute to 10 minutes. In every group, teachers monitor the clock ("it's 5:00", "we have 11 minutes left") or otherwise demonstrate sensitivity to time, task, and pace, as when Lora abandons discussion of her classroom dilemma to return to the question of getting "on 
track". Altogether, representations and considerations of classroom practice in the ongoing stream of talk tend to have a certain ephemeral character.

Despite these interpretive challenges, analysis of teachers' situated interaction offers purchase on how teachers employ representations of classroom practice in the course of everyday work outside the classroom, and how those representations constitute resources for teacher community and teacher learning. In some respects, these three episodes confirm and illustrate the features that have come to be associated with "teacher learning communities" on the basis of interview and survey studies (see especially McLaughlin and Talbert, 2001; also Little, 1999; Louis and Kruse, 1995; Westheimer, 1998). That is, the groups demonstrably reserve time to identify and examine problems of practice; they elaborate those problems in ways that open up new considerations and possibilities; teachers readily disclose their uncertainties and dilemmas, and invite comment and advice from others; artefacts of classroom practice (student work, lesson plans, and the like) are made accessible. In all these ways, the groups display dispositions, norms, and habits conducive to teacher learning and the improvement of teaching practice.

Yet our records of situated practice also reveal aspects of teacher community that are less evident in other data. To begin, these records show with needed specificity what is available for consideration by way of talk and material artefacts - that is, what is brought within the horizon of observation. The Academic Literacy Group and the Algebra Group both express a felt responsibility to student success, an orientation toward instructional innovation, and a commitment to close and supportive collaboration with colleagues. Yet the specific resources made available in their out-of-classroom exchanges differ markedly. What is available in the Academic Literacy Group episode, for example, centres largely on problems for the coordination of the activities and pace of classroom instruction, while the resources available in the Algebra Group episode centre on ways of thinking about and responding to students' learning difficulties in mathematics.

Further, records that preserve the flow of interaction show how teachers $c o$ construct representations of practice, in part through the ways that they reify or interrupt the language of practice (e.g. "norming" or "fast kids, slow kids"). Tracing the trajectory of these co-constructions within and across episodes, groups, and time will enable us to link the general normative disposition of a teacher community with specific resources for teaching practice and teacher learning that its members make accessible (for example, resources for helping students learn algebra). Systematic attention to participation patterns (who contributes in what ways? what participation norms and structures emerge?) additionally shows how opportunities to learn and participate are also collectively shaped, co-constructed, and distributed.

Finally, these situated records complicate some of the existing typologies of teacher community by showing how ongoing interactions both open up and close off opportunities for teacher learning and consideration of practice - in the same groups and sometimes the same moments. Even within these groups that would reasonably be considered collaborative, innovative, and committed to improving practice, teacher learning seems both enabled and constrained by the ways that the teachers go about their work. The force of tradition and the lure of innovation seem simultaneously and complexly at play in the teachers' everyday talk. Habitual ways of thinking or acting coincide closely with moments of surprise ("aha"); the impulse to question practice resonates against the press simply to get on with it. If we are to understand more fully 
what distinguishes particularly robust professional communities, we may have to understand the interplay of the conventional and the creative in all of them.

\section{Conclusion}

In this analysis, I have begun to examine the intellectual, social, and material resources of professional community, particularly as those are constituted through representations of classroom practice in out-of-classroom interaction. The analysis is designed to build on - but also to deepen and challenge - research of the last decade that has steadily converged on a claim that strong professional communities are important contributors to instructional improvement and school reform. Claims about the generative power of professional community for individual development and for whole-school reform frequently founder on evidence that not much has changed at the level of teaching and learning in the classroom. There are many reasons for conservatism of teaching practice, but one avenue is to explore what constructions of practice are afforded by and through the ordinary exchanges that constitute teachers' communities of practice. Looking close up at teacher interaction, across a range of settings, stands finally to open the black box of professional community and to show when and how it is conducive, or not, to the transformation of teaching.

\section{Notes}

1 Of course, there are other problems of professional community and teacher development worth considering. Most central among them is how strong traditional communities are created and sustained, and what constitutes teacher learning within those communities. Further, our focus on groups with high rates of personal interaction and high levels of interdependence results in relative inattention to the more diffuse professional interactions and learning trajectories of teachers whom Huberman (1993b) described as "independent artisans". A comprehensive research agenda would encompass these related problems.

2 Other members of the three-person research team were Ilana (Lani) Horn and Lora Bartlett. Each of them took up a participant researcher role in one of the groups whose interactions are examined here, Horn as a mathematics teacher and Bartlett as an English teacher.

3 See Aguirre (2001) for one example of a reform-oriented math department whose interactions nonetheless serve to reinforce traditional beliefs and practices.

4 See also Wenger (1998) on the related concept of "reification". It is in the reifications, including classification schemes, that the historical and institutional characteristics of teaching as an occupation are made particularly evident in the more micro-interactions of day-to-day work.

5 I credit Maryl Gearhart with introducing me to the contemporary use of this term in cognitive science and with suggesting its use for analysis in a study we are conducting together on teachers' joint review of student work or other evidence of teaching and learning, and the potential for such joint reviews to stimulate teacher learning.

6 This episode is the last of three major segments in the meeting. In the first two segments, the department members (1) consider a possible teacher education partnership with a nearby university and its implications for the department's existing relationships with other teacher education programs; and (2) talk about possible purposes and processes for introducing peer observation among the English teachers this year.

7 Ilana Horn (2001) offers a more complete and fine-grained analysis of Tina's problem and its treatment in her paper. She develops more fully an analysis of classificatory systems and the way they operate both to construct taken-for-granted features of practice and 
(under some circumstances) to orient participants to its internal contradictions and problematic aspects.

8 Relying solely on audiotape, it is not possible to examine the non-verbal stances exhibited by the participants and to gauge any indications of impatience from the others. However, Karen has already indicated to the group that she finds this a problem of some urgency. Early in the meeting, she declares: "All I'm saying is that I think that I'm stressed about it, and I'm partially stressed because I don't know, I feel this need to stick to the schedule ..." A few moments later she adds: "And as you all, I'm sure, haven't figured out yet, I'm incredibly anal about knowing what I'm doing. You know, I can't stand just even, you know, not knowing what I'm going to teach in two weeks. It's difficult for me. So if we're going to be off [track], I want to know."

9 In this sense, teachers' circumstances for talk about classroom practice bear less resemblance to Lave's tailors or Hutchins' navigators than to those of the machine repair technicians studied by Julian Orr (1996). Orr describes the talk among technicians about "how it is in the field" as they gather for coffee before going off on independent assignments (pp. 15-23). Like teachers, technicians accomplish most of their daily work independently, out of sight and hearing of fellow technicians.

10 One of the fruits of the marriage between ethnomethodology and conversational analysis has been to underscore two central features of talk as social practice: the simultaneity and multiplicity of meanings constructed through talk, gesture, and material artifacts; and the use of various devices, including classifications schemes, to create and sustain social order and to remedy ambiguity and uncertainty of meaning. The relevant literature is large and spans several disciplines, but see Gumperz and Hymes, 1972; Have and Psathas, 1995; Kjolseth, 1972; Moerman, 1988; Sacks, Schegloff and Jefferson, 1974.

11 This isn't to say that to observe practice directly or to observe videotaped records of classroom life is to grasp completely what its participants "know" and act on. On the limitations of video records, see Lampert (2000). 


\section{Chapter 7}

\section{The Contemporary Basic Values of School: "The Emperor's new Clothes"?}

\section{Kennert Orlenius}

In the famous Danish story by H.C. Andersen, "The Emperor's new clothes", the emperor was deceived by two frauds because he was naïve and caught in his own perspectives. He was absent from reality. Moreover, nobody close to him dared to tell him. They didn't want to be seen as non-educated and foolish. In fact the emperor was naked; the clothes were an illusion. Nobody seemed to bother but accepted the authority. Finally, a small child discloses the truth.

My intention is not to ridicule or make sport of a serious phenomenon in school, but I want to raise these questions: Is there any substance in the contemporary basic values in school? Are they naked and without any relevance? I approach these issues from different points of view. My point of departure is the curriculum in Scandinavian countries (Denmark, Norway and Sweden) and statements from the governments. I maintain there are palpable differences and that these can be understood from the concepts of Liberal Universalism and Communitarianism. I will also discuss the relevance of contemporary basic values from a postmodern point of view. To extend the perspective, I also connect the aim and discussion of basic values to different educational-philosophical interpretations.

\section{Basic Values}

In 1993, the School Curriculum and Assessment Authority (SCAA) in the UK published a discussion paper, "Spiritual and Moral Development", and later a National Forum for Values in Education and the Society was set up. The 150 members decided that there are a number of values to which everyone would subscribe, irrespective of their ethnic group, religion, gender etc. - such as friendship, justice, freedom, truth, care of the environment and so on. These kinds of values can be found in most curriculums in Western countries as well as in the curriculums of Scandinavian countries. Moreover, it is no exaggeration to maintain that values and virtues such as telling the truth, helping others in distress, caring for others and the environment are all natural part of life. Normally, we do not need to reflect on why we should not murder or hurt somebody, 
because basic moral rules reflect our human nature. Why then be concerned with basic values?

When we talk about basic or fundamental values (or the value foundation) we usually allude to two aspects:

- There are some strong, permanent and irreplaceable values that are not objects of negotiation. They are axioms in relationships of human beings.

- These values are a "lowest common denominator" that everyone should accept.

However, there are several problems. These values often seem to be taken for granted. When we talk about values we believe that we are talking about the same thing but the interpretations differ. For instance, the concept of justice has various meanings to different people. Concepts like freedom and solidarity sometimes counteract each other and could be incompatible. People appreciate and salute freedom but on the other hand also want to limit freedom. Freedom does not seem to be selfevident even in a country that espouses democracy. My tentative studies among head teachers point out that their ideas of the concept of democracy are quite different. Civil disobedience is seen by some as a threat against democracy and is seen by others as an instrument for its development. A head teacher in Sweden who firmly and strongly acts against tendencies of racism in school can be seen as a true and genuine democrat and a moral hero; but at the same time from a legal point of view as a lawbreaker and an anti-democrat if he counteracts freedom of speech.

The problem in practice is that these values often seem to turn into an empty code. Moreover, when we talk about basic or fundamental values, appearances are deceptive and this kind of rhetoric (formulated by the authority) can act as a doorkeeper: in practice, it prevents insight. The formulations are interpreted as a description and characterisation of school today. What is the alternative? Let us first give an overview of aims connected to different values in the Scandinavian countries and also discuss these values from different points of view and look at the philosophical influences, before drawing some conclusions.

\section{A Description of Basic Values in Sweden, Norway and Denmark}

\section{Sweden}

The first sentence of the Swedish curriculum, "Curriculum for the compulsory school, the pre-school class and the after school centre, Lpo 94/98" (Läroplan för det obligatoriska skolväsendet, förskoleklassen och fritidshemmet) marks the foundation. Under the heading "Fundamental values and tasks of the school" it is proclaimed that "Democracy forms the basis of the national school system". If Christianity was the cement or glue for school during the first hundred years, formal democracy has been the equivalent since $1962 .{ }^{1}$ Democracy is the hub of the vehicle - in the formal rhetoric.

Accordingly, from a traditional, political notion of democracy, human rights are stressed, especially the following intrinsic values: the inviolability of human life, individual freedom and integrity, the equal value of all people, equality between women and men and solidarity with the weak and vulnerable. These values are desirable and indisputable. They seem to be non-negotiable and no object for compromise. This is reinforced by the concept "värdegrunden" (the value foundation) 
in singular form. ${ }^{2}$ In "Læreplansverket for den 10-årige grunnskolen" (1997) in Norway similar terms "verdigrunnlaget" and "verdiplattform" are used. The superordinate idea is democracy. Representatives of the Ministry of Education talk of democracy as being a "superior ideology" (överideologi) and of "democratic values" (Zackari and Modigh, 2000).

\section{Norway}

The Norwegian curriculum of 1994, "Læreplan for grunnskole, videregående opplæring og voksenopplæring - generell del", begins as follows:

Education shall be based on fundamental Christian and Humanistic values. It should uphold and renew our cultural heritage to provide perspective and guidance for the future. (p. 7)

The curriculum clearly emphasises that values of school and society are founded in the Christian and Humanistic tradition. It points out the cultural heritage and the importance of preserving this heritage. Consistently, the curriculum also stresses the concept of identity. The mission of school and education is in respect for the human being to nurture the child into becoming a person strongly aware of his or her individual and national identity. Values are instruments to reach that kind of aim. A good general education must contribute to national identity ... in language, tradition and learning. Newcomers are more easily incorporated into our society when implicit features of our culture are made clear and exposed to view (p. 29).

The aim of school is assimilation and the preservation and development of the community; a society characterised by homogeneity and unity. The curriculum stresses the great importance of a common value system, i.e. a consensus about basic values (Telhaug, 1995). This unity is also stressed in "Læreplansverket for den 10årige grunnskolen (L97)" by an aim unlike the curriculum in Sweden. In plain terms, it is emphasised that school should contribute to reducing and levelling social diversity and barriers in society.

\section{Denmark}

In Denmark, there is a subject called "Kristendomskunskab", i.e. Christian Studies. In Sweden, it has been called "Religionskunskap", i.e. Religious Studies, since the 1960s. The corresponding subject in Norway is "Kristendoms-, religions- og livssynskunnskap", i.e. Christianity and general religious and moral education. ${ }^{3}$ These differences seem to reflect the discussion about values in these countries and the connection to the cultural and religious heritage, also with the future in mind.

In Denmark, the Elementary school law's primary aim is: "The central topic of Christian Studies is the Evangelical-Lutheran Christianity of the established Danish church (den danske folkekirkes evangelisk-lutherske kristendom, my translation in English)" (\$6). The religious dimension is a clear part of education and in the aims for the subject it is said that education should take the starting-point in Christianity, even if outlook on life and religious studies are also included. ${ }^{4}$ Unlike in Norway (and to some extent in Sweden), it seems that there has not been a controversial discussion in Denmark about Christian heritage and its importance in school values. "The Act of elementary school" of 1995 (Folkskoleloven) settles that "the Folkskole shall familiarise the pupils with Danish culture and contribute to their understanding of other cultures and of man's interaction with nature" (Undervisningsminsteriet, 1995). 
In light of these facts, I find the content in "Values in practice", ideas and thoughts presented by the former (until 2001) Minister of Education in Denmark (Vestager, 2000), very interesting. The document is written with a sense of openness and invites "an intense and lively debate" about fundamental values, i.e. it is not written in a normative way. Key concepts include new society, a less predictable world, emancipation, challenge, and dialogue. These are features that do not deny cultural and religious heritage. The Minister of Education maintains that the above-mentioned fundamental values are "the same as they have been for the past 100-150 years" (p. 19). She does not deny the contribution of classical values to the contemporary school and society but underlines that they have to be interpreted in a new society with new conditions.

Furthermore, the Minister adds "democracy constitutes the cornerstone of our society". She refers to the legislation - the need of it - and to the rules that punish and also defend fundamental values. But her point is that "in everyday life values are relatively intangible ... A sense of one's own worth and commitment are elements that are not easily woven into the stiffly formulated sections of an act" (p. 9).

She also adds that "our lives no longer follow the beaten track" (p. 7). Everyone needs to interpret and formulate his or her own value basis. It is also an obligation for all schools. Finally, the Minister concludes, "practice without values become emptiness, values without practice will not have the impact to change our society for the better" (p. 52); but she also talks about "a dialogue without referees" (p. 40).

\section{An Analysis of Basic Values and the Curriculum from a Social- Philosophical Point of View}

The Swedish curriculum mainly represents Liberal Universalism (Gustavsson, 1996; Strike, 1996). According to this idea the core of democracy is universal, civil rights. The motive for Universalism is the defence of human dignity and keywords here are freedom and integrity and include matters of justice. From this liberal point of view it is stressed that the mission of school and society is to guarantee individual freedom and integrity (as long as it does not threaten or hurt others). This idea is a so-called negative concept of freedom with freedom meaning the absence of unfair treatment or encroachment.

The Norwegian curriculum mainly represents a communitarian approach and theory of values in school and society. For instance, freedom in a communitarian tradition is a positive concept of rights. It is not a question about freedom from (the evil) but freedom to (the good). Here the aim is to promote the vision of a society in community, a sustainable and common value system, i.e. a consensus about fundamental values. For schools this means that their mission is to be active and should promote a good moral environment, where adults are to be seen as models. Pupils (and people in common) are not self-creating rational agents but socially constituted, so the learning context is seen as important. This approach, to serve as a model, is also emphasised explicitly in the Norwegian curriculum (Engelsen, 1994; Løvlie, 1997).

The theory of Liberal Universalism stresses the scientific and the ability to hold an intellectual standpoint based on human reasoning and sense. The communitarians on the other hand point out character building and virtues. If freedom and integrity are the most important concepts in a universalistic tradition, unity and community are the corresponding concepts in Communitarianism. Defenders of universalism focus on individual civil rights but people who advocate the communitarian 
theory stress the individual as a citizen. Liberal Universalism has its roots mainly in the era of Enlightenment and ideas from thinkers like Immanuel Kant. Communitarianism can be seen as a reconstruction of Aristotle's ideas about virtues and also ideas subsequently formulated by Michel de Montaigne and others. ${ }^{5}$

What interpretation could be made of the curriculum and the previously mentioned standpoints by the Minister of Education in Denmark? Elements from both Liberal Universalism and Communitarianism are notable but the Ministers' statements give expression to a postmodern point of view. The concept of postmodernism and the postmodern society have been controversial and an object of much dispute. If the ideas of postmodernism here are limited to openness of differences, ambivalence and uncertainty for social structure, and if the individual is seen more as a vagabond or tourist (a rambler in life) than a goal-oriented pilgrim (accordingly to Zygmunt Bauman), ${ }^{6}$ it seems to me that the former Danish Minister of Education is a spokesperson for these kinds of ideas. She asks: "For if it is no longer given traditions and family patterns that bind us together - what does?" (p. 8) and also maintains that the same agreements as previously do not exist; our perception of life is changing, traditions are replaced by emancipation and common collective experiences are being demolished.

Modern industrial society is about to be replaced by a knowledge society based on new attitudes, views and behavioural patterns ... The changes have meant that we have become more emancipated and have been given a greater opportunity to interpret ourselves and society in new ways (pp. 13,18).

An analysis of the syllabuses carried out in Sweden, Norway and Denmark in the mother tongue subject also gives support to this conclusion. There seems to be a pattern that even permeates that subject. Aarsæther (1997) maintains the following:

The Danish syllabus takes up a postmodern position and outlines a concept of culture and qualification that shall foster students to be conscious and obtain the ability to act in new, unpredictable situations and contexts; the Norwegian one is an answer to cultural fragmentation ... The Norwegian syllabus can be described as a project of national romanticism. (p. 54; my translation)

To sum up so far, the intention of my analysis is to use the above-mentioned theories as instruments to understand the rhetoric of basic values. There are patterns that indicate differences in the three Scandinavian countries. I also would like to make a note of the fact that the question about basic values in fact is a mark of a firm liberal universalistic tradition with a stress on the political view of democracy. Value is an example of a core concept within the idea of Liberal Universalism. A postmodern departure brings matters to a head - no permanent values exist. From a communitarian standpoint, virtue is the important concept.

\section{An Analysis from an Educational-Philosophical Point of View}

From an educational-philosophical point of departure the above description and differences could be discussed from the outline shown in Figure 7.1 (from Orlenius 2001). ${ }^{7}$ 
The core of Essentialism is that knowledge should be based on a scientific, valid and tenable foundation, i.e. the essence of knowledge. The core of Perennialism is that the purpose of school is the transmission of eternal truths. A perennialist maintains that there are truths independent of time and contexts. The teacher is seen as a model and a link between history and the future. According to Progressivism (influenced a great deal by the ideas of John Dewey) the mission is to support the students' personal development so they can take responsibility for the progress of a democratic society. Here learning, rather than teaching, is the educational strategy. Finally, the core of Reconstructivism is that school is to be seen as an agent for the reconstruction of society. The aim is to foster independent and conscious students who want to change society. A critical analysis of social, cultural and political conditions and phenomena is an important part of education, and contemporary problems and injustice should be discussed.

Using these concepts as a point of departure, I hopefully have extended perspectives of the curriculum and statements in Scandinavian countries. My interpretation is that the Norwegian curriculum mainly expresses ideas of Perennialism and represents a conservative tradition. School is seen as a transmitter and preserver of culture and national identity. The curriculum argues for permanent and durable values. The Swedish one holds a middle standpoint in Figure 7.1. It is influenced both by ideas of Essentialism and Progressivism. Finally, the former Minister of Education in Denmark seems to represent ideas of Reconstructivism. Her standpoints and perspectives claim that school must support an open and intensive debate about a new, unpredictable and changing society. Values are stressed more as instruments in practice than goals to be attained. The process - without any secure answers - seems to be more important than the product.

\section{Conclusions and Discussion}

There is a revitalised interest in basic or fundamental values in Scandinavian countries but these values have to be discussed. One problem is their abstract character. They need to be made concrete in practice otherwise they are an empty code. They are also used in Sweden as instruments of control (steering by goals) but my suggestion is that they should be seen as instruments for orientation and interpretation. The task from a social and educational-philosophical point of view is to make clear different kinds of interpretations and perspectives but also to support and elaborate theories and concepts (a discourse) that can be used when talking about basic values. Basic values need to be discussed from different standpoints, for example, what is the mission of school preservation or change (reconstruction)? Should ethics and values be like oil or gravel in the machinery of society? Without an analysis of the cultural and religious heritage, there is a risk that "we throw the baby out with the bathwater". What kind of contribution to basic values can our history afford for a postmodern school and society? Maybe that is the most important challenge for future education about basic values. My conclusion is that it is unrealistic to seek old-fashioned solutions to modern issues, but on the other hand we have to start discussing the same issue as was current in the old Greece: the vision of the good society. The point is that schools must be based on an awareness of the importance of values, bring them to the fore and give students time to reflect on and discuss such issues. 


$\begin{array}{llll}\begin{array}{l}\text { School and } \\ \text { society }\end{array} & \begin{array}{l}\text { School as a } \\ \text { preserver }\end{array} & \begin{array}{l}\text { School as subordina- } \\ \text { ted or a part of social } \\ \text { progress }\end{array} & \begin{array}{l}\text { School as an agent of } \\ \text { change and emancipa- } \\ \text { tion }\end{array} \\ \begin{array}{l}\text { Central } \\ \text { activity }\end{array} & \text { Mediation } & \begin{array}{l}\text { Mediation/ } \\ \text { learning by doing }\end{array} & \begin{array}{l}\text { Dialogue/ } \\ \text { critical reflection }\end{array}\end{array}$

Educationalphilosophical orientation

\section{Essentialism \\ - Scientific based \\ knowledge}

\begin{tabular}{|c|c|}
\hline $\begin{array}{l}\text { Perennialism } \\
\text { - Mediation of } \\
\text { eternal truth } \\
\text { - Classical } \\
\text { education and } \\
\text { learning; } \\
\text { the cultural } \\
\text { heritage }\end{array}$ & $\begin{array}{l}\text { Progressivism } \\
\text { - Students as creators } \\
\text { of knowledge based on } \\
\text { their own experiences } \\
\text { - Interdisciplinary } \\
\text { content } \\
\text { - Collaboration and } \\
\text { social development } \\
\text { - Student-influenced } \\
\text { ways of working }\end{array}$ \\
\hline
\end{tabular}

Reconstructivism

- A critical approach towards society - Developing citizenship and changing the society of future

- Emancipation

Figure 7.1 Different educational-philosophical points of view (Orlenius 1999)

\section{Notes}

1 In 1962, a nine-year compulsory school was established. The Swedish "folkskola" (elementary school) was instituted in 1842 .

2 This is not unproblematic according to teachers. In a study by the National Agency of Education (Skolverket) in Sweden (1999), several teachers point out that "värdegrunden" (the value foundation) is a ticklish concept and "everything includes the value foundation". When the Ministry of Education translates this concept into English, it is called "basic values" (1994) and later on (from 1998) "fundamental values" (in plural).

3 Since 2002 the subject has been revised. Formerly it was called "Kristendomskunnskap med religions- og livssynsorientering". The education shall be objective, critical and pluralistic, with no missionary preaching. But still the main part of the subject should be about Christianity.

4 In Finland it is possible to choose either Religious Studies or Ethics.

5 Maybe it should be observed that even Aristotle and Montaigne expressed their confidence in the human intellect and were epistemological rationalists. Virtues should be deliberated on the base of "ratio" (intellect). 
6 According to Zygmunt Bauman, postmodern society is modern society without illusions. The illusions that have been lost are the idea of progress, development towards unity and an all-embracing community and the idea of harmonic order.

7 A more detailed account and discussion of what is presented here was carried out by Theodore Brameld more than 50 years ago. He published Patterns of Educational Philosophy (1950) and discussed these philosophies of education. In Toward a Reconstructed Philosophy of Education (1956), he argues for the idea of Reconstructionism. Later, Professor Tomas Englund used these concepts to analyse Swedish politics of education during the 20th century. In an article in the Journal of Curriculum Studies (no. 2, 2000) he discusses John Dewey's influences on Progressivism, Reconstructionism and Neo-pragmatism. 


\title{
Chapter 8
}

\section{Exploring the Landscape of Teachers' Tacitly Implied Ethics: An Aristotelian Uncovering}

\author{
Jukka Husu
}

\section{Starting with Philosophy - Is it of Any Help?}

Educators are called upon to mediate many private and public interests pertaining to personal, professional, organisational, and societal values. The work of mediating conflicting values relates to guarding and promoting the best interests of a student. But what is meant when we say we are making decisions in the best interests of students? Each of the philosophical, ethical, and pedagogical justifications contributes content and meaning to the phrase.

Van Manen and Li (2002) argue that the modern pedagogical task of teaching is ambiguous because contemporary policy perspectives and public discourse on education tend to focus on issues largely external to teachers' everyday occupations: productivity, accountability measures, instructional technology, and so on. The point is that these perspectives and orientations do not adequately reflect the ways that teachers and students experience the tasks and duties of school life. In their experience, teachers' ongoing concerns deal mostly with the success of their students, their personal relationships with students and colleagues, and the interpersonal (moral and emotional) dimensions of their actions. In this sense, the focus of teachers tends to be on the complexity of their everyday interactions with their students and colleagues. Thus, teachers' work can be seen as a pedagogical challenge for knowing how to deal in appropriate ways with the contingencies of everyday events of school life (Husu, 2001). Seen in this way, pedagogy makes the practice of teaching possible in the first place.

As Simon (1992) noted, pedagogy is not only comprised of the teaching of ethics, but is itself an "ethical vision" (p. 62). This makes teaching a reflective practice, and accordingly, school teaching is "deemed to be an interpretative or deliberative science - a branch of moral or social philosophy" (Hamilton, 2001, p. 121). This kind of reflective practice presupposes that philosophical analyses should be attentive to 
empirical work, and consequently, that empirical approaches should be responsive to philosophical discourses. However, the philosophical and empirical modes of inquiry are seldom brought together to gain a better understanding of pedagogical ethics in the natural settings of school life. Here, it is hoped that this kind of combination of philosophical and empirical work provides interpretative lenses for the deliberation of pedagogical practices.

The purpose of this study is to shift focus on the scene where the conditions and contingencies of ethics in teaching may be found. This means exploring day-today details of pedagogical encounters to see what they might offer in putting forth an understanding of teaching as a site of implied ethics (Todd, 2001). Exploring this idea necessitates interpreting teaching encounters for the way they promote or prohibit conditions for pedagogical ethics. The chapter aims to show how abstract ethical theories can be translated into "real world ethics" (Nash, 1996) in teaching and how these reference points can help teachers in their practical ethical reflection.

\section{Theoretical Framework - Combining Ethical Competence with Action Competence}

The term phronesis comes from Aristotle's texts in the Nicomachean Ethics (N.E., 1140a24-1140b12). Phronesis refers to deliberation about values with reference to practice. It is variable and context-dependent. According to Aristotle, "[w]e may grasp the nature of prudence [phronesis] if we consider what sort of people we call prudent. It is thought to be the mark of a prudent man to be able to deliberate rightly about what is good and advantageous" (N.E., 1140a24). The stance focuses on the question "What should I do in this situation?" Therefore, in order to understand what phronesis means, we must look at a person who possesses it: the phronimos. That person is in "a true and reasoned state of capacity to act with regard to the things that are good or bad for man" (N.E., 1140b5).

The different interpretations of this statement are indicative of the different directions that the philosophical discussions and the educational applications of phronesis can go. Next, this chapter concentrates on three philosophical interpretations and their educational applications: the rationality code, the situational code, and the moral character code (cf. Noel, 1999). The process of analysing and interpreting the data through different frames provides a forum for comparing the similarities and differences in the findings that emerge from different perspectives. This multi-focal process involves viewing from one lens and subsequently reconsidering the phenomena from another.

\section{Rational code}

Within the rationality interpretation, the teacher approaches the problem of what to do in a given situation with actions based on reason. When examining how a teacher explains her/his actions, we are interested in the rationality evident in them. According to Audi (1989, pp. 6-7), we must take into account at least two questions: (i) what does it mean for a teacher to act for a reason? (ii) is there a pattern of reasoning by which her/his actions can be explained? This approach can be called the "reasons giving" approach to the analysis of teacher behaviour. The interpretation calls for aspects of rationality that make actions intelligible because "these actions are based on at least one proposition (major premise) which is held as a guiding principle" (Audi, 1989, p. 25). This provision of reasons makes the action sensible to the teacher. 
As Fenstermacher (1994) emphasises, such reasoning may show that an action is "the reasonable thing to do, the obvious thing to do, or the only thing one could do under the circumstances" (p. 45). This kind of rationality interpretation seeks to structure teachers' experiences and actions.

Moral dilemmas can also be viewed from this rational and principle-based perspective. The approach "judges educational decisions according to implicit and explicit rules and duties owed", and the focus tends to be "on the policy decisions (means) and on the educator's conformity to an ethical principle or a set of rules" (Walker, 1998, p. 298). The rationality code is procedural by its nature. It relies on implicit and/or explicit accounts of appropriate guidelines of how to act. The stance provides a general guide to action, a certain authority in ethical decision-making. Rationality code indicates the moral rights and obligations that are at stake in a dilemma and provides the standards by which ethical actions and decisions are made.

\section{Situational code}

Within this interpretation, the phronetic question "What should I do in this situation?" is answered by focusing its primary attention on the circumstances. The stance addresses to perceive all that is involved in the situation, and was emphasised by Aristotle as he wrote, "practical wisdom is concerned with the ultimate particular which is perception" (N.E., 1142a25-7). The necessities of everyday school life presuppose that teachers must take into account many different things when they consider their situations. Teachers need practical perception to determine what type of circumstances they are in and what type of actions they are actually doing. Pendlebury (1990) calls this "situational apperception". Pedagogical situations requiring actions are often full of possibilities, and the teacher should be capable of perceiving those possible actions.

Instead of merely perceiving what is present, the situational code focuses on how things appear to teachers. Here, "both emotions and imagination play an essential part of the proper grasp of situations" (Pendlebury, 1990, p. 147). It is through imagination that teachers discern an event in the school context as something that requires their practical concerns or interests. In this sense, the situational code allows teachers room for flexibility and improvisation. This is because there are usually no formal criteria by which to compare the claims of the competing ways of thinking and acting. Thus, situational interpretation is largely based on experientially developed phronesis. Due to their experiences and personal relationships, teachers have their own unique insights into the practical situations they face. What they perceive can be something that may not be at all apparent to others who are also present in the situation but do not have an "eye for it", i.e. they are not in the same position or they do not share the same experiences.

\section{Moral character code}

The circularity between phronesis and virtuous character is evident. According to Sherman (1989), this circularity aims "to capture the way in which the sentiments and practical reason together constitute character ... [and] to demonstrate that character is inseparable from the operations of practical reason" ( $p$. vii). Aristotle laid the foundations for this interpretation by stating that "it is evident that is impossible to be practically wise without being good" (N.E., 1144a29 b1). Thus, phronesis is not a concept that can be used or determined separate from the individual. Rather, it lies in the person and is part of the way that one goes about her/his everyday life. 
Phronesis is not a cognitive capacity that a teacher has at her/his disposal. Rather, it is closely bound up with the kind of person that the teacher is. The teacher's actions and her/his possibilities can only be found within particular situations, informed by particular histories and school institutions. The actions of the teacher are made strong by repeated encounters with those actions and possibilities. Consequently, the teacher sees it not only as a way of behaving in particular contexts, but also as her/his "way of being" that arises in those situations. As a result, phronesis for a teacher has "its own personality which is rooted in a definite ethos with its own favoured dispositions and habits" (Dunne, 1993, p. 273). The way a teacher acts allows for the development of her/his phronesis and moral character. Without this standpoint, a coherent moral dialogue between teachers and their contexts cannot take place.

\section{Empowering Ethical Reflection}

These three interpretations of phronesis should not be separated from each other. Rather, each interpretation is linked to the others. The combination of the different interpretations makes up the concept of phronesis as a totality. In this form, the nature of practical knowing contrasts with the certainty often attributed to the concepts of "formal" or "propositional" knowledge (Fenstermacher, 1994).

In schools, ethical dilemmas are often interpreted through a calculation of the probable positive and negative consequences (short and long term) of a particular educational decision. Once the likely outcomes are predicted, the alternatives that provide the greatest benefit and least harm may be chosen. The best interests of students are served if the negative consequences are minimised and positive benefits are maximised (Walker, 1998, p. 300). The problems usually compel teachers to choose between competing goals and values. Teachers may choose a solution that aims to maximise the desired results across a range of students involved, but some will suffer at the expense of others. Usually, teachers cannot see their goals as a neat dichotomy between one and the other and their job as making clear choices. In many cases, teachers' aims for any particular student are entangled with teachers' aims for each of the others in the class and in the school's professional community.

In sum, pedagogical ethics means critical and responsible decision-making: how should teachers act? As presented, pedagogical ethics mainly belongs to situations which cannot be mastered by linear rationality to situations where teachers cannot exactly know in advance what will happen when they start acting. Within this stance, the means cannot be distinguished from the end in a given context until the process of inquiry is complete and the relations between the persons involved are well established. Therefore, in practical reasoning the good is not a fixed end. Dewey $(1916 / 1966)$ took this premise to its conclusion by stating that "ends are, in fact, literally endless, forever coming into existence as new activities occasion new consequences". That is why this chapter highlights the connection between teachers' ethical competence and action competence.

\section{Data and Method}

The method of this study used narrative interviews with 33 Finnish lower secondary school teachers ( 22 females and 11 males). In the interviews, the teachers were asked to tell about a real-life pedagogical problem they had experienced in their work. They 
were encouraged to choose a situation in which they had had difficulty deciding the right way to act. The interview focused on the professional character of the teachers' work: their manner of conduct within an occupation and the integration of their obligations with their professional knowledge and skills.

The analysis adopted a qualitative reading guide (Brown et al., 1991) to examine the moral qualities underlying teachers' reflection. The reading guide is based on the evidence that teachers simultaneously know (can recognise, speak in, and respond to) various different perspectives in discussing their work. It aims to highlight the various perspectives, as well as the sense of tension teachers often convey in their interviews.

The following three consecutive readings were done:

1. The rational code perspective aimed to reveal the practical action guides the teachers relied on. Rules and principles were usually brief statements of what to do or what should be done in a particular situation encountered in practice. The major purpose of the perspective was to justify or defend educational decisions based on certain rational principles.

2. The situational code distinction investigated the emergent dilemmas when rational premises were put into practice. What kind of pedagogical dilemmas arose, and how did teachers try to cope with those situations? The stance focused on the evaluation of the taken or intended actions and their possible results. Solutions to moral conflicts were often found only by doing something, by acting.

3. The moral character code tried to uncover the personal ends of the pedagogical practice in question. According to this stance, within the domain of moral judgment, a personal assessment comes before the specific practical actions. The perspective focused on the teacher's expressed concerns about the sources of the problem. It was a question of attitudes and attitudes revealed in actions to work out, or live with, the problems faced.

The process of analysing and interpreting the data through different frames provided a forum for comparing the similarities and differences in the findings that emerged from different perspectives. This process involved viewing the data from one lens and subsequently reconsidering the phenomena from another. The two researchers read the cases a total of three consecutive times from three perspectives. After each reading, the readers checked the reliability of their interpretations by comparing their findings with each other. In mutual discussions, some of the interpretations were changed. All disagreements were discussed to reach common interpretation.

The process of getting to know required various phases of reflection. It often took longer as well. Indeed, Jackson (1992, p. 406) has recommended a data/ reflection ratio on the order of $1 / 10$. When applied to this study it meant one sheet of transcribed data, followed by 5-10 pages of interpretative remarks of reflection. Thus, the next section focuses on one particular case report and presents examples of its analysis.

\section{Results of the Multifocal Analysis}

As presented, the aim of this chapter is to explore what moral issues mean to teachers in their pedagogical practice. The chapter tries to interpret and translate teachers' 
understandings from the language they use, and to give concrete expressions to these interpretations by their daily actions.

\section{The case}

The teacher behind the case report was a 37-year-old woman who taught history and social sciences in a large suburban school near Helsinki. She had 9 years of teaching experience and she was also qualified to teach at college level. Her enthusiasm for teaching was apparent and she was willing to talk about her ideas and work. Her students were mainly between 13 and 16 years of age. Overall, she was quite satisfied with her school. She liked her students and regarded her colleagues as professionals in their own fields. However, she reported smoking to be a constant problem in her school.

Smoking is forbidden by law in Finnish schools. Nobody should smoke during the active school hours. However, both teachers and students break this rule in several ways. Schools have different practices and teachers often disagree with each other and with their students about the best practices. Therefore, smoking has been identified as a typical ethical dilemma in secondary school communities that lacks common standards and rules. Compared with drugs, violence, disruption, and sexual misbehaviour, it is, naturally, a minor problem. However, it is an emotionally loaded, symbolic, and repetitive theme in schools. Here, it is used for its illustrative purposes for training teachers' ethical discernment.

The following excerpt from her case report presents this complicated situation: I have been very concerned about the smoking policy in our school. I think a great number of our students' smoke and many of the teachers smoke as well. This is an acute and frequent problem that I have to consider every single day in my work. Everybody knows that students smoke under the bridge that is located next to our school. However, the law forbids smoking during school hours. We have this law but hardly anybody observes it. Some teachers smoke, too, and other teachers and students know it. And the law also forbids teachers to smoke during school hours. Nobody really knows what to do about smoking. I know myself that smoking is bad for your health and students know it too. It is not a question of not being informed about the negative consequences of smoking. What can I do as a single teacher to change the situation? It doesn't help to send notes home if I am the only teacher doing it. I think homes and elementary schools play a key role in finding solutions to this problem. The complicated thing is that some teachers smoke with their students. They might even suggest a break to have a cigarette. I know that notes home and forcing the students to stay in school after hours don't help the situation. I smoked myself for fifteen years; I know what I am dealing with. I have tried to be a role model for my students and I have told them about my former smoking habit. I have assured them that it is possible to quit smoking. Every single morning I walk by the bridge and tell the students to put their cigarettes away. Some of the students obey me and some don't. I have also tried to talk with my colleagues. I talked with the music teacher about a girl who has a beautiful voice. I think she could be a professional singer some day and smoking might seriously damage 
her voice. I asked the music teacher to talk with this girl about protecting her voice.

I don't see any concrete way to influence our school community. I should build a fence to stop the students from going to the bridge. However, then they might start to smoke in the toilets and that would be even worse for those who don't smoke. The principal should do something. We used to have a smoking room for teachers but it was shut down. Now the teachers smoke outside as well. The principal should take steps to prevent teachers from smoking during their working hours. I don't think we can solve the problem with students before we can influence the teachers.

\section{Rational code: professional and institutional obligations}

In looking for evidence of rational justifications, we were not interested primarily in statements having an outward form of a rule or a principle, but rather in the way such statements operated in structuring the teacher's knowledge. At first sight, the teacher's statements looked like mere description, yet they functioned as a rational code. The code functioned as a guide to action and presented an authority in the teacher's decisionmaking. This stance was basically procedural: it led the teacher to identify the relevant, yet often-implicit rational principle, apply it to the case, and act accordingly.

Professional role obligations guided the teacher's perception of the situation and what she experienced as good or bad, right or wrong, important or unimportant. When she talked about responsibility, the law, rights, and professional obligations, she was actually describing certain fundamental assumptions of the teaching profession. These assumptions seemed to be the ultimate bases by which the teacher made her decisions. Behind this perspective lay the fact that the law prohibits smoking. From the professional perspective the prevailing situation was unbearable because both teachers and students consciously broke the law. Due to the nature of the dilemma she argued that the responsibility lay with students' parents. This belief was reflected in the teacher's scheme of justification: someone else has to do the job.

Also, the institutional standards of the school system called for a certain kind of morality. These obligations emphasised the teacher's belief that her professional role demanded her to instil in her students an adherence to public school life. This code concerned ideals about what students needed to learn socially about school life. They were things that students need in their life. For example, what does it mean to act legally; what are the consequences of breaking a norm? Accordingly, the stance led the teacher to question several of the purposes of her actions within the school context in which she worked: what was this educational organisation trying to achieve? What was the right way to go about this task? Did all teachers and students see the purpose in the same way?

\section{Situational code: balancing of pros and cons}

From the teacher's point of view, the intention to act in a professionally coherent manner led to even more problems. She could not hope to arrive at the "right" solution or action in a sense that the preceding perspective, the rational code, can be said to be "right". This was because each member of the community brought her/his own, often contradictory aims to the situation, and the resolution of their dissonance could not be 
neat or simple. In practice, all the possible "solutions" seemed to lead to further problems. The teacher felt that she could not choose a solution without compromising other goals she wished to achieve. Instead of engaging in a decision-making process that would eliminate various alternatives, she pursued a series of loose arguments with herself as she considered the consequences of the practices.

Nevertheless, the teacher's actions were determined: some action had to be taken. She did not consider the conflicts as a choice between abstract beliefs or between competing rules and principles. What the teacher perceived were tensions between individual colleagues, and personal confrontations between her and a particular group of students. She could not see a neat and workable scheme to guide her job as making clear choices. The juxtaposition of varied views and responsibilities led to even further paradoxes. Even if the teacher could not find the "right" solution, the problem had to be answered in some way or another - even if the answer was to decide to do nothing in order to avoid causing any further problems. As a result, the teacher's intentions to act in a professionally coherent manner led to even more problems: her professional duties collided with the organisational realities of a school system.

\section{Moral character code: it's hard to be good}

When the teacher was talking about responsibility, the law, rights, ideals, and professional obligations, she was simultaneously describing her most fundamental assumptions. They guided her perception of educational practice and what she experienced as good or bad, right or wrong, important or unimportant. The stance led her to question several of the purposes of her actions within the school context where she worked.

Where necessary, the teacher was dedicated to take actions to help those students deprived of their right to good education to begin to enjoy it. On this level the teacher relied on her personal implications, which guided her decision-making. She identified herself as a committed professional who had a set of norms by which she lived and which she was willing to stand by and defend. The prevailing situation clearly broke both professional norms and their organisational applications. Therefore, the teacher felt an obligation to do her best to protect her students from those who would deprive them their rights. The case report reflected this mediation between the teacher's thought and action. Rules and duties functioned as guidelines on or from which the teacher acted; she followed their often implicit and personal dictates. As the data showed, the teacher's actions grew intuitively out of her personal experiences.

These aspirations, as well as the way in which they were strived after, tell us something characteristically about the person of the teacher. From this personally held life-space the teacher experienced educational dilemmas from the vantage point of her own unique perspective of meanings. This personal life-space was her vantage point, her ethical centre of reference. The teacher reported that she had smoked for fifteen years and she was very concerned about the smoking policy in her school. She was confident that eventually students could quit their smoking habit.

\section{Discussion}

Our case provided an example of a real-life pedagogical situation that it was not possible to understand using only one interpretative perspective. The case required different ethical perspectives to inform the teacher in her pedagogical decision-making. 
As presented, the teacher tacitly used different ethical perspectives in her practical reflection.

We believe that the use of more than one theoretical and practical approach will expand and complement our understanding of teachers' professional ethics. It may help us better understand the problems teachers face in their work; the dynamics of educational contexts; and value the impact of different approaches on teachers and students. We also hope that using more than one approach will increase the trustworthiness of research findings because each approach can serve as a check on the other. As a result, our ability to understand teacher development should be moved to a level of deeper understanding.

The plurality of understandings is an integral part of the teaching profession. It is one of the teachers' professional tasks to discern how these competing interests can be served practically. Generally, the social processes involved in teachers' pedagogical settings are not based, to any great extent, upon pre-established ethical reasoning, but in "socially shared identities of feeling" (Shotter, 1993, p. 54) that teachers create in the flow of activity between them. The ethical "argument" in this art is not the construction of a "proof", as is commonly assumed. Rather, the idea of pedagogical argumentation ties together the issues debated until a course of action is found. This type of rhetorical understanding of ethical reasoning enables teachers to distinguish between the different sides of conflict problems and to gain a better conception of them. 


\section{Chapter 9}

\section{Cultural Scaffolding: The Arts and Crafts Teacher's Mediation}

with Her Students with Behavioural Problems ${ }^{1}$

\section{Tove Pettersson, May Britt Postholm, Annlaug Flem, Sigrun Gudmundsdottir and "Tina"}

In recent years there has been a wave of interest around the globe in forms of instruction that capitalise on the socio-cultural nature of classrooms. This interest encompasses a wide range of subject matters. Among them we find the subject of Arts and Crafts which, in itself, is well rooted in tradition and founded on a solid cultural basis. Within this arena, both researchers and teachers are examining what is happening during instruction and learning. They want to understand and improve meaning-making processes within the subject in multi-voiced classrooms where students with behavioural problems are present. Cultural scaffolding as a tool for meaning-making processes in classroom instruction lies at the heart of socio-cultural interactions in which students are enculturated as to how to respond to learning tasks. This paper deals with some aspects of this heritage using the socio-cultural theoretical foundation established by Vygotsky and some of his successors, including Bakhtin, on the importance of language in learning.

The inclusion of students with special needs in regular classes raises the demands on the teacher, whose responsibility is to nourish multiplicity and the student community. In this arena, the teacher often operates as a cultural scaffolder without the benefit of special education resources. A number of strategies and teaching aids are required if children with special education needs are to succeed, even in this subject. By examining the cultural scaffolding of an experienced Arts and Crafts teacher, we want to emphasise the importance of cultural scaffolding as a useful tool for approaching dialogue and interaction, or mediation, with students with behaviour problems to help them accomplish discrete learning tasks in the subject. As the focus of our study, we made a challenging seventh grade classroom at "Berge" school in central Norway our research arena, with the cultural scaffolding that took place in a class with a number of academically weak and restless students and their cultural scaffolding teacher, Tina (Pettersson, Gudmundsdottir, Flem, and "Tina", 2000). 


\section{Method and Context}

The observations of Tina and her 23 seventh-grade students ( 13 boys and 10 girls) started in September, shortly after summer vacation. Tove observed regularly up to the second week of February, allowing only school holidays, excursions, and project periods to keep her away. Data were compiled by means of observations, video-recordings of the instruction given in the listening corner and at the students' desks, and taped interviews with Tina. This material was transcribed and totalled 205 pages. The data also includes 70 pages of observation notes and 211 pages of notes concerning the 16 observations. Furthermore, the material includes the school's activity plan, the yearly and weekly plans and the teacher's syllabus.

The illustrations in this paper are collected from the listening corner in "Images - pictorial art". The assignment for the class was to draw a human body, employing the technique Tina has taught them of dividing the body into different proportions. This topic is familiar to the students and has been on the agenda for the last three weeks. As a teacher, Tina is recognised as a goal-oriented, committed, and reflective person. She has 25 years of teaching experience in primary school, six of these years as a teacher-training supervisor.

The students have a reputation for being a noisy, academically challenged class whose conduct often inhibits learning. Among them, Tina found a group of six boys with behaviour difficulties who challenged both her instruction and the students' learning. These boys exhibited "a behaviour that broke with the school's rules, norms and expectations. Problem behaviour inhibits teaching and learning activities and thus also the student's learning and development, and also got in the way of positive interaction with others" (Ogden, 2001, p. 15). Tina stressed the importance of seeing both the students and their learning environment. She wanted to help change or improve the cultural climate, including the students' attitude towards proper behaviour when responding to assignments in Arts and Crafts.

Cultural scaffolding as part of enhancing the learning culture of the school, to the benefit of the students and the class, is one of the main features of culturalhistorical activity theory as well as Bakhtin's theory on the importance of language, or more precisely, language in context.

\section{Theoretical Background}

The basic idea of cultural-historical activity theory, or socio-cultural theory, can be summarised in the familiar "general law of cultural development" with Vygotsky's (1978) theory that "higher mental functions originate from the individual's interactions with other people" (p. 86). The core concept, the "zone of proximal development", is defined as the range a child can manage with assistance from an adult or in collaboration with more competent classmates.

In Norway, as in other countries, school is an important socialisation arena in the lives of students. In fact, there is a solid Scandinavian Grundtvigean tradition dating back to the mid-1800s of a school culture which emphasises the qualities of "the living word" being activated when two partners meet in a living interchange coloured by a free, natural, spirited, and fertile conversation (Pettersson et al., 2000). The culture of inclusion is very much open to dialogue and interaction with other children and the teacher. Through 
a dialectic relationship with other more experienced persons, the students acquire cultural knowledge, skills, and attitudes, both academically and socially.

Cultural scaffolding (Wood, Bruner, and Ross, 1976) stresses the importance of semiotic mediation by means of words and signs, written and oral, verbal and nonverbal. These are all means that initiate meaning-making processes between partners. Semiotic mediation is a useful tool for acquiring information about how students perceive a situation (situation definition), so that the parties may attain a common situation understanding (intersubjectivity) (Bruner, 1985/95).

Bakhtin's ideas on the importance of language constitute an important supplement to Vygotsky's concepts on the relationship between language and human development (Wertsch, 1998). Bakhtin's (1981) "the inner convincing word" strongly contrasts with what he refers to as "the authoritative word". The significance of "the inner convincing word" is connected to its ability to mediate in communication and interplay between teacher and students.

The special nature of the subject Arts and Crafts invites language, ideas, use of models and other specifics, such as cultural artifacts, for stimulating mediation as part of a creative and lively activity. According to Bakhtin, meaning and understanding cannot be transferred from one person to the next; rather they are created when voices speak to each other or reflect each other (Bakhtin, 1986). To exist, each and every utterance, whether it consists of one single word or a long sentence, requires production. It needs to be expressed. The concept of voice is coloured by the person's awareness or personality when speaking. Voices can only exist in social environments in stimulating interaction with other voices - what Bakhtin calls polyphony, which is a concept most teachers recognise from their classroom. All my utterances depend on other people's utterances. Our utterances are linked together in a communicative chain, acquiring new qualities of reflection and anticipation of future response as part of meaningmaking processes (Bakhtin, 1986).

\section{Prelude}

The first illustration leads us into the centre of the listening corner where total silence prevails. Tina has just discovered that six of the boys have boycotted the assignment she gave the class: to draw a human body. Tina immediately stops the drawing activity and, after reviewing the products of all the students, turns to the blackboard and makes two copies of students' provocative drawings of the human body.

\section{Illustration 1: "Monologic introduction"}

T: Tina: the teacher

S: Students: Erik, Jonas, Marius, Robert, Per, and William: Some of the young provocative "artists"

(1) Tina: (Points at the illustration while looking at the students, requesting) Look at the blackboard!

(2) Students: (Everyone is looking at Tina or the blackboard. Many of the boys who had boycotted the assignment are grinning.)

(3) Tina: Look at this hand! (Takes her time while glancing around the circle, pauses and then continues in a low voice) And look at that face! This is the way 
some of you seventh graders draw. (Looks at them, pauses before she continues) This is not the way we draw a human being! (Pauses, then smiles) Even preschoolers can manage this.

(4) Students: (Most are looking at the board and Tina. Jonas, Erik, and Robert are looking down. Erik is blushing and squirming.)

(5) Tina: (Loudly, in a firm voice) It's childish to draw heads and fingers the way you do! (More vividly) We have to learn how to respond to an assignment in the Arts and Crafts class. (Pointing at the blackboard) Drawing smiling faces like this is not good enough!

In "Monologic introduction" we meet the teacher Tina as the protagonist, the one who masters the play. Her part in the play is demanding. The students are her audience. She must arouse her public's interest in the proceedings and maintain interest while events unfold. The protagonist in Bakhtin's scenarios has the dual role as both the self and the other (Holquist, 1990). It is Tina's responsibility and duty to scaffold the students when they are neglecting their schoolwork. Tina reacts without hesitation. Her scaffolding is firm, using a wide range of cultural-mediating artefacts. One of the most important is her rhetoric, her choice of text-type or discourse. The sequence above is an authoritative discourse-dense and indivisible-inert and given. The semantic structure is static, dead, and entirely complete. In our consciousness we can "either totally affirm or acknowledge it, or totally reject it" (Bakhtin, 1981, pp. 342-343). "Monologic introduction" is a commanding text with no room for student interplay. As a cultural text consisting of complex activities around us, it is nevertheless readable for the students (Bakhtin, 1981, 1986; Bruner, 1985, 1990; Geertz, 1973, 1983; Gudmundsdottir 2001). Among the texts the students can read is Tina's way of scaffolding, using cultural artefacts such as signs, modelling, drawings on the blackboard, and the unfinished drawings of the students. Thus she mediates ideas about academic levels and effort (Vygotsky, 1978; Wertsch, 1984, 1991, 1998).

The students are taken by surprise. Tina's triple-utterances $(1,3)$ : "Look at the blackboard!" "Look at that hand!" and "Look at that face!" are formed as a triple appeal. The clear, succinct form of appeal further reinforces the impact of her message. She mirrors (3) her students' achievements in a lively way, and compares their work to preschoolers. The students sit virtually paralysed. Some of the boys who have neglected to do the task respond (4). Erik's response is most evident (4). He is one of the most gifted students in Arts and Crafts. The students presented themselves through their drawings. These products are the utterances Tina uses as links for further use in the communicative chain between herself and the students.

\section{Interplay}

Tina's invitation to academic dialogue, showing the students their products, does not succeed. The funny drawings awake laughter among the students. This is a critical turn for what now happens.

\section{Illustration 2: "Approaching dialogue"}

(6) Tina: (Showing a silly drawing of a skateboarding "macho" man with lots of "creative" solutions when it comes to proportions.) 
(7) Students: (Bursting into laughter.)

(8) Tina: (Looks over the edge of the paper and down to the drawing that has caused the laughter. Suddenly smiles, her hands holding the drawing resting in her lap, and asks) Which parts of this drawing are incorrect? I'd like to have your comments on that. (Many students put up their hands to answer, but Per is given the nod.)

(9) Per: (Loudly) The legs are much too long.

(10) Tina: (Quickly) Yes!

(11) William: (While raising his hand) The fingers are wrong.

(12) Tina: (Slightly nodding) Yes.

(13) Robert: (Loudly) It's a silly drawing.

(14) Tina: Yes. (Looks down over the edge of the drawing) Yes, the legs are too long. (Stands up, pointing to her own legs. Smiles, then asks) The legs, what about the proportions? What have you learned?

(15) Erik: They make up half the body.

(16) Tina: (Quickly, smiling) Exactly! (Points at the outside of the top of her thigh and gestures down, calling them thighbone and calf. Repeats these terms and the proportions of arms and joints of elbows and shoulders while standing. Demonstrates on herself that her hands reach the middle of her thigh when hanging straight down, and reviews how to render bent arms and legs.)

(17) Students: (Most of the students participate eagerly, revealing their knowledge of the human proportions.)

(18) Tina: (Afterwards while sitting, looking at her students, smiles. The voice is low, appealing) Do you understand why I introduced the topic of "silly drawings"?

(19) Students: (Some are nodding, others confirming) Yes. Hm-m.

(20) Tina: (Raises her hands in a lifting gesture, palm up) I wanted to emphasise what my wish for you is. I want to lift you to another level when it comes to drawing! Lift you above the level of a 5-year-old child. (Pausing, then saying almost inaudibly) I don't appreciate the way you fool around with your drawings.

The laughter of the students affects Tina, too (8). She redefines the situation. The first sign of a growing intersubjectivity is appearing (Wertsch, 1984). The strict ścaffolder we met in Illustration 1 has stepped aside in utterance (8). Now Tina activates new sides of her rich register of scaffolding techniques. Her total communication, choice of words, intonation and non-verbal behaviour, signal a softer, more including invitation to interplay (8). The more authoritarian: "This is not the way we draw a human being!" (3) has been replaced by a softer invitation to new interplay: "I'd like to have your comments on that" (8). The students respond immediately (utterances $9,11,13,15$ ). The interplay is activated. In utterance (13) we can see the inner convincing word (Bakhtin, 1981) starting to work; Robert, one of the tough leaders among the students, is the first one to identify the drawing as a "silly" one. It is interesting to note that of the six boys who neglected to do the assignment, four of them respond verbally $(9,11,13,15)$. In the second sequence (18 and 20 ), Tina mediates the academic and social ambition level she poses, both for her students and for her own instruction (20). Thus she indicates a new direction for further progress through the different zones of development for her students (Vygotsky, 1978). 


\section{Discussion}

Tina takes a chance while scaffolding, using the miserable products of some of the students as mediating artefacts for modelling. In performing this action she appears in an authoritative manner. Through her authoritative, unambiguous "no", she confronts the class combatants with their less-than-ambitious efforts. In Illustration 1, "Monologic introduction", her total scaffolding is commanding, dense, and indivisible (Bakhtin, 1981). There is no room left for any student interplay. Their roles are that of an audience. There is no transferral of meaning, no direct transferral of Tina's awareness, thoughts, or mental functions into the minds of the students.

All functions in a child's cultural development have first to appear in social contexts when the child is interacting with others. All higher mental functions in a student's cultural development must first take place in social contexts when the student is interacting with the teacher or the peers (Vygotsky, 1978). Tina and her students have every possible opportunity to interact socially, sitting in the listening corner. Tina's monologic introduction, however, functions more like a brake for dialogue and interaction. Now it is urgent to stimulate processes that can activate meaning-making processes, so that Tina and her students, who have boycotted the assignment, can put voice to and express their thoughts, feelings, attitudes, skills, and cultural knowledge, and make their contribution to the communicative chain between the partners in the subject of "silly drawings" (Bakhtin, 1981, 1986).

In a challenging situation like this, even "silly drawings" may function as a mediating artefact and stimulator, so that the first signs of an approaching dialogue can be observed. This is exactly what happens. In Illustration 2 , "Approaching dialogue", we are witness to an awakening of "the inner convincing word", stimulated by the exaggerated proportions of the drawings. In this case, the vibrant activity of "the inner convincing word", represented both by the drawings themselves and the students' cheerful response, has an effect on Tina, too (Bakhtin, 1981). She admits, rather reluctantly, that "silly drawings", as a readable text, may also be seen as "funny drawings". Tina's smile and appealing response becomes the very necessary chain in the further conversation between her and the students. Her reaction becomes the turning point where meaning-making processes are evoked and evolved (Bakhtin, 1986). A central part of Bakhtin's theoretical ideas on language are that knowledge construction might involve not only polyphony in harmony, but tensions, disharmony, and conflicts (Bakhtin 1981; Wertsch 1991). It is therefore important that Tina as a scaffolder risks involving herself in discourses coloured by tensions, as was the case here.

\section{Final results}

For Tina, but also for her students, cultural scaffolding was hard work. Summing up some of my findings, we would like to point out both the qualitative and quantitative variety of cultural scaffolding. First, Tina's cultural scaffolding meant qualitative variety, such as the use of language, by means of "the authoritative word" and "the inner convincing word", the use of models, such as drawings and illustrations on paper and the blackboard, and verbal and non-verbal behaviour. Second, Tina's cultural scaffolding meant quantitative variety, following a line from emphasising forceful, dense and unambiguous scaffolding to a gradual withdrawal into milder, more open, but also more 
daring forms of scaffolding, opening up for success as well as failure when it comes to stimulating meaning-making processes. In this case the scaffolding was a forceful stimulus for restarting the process so that an alternative assignment, making a drawing of a live model, might be possible; however, that is another story.

Many teachers may have experienced similar episodes to Tina's mediation with some of her students with behavioural problems. Not every teacher will experience confrontation with a whole group of boys neglecting an assignment as Tina did. It is a part of Tina's repertoire to be prepared to take "considered risks" (Heathcote, 1984, p. 176; Pettersson and Postholm, 2003). Nevertheless, meeting behavioural problems is a major challenge in the inclusive school of the millennium, especially in the western world. Tina used a wide range of strategies and mediating artefacts. Cultural heritage and values like accomplishing discrete learning tasks in a subject was challenged. The socio-cultural nature of a classroom became the fundament for cultural scaffolding processes. Culture and cognition create each other (Cole, 1996). They were, so to speak, two pieces of the same item. In steadily ongoing efforts to establish meaningmaking processes as the heart of instruction, we have access and allowance to capitalise the mighty socio-cultural nature of the classroom. The first step towards internalising cultural knowledge, skills, and attitudes depends on goal-directed mediation arising in fertile soil for cultural activities.

\section{Notes}

1 This essay has since been developed in much greater depth and, at the time of this writing, is pending publication in a forthcoming issue of Teaching and Teacher Education. Tove Pettersson is the first author, and May Britt Postholm co-author. Sigrun Gudmundsdottir and Annlaug Flem were their supervisors. When this paper was presented at the ISATT Conference 2001 in Faro, Portugal, Professor Sigrun Gudmundsdottir was present. It is with no small sadness, therefore, that we mark her passing as the essay is published in book form - Sigrun died in June 2003. "Tina", teacher and informant, is granted a fictitious name to protect the anonymity of her students. 


\section{Chapter 10}

\section{What is Actually Happening in Secondary Classrooms? The Rhetoric and Reality of Curricular Reform}

\section{Barbara Šteh and Barica Marentič Požarnik}

\section{Introduction}

In Slovenia, the recent curricular reform has set itself very ambitious goals, such as to raise overall quality and long-term effects of students' knowledge, to develop strategies of creative, critical, independent thinking, and to foster a deeper understanding of problems. But the strategies to bring about the necessary changes in the teaching and learning process (for example, less transmission and more student-centred teaching, leading to more active learning and higher cognitive processes) have not yet been elaborated. New curricula, regulations and textbooks cannot by themselves lead to changes; the increasing importance of external examinations (testing) can even prevent them or lead in the opposite direction by encouraging low-level, surface learning.

We know very little about what is actually happening in the classrooms, how the reform is being experienced by students and teachers, whether it is in accordance with its general aims, and how it is affecting the quality of the learning process and its results. Attempts to evaluate the curricular reform have up to now relied almost exclusively on gathering quantitative and objective data through large-scale surveys and external achievement testing. The level of classroom discourse, the quality of teaching and learning processes and the perspectives of students and teachers have been largely neglected.

In the present study, we intended to achieve two shifts: from results to processes and from an external to an internal perspective.

Learning results of high quality, characterised not only by long-term retention, but also by deeper understanding and by the ability of students to apply knowledge to different settings, to learn independently and to reflect critically, can be achieved by creating a context favourable to active learning and by using a broad spectrum of interactive methods that are congruent (or constructively aligned - Biggs, 1999) with 
the aims and enable active learning to take place. As shown in some previous research (Šteh Kure and Marentič Požarnik, 1998) the traditional role of the teacher as information transmitter still prevails and is also favoured by secondary students in Slovenia. A shift in conceptions of the teacher's role to a facilitator of learning (Kember and Gow, 1994; Prosser and Trigwell, 1999) and a corresponding change in teaching strategies (from teacher - focused to learner-focused teaching) are not easy to achieve.

Rappaport et al. (1999) point out that all serious attempts to improve quality and effectiveness of school learning and teaching start with an understanding of teachers' and students' current classroom activities (Hayward et al., 1999). Teachers should be made aware of how their students experience the school context and perceive some important features of the classroom situation. Our classroom-based research was guided by the model of awareness, which "is meant to be interpreted in ways that help describe students' and teachers' experience of particular learning and teaching situations" in order to help teachers to better understand their own experience (and not to seek causal explanation) (Prosser and Trigwell, 1999, p. 172).

\section{Aim of the Study}

The aims of the study were:

- To find out what is actually happening in secondary school classrooms: to what extent the observed processes are aligned with and supportive of higherlevel curricular aims, like problem solving, deeper understanding and independent thinking. Are the aims of classroom activities and criteria of assessment clear to students? How do they perceive the scope of their initiative, opportunities for active learning, group work and discussion?

- To compare the perceptions of students, teachers and observers of classroom processes and the context, and to discover possible discrepancies (Šteh Kure, 2000).

\section{Method}

In planning the research approach we had to solve the key problem of how to produce an authentic report about life in the school or classroom, without forcing data into a predefined theory or mould of reality (Hitchock and Hughes, 1989 cited in Sagadin, 1991, p. 346).

Deliberately, a combination of quantitative analytic and qualitative interpretative methodology has been used, the first one mainly in the "extensive", the second one in the "intensive" approach.

In the framework of an extensive approach, we administered a questionnaire to teachers, and a similar one to students. The main ingredient was a series of rating scales to rate the frequency of occurrence of various classroom activities on a fivepoint scale, from 1 - very seldom to 5 - very often.

The focus was on activities of a higher taxonomic order (problem-based approaches, active roles of students). In the questionnaire for teachers, some questions were added about their reasons for including different classroom activities and their conceptions. The questionnaires were sent to a sample of first grade students of general 
secondary schools (gimnazije) and their teachers. We received responses from 568 students and 83 teachers.

We were well aware that the questionnaire, especially the closed items, would give us only a limited insight. Also, we should not forget that the formulation of items originates from the conceptual frame of the researcher (Miles and Huberman, 1994).

Therefore, in the intensive part of the study, we decided to complement the analytical approach with a more holistic one, which gives more valid results. The data obtained through structured observation give us a more detailed insight into classroom processes. While these data, too, need to be clearly interpreted, they represent a good basis for interviewing. So we included the following instruments:

A two-dimensional observation schedule of classroom events (comprising elements of problem-oriented teaching and the level of students'/teachers' activity and initiative - see Figure 10.1). The schedule comprised broader categories of classroom events, with "high inference" units (Wragg, 1994).

A semi-structured interview, carried out by the observer with the teacher and separately with three of the students in each classroom immediately after the observed lesson. The aim of the interview was to reveal and compare different understandings of the context and processes by teachers and students. It also enabled us to compare the perspective and interpretation of the same classroom processes between the observers, teachers and students.

The interview included questions connected to the interpretation of concrete classroom events and also more general questions about the conceptions of knowledge, teaching, learning, teacher's and student's role; desirable changes, incentives and obstacles to introducing changes.

The observers and interviewers were educational experts - school counsellors, former teachers of different subjects from the National Education Institute. All of them had teaching and counselling experience and they were given additional special training in observation and interviewing. In spite of this, the data in some subject areas were incomplete (missing parts in interviews - the interviewer did not probe deeper at the right moment, etc.). Therefore, not all analyses were equally fruitful.

For the detailed analysis in this paper, we have chosen only the data obtained on two subjects, Slovenian language and History. The observations and interviews were carried out during and after two different lessons, with 9 teachers of Slovene and 7 teachers of History.

\section{Results and Discussion}

\section{Extensive approach}

The analysis of responses to the questionnaire (rating scales) revealed that, on average, teachers' frequency ratings of various desirable/significant classroom activities were much higher than students' ratings of the same activities; students tended to be more critical (see Figure 10.1). All differences in mean ratings between students and teachers were statistically significant. Especially large discrepancies (differences in mean ratings) were revealed for the following items:

Clear assessment criteria $(1,54)$

- Clear feedback $(1,41)$ 


Teacher makes connections to
other themes and subjects
Teacher makes connections to
life situations and practical
applications
Teacher encourages students to
look for applications and
connections
Teacher checks for
understanding
Opportunity for additional
explanation
Teacher includes thinking
questions

Figure 10.1 Profile of mean ratings of various classroom activities by the sudents and the teachers

- Teacher encourages students to look for connections and possible applications $(1,39)$

- Teacher includes "thinking questions" $(1,27)$

- Teacher relates content to real-life situations and points out its practical application $(1,22)$.

The discrepancies could be partly explained by the teachers' wish to give socially desirable answers or to maintain a high self-concept. Maybe teachers were sometimes convinced that they included aspects that were important for quality learning; 
for example, to activate students' thinking by asking high-level questions, by encouraging them to think independently and by giving them clear feedback. But their message did not reach the students.

The results show that the teachers remain inside their own experiential horizon: if they themselves see certain connections and explain them, they are convinced that students see them also. But students are confronted with certain problems for the first time and, for them, the connections remain obscure. The broadening of teachers' awareness is a prerequisite for more student-focused teaching.

Further statistical analysis has shown that perceptions of students with less developed conceptions of learning and teaching differed a lot from the teachers' perceptions. Students with developed conceptions could better understand teachers' intentions. This can be explained also by their better knowledge and approaches to learning. It is in line with the findings of a recent study, which has revealed that students with deep approaches generally perceived the same learning environment differently from those with surface approaches - they showed more understanding of the active learning that their teachers tried to encourage (Campbell et al., 2001).

The questionnaire data also pointed out significant differences between students and teachers in ratings of the frequency of teaching-learning activities of various taxonomic levels. While students observed about two-thirds of classroom activities where routine tasks required low-level cognitive effort, teachers reported only about one half of such activities.

The answers to open-ended questions revealed additional discrepancies, and also partly explained them. For example, very few teachers (about $11 \%$ ) mentioned that teaching goals guided them in planning the methods and criteria of assessment. Their choice of assessment questions and criteria was mostly intuitive, based on experience. Therefore, they most probably rated themselves too highly on presenting teaching aims, giving clear assessment criteria and feedback to students.

\section{Intensive approach}

The comparison of classroom observation data from trained observers and teachers' interpretation also shows that the teachers probably overrated the frequency of certain classroom activities. Observers' frequencies were more in line with students' ratings. For example, observers noted very rare instances of connecting content with its application and real-life situations (less than 3 percent of classroom activities in History, and about 8 percent in Slovene were characterised by this). Certain further similarities but also differences between lessons in Slovene and History were observed that were not obvious from questionnaire data.

It should be explained that the curriculum renewal was more radical in Slovene language than in History. In Slovene, there was a shift from learning about language grammatical rules, terminology etc. to learning the language as a communication tool. Textbooks already embodied this shift, whereas in the History curriculum, only some chapters were rewritten or added to due to the new socio-political situation.

We shall limit our analysis of observation and interview data to the following areas:

- Relationship between perceptions of aims and actual teaching approaches, including the level of students' active involvement and initiative-taking during lessons

- Clarity of aims and assessment criteria in the eyes of students and teachers. 


\section{Aims and Approaches to Teaching}

Teachers in both subject matter areas reported in the interviews that they fully supported new, higher-level aims, like development of critical and creative thinking, problemsolving abilities, application of knowledge in real-life situations. They regarded them as realistic and important. But observations showed that prevailing classroom activities were very teacher-centred and did not match those aims. An important finding is that in both subjects observations revealed a complete absence of communication leading to the declared aims of critical thinking and evaluation of ideas. The gap between goals and strategies/activities seemed to be somehow smaller in lessons in Slovene, where there were more student-initiated activities and more discussions. History was taught in a more traditional transmission mode with whole-class activities and teacher talk prevailing; interestingly, during the second round of lesson observation there was an increase in group and individual work.

In the interviews following the lessons in Slovene, students mentioned that they liked to be more active: Today we came to nearly all conclusions by ourselves. We could have been even more independent I feel more self-confident as I can better communicate also outside the classroom. On the other hand, they remarked that the observed lessons were not quite typical: Usually, we are more in a hurry. We usually do discuss things, but there is no time for group work, which we like best.

The teachers of Slovene embraced new high-level communication aims as important. When introducing more interactive teaching they feel hampered by time pressure. In particular, teachers with an inconsistently developed philosophy of teaching are vulnerable to context variables and falling back on traditional modes of teaching. For example, one of the teachers stressed: Most of the lessons are conceived in such a way that students discover new knowledge on their own; such lessons are also the most fruitful. But at the same time she said: I encourage students to express their own views, but not always to the same extent as in the observed lesson; we would fall behind too much. The observer and students also mentioned the feeling of time pressure. Also, the observer reported that the teacher presented conclusions, prepared in advance, herself.

Teachers of Slovene expressed hope that the new catalogue, which represents knowledge standards for external final exams, would not be as overburdened with facts as the former one. As they did not know the contents of the catalogue yet, so they did not feel constrained to teach to the test.

To the teachers of History, the higher-level aims seemed important as well, but when they planned the lesson, they thought primarily of the content to be covered. For example, The students should be brought to thinking about the past and also the present, to understand causes of events. This teacher stressed that students have to do this by themselves, but at the same time she is convinced that the teacher has to give them a firm foundation. She is occupied by covering all the important topics and teaching mainly in a traditional mode. The majority of History teachers were convinced that students would reach a deeper understanding if they were able to take in everything the teacher offers to them. When asked about desirable changes, teachers of History were stressing aspects of improving their own presentation - to make it more picturesque and varied; very rarely did they mention ways of activating students.

The inability to differentiate between aims and content of teaching was also very obvious. My aim is to present the content in such a way that the students will 
understand and remember it. This view by one of the teachers is being echoed in many remarks of the interviewed students: The goal is that we work through the content step by step, I think that we reached the goal as we went all the way from prehistory to the Roman Empire.

The students perceive the goals as something the teacher does or wants them to do, and not something they themselves are supposed to reach. For example: She wanted to teach us the reforms of Emperor Augustus. She intended to explain the expansion of the Roman Empire, the way of life and illustrate it with additional historical sources.

Sometimes, the teacher decided to use various active methods in accordance with the aims, but only half-heartedly, as this was not supported by the prevailing conceptions of learning and teaching. The students should improve their ability to communicate, not only to learn topics from the curriculum. Therefore, some dialogue is introduced; but I cannot reach the goals if the pupils talk too much; I have to explain everything clearly, so that they can write it down and remember. In this way, the students get conflicting messages about what is expected of them.

\section{Aims, Criteria of Assessment and Feedback to Students}

In the interviews, the students often complained that criteria of assessment were not clear to them, although the teachers were convinced that they explained them thoroughly. For example, in Slovenian language, the criteria for grading oral presentations that were developed in cooperation with the students seemed very clear to them (but not so to the teachers). On the other hand, criteria for assessing essays, which were imposed from above (external assessment) were clear to teachers, but not so to the students.

On the whole, students got the message that quantity of knowledge was more important that quality. Quantity is well-defined, other criteria remain obscure: For the highest grade, you have to know everything that is in your textbook and also what she (the teacher) told us and what we have read someplace ourselves. Or If you know everything and add your own examples and interesting remarks, you get a good grade. If the teacher has to help you with additional questions and you know less, you get a lower grade.

The feedback to the students was usually only numerical (in terms of grades 1-5) and did not entail any detailed information on quality of knowledge, deeper understanding, making connections etc. or suggestions for improvement. The majority of teachers are convinced that this is sufficient.

Traditional transmission teaching is still deeply ingrained in Slovenian school culture. The new final (external) exams, which to a great extent require reproduction of memorised facts, rules and the thoughts of others, have not improved the situation. They seem to "cast shadows" even into the first grade.

\section{Concluding Remarks}

The study revealed certain large discrepancies between the high-level aims of school reform and prevailing classroom activities on the one hand and between teachers' and students' perceptions of the same processes on the other. The data from classroom 
observations were more in congruence with students' than teachers' perceptions. There was not much space for student initiative and possibilities for discussion. The messages (about goals, criteria of assessment etc.) that the teachers intended to convey or were convinced to have successfully conveyed to the students did not always reach them in the intended form. Teachers, especially those in History, were still much more disciplineoriented than student-oriented, and firmly believed in "clear presentation" of everything the students had to know.

The instances when active methods have been introduced, like dialogue to develop independent thinking and communication skills in Slovene language, proposed by the new curricula and textbooks, were well received by the students. This shows that it is possible to break the vicious circle of transmission and more or less passive reception. Some teachers in the study even improved their teaching approach from the first to the second observed lesson and apparently reacted favourably to the interaction during the interview.

On the whole, teachers are going to need a great amount of long-term support and focused in-service training of high quality in order to raise their awareness of their own conceptions and aims, of the conceptions and perceptions of their students and of existing discrepancies, especially between aims and teaching/assessment strategies. Teachers also need more opportunity to experience and try out new teaching approaches, reflect and discuss their implications (Korthagen and Lagerwerf, 1994; Dolk, Korthagen and Wubbels, 1995; Niemi, 1997). This is especially important as Slovenian secondary teachers are still getting a heavy discipline-oriented education, with little professional theory and almost no practical training.

On the basis of our results, we plan opportunities for collaborative learning of teachers in the form of experiential and action-oriented workshops. The responsibility to improve the broader context (not too overburdened curricula, better textbooks, more time and opportunity for introducing active methods, less pressure from external examinations) rests with the general school policy. 


\section{Section C}

\section{Higher Education}

Tertiary education is an increasing area of interest in the ISATT community. Fernando Ribeiro Gonçalves, Sandra Valadas, Carla Vilhena and Luís Faísca, (University of Algarve, Portugal) open this section with their chapter: "Students' Voices at a Portuguese University: Academic Motivation and its Relationship with Academic Success". Student perceptions of their academic institution, themselves, their teachers and the curriculum were examined with the assumption that "students are the privileged informants about their own academic experience". Academic motivation was examined and related to attributions of failure and students' own views about the experience of failure. Responses varied by a number of demographics yet produced a coherent pattern. The understandings this study provided have developed a rationale for an intervention program.

Andrew Short (Brock University, Canada) addresses an emerging topic of great interest and serious concern among teachers in higher education in his chapter: "Discourse Dissonance in University Policy Concerning Intellectual Property". He contrasts the uses of policy language surrounding intellectual property by stakeholders in the university including faculty and external sources including government and corporate interests. The differences in the communities defined by interests and orientation contributes to antagonistic rhetoric. Faculty positions as expressed through associations of university teachers (UK and Canada) use strong language asserting the ownership and rights of use over work produced by faculty. Tensions between ideas of what the university and the human capital associated with it represent seem evident in an association of shared ideology between government and corporate interests in shaping dialogue and language. The idea of universities as locations of production for ideas that can be used to generate profits, licences and patents has become attractive to the point that faculty exploitation has been transposed to representing "common good". Short encourages further dialogue and understanding of the implications of such growing initiatives in policies and practices.

Michael Kompf (Brock University, Canada) builds on the ideas introduced by Andrew Short and considers fundamental shifts in what the university is all about in his chapter: "When Angels Dance with Devils: What is Sacred and Profane in the University?" He describes the seductive environment of information and communications technology and how its embrace has led many faculty to buy into the production model of governance and teaching. Manufactured crises have led the way to changes justifying alterations in workload and the types of work most prized in the academy. Such influences transform the values of new faculty and disrupt understandings of development throughout professional life. Power relations, the use of part-time faculty, unionisation and the search for tenure are not only measured differently but quell activism and have created unalterable and inexorable change in the way university education and professing are thought about.

Ruth G. Kane (University of Otago, New Zealand) in her chapter: "Listening to Students'Voices: Self Study of Teacher Education Practice", investigates the contrasts between changes in ways of thinking and ways of doing teacher education. Reforms, 
while attentive to calls for change, have been inattentive to teachers' voices in the process. Teaching as telling or transmission reinforces a dysfunctional model of technical rationality that gives little credence to learning from or in experience. Initiating new teachers into the critical responsibilities of teaching means asking questions like "What does it mean to be a teacher?", "What are the purposes of education and schooling?" and "What are the forces that contest the nature of teaching, schooling and education?" are explored through examinations of course interactions experienced by Kane and critically examined through reference to theory and a humanistic and equitable way of considering teacher education and practice.

Pam M. Denicolo (University of Reading, UK) examines the highest level of accomplishment for educators in her chapter: "Doctoral Degree Assessment Criteria: Towards Transparency through Exploring Teacher Thinking". She considers the generic problems that exist in this process by discussing the "neglected species" of higher education. Through illustrations of policies and practices and a walk-through of the processes expected of graduate students, she illustrates the conflicts, conundrums and seemingly unconnected tasks used to produce students with advanced degrees. The level of institutional preparation and the amount of forethought used in program design, rationale and expectation seem to defy the basic purposes. Whether or not order can be made out of chaos seems to be a task left to individual students and their advisors, often left adrift in the sea of administrative confusion, contradiction and fuzzy thinking. 


\section{Chapter 11}

\section{Students' Voices at a Portuguese}

University: Academic Motivation and its Relationship with Academic Success

\section{Fernando Ribeiro Gonçalves, Sandra Valadas, Luís Faísca and Carla Vilhena}

In this chapter, we present evidence that emerged from data collected during the year 2000 by the Permanent Observatory for Teaching and Learning Quality of the University of Algarve. Data presented here will refer exclusively to students' representations of the institution, themselves, their teachers and the curriculum, since we consider that students are the privileged informants about their own academic experience. The main topic explored refers to students' evaluation of the influence of academic motivation on the decision to drop out from university. The theoretical framework will also be presented.

We will present some behavioural symptoms that students evaluated as relevant indicators of lack of academic motivation. Furthermore, we intend to analyse the students' attributions of academic failure as well as the students' point of view about their own failure, according to their academic experience. Results will be analysed in the context of current theories that explain students' adaptation and academic success in a higher education institution. The influence of teacher pedagogical practices on the students' level of academic motivation will also be examined. In addition, we will discuss models of quality concerning learning and teaching in higher education and will propose a set of intervention dimensions.

\section{Theoretical Framework}

The transition from high school level to a higher education institution has several implications for students' lives, considering the demands in terms of academic, personal, social and vocational areas of development (Baker et al., 1985; Ribeiro Gonçalves, 2000; Soares, 1998; Valadas, 2001). Pascarella and Terenzini (1991) refer to the wealth of contexts associated to the higher education reality as factors that lead to new 
acquisitions and personal restructurings. Other authors consider that the attendance at a higher education institution represents a particularly important phase in the development of a student.

The relationship between academic success and adjustment to a higher education context has been studied in the past twenty years by several authors. Some of those authors (Chemers et al., 2001; Gerdes and Mallinckrodt, 1994) point out that such adjustment does not always occur in a positive sense. Frequently, this statement leads to poor performance levels as well as to low levels of academic motivation for continuing studies.

It is important to consider the complexity of academic success in its socialrelational and bio-psychological components (Tavares et al., 2000). In fact, academic success has a subjective nature that leads us, on the one hand, to reflect upon academic adjustment and its evaluation, and on the other, to focus on the relationship between students' performance and personal learning goals. Conceptualising success under its academic perspective invites us to: (a) analyse study competences and learning strategies, and (b) consider relationships with academic performance. Several studies have shown that academic performance depends, partly, on students' approaches to learning. However, we cannot overlook other factors such as the teachers' evaluations and performances (Hativa and Birenbaum, 2000, Trigwell et al., 1999), career development, personal satisfaction, interest, and individual motivation. In other words, although instruction is regarded as the major environmental factor affecting scholastic success, there are other factors that can become more important in situations where teaching is not producing the desired results. In fact, academic performance in higher education ultimately involves a complex interplay between student attributes and the educational environment.

In their studies, Weinstein and Mayer (1986) verified that students with a high level of academic performance ("good students") use more learning strategies and have what they call more flexibility and adaptation capacity to productively use these strategies. In this sense, students are able to improve learning (Weinstein and Mayer, 1986; Zimmerman and Martinez-Pons, 1990) through the development of different forms of processing information, and the increase of their own academic performance (Zimmerman and Martinez-Pons, 1986). On the other hand, students with lower performances are more often influenced by emotional factors that interfere with learning (Biggs, 1994; Marton and Booth, 1996; Weinstein and Mayer, 1986; Zimmerman and Martinez-Pons, 1990), and therefore seem to possess a smaller capacity to monitor and regulate the learning process.

Because the selection of learning strategies depends on indicators other than motivational aspects, we may argue that students' approaches to learning constitute one of the factors that influence academic performance and success. In several studies that examine university life from the student perspective (Kember and Leung, 1999; Pressley and Ahmad, 1986), from the analysis of students' perceptions of the motivational aspects of curricula, motivation emerged as the aspect most frequently cited and raised by the students in comparison to all the other curriculum elements combined. Other studies (Gonzalez Pienda et al., 1997) highlighted the importance of self-concept in the regulation of cognitive-motivational strategies involved in learning and academic performance.

The data from investigations frequently suggest the existence of a lack of interest in a specific course that can be related to (i) teacher performance, (ii) the 
perception of the interest and utility of contents, (iii) the relationship with colleagues, and (iv) the occupation with extra-curricular activities. Although the literature indicates that students who use and optimise good learning strategies attain a better performance in their studies (Marton, Watkins and Tang, 1997), we cannot infer a linear influence (Arias et al., 2000).

The effectiveness of student learning is determined, in part, by motivation and ability to deal with related contextual demands (Shuell, 1986; Snowman, 1986). Students who are capable of clearly identifying learning goals can successfully achieve them and monitor their own progress. However, the degree to which students can reach these conditions depends (at least in part) on the way they face their own learning process (Biggs, 1985; Entwistle and Ramsden, 1983; Norton and Crowley, 1995).

Research into student learning has been based on two main theoretical sources: information processing (IP) and contextually based work on students' approaches to learning (SAL) (Biggs, 1993). IP models assume that student learning takes place within the student, while the SAL tradition emphasises a within-the-teaching/learning context. The constructs underlying the SAL paradigm have already reached significant consequences concerning teaching and learning, and constitute a valid base for applied work aimed at improving the quality of learning and teaching through the recognition of contextual variables in learning (Kember and Leung, 1999).

\section{Method}

\section{Participants}

During the 2000/2001 registration period at the University of Algarve, we collected the beliefs of more than 6000 undergraduate students on academic achievement and motivation using a self-filling questionnaire. In Table 11.1 we present the distribution of the participants according to academic year.

\section{Variables measured}

A set of eight questions evaluated the importance that students attributed to different types of behaviour as indicators of lack of academic motivation.

Specifically, in those questions, we asked if the lack of motivation could be revealed by the following symptoms:

Symptom $1 \quad$ Negative image of the teacher

Symptom $2 \quad$ Poor interaction with the teacher

Symptom 3 Lack of interest in the course

Symptom $4 \quad$ Lack of motivation to study

Table 11.1 Distribution of the participants according to academic year

\begin{tabular}{lrr}
\hline Year & $N$ & $\%$ \\
\hline 1st year & 483 & 7.9 \\
2nd year & 1686 & 27.7 \\
3rd year & 1703 & 28.0 \\
4th year & 1707 & 28.0 \\
5th year & 514 & 8.4 \\
Total & 6093 & 100.0 \\
\hline
\end{tabular}




$\begin{array}{ll}\text { Symptom 5 } & \begin{array}{l}\text { Lack of motivation to attend classes } \\ \text { Minimising the importance of a particular course when } \\ \text { compared with other courses }\end{array} \\ \text { Symptom 7 } & \begin{array}{l}\text { Lack of motivation to take examinations } \\ \text { Symptom } 8\end{array} \\ \begin{array}{l}\text { Lack of motivation to take extra examinations to improve } \\ \text { academic results }\end{array}\end{array}$

An 18-point response scale was used to express students' opinion about the pertinence of each one of those symptoms as indicators of lack of academic motivation: weak ( 1 to 6 ), moderate ( 7 to 12 ) and strong (13 to 18 ). In order to understand what students think about the occurrence of academic failure, we asked them to attribute one or more possible meanings to that failure. A closed question was used (students could choose more than one category) and the categories available for response were as follows.
Academic failure is:
Meaning 1 a reason for not keeping on studying
Meaning 2 a reason for familiar worries
Meaning 3 a source of financial problems
Meaning 4 a reason for the weakness of self-confidence
Meaning 5 a reason for academic desertion
Meaning 6 just a question of bad luck
Meaning 7 a reason for lack of academic motivation

We also asked students to evaluate their academic performance using a 5-point scale ranging from very weak to very good.

In addition, students who evaluated their academic performance as weak or very weak had to choose one or more possible explanations for their academic failure among several alternatives. The set of possible options was:

$\begin{array}{ll}\text { Explanation 1 } & \text { I don't know how to study } \\ \text { Explanation 2 } & \text { I am not motivated to study } \\ \text { Explanation 3 } & \text { I share my attention with other activities } \\ \text { Explanation 4 } & \text { The place where I study is not the most adequate } \\ \text { Explanation 5 } & \text { I miss a lot of theoretical classes } \\ \text { Explanation 6 } & \text { I miss a lot of practical classes } \\ \text { Explanation 7 } & \text { I don't keep the contents of the courses updated } \\ \text { Explanation 8 } & \text { I don't take notes in classes } \\ \text { Explanation 9 } & \text { I don't organise my notes after classes } \\ \text { Explanation 10 } & \text { I don't ask teachers for help } \\ \text { Explanation 11 } & \text { Other reasons }\end{array}$

\section{Results}

All behaviours were evaluated as having moderate pertinence as symptoms of lack of academic motivation. However, students seem to attribute more importance to symptom 3 , considering that the lack of interest for the course is the strongest indicator of their weak level of motivation to continue their studies. Special attention should also be given to symptom 4, referring to the lack of motivation to study. On the other hand, the 
Table 11.2 Pertinence evaluation for each symptom: descriptive statistics for the global sample (mean and standard deviation)

\begin{tabular}{|c|c|c|c|}
\hline \multicolumn{2}{|c|}{ Behavioural symptom } & \multirow{2}{*}{$\begin{array}{c}\text { Mean } \\
11.1\end{array}$} & \multirow{2}{*}{$\begin{array}{c}\begin{array}{c}\text { Standara } \\
\text { deviation }\end{array} \\
3.73\end{array}$} \\
\hline 1 & Negative image of the teacher & & \\
\hline 2 & Poor interaction with the teacher & 11.2 & 3.54 \\
\hline 3 & Lack of interest in the course & 12.4 & 3.53 \\
\hline 4 & Lack of motivation to study & 11.8 & 3.69 \\
\hline 5 & Lack of motivation to attend classes & 11.4 & 4.23 \\
\hline 6 & $\begin{array}{l}\text { Minimising the importance of a particular course when } \\
\text { compared with other courses }\end{array}$ & 11.3 & 3.64 \\
\hline 7 & Lack of motivation to take examinations & 9.6 & 4.48 \\
\hline 8 & $\begin{array}{l}\text { Lack of motivation to take extra examinations to improve } \\
\text { academic results }\end{array}$ & 10.3 & 4.38 \\
\hline
\end{tabular}

lack of motivation to take examinations is the less relevant indicator. Table 11.2 presents the sample mean evaluation for each symptom.

Additionally we constructed profiles for each academic year (Figure 11.1), in order to appraise the effect of academic experience in the evaluation of those symptoms.

Students from the 1st year show systematically lower results than the other students, which mean that they consider all the behavioural symptoms as weak indicators of the lack of academic motivation. However, a direct effect of academic experience in symptoms evaluation could not be detected.

To understand what students think about the occurrence of academic failure, we present the percentage of students that attributed different meanings to that failure (Figure 11.2).

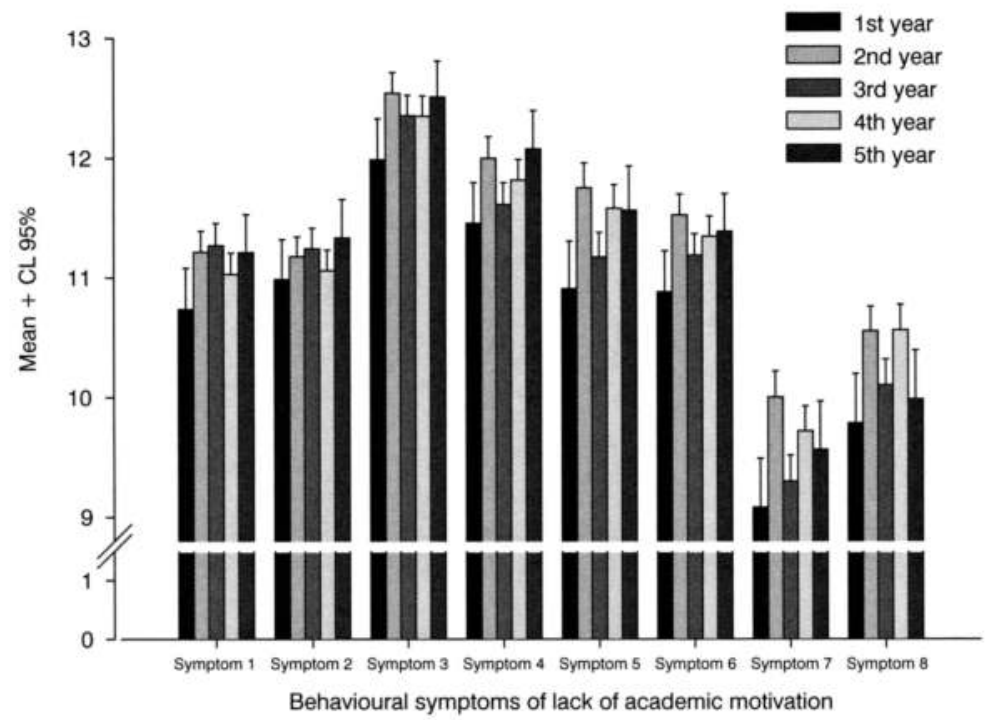

Figure 11.1 Responses for each academic year (mean and uppper confidence limit 95\%) 


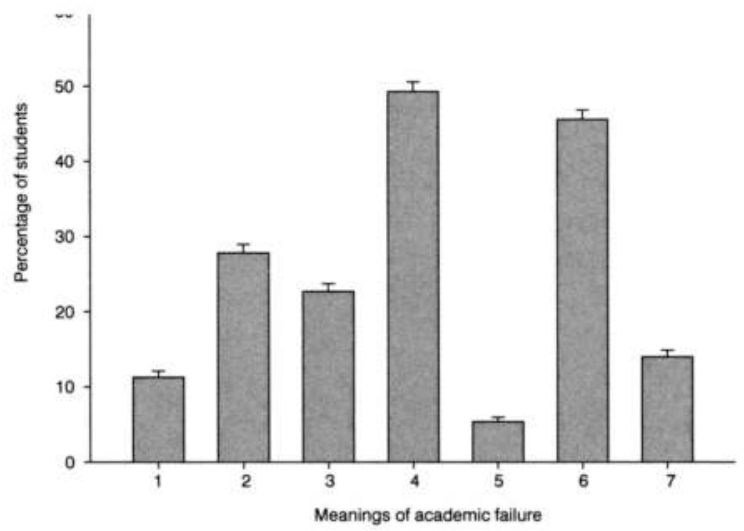

Figure 11.2 Percentage of students choosing possible different meanings of academic failure (percentage and upper confidence limit 95\%)

Figure 11.2 shows that meaning 4 and meaning 6 are the most referred to by students. The occurrence of academic failure seems to be strongly felt as a reason for the weakness of students' self-confidence. It is also interpreted as a question of bad luck.

The meanings related to academic dropout (meanings 5,1 and 7) seem to be less important.

A multidimensional scaling representation was used to illustrate the cooccurrences of the different meanings that each student attributes to academic failure in higher education. A minimum spanning tree (mst) connecting the meanings more frequently chosen by the same student was imposed over the data. This tree shows a radial structure that emerges from meaning 4 , clustering meanings related to familiar and financial problems that can even lead to not keeping on studying (meanings 2, 3 and 1) and clustering meanings that attribute to academic failure a role of the weakness of academic motivation (meanings 7 and 5). Considering academic failure as a question

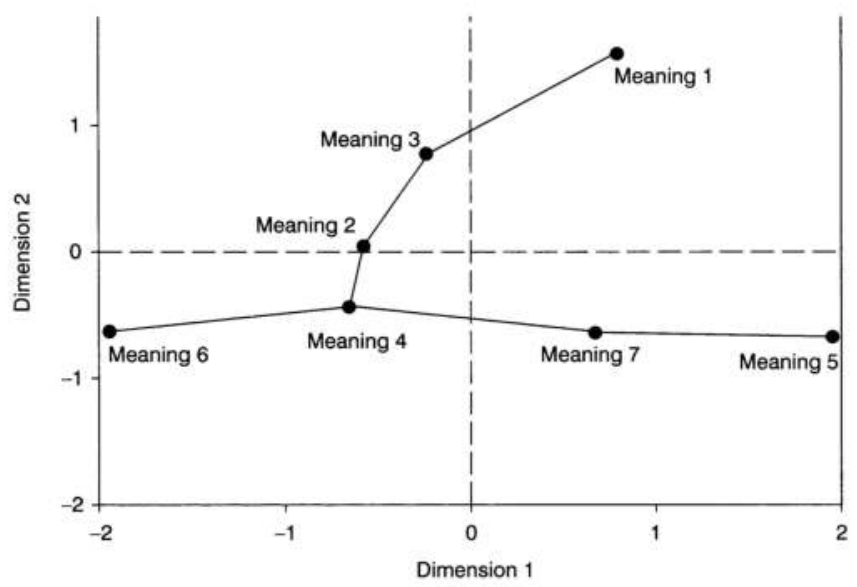

Figure 11.3 Multidimensional scaling for co-occurence of meaning attribution to academic failure (stress $=0.005$ ) 

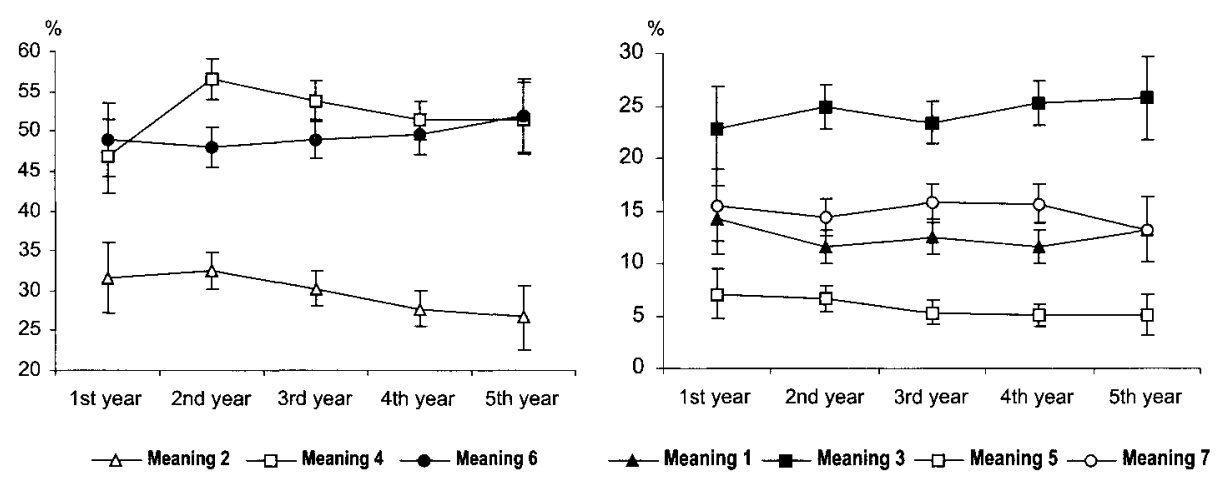

Figure 11.4 Response profiles for each academic year (percentage \pm confidence limits $95 \%$ )

of bad luck is an isolated way of explaining this failure. Figure 11.3 presents the multidimensional scale where the mst is represented.

In order to illustrate the effect of student experience in the process of meaning attribution to academic failure, we have established a comparison between academic years for each type of meaning considered. Figure 11.4 shows the response profiles for each academic year. Results do not show interactions between academic year and the meanings considered by students. However, meaning 4 is particularly chosen among 2nd year students; the importance of meanings 4 and 2 seems to decrease with academic experience.

Table 11.3 presents the distribution of students according to their estimated level of academic performance (mean $=3.08, \mathrm{SD}=0.79$ ).

Data show that most of the students consider their level of academic performance as sufficient. However, $19.7 \%$ of the participants believe that they are weak or very weak students. Figure $\mathbf{1 1 . 5}$ plots the evaluation for academic performance level against academic year.

Although academic performance evaluation increased with academic experience, the biggest difference is found between the 1 st and the 2 nd year.

The next analysis is restricted to those students who evaluated their academic performance as weak or very weak $(\mathrm{N}=1182)$. Figure 11.6 shows the percentage of students that have chosen different types of explanations for their low level of academic performance. None of the explanations reached a consensus of $40 \%$, with explanation 11 the most chosen by students ("other reasons"). These results show that participants

Table 11.3 Distribution of students according to the estimated level of academic performance

\begin{tabular}{lrc}
\hline Level & $N$ & $\%$ \\
\hline 1 Very weak & 184 & 43.1 \\
2 Weak & 998 & 16.6 \\
3 Adequate & 3094 & 51.5 \\
4 Good & 1625 & 27.1 \\
5 Very good & 103 & 1.7 \\
$\quad$ Total & 6004 & 100.0 \\
\hline
\end{tabular}




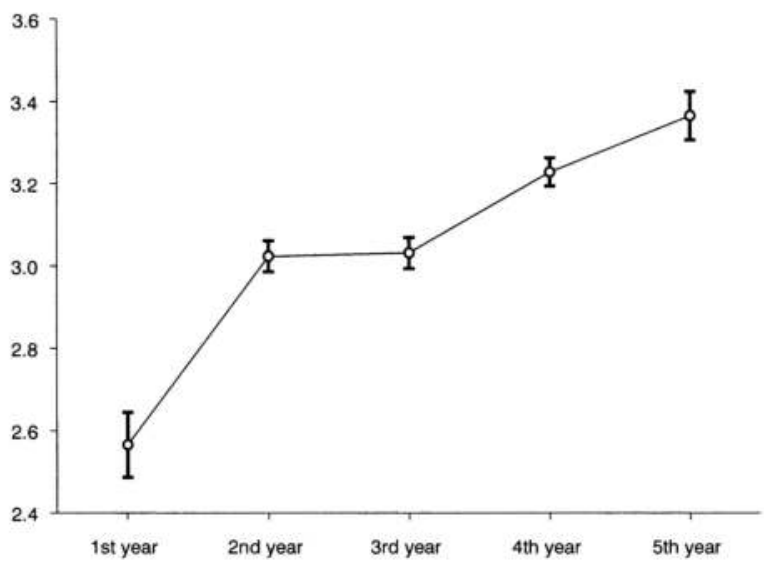

Figure 11.5 Evaluation of academic performance for each academic year (mean \pm confidence limits 95\%)

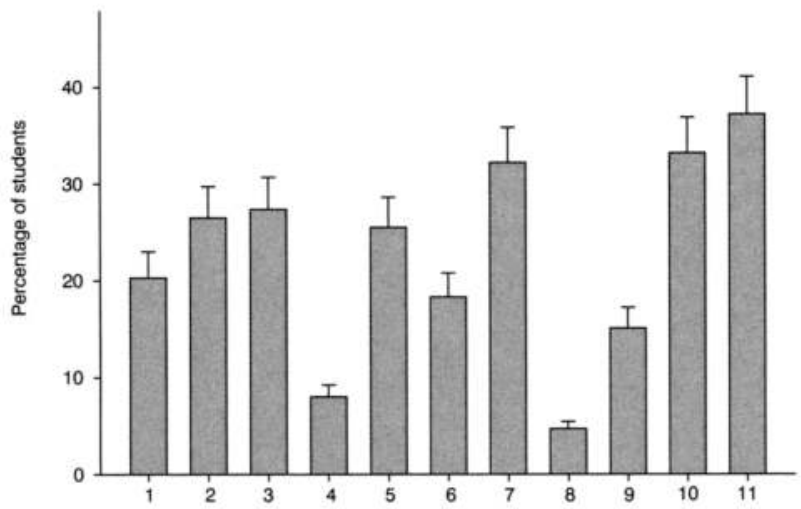

Figure 11.6 Explanation of a weak or very weak academic performance (percentage + upper confidence limit $95 \%$ )

did not accept available answers as viable ways of explaining their academic performance. Explanations 8 and 4 are less important, meaning that students do not think that the places for study and taking notes are pertinent explanations. Participants chose explanations 7 and 10 more often, suggesting that not asking teachers for help or not keeping course contents updated are the most plausible explanations for their weak or very weak performance.

Again, we used a multidimensional scaling representation to illustrate the proximity between the explanations chosen, due to the co-occurrences of students' response. A minimum spanning tree (mst) connects the explanations that are preferentially given by the same students. The tree shows a radial structure that emerged from explanation 2, "I am not motivated to study", suggesting that, when explaining their poor academic performance by a lack of motivation, students tend to add other explanations. Those patterns of response are easily identified in Figure 11.7. We can find a cluster grouping explanation 10 (don't ask teachers for help), 9 (don't organise 


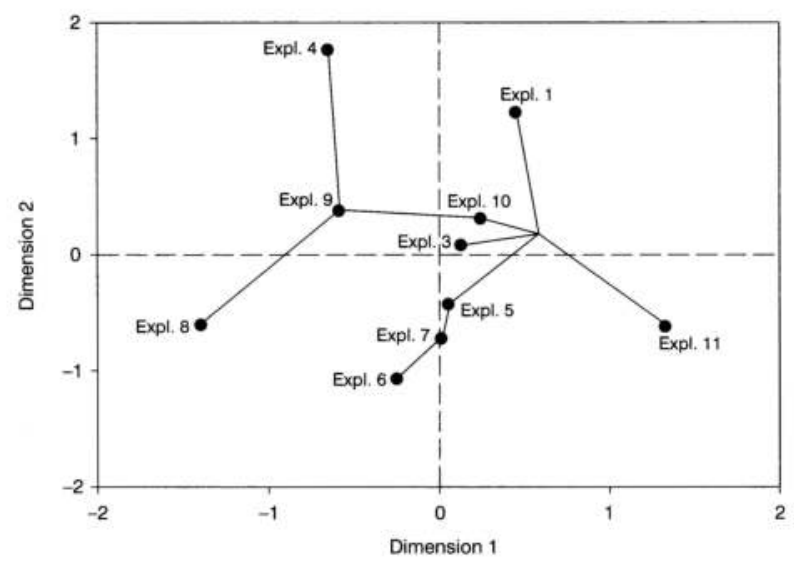

Figure 11.7 Multidimensional scale for preferences among the explanations: mst is also represented $($ stress $=0.10)$

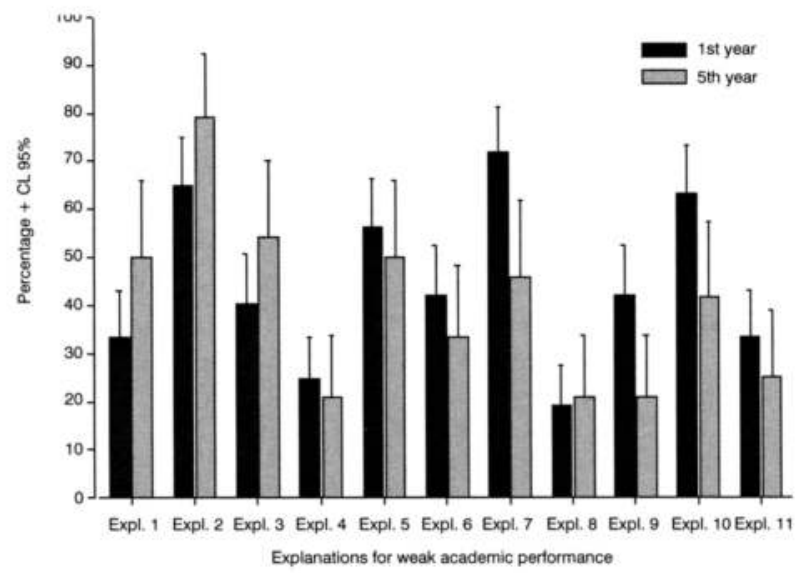

Figure 11.8 Response profiles for 1st versus 5th academic year (percentage + upper confidence limit 95\%)

notes after classes), 4 (place of study not adequate) and 8 (don't take notes in classes). On the other hand, we can identify a group of explanations related to student absenteeism (missing theoretical and practical classes, explanations 5 and 6) and also with explanation 7 (not keeping the contents of the courses updated). Finally, there are isolated explanations that establish connections only with the more general explanation (not being motivated): students who don't know how to study (explanation 1) and students who share their attention with other activities (explanation 3 ).

To evaluate the effect of academic experience in beliefs about the reasons of a poor academic performance, we have compared the percentages of students choosing each type of explanation in the 1st and in the 5th academic year. Figure 11.8 presents the response profiles obtained. 
The response profiles show that a set of explanations is more frequent in the 5 th year than in the 1 st year (explanations 1 and 3), while explanations 6 and 9 are less frequent in the 5 th year. Also concerning explanations $2,4,5,7,8,10$ and 11 we do not observe any significant difference $(\mathrm{p}>0.1)$.

\section{Discussion}

In general, we can point to six reasons that are strongly responsible for the students' levels of academic motivation to continue their studies in a higher education context: the performance as student, the interest in the contents of the courses, the degree of difficulty of the courses, the performance of the teachers, the conditions offered by the Faculty, and, finally, the quality of the University support services.

In this study we have investigated the representations students have about their own academic performance and behaviour, in order to further our understanding of the complex reality of academic motivation. In fact, students are one of the most important sources of information in the analysis of their own academic experience. In our opinion, the representations students have of themselves, of academic life, and the institutional context, can significantly contribute to a valid perception and understanding of the reality of higher education. However, we realise that to further understand this reality it will also be crucial to consider the opinions of teachers, and service and executive personnel.

According to the students' opinion, academic motivation to continue studies is mainly influenced by the lack of interest in a given course. At this point, it seems important to understand the meaning of the expression lack of interest in a course, identifying specific behaviours that reveal this symptom. The existence of a number of closely related behaviours underlines the importance of operationalising this symptom. Students also think that the lack of motivation to study is a moderate indicator of a lower level of motivation, whereas attending examinations is not considered a significant symptom.

Although it was not possible in this study to identify any pattern of association between symptom evaluation and academic experience, several investigations point to different results (Hayes et al., 1997; Richardson, 1995). In fact, attending a higher education degree is a development task involving significant changes in academic, social, vocational and personal domains (Baker, McNeil and Syrik, 1985; Ribeiro Gonçalves, 2000; Soares, 1998; Valadas, 2001).

Another result shows that most participants evaluated their academic performance as sufficient, being gradually more self-confident with academic experience. However, a significant difference occurs between the 1 st and 2 nd years. Several authors (Almeida et al., 1999; Pascarella and Terenzini, 1991) consider that the 1 st year at university is a critical period that can lead to crisis and developmental changes concerning relationship demands, different levels of responsibility, learning strategies and study habits. Almeida (1998) highlights personal, interpersonal, and institutional variables as determinants of a student's adaptation and integration process in a higher education context.

Those students who consider themselves as weak or very weak students evoked relationships with teachers, motivational factors and learning strategies. Some differences in these explanations were found between 1 st and 5 th year students, who mentioned the nature of tasks demanded and the development level of students as possible explanations 
for their failure. The fact that 1 st year students attributed their lower level of success to not attending classes reflects the social and familiar demands they are facing in this integration period of their academic life (Biggs, 1994; Tavares et al., 2000). On the other hand, 5th year students seemed to attribute their failure to the incapacity for developing adequate learning strategies and study habits. In summary, while 1st year students mainly referred to integration and adaptation demands to explain their weak academic performance, 5th year students favoured explanations concerning an inadequate development of study habits. This is consistent with results obtained in other studies (Biggs, 1994; Weinstein and Mayer, 1986; Zimmerman and Martinez-Pons, 1986, 1990).

Concerning the meaning students attributed to academic failure, although they considered it a possible cause for depleting self-confidence, they mainly believed that it is just a question of bad luck, not to be taken as a valid reason for academic abandonment. The meanings associated to academic failure do not change significantly with academic experience.

The results obtained clearly show that academic motivation is closely related to a multitude of factors that must be examined, taking into account a number of evidences on teaching and learning processes in higher education. First, the culture of pedagogy must arise inside the institutions themselves and we think that such culture should move towards continuing education as a way of life for all the academic staff. To accomplish this, universities should have a service for observing and analysing the status quo of the items mentioned above, in order to provide feedback for the psychological and social services, as well as for the faculties within the universities and, at the same time, promoting ways of facing and dealing with those items. Furthermore, the curriculum design must reflect the needs of the wider society, culture and labour market needs and demands, i.e. the students have to feel that the subjects of the courses they undertake are useful for their future.

Another aspect that deserves our attention refers to students' academic skills. In fact, these skills show a gradual progress from their first academic year until the end of their courses and that is why this is a challenge that all teachers have to face in terms of pedagogy inside the classrooms. Special attention must also be given to the development of good learning strategies. Students do have their own experiences, their potential concerning scientific preparation and study habits. Several studies have showed that students who have the capacity to create adequate learning strategies, easily develop study skills that allow them to obtain higher academic success.

Concerning the influence of teachers' practice, it is also important to refer to some factors regarding their pedagogical competences that might influence students' opinions. By this we mean teachers capacity to understand students needs and difficulties, their flexibility on the pedagogical/didactic approaches, their comprehension of the evaluation process (as a tool for diagnosing and rescuing, rather than for punishment), their capacity to establish/create good interaction environments and to help students, and finally, their scientific competence.

We propose an intervention programme in which we have to research, diagnose, intervene and evaluate; invest in training and provide help and information for students, teachers and other personal. A Permanent Observatory for Teaching and Learning Quality inside the University of Algarve has already been created, but it is necessary not only to develop continuing education and training services for the academic staff, but also to improve the quality of the Psychological and Social Services. 


\section{Chapter 12}

\section{Discourse Dissonance in}

\section{University Policy Concerning Intellectual Property}

\section{Andrew Short}

The purpose of this chapter is to contrast the use of policy language by stakeholders concerning intellectual property in the university environment. While the idea of knowledge ownership has implications far beyond the university, the stakeholders examined in this chapter will be limited to faculty within a university environment, and external sources including government and corporate interests. The underlying assumption is that these two main groups represent different discourse communities, which shape language use and meaning to their own purposes and goals. It should also be recognised that while treated as a single discourse in this chapter, universities include many discourse groups such as staff, administration, faculty, and students. In addition the discourse of faculty can also be broken down into discipline, Faculty, or department. Also, individuals themselves in any environment are seldom if ever members of a single discourse community but function in several simultaneously.

Items to be investigated include intellectual property language, and the question of policy discourse concerning intellectual property for both faculty and external interests. Examining different discourses means attempting to find common ground in how meaning is shaped and then presented as a definition by different interests. For this reason there are as many definitions of intellectual property as there are producers and users of it. The definition of intellectual property and its usage is therefore dependent on the purpose behind the policies of stakeholders and this is either implied or stated in policy documents.

\section{Faculty Associations and Intellectual Property Language}

Faculty associations have taken a leading role in mapping out the language of intellectual property policy for their respective faculty memberships. The role of faculty in the production and dissemination of intellectual property is an international issue. The Association of University Teachers (AUT) in the UK, have recently produced a guide for faculty concerning intellectual property issues (Association of University Teachers, 1999). The policies in this document were designed specifically for the discourse 
community of university teachers regardless of individual institution. In other words: "The aim of this booklet is to give every member a tool with which to control and assert their intellectual property rights within an employment environment, recognizing at the same time that they are professionals in their own right, as well as employees" (p. ii). The language here is interesting because a separation is made between being a professional and being employed. The implication is that a member of the association may produce materials that may not be subject to the control of university employers and their policies. The choice of the word "professional" implies that individual members may be members of an employee discourse, but are also members of a separate group whose policies and or regulations also apply to the individual.

This discourse membershipping empowers the AUT to assert its own guidelines for intellectual property creation and use by its members regardless of institutional policy regulation. Intellectual property is herein defined as a set of rights held by faculty members who produce the intellectual property. These include: "copyright, author's moral right, public lending right, performer's rights, database right, design right, registered design right, rights in semiconductor design, rights in trade and service marks, patent rights, plant variety rights, and rights over know how and confidential information" (p. 1). In terms of work done while employed by an institution, the AUT guide states that "in principle the copyright of all material produced by employees legally belongs to the employer if it has been produced in the normal course of employment or during assigned duties" (p. 2). However, the guide qualifies this by adding that there is usually "an implied term that the employer waives all rights in respect of 'scholarly works', which include books, articles, and conference papers" (p. 2).

The main purpose of the language used in the AUT document is to protect the rights of its members who are involved in creation and dissemination of intellectual property in UK institutions. Members are seen not only as employees of higher education institutions but also as independent professionals whose profession is to produce intellectual property regardless of the specific terms of employment within the institutions.

In Canada, faculty groups and associations are producing other policy documents. The Canadian Association of University Teachers (CAUT) has produced policy documents for its membership to alert them to potential problems in the current push by external forces to commercialise intellectual property. The CAUT claims that "The common good of society depends upon the search for knowledge and its free exposition. Universities are the principal sites where these activities can take place through teaching scholarship and research" (CAUT, 1999, p. 1). The language here suggests an enemy mentality and a fortifying of the barricades against intrusion into the domain of those who produce intellectual property. In essence the argument states that producers should be given control of the property they produce because they have the interests of the public at heart. For instance, "But the freedom to pursue knowledge has always been endangered by those who put their special interest ahead of the public interest, and even more so, by those who define their special interest as the public interest" (p. 1). However, this language, though sincere in tone, is ironic in function. In short, the interests of a group of people who produce intellectual property are by their very existence special interests and therefore their policies have no more application to general problems than do the policies of other special interests. The righteous indignation expressed both calls attention to this contradiction and signifies that discourse communities cannot themselves invoke blanket or comprehensive 
policies, which apply to "society" because the language they use is not inclusive, but is limited to a specific group.

The hegemony indicated by the CAUT document employs protectionist language in an effort to safeguard the faculty discourse group. Reiterating that university faculty creating intellectual property add to the public good in opposition to other interest or discourse groups does this. Specifically the CAUT is concerned about the influence of private or corporate interests in references to universityproduced materials. "Private funders, not surprisingly, often want to steer research and inquiry so that it serves their ends. Not only does this threaten the intellectual integrity of university teachers and researchers, it goes against the larger public interest since most of our social and economic gains have come from basic research and curiosity-driven scholarship and inquiry" (p. 1). In this case the policy rhetoric sets up a dichotomy of interests lauding the efforts of the faculty and demonising those of corporate interests.

Government interests in intellectual property policy are lumped together with corporate interests to further entrench the idea of the university as an island under attack. The document raises an important point when it reports that: "Governments and the private sector should not forget that universities have other important tasks besides research and development such as teaching and service to the community in general" (p. 1). Conversely, it must also be argued that universities are simply not institutions of teaching and community support but that there does exist some responsibility on the part of the university and its faculty to serve the community at large by producing "useful" knowledge. However, the definition of what is useful depends on your context or discourse.

In short, the CAUT document expresses concern at the possibility of external influences shaping the discourse of universities around the issue of intellectual property. The difficulty is that the CAUT serves its own interests by construing corporate sources as having interests antithetical to those of the university. For example, within the discourse of the university collaboration is seen as an essential tool for construction and co-construction of knowledge. Private or corporate funding implies competition for research dollars, which means that instead of collaborating, faculty members are duelling for dollars head to head (p. 5). As a result of this shift from an internal cooperative discourse to one of competition, faculty will be rewarded more for not sharing than for sharing ideas. Infiltration of corporate stakeholders into the once sacred domain of the university will change the language and discourse of the environment by implementation of profit-centred policies.

\section{The Corporate Discourse}

Not all sources agree that the discourses of the university and of private interests should be separated. Huber (1992) maintains in general that universities are businesses and that they should therefore be treated as belonging to the same discourse as all other business interests. Huber's thesis seems to be that university professors are the scourges of a capitalist system as they do not conform to general business policy and that they should be made to do so. Other interest groups such as the Canadian University Intellectual Property Group also propose that universities should adopt a more businessoriented model when considering intellectual property policy. 
The Canadian University Intellectual Property Group, comprised of the Directors of Intellectual Property/Industrial Licensing offices from the Universities of: British Columbia, Alberta, Waterloo, Western Ontario, Toronto, Queens, Montreal, McGill and Laval, have put together a guide for faculty members defining in detail the limits of intellectual property (Canadian Intellectual Property Group, 2000). While similar to the AUT document in terms of what is and what is not considered to be intellectual property, the difference is that this document is issued by those who have already embraced the commercialisation of intellectual property by creating offices within the universities dedicated to its propagation. According to the document, intellectual property is "simply defined [as] any form of knowledge or expression created with one's intellect. It includes things such as inventions, computer software, trademarks, literary artistic musical or visual works and even simply know how" (p. 1). While this appears to respect the creative work of university faculty and fit the discourse parameters demonstrated by the faculty association documents, the language of the document also calls for responsibility on the part of the faculty member to attempt commercialisation of his/her intellectual property. This in turn signals a change in the purpose of the policy. The document states that: "As Canadians we must learn to capitalise on the knowledge which is created within our university ... if we are to be competitive in the years ahead. In order for this to happen, researchers and administrators must have an awareness of the importance of inventions and software, what should be done to protect these types of intellectual property and how the intellectual property can best be exploited to benefit the Canadian public" (p. 2). The word "exploited" does not appear in documents written by faculty associations. The reason being is that while the policy appears to address the intellectual property rights of faculty it is also calling for the exploitation of their work. It therefore does not represent the general discourse of faculty or faculty associations but has tailored its language for those who do or are willing to exploit their own intellectual property. Instead of serving the "common good" by producing intellectual property, the language of this document intimates that information has no value unless sold. For example, while the words "know how" cited earlier, referring to a type of intellectual property, may in some circles mean a learned or innate ability, in the context of this document "know how" refers to the ability of the individual to create intellectual property for reasons of commercialisation.

In 1999, Statistics Canada released a report entitled "The survey of intellectual property commercialisation in the higher education sector". This document uses language very similar to that of the Canadian University Intellectual Property Group. However, the language is even more extreme in that it barely recognises that universities have roles other than the creation of intellectual property. The words, which stand out in this document, include terms such as "linkages", "spin off companies", and "management of intellectual property". The policy of this document is to impose a business model on the university for development of its intellectual property. Reminiscent of the piece by Huber, mentioned earlier, this government report emphasises that universities must compete in order to be successful. In order to achieve success, universities must stress innovation as "innovation makes firms competitive" (p. i). If in the parlance of government discourse such as this, universities are firms, which produce intellectual property, one must consider what place students have in this discourse. In university policy concerning the job requirements for faculty an example of the breakdown would be $40 \%$ research, $40 \%$ teaching, and $20 \%$ community 
service; thus the teaching of students has a prominent role. However, in the case of the Statistics Canada document, students are mentioned very briefly. The report concedes that it is necessary to "prepare students for the future and to pursue knowledge in the general interest of the community. Nevertheless, the institutions themselves have also taken on an important role as developers of new technologies with commerciai applications" (p. 1). This is an instance where the purposes and therefore the discourses of the university and of external sources are in conflict. The language of business is being applied to the university sector to assimilate the university sector and its discourse. For example, the University of British Columbia is said to have created 71 "spin-off companies ... accounting for 1502 jobs" (p. 1). Universities have two choices when marketing their intellectual property: a licence agreement or the creation of a spin-off company (p. 22). Therefore, the university is not only supposed to function as a business but is also a creator of more and more businesses. Almost half of the spin-off companies created at universities were established for the sole purpose of licensing intellectual property (p. 24). The purpose of the commercial discourse is therefore to create policies that generate profit.

\section{Conclusion}

The language of policy and its documents is carefully chosen and shaped to represent the ideology of a discourse community. These communities each have purposes, which determine the shape of the policy developed. The university is an environment with goals that are now changing in response to increased contact with, and demands from, other discourse communities such as those interests which seek to exploit intellectual property conceived of by members of the university community. As a result, policy decisions to be implemented within universities are increasingly made by those outside of the university. There is a larger societal discourse in which all stakeholders in university-created intellectual property are members competing for influence over policy creation and dissemination. 


\section{Chapter 13}

\section{When Angels Dance With Devils: What is Sacred and Profane in the University?}

\section{Michael Kompf}

\section{Introduction}

This chapter is a discussion of a change in what is viewed as sacred and what is viewed as profane for the professoriate when personal ideals, ethics, and scholarship meet changing conditions of practice. New higher education faculty members portray themselves as signifiers of idealism when interviewing for professorial positions.

It is not difficult for each of us to remember the fresh-faced naivete with which the first academic appointment was met. Characterising the hope, expectations and goals of new faculty as angelic is an expression of the ideals for positive change brought to the vocation, career, and lifestyle of the professoriate. To paraphrase Hobbes, the honeymoon period for new faculty in search of tenure, can be a nasty, brutish, and long affair. Tenure, as the gold at the end of the rainbow, often brings practices and politics that compromise and transform the ideals brought to learning, professing, and professional practice. Many in the academy meet an increasingly common wall and potential fate of institutionally inflicted spiritual sclerosis.

If portraying university administrators and those under whose wishes and whims academic institutions are guided as devilish or engaging with the profane side of higher education seems harsh, it is because of the modes and methods of change with which evolving learning and organisational circumstances have been met. Through variants of social reproduction, cultural production and the contagion of careerism, ideals central to the core meanings of scholarship, the collegium and the professoriate have undergone many small shifts. When small, and not so small, shifts in policy and practices are viewed over time, movement is more visible than during the conduct of everyday life.

Associating the idea of angels dancing with devils and the topic of what is sacred and profane in the professoriate is well illustrated by the transformation of purpose in higher education from professing, learning, and the search for knowledge to a more commercial enterprise. Universities, for the most part, have reacted to the rapid change stimulated by information technology (IT) and fiscal constraints with movement towards corporatisation and the merchandising of both knowledge and the 
learning process. The dance between angels and devils is the process through which the professorial raison d'être has become the unwitting hub of social and cultural production in the commodification of education. Entranced with technology and the prospects of playing with new toys, teaching methods and student populations, faculty have somewhat unwittingly been seduced (by others or self) or duped into embracing techniques and methods of delivery that contain the seeds of drastic reductions in personnel and transformations amongst the professoriate.

Unlike recognising and understanding the gradual process of paradigmatic shift in scientific thinking, so wonderfully explained by Thomas Kuhn (1970) and others, the dominant paradigms of governance and practice in higher education have shifted in unthinking response to perceived threats against organisational survival. The late Thom Greenfield (1984) claimed that an organisation's main purpose was to continue its existence and that the costs of organisational survival are borne directly by the members it exists to serve. His warnings are visible as increasing trends towards part-time educational workers, the promotion and co-option of faculty curriculum for mass delivery, reduced interest and funding in programmatic areas, e.g. liberal arts, increased class sizes and workloads and the dramatic increase in expectations of faculty to attract and develop revenue streams. There seems no question that the worth of knowledge production has changed in its measure and meaning.

Transformations are not merely local, as experiences and circumstances reported by international colleagues seem increasingly similar. Educational predicaments, while usually arising over time, can also be contrived as excuses for change and the exercise of power as happened in my home province, when the then Minister of Education, in a newly elected government, was overheard discussing the manufacture of a crisis in the educational system for such a purpose. The subsequent perception of crisis resulted in massive cutbacks, raised tuitions, and produced questionable exercises in accountability. Movement in this direction provided justification for administrative reframing of all aspects of higher education. Some ten years later, reeling from increased enrolment, resource, faculty and space shortages, colleges and universities look to donations and spin-off business developments as saviours. Tuition increases and large graduate debt loads disappear against the backdrop of successful marketing of programs and image buttressed by popularised performance indicators.

While the foregoing may spark debate and be decried as reactionary, the intellectual, emotional, physical and spiritual circumstances of professing have changed. Senior academics, while lamenting the passage of better days, have the responsibility to bridge past, present and future by providing context for succeeding generations of scholars. Having made the foregoing statement, I am no longer as sure that the advice I received on admission to the academy has much practical and survival value to new colleagues. (A senior colleague told me to "Think well, teach well, write well and help others to do the same".) My development as a faculty member has spanned 20 years and led me to judge that most sacred principles that captured the spirit of professing and learning in higher education have now become devalued and somewhat profane in today's university.

\section{The Underside of Personal and Professional Change}

"Underside" is not used in a pejorative sense but intended to convey that which is hidden away, or not normally visible unless turned over and examined. Change and 
decision-making processes that underlie developmental actions are masked by outcomes as the immediate "what" happened of an event with priority over "why" the event has happened or turned out the way it has. The "why" aspect of events has both anticipative and reflective components that unite past, present and projected experiences. In other words, when faced with casual or significant planning opportunities or decisions that have short- or long-term implications a focus occurs best described by Kelly's (1955) well-known fundamental postulate that may be reframed: “a person's (or university's) processes are psychologically channelised by the ways in which he (or administration and government) anticipate events". While consensus building is the ideal outcome, implicit tensions may arise over dominant visions, a situation met by Greenfield's observation that "organisations don't behave, people do".

In all relationships and interactions, reality is a co-construction of participant versions of the text, context, subtext and meta-text of exchanges. Zones of intersubjectivity allow individuals to share in constructions of events and establish commonality, differentiation, and direction. Environment, purpose, methodology, and promotion of the likelihood of successful outcomes fuel dreams and decision-making in the personal and professional life course of professors.

Unique because of the status and trust conferred with tenure and academic freedom, the professoriate and the university context in which it exists, stand apart as individuals and institutional bodies that legitimate and encourage the unfettered pursuit of knowledge through research, professing and learning. Those who "profess", i.e. the professors, do so as an expression of learned inquiry that communicates by fact and example, the critical expectations of higher education and the society in which it occurs in spite of occasional student criticism that she or he "doth profess too much". Nonetheless, the university is the traditional apex of learning attended by those who would become educated.

The university also serves the purpose of challenging the status quo. Professors are thus more than knowers and producers and facilitators of knowledge. Their role has the additional responsibility of edge-finder, gatekeeper, and participant in actualising the most favourable milieu in which professing and learning might occur. Individuals who would and do enter the professoriate do so in large part because personalised goals, values, ideals and other anticipations seem most favourably met in the university. As with many goals, attainment leads to other quests not previously visible which in turn lead to aspects of personality and behaviour not yet thought possible or probable. In Kompf and Neufeld (1997), we argued that the quality of practice in universities depended on "the person the professor is". ISATT colleagues have explored similar interests and indicate that more discussion, research and writing are needed but there is little doubt that if you change the content and context of professing you change the academy. If the academy changes, then so must the definitions of teaching, learning, and education.

\section{Professors and Development}

Most of what researchers know about adult development in the field of education has to do with teachers in school systems. The pioneering work of Michael Huberman (1992) stands as the most significant marker in this area of study for several reasons. Huberman broke the age and stage barrier in developmental studies by considering 
duration of time in the profession as the key element of professional development and instructional mastery. Previous theorists tended to focus mainly on chronological age and normative age-related expectations. While such is useful for understanding fixed aspects of biological development in the young and old, it is less useful for understanding the mature years before, during and after a career and asserting that development does not end at age thirteen.

The professoriate differs from the main body of teachers in several ways including but not limited to such factors as level of education, research and theoretical interests and participation, terms and conditions of employment, work-related activities and aspects of academic freedom. Because these differences exist, differences will emerge when applying aspects of Huberman's work to the professoriate. While no known replication, to this date, of Huberman's study has been carried out in higher education, aspects of his findings have been used in professing and learning activities sufficient to give indications of important and significant departures that might provide a roadmap should a full-scale study opportunity arise.

While Huberman's roadmap includes stages of development and the dynamics associated with them, departures dictated by the circumstances and conditions of university practice are necessary in some areas. One aspect of Huberman's legacy for the professoriate covers the middle years of practice during which what appears to be a competition between activism and complacency takes place. Activism in the university is linked to a process not unlike Freire's (1970) idea of consciencisation in which increased levels of awareness and fluency with one's environment is established. Organisational literacy in the university is established by reading, participating, observing, and developing an appreciation for the milieu.

"How to be" as a professor may reach levels beyond demeanour, in ways that resemble Kohlberg's (1981) post-Piagetian moral stages of development. Kohlberg argued that thought processes differ when actions undertaken require decision-making based on moral choices. Whether choosing to steal or not, to steal or commit civil disobedience, practical moralising has three levels comprised of six stages. Of most interest in this discussion are the Conventional Level, Stage 4 - Law and Order Orientation and Postconventional Level Stage 5 - Social Contract Orientation and Stage 6 - Universal Ethical Principle. In the Conventional Level, Stage 4 - Law and Order Orientation, doing one's duty, respecting authority and maintaining social order for its own sake are the reasons for decisions and behaviours. In the Postconventional level Stage 5 -Social Contract Orientation processes are concerned with doing what is right in terms of generalised individual rights and standards agreed to by the whole of society. In Stage 6 - Universal Ethical Principle what is right is defined by conscience according to ethical principles determined by an individual. Such principles may be abstract and not as specific as for example the Ten Commandments.

Moral ascendance is an expectation of social and cultural elders and exemplars whose actions and rationale stand as landmarks in the journey to lead a good life. Understanding conduct by using Kohlberg's latter stages is a fair measure for the academy because of its leadership role in thought and learning. While many would ascribe to the highest stages, practice and the individual perceptions of role and life choices may and do bring about moral compromise. Individual moral development is a learned process and an artefact of age, experience, education, and interactions. Each person is moral in ways that are reflected in the "why" of decisions and actions. When faced with usual experiences, the usual sets of moral filters are in action, seldom 
requiring deep processing. When novel situations arise, these too may be filtered in a usual way unless recognised as important or imperative matters. Taken-for-granted responses, directions and decision-making processes and actions represent an accumulation of familiarity that may dull perceiving the nature of matters and effects that follow. For example, a student caught in red tape over an administrative matter he claimed to be unfair was given the explanation that while the situation did seem unfair; it was at least equally unfair to all.

Moral behaviour cannot be limited to individuals but must also consider the anthropomorphised organisation. Universities, faculties, and departments arguably have personalities comprised of individuals and traditions held near and dear that create the milieu into which new faculty enter. Much is made of the character and traits embedded in the granite or ivory towers sprinkled throughout campuses. The public persona of higher education institutions often belies the dynamics found from an insider's view. Universities are seldom democratic and resemble most closely a political bureaucracy.

\section{The Descent to Power}

Harry S Truman is credited with the following insight: "The reason that politics in the university are so vicious is because the stakes are so low". This seems an accepted truism for both faculty and administrators as the rules of engagement are usually only understood when perceived or real violations occur; only in the breach are the rules enforced or deeply appreciated. In the university, few professional administrators can be found with exceptions in some areas such as financial and human resource functions. All other governance and administrative functions are filled with those from the ranks of the academy save and except for staff positions. Staff positions are the backbone of a university and are much like civil service positions in a government. From civil service perspectives, the flow of elected or appointed politicians seldom gets in the way of a smoothly running bureaucracy.

In universities, while the lines that connect administrators with students are shorter than the line than connects politicians with voters, accessibility and access seem about as remote. In most cases, once elected or appointed to an administrative position, the rules, regulations, and functions of that position form a job description of sorts. While the role of Department Chair, for example, carries differing connotations across universities, the common role seems to be equally comprised of administrative and academic functions. Included duties are timetables, staffing, budgeting, developing, and enforcing academic standards, conflict resolution, and so on. Accountability of late for Chairs and Deans has more fiscal connotations than academic. An environment of administrative multiple personality sees the dual roles of senior academic and beancounter often at odds with each other. For example, in an increasingly common debate, budgets for part-time faculty shrink while the roles they might fill expand. Professing shortfalls usually land at the feet of full-time faculty. It seems problematic that in spite of a governmental and administrative desire to reduce full-time faculty membership and rely more and more on part-time contract faculty, the terms and conditions of such employment carry the glory in titles rather than wages. For example, a part-time faculty member teaching four half-courses will earn approximately $14 \mathrm{~K} \mathrm{CDN}$ in an academic year, while a full-time counterpart earns about $70 \mathrm{~K}$. The former case is most preferred by administration because no benefits or other commitment to the professor is needed. 


\section{Administration vs. Faculty or Management vs. Workers}

University faculties in Canada are unionising. Collective agreements have redefined the rights and obligations of educational workers and management. The concepts of workload and duty have been defined contractually in ways that capture performance objectives but fail to address the spirit of university professing. Grounded forms of trade unionism have an embedded adversarial predisposition towards management, i.e. administration. Contract negotiations are seldom clear-cut and peaceful. Most seem based on each party assuming the other is greedy and in turn threatening the quality of personal or organisational life. The principles outlined in collective agreements spell out each party's rights and obligations towards the other and the process by which violations are addressed. Problems arise when the letter of the agreement precludes or discourages the spirit of the tasks covered, as might be expected with the open-ended nature of emergent roles in education.

Unionisation has caused interruptions of teaching and learning through strikes. At issue are mainstays such as wages, benefits, and working conditions. Increasingly, new matters such as intellectual property rights and copyright have become grounds for disputes in ownership of faculty-produced materials. Few universities have managed to effectively meet this information technology-induced morass. International conventions and agreements provide the basic framework that assures individual rights and local provisions, either as contained in a collective agreement or defined by accepted custom set the rules of practice. However, as the commodification of learning increases and government subsidies decrease, universities and colleges have transformed from public institutions into businesses that must attract clients, i.e. students, and service them at minimal costs. Inflation, cost-sharing and infrastructure development have translated into higher costs that are ultimately absorbed through increased tuition and other fees and fiscal strangulation of collective bargaining benefits.

The question of whether or not educational workplace change brought about by reasons other than the conditions and outcomes of providing a defensible learning experience has transformed the academy is moot. Underlying questions concerning the intent, interactions and outcomes of attaining a university or college education and a fundamental shift in what is deemed to be of worth seems more the central issue. Worthwhile work of professors is usually quite clear and relates to the ways in which faculty are evaluated. For example, the following descriptions were extracted from a current (anonymous) collective agreement:

As part of workload a faculty member must remain active in terms of research, scholarly, and creative activities in a discipline or field, except when other arrangements have been agreed upon under the terms of ... as appropriate: advancement, dissemination and synthesis of knowledge; supervision of students and others involved in research, scholarship and creative activities; securing funding for research, scholarship and creative activities as appropriate for a discipline or field; scholarly publications, papers and presentations; live performances (including performing, composing, editing and direction), broadcasts, exhibits, recordings, films, video, media works and events, adjudication of festivals and competitions, and professional workshops as appropriate for a discipline; contributions to the development of software, hardware or technologies appropriate to 
the discipline or field; developing potential external sources of support for research.

Noting that two of the seven items pertain to financial subsidy matters, the "what one must do" in general areas of required demonstration leave the fuzzy areas of "how" one ought to be while one is doing what one must do for individual and micro-social determination. "How" is inextricably connected to the "why" of the professoriate.

For new faculty the how and why of intentions and fates can only emerge over time. Impressions formed through the shaping process experienced by new faculty indicate that quality of work life is comprised of the intersection at which personal and professional ideals meet the conditions of practice and clearly move beyond the advice of "think well, teach well, write well and help others to do the same".

\section{Tenure and the Changing Face of the Collegium}

From casual observation it seems that since the late 1980s an entire generation of academics have moved on, to be replaced by another group that are now anticipating retirement. In some cases, a five-year period has seen as much as a 30 percent turnover in faculty. In Western countries, these massive personnel transitions seem linked to the movement of baby boomers through the demographic ranks. Responding to the ebb and flow of an ageing population with an unusual demographic character means that the stability, predictability, and security that provided orderly and regular change of personnel is no longer. Waves of changing faces create organisational and institutional flux that prevents and presents many opportunities for redefinition of purpose and practices in ways that may or may not be visible. George Kelly's comment that individuals are best understood over the passage of time rather than in the flicker of passing moments seems an appropriate perspective from which organisational change may also be viewed.

While the professoriate is not yet comparable to a commission-based work force, contributions are clearly expected to go beyond the traditional concepts of research, professing and service. Questions of: What constitutes a strong CV? On how many faculty and university committees should I serve? How many students should I supervise? Who is aligned with whom? How do I write a successful grant application? Where should I publish? must be continually and continuously investigated. Pre-tenure means serving under a microscope in ways not clearly understood except through extra duties and the expected over-compensation that shows sufficient promise.

The pre-tenure demeanour of university faculty could easily be caricaturised were it not so tragic. Those of us who have survived this rut of passage know well the tortures of pending performance reviews and the perils of speaking out too often and too vocally without the safety net of job security. Pre-tenure means building the Curriculum Vitae, serving on more committees than possible, and biting one's tongue when receiving droppings of wisdom from intellectually sclerotic gatekeepers of the academy and the collegium.

Pre-tenure covers roughly what Huberman called the "honeymoon" phase or that culture shock period new teachers face that is filled with tasks of survival and discovery. For newly-minted PhDs, the prospect of paid work and eventually gaining 
a secure perch from which to view the world, is in the words of an unnamed colleague "getting the best job in the world" and "this is what I want to be when I grow up". The honeymoon involves both transformation and trance-formation.

The transformation from graduate student to faculty member with increasing rank is inexorable and marches in time with the rhythms of workplace and professional socialisation. Tasks include but are not limited to: recognising, acknowledging and accepting one's place in the department/faculty pecking order; understanding universitywide, discipline-based and local politics (including the dynamics of the ideal and real distribution of power and authority); comprehending the meta-game of scholarly competition; tangible demonstration of scholarly "promise" (i.e. publish or perish); and professing superbly, or at least at levels that avoid embarrassment.

Trance-formation, on the other hand, is the process that deals with the selfentrancement that accompanies realisation of getting to the top of the intellectual heap. The shelving of graduate student sackcloth and ashes and the gradual assumption of a professorial role; or as I have heard it described, "the long walk to the other side of the desk" are within reach. The thoughts and behaviours associated with professing and becoming a professor involve role development at a conscious or unconscious level. The acquisition of professorial demeanour crosses over and blends the cares, compromises and outcomes of developmental wrestles in the physical, emotional, intellectual and spiritual domains. When teaching (as one was taught or wished to be taught) the extension of one's own learning style informs and re-forms class experiences and shapes self-asprofessor. Tension between role expectations defined by self, department, colleagues, superiors, and the organisation provides the backdrop against which the unfolding drama of the person the professor is, and the professor the person is takes place.

Of special interest are the transitions between Huberman's stages of survival and discovery and that of stabilisation and experimentation. During the greatest part of a teachers' career a politicising of one's activities may come about because of job mastery or taking seriously the task of professorial activism. In the university, activism was once sacred but now seems profane. Activism under the protection of academic freedom may relate to such issues as unionisation, program expansion or restriction, delivery methods, faculty acquisition, student access and performance, gender and social issues and global matters such as the environment and anti-terrorism.

Activism may be vocal or silent. Vocal activism attracts attention that may add to or detract from the university, bringing credit or coldness. While according to the previously cited (anonymous) collective agreement, "Faculty members shall be ... free to discuss and criticize, including criticism of the University and the Union; and they shall be free from censorship by the Parties", such actions are usually counselled as politically unwise and can lead to diminished levels of comfort and expected congeniality. Passive criticism seems to be more the emergent rule as faculty increasingly work to rule and hold tighter to the provisions of collective agreements, where they are in place, with hopes for equal and equitable consideration. Issues of gender and culture, while moving forward in many countries and universities, still remain as obstacles. Heightened senses of exploitation and deteriorating working conditions seem significantly related to the commodification and corporatisation of universities. Fiscal accountability as the most important standard has become the measure by which most, if not all, organisational behaviours are judged. While strong arguments exist for the imposition of changed working and career conditions, collaboration with unacknowledged and absent stakeholders seems missing. 
Full analysis of the university system as it is evolving from a critical theory perspective might more clearly delineate the nature of oppression in the community of knowledge-producers and explore the shop-floor cultures that now define professorial life. Attention can then be turned to the expectations and implications of redefined teaching, learning and education.

\section{Returning to the Sacred}

The types of relationships and communication patterns that exist between and among superiors, colleagues, and co-workers creates or is created by the role each person occupies and the developmental patterns they experience. Political correctness, inclusivity, and collective bargaining rights dictate protocol for interaction and communication. Formal relationships with individuals filling elected or appointed roles who carry legitimate power and authority have structure and meaning as dictated by existing rules of governance.

Collegial, congenial and constructively critical relationships were the idealised norm that characterised the traditional academy. Time, tensions and temptations have worn that ideal to a more gritty edge in which the norm has become "every person for herself or himself" and the seductive lure of careerism. Better advice seems to be to remember that administration is management and the university is a business. A colleague advised new faculty that the thickness and reliability of collegiality and friendship in the university is inversely proportionate to ambition and personal goals.

I am a professor. My university and my position exist because of students. I have learned the difference between my job and my work. My job consists of the contractual agreement I have with the university. I teach X number of courses per year; I write and produce research; I serve on X number of committees. My work consists of tapping into the enthusiasm and undercurrents of learning that occur in everyday life. I am not a funding generator but would do so if it benefits and advancement of scholarship for students, rather than act as a vehicle for the advancement of corporatism and the commodification of learning. Whether or not these views are sacred or profane is in the mind's eye of the beholder. The dance continues, partners willing or not. Who picks and plays the tune is less obvious. 


\title{
Chapter 14
}

\section{Listening to Students' Voices: Self Study of Teacher Education Practice ${ }^{1}$}

\author{
Ruth G. Kane
}

\section{Introduction}

Teacher education programmes are perceived to have changed very little in recent decades in spite of increased research and scholarship on the knowledge base of teacher education and widespread reforms within the compulsory education sector (Fullan, 1982; Goodlad, 1999; Sarason, 1993). The complexities, ambiguities and uncertainties of teachers' work and of learning to teach are being recognised in repeated calls for reform of the ways in which teachers are prepared (Britzman, 1991; Bullough and Gitlin, 1995; Goodlad, 1991, 1994; Korthagen and Kessels, 1999; Loughran, Brown, and Doeke, 2001; Russell and McPherson, 2001; Sarason, 1993). The curriculum of teacher education programmes has been described as: fragmented and lacking in continuity (Ben-Peretz, 1995; Bullough and Gitlin, 1995; Levin, 1995); curriculum focused (Shulman, 1987); and contributing to the dichotomy of theory and practice (Ethell, 1997). Teacher education has been criticised for dismissing too easily the voices of student teachers (Korthagen, 2001; Russell, 2001). Increased external quality assurance requirements and repeated calls for internal and external accountability protocols reflect a "reductionist approach to teacher education that suggests new teachers should simply focus on a repertoire of basic teaching skills undergirded by a onedimensional notion of classroom pedagogy" (Vavrus, 2001). This reinforces technicist constructions of teaching and of learning to teach that underpin recent school and educational reforms where education is equated with training.

Pre-service programmes continue to prepare teachers in ways that reinforce a transmission model of teaching as telling (Bullough and Gitlin, 1995; Kagan, 1992b; Korthagen, 2001; Russell and McPherson, 2001). Teaching as transmission is grounded in an epistemology of technical rationality that construes teachers as technicians delivering a prescribed curriculum and gives little credence to learning from or in experience (Schön, 1983, 1995). In this context, there is a focus on "what" to teach (content) and "how" to teach (skills) with little acknowledgement of the importance of the "whom" or the "why" of teaching. Cole and Knowles (1993) assert 
that "most pre-service programs concentrate almost entirely on teaching pre-service teachers to teach; little attention is placed on helping them to become teachers" ( $p$. 469).

Moving towards increased school-based apprenticeship models of teacher education (an increasing practice in New Zealand) may provide opportunities for students to "practice" their teaching, but often few opportunities for student teachers to examine critically their own understandings of education or themselves as teachers. While students may develop skills of curriculum delivery, all too often beginning teachers fail to develop a deep personal understanding of themselves as teachers, or of what it means to teach. Few teachers reflect on their teacher education programmes as making a significant contribution to their understanding of teaching or of themselves as teachers. Russell and McPherson (2001) suggest that the first year survival phase is accepted in staff room folklore as "the way we learn to teach" (p. 3). In New Zealand the Post Primary Teachers Association report that 25 percent of beginning secondary teachers leave teaching within the first two years of their appointment to the classroom (PPTA, 2000). The overwhelming message is that in spite of decades of research that advances knowledge on the quality of teacher education, we continue to graduate beginning teachers who fail to understand the role of the teacher and so experience significant discontinuities in the transition from pre-service teacher education to first year teaching (Loughran et al., 2001).

\section{Learning to Teach}

The nature of teachers' engagement with education depends on their understanding of teaching, and their sense of what it means to be a teacher. By the time student teachers enter teacher education programmes, their socialisation as teachers is well underway; they have developed a body of values, commitments, orientations and practices about teachers, teaching, students and classrooms. They have each served their "apprenticeship of observation" (Lortie, 1975). That student teachers' beliefs and preconceptions are formed as a result of their socialisation as students is not in itself unexpected or problematic. The enduring nature of student teachers' beliefs and preconceptions, formed predominantly without an understanding of pedagogical principles and theories, nor an appreciation of the role of teachers and the purposes of education, however, raises significant concerns for teacher educators. Students entering teacher education typically expect to learn to teach as they were taught. They expect that their prospective students will learn as they themselves have learned in high schools and undergraduate courses (Beattie, 1997; Ethell, 2000; Lortie, 1975). There is limited understanding or appreciation of the complexities and sophistication of teachers' work.

Teacher educators face the challenge of preparing teachers who are able to articulate their own understandings of teaching and of their role as teachers. In addition to the what and the how of teaching we have the responsibility to initiate student teachers to conversations on the scholarship and practice of teaching. We can reopen this critical debate by asking: What does it mean to be a teacher? What are the purposes of education and schooling? What are the forces that contest the nature of teaching, schooling and education? To do this we must examine critically our own rationality, our own understandings of what it means to teach and what it means to learn to teach. 


\section{Teacher Education at the University of Otago: A Challenge and a Lesson!}

In 2000 , the University of Otago introduced an innovative graduate entry, pre-service degree programme for secondary teachers that sought to transgress the traditional preservice teacher education approaches within New Zealand. The Bachelor of Teaching (Secondary) [BTchg ( $\mathrm{Sec})]$ is a graduate entry two-year programme that students enter after completing a subject-based undergraduate degree. It is conceptualised within a framework of situated cognition, critical inquiry and reflective practice and has as its focus the construction of beginning teachers' professional "knowledge-in-action", the reconciliation of theory and practice, and the development of understanding of what it means to teach. Situated cognition reflects strong links with the learning to teach theories of Dewey and Schön and revives the Deweyan notion of the learner interacting with knowledge through action and experience in appropriate contexts.

I co-ordinate the course EDUC 290 Professional Practice: a compulsory yearlong first year course that comprises on-campus weekly tutorials and an end-of-year four-week block practicum in rural secondary schools. EDUC 290 has been developed as a forum through which the students and I are negotiating new ways to understand the learning to teach process and what it means to be a teacher. The students complete their curriculum studies courses with local exemplary teachers within their major curriculum area. These classes are predominantly school-based and involve a minimum of four hours contact with their mentor teacher per week. Mentor teachers have each attended workshops to introduce them to the underlying philosophy of the BT $\operatorname{chg}(\mathrm{Sec})$ programme with a special emphasis on the importance of reflective practice, the principles of situated cognition and the reconciliation of theory and practice.

A commitment to situated cognition assumes that student teachers have the opportunity to engage with real situations of classroom practice. Through critical reflection on the experience of self and others within a framework of contemporary research and scholarship it was intended that students would negotiate new ways to understand teaching and learning to teach. This paper draws on the voices of the student teachers to reflect that what was intended does not always match with the reality experienced by the students. While students valued the EDUC 290 course, their experience of the first year of the BTchg( $\mathrm{Sec})$ was constrained by the lack of teaching experience that was offered in the curriculum components of the programme. While I was arguing for reflection on the practice of self and others, some of the students' experience was limited to observing the master teacher. Some mentor teachers were locked into an apprenticeship model of teacher training. This has been a sobering lesson in self-study of teacher education practice.

\section{EDUC 290: My Intentions}

It was important to me at the outset to introduce the students and mentor teachers to the idea that teaching and learning to teach is not just about learning what (the curriculum) or about learning how (teaching strategies), it is also about who (the person of the teacher) and why (purposes of education). It was also important (in light of my commitment to situated cognition and reflective practice), that I was explicit about my own understandings and intentions, and that I supported my position with reference to 
recent scholarship and practice of teacher education. In trying to articulate what I understood about the learning to teach process, I found it easier to articulate what learning to teach is not. There were three longstanding myths about learning to teach that I sought to actively dismantle in EDUC 290.

- Learning to teach is not achieved through a process of putting theory into practice where students are introduced to what and how to teach (content and skills) in universities and subsequently practise these skills in schools (Bullough and Gitlin, 1995; Korthagen, 2001; Russell, 2001).

- Learning to teach is not achieved through apprenticeships or cloning where student teachers observe more experienced teachers in school classrooms with little appreciation or understanding of the social purposes, pedagogical intentions or goals underpinning the teachers' observable practice (Ethell, 1997; Stones, 1992).

- Learning to teach is not achieved through learning from survival in the first years of teaching where beginning teachers adopt "hit ' $n$ miss" strategies that appear to work (Bullough and Gitlin, 1995; Russell and McPherson, 2001).

I viewed learning to teach as an ongoing personal journey guided by the individual teacher's beliefs and conceptions about teaching and learning and building on the varied experiences that the student teachers bring to the role of teacher and what experiences they have during pre-service. I accepted that students enter pre-service programmes with personal beliefs and theories about teaching and the roles of teachers that have been formed through their experiences of schooling. These beliefs and theories, like those guiding the practice of experienced teachers, are typically tacit, grounded in experience and difficult to articulate (Ethell, 1997). They are also robust, enduring and difficult to change (Kagan, 1992a; Prawat, 1992; Wubbels, 1992). My role, therefore, was to establish a context where student teachers could make explicit their hitherto tacit conceptions of teaching, examine these in light of the conceptions and practice of themselves and other teachers and through critical "conversations" with peers, teachers and the scholarly literature. In this way I sought to provide opportunities for student teachers to re-form themselves as teachers through engaging with new theories and new practices of teaching, learning and self as teacher.

The importance of coming to terms with the person of the teacher (who) and listening to voices of teachers and student teachers is argued by scholars such as Palmer (1998), Russell and McPherson (2001) and Smithrim (2000). Having students examine critically the purposes of teaching within the current New Zealand context (why) allowed me to draw on the writings of Dewey (1916), Freire (1983), bell hooks (1994), Malin (1999) and Smith (1999), some of which the students had been introduced to in other classes within the BTchg( $\mathrm{Sec})$.

\section{Exploring the Personal: Who Are We as Teachers?}

In keeping with my commitment to articulating and exploring our personal conceptions and beliefs about teachers and teaching (Beattie, 1997; Ethell, 1997), we embarked, together on the writing and examinations of our personal histories following the practices advocated by Knowles (1991), and Bullough and Gitlin (1995). In presenting my own personal history I revealed to the students how I located the personal and 
idiosyncratic process of becoming a teacher, and subsequently a teacher educator, within the context of my evolving life story. To support the students I introduced them to writings by others, which emphasised the personal nature of learning to teach and the struggles of others in developing ways of examining themselves as teachers (Featherstone, Munby, and Russe1l, 1997; Smithrim, 2000). The readings both affirmed and challenged the students' current experiences of learning to teach.

Who would have thought there were so many opinions about teaching! This is going to be hard - I thought Ruth would teach us all the stuff we needed to know to be teachers. Trying to work out what $I$ already understand about teaching is a bit more hard work. (EDUC 290 Student Journal)

\section{Exploring the Purposes of Education: The Why of Teaching}

In following weeks I introduced students to debate on the purposes of education - why teach? This initially puzzled the students as many had not previously questioned the purposes of education - it was what teachers did in schools. I used writings by Noddings (1998) and Halliburton (1997) (about the philosophies of Dewey who students had encountered in their educational studies papers); bell hooks (1994); and Freire (1983) in an effort to encourage students to think about the purposes and responsibilities associated with teachers' work. The writings of Meridy Malin (1999) and bell hooks (1994) argued imperatives of "challenging racism" in classrooms and schooling. The work of Smith (1999) located the Freirian ideas of transformative praxis within the New Zealand bicultural educational context with particular attention to our responsibilities under the Treaty of Waitangi. Locating debate on the purposes of education and the role of teachers within the New Zealand context was critical to ensuring the students develop understandings of their responsibilities under the Treaty of Waitangi. The Treaty of Waitangi is a founding document of New Zealand signed by the indigenous peoples - Maori, and the colonisers - Pakeha. Although honoured more in breach than observance, the Treaty is not a historical artefact but a living agreement that locates Maori and Pakeha in partnership in Aotearoa - New Zealand.

\section{First Sign of Disquiet}

While conversations in our weekly sessions continued, it became evident that references to personal experiences of teachers and teaching and to students' own personal histories decreased. I had inadvertently created a weekly pattern where students seemed to engage with key issues predominantly at a distance through using the readings, stories of other people's experiences, as the basis of discussion. They did not locate self in the conversations, they avoided placing self at the centre of conversation, nor did they appear to engage in a deep personal way with the critical issues. There was reluctance by many in the class to "think aloud", to critique or challenge the readings. There were repeated questions about "the right answer" and "the right way" of dealing with teaching situations related to the key issues. References to practice were often limited to stories from my experiences as a teacher - I was doing too much talking! 
I had begun the EDUC 290 programme committed to enabling students to talk about teaching, and come to know themselves as teachers through critical conversations grounded in the scholarship and the practice of teaching - but I felt like I was doing all the talking. Was I reverting to "teaching as telling"? I was unsure whether students were engaging with the ideas or merely tolerating them and playing the game. I was frustrated and disappointed. I broached this in class, seeking to understand why the students were not connecting with the ideas in a more personal way.

The students were very positive about the discussion-focused approach used in EDUC 290. They appreciated the open and encouraging manner in which I sought their perceptions and opinions and valued the way in which discussion was supported through stories of personal experience.

You model how to critically reflect and seem able to turn everything into questions about things that we take for granted and only see the surface of. It is good to be able to talk openly in the environment we have created about things that matter to us about teaching. (EDUC 290; Student Feedback)

In spite of such assurances there continued to be polite interaction in class that reminded me of a reference in the work of Meridy Malin in her programmes of social justice in teacher education where she explains that "Passive resistance through refusal to engage provides little avenue for learning" (Malin, 1999, p. 10).

\section{Listening to Student Voices}

It was in reading the student teachers' reflective journals that I discovered the students' voices and I began to understand their experiences of EDUC 290. The journals contained questions, dilemmas and personal puzzles about some of the issues of racism, professional responsibility, professional identity and power that we had explored in the literature.

How can I connect with students without being patronising and superficial when our life experiences are so different? I need to come to terms with ways in which I can understand perspectives and needs of students and how my decisions in class may actually be perpetuating racism. Even the school structure may be contributing to injustice and as a teacher I am part of the schooling system. (EDUC 290 Student Journal)

Can a middle class white male/female talk about class or racism without ever experiencing the disadvantages? (EDUC 290 Student Journal)

The journals also revealed the students' increasing frustrations at not being able to engage with teaching and learning to teach through their own experiences in the classroom. Overwhelmingly the students revealed tensions, anxieties and frustrations at their lack of access to real teaching experience.

I suppose I just want to get out there and start teaching. (EDUC 290

Student Journal) 
I was getting frustrated that I wasn't getting any teaching time, and felt like I was wasting my time trudging over to $<>$ High School every day. I wasn't feeling like a teacher and was still being referred to as a "Big Person". (EDUC 290 Student Journal)

Impatient is what I feel. I feel like I am up to full on teaching now and I am not going to get a chance till the end of the year. (EDUC 290 Student Journal)

This lack of access to teaching experience and the lack of coherence with what was being "said" in EDUC 290 and what was being "experienced" led to students questioned their interest in teaching and their commitment to the profession:

We also seem to just sit there and watch in class an awful lot. It is getting hard to be motivated to even go to class. (EDUC 290 Student Journal)

I have lost my enthusiasm somewhat to teach and I have certainly lost a lot of enthusiasm for < subject $>$. (EDUC 290 Student Journal)

Well, what a soul-searching time I have had. I am still not sure about becoming a teacher; it is taking so long to get to teach. (EDUC 290 Student Journal)

While I was seeking to reconcile theory and practice through discussions on the scholarship and practice of teaching, student teachers were experiencing frustration and doubt.

The students' experiences caused me to revisit the goals and assumptions underlying the design of the BTchg(Sec). They provided the catalyst for myself and the mentor teachers to critically examine our own conceptions of teaching and learning to teach. While the process of this is the focus of future papers it is important to note that the programme has been revised for semester two with greater coherence between the professional practice and curriculum components. Recent reflections in student journals demonstrate that a turning point in their commitment and passion was their first teaching experience.

I have not had as much practice as I could have so far. One of the best things about that lesson [his first] was that I am more determined than ever to be a teacher and it has given me a lot more motivation. (EDUC 290 Student Journal)

My first teaching class today. I think I have learned things to improve in the next one. It has made me want to do it again so that can only be a good thing. (EDUC 290 Student Journal)

Yah!!! Today I taught my first class! I was a little nervous but mostly I was excited and ready to give it a crack. I am feeling much more excited about my teaching career now. (EDUC 290 Student Journal) 


\section{A Work in Progress}

Through listening to students' voices I realised the contradiction in what I espoused versus the reality experienced by the students. This project is ongoing and the students and I are attempting to "frame problems in ways that expose the relationship between the technical concerns of teachers and the personal, ethical, and political dimensions of teaching" (Bullough and Gitlin, 1995). I am working on reshaping the programme so that experience is really at the heart of the students' work. The students have begun to develop confidence in examining their own, albeit limited, experience in the classroom and interrogate their own ways of thinking about teaching without feeling the need to identify the "right answer". They are beginning to view their own experiences as authentic cases for reflection and examination in light of what others (peers and literature) say. Rather than needing to "learn to teach" from my talk and my experiences, they are beginning to have their own experiences that they can explore and interrogate collaboratively in an effort to understand what it means to become a teacher.

We don't tell each other what to do - not even Ruth - but we do question each other and really sort out how we understand teaching and working with students. It is a way of finding our own selves as teachers and examining our own practice, it seems to work well so far although it is much more difficult than I had imagined. I don't think I would have ever thought this seriously about teaching before. (EDUC 290 Student Journal)

Through listening to the voices of students I have endeavoured to write honestly and from the authority of my experience as a teacher educator (Russell, 1999, p. 1). At times that experience was what Russell described aptly as a journey into "risky uncharted waters". It has raised more questions than answers and I have felt vulnerable on numerous occasions. This brief account of the beginning of my own journey with the EDUC 290 class demonstrates the critical importance of subjecting my own assumptions to critical examination. The students' voices reveal that what I was presenting as an innovative programme grounded in critical reflection was in fact in tension with itself.

As a teacher educator, while asking my students to be reflective, this experience has demonstrated that I must be prepared to examine my own underlying theories, beliefs and assumptions about teaching and teacher education. Making a commitment to examine my own practices required me to ask for and listen to the voices of my students. It provided opportunities for the student teachers to articulate elements of the learning to teach process that continues to frustrate, puzzle or confound them. Through examining the underlying purposes of our sessions together we began to be able to examine the ethical and social implications of teaching and learning to teach so that we could begin to engage in authentic conversations about: What does it mean to be a teacher?, What are the purposes of education and schooling? and What are the forces that contest the nature of teaching, schooling and education?

\section{Note}

1 This paper was presented at ISATT 2001 conference as one aspect of a manuscript on the same data set accepted for publication in Prospects, vol XXXII, no. 32002. 


\section{Chapter 15}

\section{Doctoral Degree Assessment}

Criteria: Towards Transparency through Exploring Teacher Thinking

\section{Pam M. Denicolo}

\section{Introduction}

The purpose of this chapter is to review the processes of doctoral degree assessment with the aim of learning to make the opaque transparent. To achieve this aim I will first set the scene to demonstrate the contemporary relevance of the topic. This will be followed by a description of the main issues that seem to be arising at a general level, supporting contentions by reference to recent research and literature on the debate. Then I will present data from a small study which confirms the presence of the generic problems at the micro level; it is not a problem simply caused by cultural or disciplinary differences. All of this indicates that more research is needed on this topic.

\section{From the Illusory Security of Tradition to the Apparent Vulnerability of Change}

The doctoral degree stands at the pinnacle of academic qualifications (Quality Assurance Agency for HE, 2000). Those of us who have undertaken such study and/or have supervised the efforts of others to do so, recognise that it is an arduous process demanding considerable sacrifices from the students and their close companions, not the least of whom is their supervisor. Nevertheless, in common with other forms of academic study, these vicissitudes are generally considered to be worthwhile when they are viewed from the vantage point of successful completion and the award of the degree. Some colleagues may even view them as critical components of the process, surviving the ordeal being a salient criterion or indicator of success.

However, unlike other academic awards, the aims and objectives, the learning outcomes required and the criteria by which doctoral degrees are assessed remain 
shrouded in mystery not only to the world outside academe but also to many participants within Higher Education. Other degrees and courses of study have received much attention in the last twenty years, nationally and internationally, to ensure quality of provision for students, including greater emphasis on staff development for the improvement of teaching and learning, and to guide potential employers in the selection of appropriately qualified employees. Library shelves groan with books and research papers about development of teaching and learning and about assuring quality at the undergraduate level. Academics groan too as yet more forms of teaching quality assessments are imposed. Nevertheless, over the years doctoral students, their supervisors and examiners have been the "neglected species" (Knowles, 1990) of Higher Education.

More recently, academics have raised their voices in protest at this situation. In many countries, small groups formed at conferences to discuss the disquiet they felt at being inadequately supported as supervisors and poorly informed as examiners. Gradually, research and theory based papers produced by those who had a special interest in the area began to appear. In previous papers (Denicolo and Pope, 1999; Denicolo, Boulter and Fuller, 1999; Denicolo, 1999), we have noted the increasing research attention paid to doctoral completion rates, student selection, research training programmes and supervision procedures (e.g. Black, Hill and Acker, 1994; Hockey, 1995; Pearson, 1996; Satchell and Booth, 1996; Cryer, 1996; Delamont et al., 1997).

Similarly, as institutions became more alert to the need for internal consistency in procedures and processes, so governments became conscious of the need for consistency between institutions. In the UK a series of reports were produced which focused on the need to improve provision for Higher Degree students. For example, the Harris Review (1996) noted that as the number of candidates had expanded so had the nature and purposes of the doctoral degree. At the same time changes were afoot at the staff level. Many staff experienced as supervisors and examiners had joined HE during the expansion of provision during the 1960s and 1970s and were now retiring while, in contrast, recruitment of new research-active staff has declined in the last twenty years. Thus the traditional system of learning to supervise and examine doctoral degrees by a process redolent of the "apprenticeship" model was severely stretched. The clamour for clarity from students and inexperienced staff and the demand for accountability from funding bodies which arose in the wake of the Harris Review recently reached a peak, as the examples below demonstrate.

In 2000, the British Educational Research Association (BERA) supported and funded a National Forum and Research Review on Doctoral Degree Assessment. The Society for Research in Higher Education (SRHE) held a conference on "New Challenges in Postgraduate Education" and its Special Interest Group on Postgraduate Issues presented a workshop on the purpose of the viva process. The UK Council for Graduate Education (UKCGE) sponsored a Specialist Seminar on Research Degree Examining and thereafter held a series of workshops on supervision and on the examining process in a range of disciplines. The Funding Councils in the UK produced new, more stringent, guidelines and criteria for recognition of Research Training for funded students and, more recently (2003), the Joint Funding Councils began a series of consultation exercises to develop threshold standards for postgraduate training and support.

Since the concerns of teachers in Higher Education about assessment are focal in this work, it is timely to explore these before the drums of government and funders' directives drown them out. Thus the next section considers the findings from 
seminars, workshops and informal surveys contributed to by a diverse range of academics from different countries with diverse discipline affiliations.

\section{Concordance and Diversity Across Cultures and Disciplines}

In 1999, the Quality Assurance Agency (QAA) for HE in the UK published a code of practice in relation to quality and standards in postgraduate research degrees. In that document (p.12), it was declared that postgraduate research assessment processes should be communicated "clearly and fully to students and supervisors" and should be "operated rigorously, fairly, reliably and consistently". However, little guidance was provided on how this should be achieved, nor yet were the research assessment processes themselves defined.

The seminars and workshops alluded to in the previous section represented attempts by groups of concerned academics to elucidate those processes, to consider whether they generally were, or could be, operated in the way described by the QAA. It was clear that some elucidation was required before clear and full descriptions could be supplied to students and supervisors. Several researchers, notably Tinkler and Jackson (2000), had collected and analysed institutional regulations from across the UK to discover that procedures for the examination of doctoral degrees differed between institutions, while criteria were left implicit or were vaguely couched, leaving room aplenty for variation in interpretation. This supports my own experience of examining about forty PhDs from the UK and abroad.

All the regulations studied include the requirement for an external examiner (assumed to contribute to comparability between institutions), and for more than one examiner. However, the number of examiners ranges from two to a panel of three or four, with some extra allowance if the study spans more than one discipline area (which is increasingly the case) or if the candidate is a member of academic staff. In some institutions internal examiners may already have played a part in the continuous assessment of the candidates work, while in others they are expected to have been independent of the research process. In some institutions supervisors receive a payment to be present, in others they are required to be present, or may be present if agreed by the candidate and the external, yet in many they are expressly forbidden to be present. When they are allowed to be present, the rules may allow participation, may only allow limited participation or they are required to be silent. Whichever is the case, though, they may or may not have provided a report in advance of the viva, which forms part of the examination process.

The selection of examiners is uniform in terms of requiring them to have expertise in the study field and for the majority of cases external examiners should have experience of doctoral-level examining, presumably as internal examiners. However, few institutions stipulate that they should have experience as supervisors and it is seldom a formal requirement that they should have a doctorate themselves, though it is often implicitly assumed that they will have. More disparity emerges when the choice of examiners is considered, ranging from the student having no say at all, it being a Research Committee and/or supervisor decision, through a negotiated process to one in which the student nominates, from their now considerable expertise in the field, their preference for a particular examiner, albeit that the choice has to be ratified through committee procedures. 
The criteria for attainment of a doctorate are most commonly couched in terms of the work making an original contribution to knowledge and being to some extent publishable. This is echoed in the QAA qualification framework (op. cit.), and indeed is one of the few defining differences between masters and doctoral degrees, the rest of the criteria being very or exactly similar. In essence, the QAA state that the student should demonstrate the creation and interpretation of new knowledge, through original research, sufficient to satisfy peer review, extend the forefront of the discipline and to merit publication. Thereafter, in terms of the process of examination, diversity in the system is the norm. I will here cite but a few examples and will desist from providing the arguments presented for different practices (see Green et al., 2001 for further elaboration) to illustrate my contention.

The balance of attention, and credit, given to different aspects of the research process and products is not clearly defined. For most examiners and supervisors who contributed to various research initiatives, the thesis volume formed the major source of evidence for the quality of the research and the level of scholarship, though there were several who thought that wider sources should be accessed, for instance progress reports and interim documents. However, these sources were seldom explicitly noted in published institutional policy documents. Variation occurs in the purpose and centrality of the viva examination, the length of the viva and its style and tone. For some (institutions, examiners, supervisors), the viva is ancillary to the examination of the bound thesis, being merely a forum to authenticate authorship, or to act as a rite of passage in to the guild of academics. For others, the viva is more of an examination that serves to check the candidate's oral ability to explain their work and to provide indication of their breadth and depth of knowledge by being able to answer searching questions on theory and research practice. For yet others, the viva is a confrontational experience in which the candidate is required to demonstrate their ability to argue with academic rigour while standing up to critique from other experts. Thus, the style and tone varies from celebratory and supportive, through "teacherly" and stimulating, to hostile. Examiners take different guises in the process: as positive gatekeepers, initiating newcomers in, or negative gatekeepers, ensuring that all but the best are kept out.

Supervisors of long standing reported their experience of vivas on similar topics varying in duration from one to five hours. Tinkler and Jackson (2000) found from their questionnaire study that science vivas were on average longer in duration than non-science vivas. From personal experience as a supervisor, I have had some surprising feedback from candidates. Some whose vivas were relatively short (less than an hour and a half) have felt "short-changed", as if justice has not been applied to the enormity of their efforts, while one student whose viva lasted nearly five hours was ecstatic at the examiner's enthusiasm and interest.

It appears that the degree of influence that the viva has on the final outcome is also variable. Most academics would agree that a poor viva is unlikely, of itself, to change a decision from pass to fail, in itself casting some doubt on why the process is used at all. However, an equal number agree that, in marginal cases, performance in the viva is critical. A few colleagues are concerned at the extent to which examiners try to influence the content of the thesis towards their own interests through the process of discussion and recommendation for changes.

Other disparities noted in the whole assessment process were: whether or not examiners were intended to confer before the viva or only afterwards; whether they were required to produce reports and recommendations before and after the viva or 
only after; differences in the timing of the release of the result/decision. In respect of the last point:

- Some candidates are told at the beginning of the viva that a pass recommendation will be given so they should relax and enjoy the academic debate.

- Others are told that the thesis was highly valued but some issues would be of interest to debate.

- Others receive similar accolades but are told that they must demonstrate a defence before a decision can be reached.

- Yet others are told nothing but have to wait until the very end of the process before learning of their fate.

It is understandable that students, when they share this knowledge with each other, feel a strong sense of unfairness and inequity, though they may be less aware of other discrepancies.

Other evidence points to there being some disagreement about the priority accorded to the research process, some commentators perceiving the thesis as a synopsis of that process and others favouring a means of evaluating the actual process rather than simply its reported, and somewhat sanitised, outcome. Another bone of contention concerned who or what examiners are in effect assessing, whether it is the student as a researcher, the thesis as a product or, indeed, the quality of the supervision.

Since this work has mainly been based on cross-disciplinary studies, it is not yet clear how much influence the field of study/discipline area has on the interpretation of regulations and institutional procedures. However, Tinkler and Jackson (2000) noted some disparity between science and non-science disciplines and Deem and Brehony (2000) have commented on the differential access that students have to research cultures, some of which may be subject based. Certainly different disciplines entertain different paradigms, use different constructs and methodologies and value different modes of dissemination, so it would not be an unwarranted assumption that the criteria for assessment might vary. Green et al. (2001) noted the Higher Education Funding Council (HEFCE) includes, for example, scholarship, the invention and generation of ideas, images, performances and artefacts as defining research. Thus criteria that address the traditional thesis must be flexible enough to encompass a range of other products.

My own experience of running workshops for both non-science and science based supervisors and examiners has provided some anecdotal evidence of interdisciplinary diversity worthy of further exploration. While social scientists encourage their students to publish aspects of their research in advance of the examination, it seems to be a tacit rule that they do not publish their full results until their doctorate is confirmed. There is also an expectation that it is a real possibility that students could fail. In contrast, many scientists concur that publication of the results prior to submission is not only expected but will ensure that the students will not fail. Indeed, one seasoned science examiner explained that "really one could not fail a student who has been supervised by a colleague of any distinction or if the student's livelihood depended on it", though he did concede that one could refer them to make amendments until the thesis had been polished up. This is indeed a complex issue fraught with ethical considerations. 
So far the evidence for diversity has focused on the scene in the UK. There is as much evidence to suggest that procedures and criteria differ between countries. Although the British PhD is based on the German model, imported in the second decade of the twentieth century, there are assessment differences apparent within Europe and within the Anglophone world. While vivas in the UK are private affairs, they are frequently public ones in Europe and the USA. In other countries, vivas are used only in exceptional circumstances, perhaps were there is disagreement between examiners or the decision is borderline. Similarly, different numbers of external examiners are appointed in different countries, and a panel of "judges" is frequently the norm in the USA and some European countries, though in the latter the defence is sometimes more of a ritual with the end result being relatively sure beforehand. Hartley (2000) surveyed colleagues in the discipline of psychology from across the globe and described 19 different ways in which a viva is organised and conducted.

There are also differences in the requirements of the thesis, particularly in volume and detail, between different countries. This topic demands further, rigorous study as research collaboration across country borders becomes more prevalent, as staff and student mobility is encouraged and increases and as competition between educational institutions in the global market becomes fiercer. The uncertainty arising from cultural plurality affects both the process of supervision and the examination process. Thus, since we have heard little so far from the students whose studies are affected by this, I would like to conclude this section with excerpts from reflections from ultimately successful overseas students. They had had to contend with conflict between their culturally derived expectations and the reality they met when studying in England. Both of these students, incidentally, had been academics in their homeland and returned to pursue their careers there. The first illustrates the paradigm clash:

One consideration that never crossed my mind while developing my research proposal at home was the paradigm or world-view with which I was approaching this important task. What I soon discovered after my arrival in England was that a concept of "the" or a single research paradigm did not exist ... I was overwhelmed by the discovery of literally another world of perspectives ... I felt incredibly vulnerable and naïve.

The second, referring to her transfer process which took the form of a mock viva, spoke of it as a cultural collision waiting to happen. She explained:

There is a distinct difference between the US and the UK regarding the emphasis on the practical versus the theoretical. Practical knowledge is highly prized in the US ... I never understood why a $\mathrm{PhD}$ was called a doctorate of philosophy before. I thought it was a throw back to the past, a dead metaphor.

Another question that arises is whether the wide spread of opinions and ideas revealed above is merely the result of the diverse nature of its respondents (geographical or subject affiliation) or, indeed, the result of the accumulation of opinions from activists with interesting tales to tell. (In a recent presentation we noted the analogy with childbirth "horror stories" told by those who have gone through the process to those who are about to.) The next section describes efforts to check out this potential criticism. 


\section{Concordance and Diversity Within a Discipline and Research Culture}

Hartley and Jory (2001) were concerned that many psychology candidates approached their viva armed only with "tales of the unexpected", as noted above. They strove to redress this problem of generalisation from the particular by conducting a questionnairebased survey, developed from responses in semi-structured interviews, which included both closed questions in a Likert-type format and open-ended questions so that respondents could speak for themselves. These were sent to a wide range of recent candidates, with the 100 responses received covering the range from successful - no amendments required - through minor and major corrections required, to failed. The authors provide detail of responses to the different aspects covered in the questionnaire but the main findings show that, despite the fact that 85 percent were ultimately successful, only 44 percent found the viva a positive experience, 82 percent thought that their viva was fair and 60 percent made suggestions for improvement of the process. The data also demonstrate the wide variation in the process experienced by the candidates.

This research stimulated us to conduct a similar within-discipline study (education) but this time focusing on the criteria used to assess doctoral work. A questionnaire was designed based on the concerns expressed in the literature and by candidates and colleagues.

The questionnaire form asked respondents to indicate anonymously their experience of the doctoral degree process by ticking the appropriate descriptors listed, ranging from "Higher Degree Research Student in Progress" to "Experienced Examiner of Higher Degrees (three or more theses)", including categories that indicated supervisory experience and own success at doctoral level. Thereafter the questions were open-ended and focused on:

- $\quad$ the purpose of the $\mathrm{PhD}$ examination process;

- the priority that should be given to various sorts of evidence;

- the dimensions of quality sought in each form of evidence;

- the dimensions of quality essential for a straight pass;

- the general nature of minor and major amendments;

- the sorts of problems that would indicate a fail.

\section{Additional Comments on Criteria Used in Examining Higher Degrees by Research}

The questionnaires were distributed to the academic staff, all current students and all students completed in the last four years in an Education Faculty (a total of 80 potential respondents). A total of 32 fully completed responses were received while, significantly, 20 were returned partially completed with apologies from respondents that they "were unsure or didn't know the answers". This in itself is a finding of importance since all those people could be considered to have a vested interest in being clear about assessment criteria.

This study was primarily intended to promote reflection amongst immediate colleagues and to act as a form of staff development for all of us so that we might improve the service we provide to our doctoral students. Nevertheless, a review of the results so far is worth sharing with colleagues in a wider forum because the trends are worrying. They indicate diverse opinion, and presumably practice, and a good deal of uncertainty about the process. 


\section{Purpose of assessment}

All of the respondents saw the purpose to be to "assess the quality of the work conducted", with examiners, supervisors and previous candidates including phrases about "contributions to the body of knowledge", redolent of the rubric of institutional documents. Current students did not mention this aspect but many included a reference to "checking if the research methods were appropriate". All the staff contributors included "buzz" words such as "verify", "evaluate", "test" etc. but the dimensions that were the focus of this assessment varied from detail such as "understanding of the literature", the "appropriate use of methods", the "quality of argument", "whether candidates are aware of the limitations of the work", to generalisations such as whether or not it was "of the level required of doctoral work". One colleague, a supervisor, said the purpose of assessment is "to determine success or failure - this is the only one that matters to the candidate".

\section{Priority of different sources of evidence}

All respondents indicated that the thesis document had the highest priority as a source of evidence. All the examiners suggested that the viva had something important to contribute but was less of a priority than the thesis document. Supervisors in general rated the viva as having some but small import in the assessment process, while recent candidates and students gave answers ranging from "no importance at all" to "some but minor importance". Many students seemed convinced that the viva was only used to "check that it is your work". Examiners indicated that no other form of evidence than the thesis and the viva was currently considered, though they and other respondents felt that indicators of competent engagement throughout the process of the research ought to be included.

\section{Dimensions important when deciding the pass level}

The data provided in response to questions on this topic is extremely complex and diverse, within and between groups, and deserves a more thorough analysis than it is possible to present here. However, it is clear that standards considered appropriate for a straight pass are extremely stringent - most respondents, including students, would only tolerate a few minor typographical errors, or minor problems with writing style (especially if the candidate were not a native English speaker). The diversity becomes most profound when the grade awarded required amendments. Of course, major amendments tended to be more substantial but there is a substantial overlap in dimensions considered to require minor or major amendments. One commonly quoted criterion was "what could be achieved in the time allowed". This indicates that part-time students might be disadvantaged but it is worthy of note that different institutions allow different timescales in which amendments can be made. It seems that whether candidates receive a result that demands minor or major amendments is very much dependent on which institution they are registered in and who the examiners are, as well as on the support and preparation for submission that they receive from their supervisor.

\section{Additional comments about the assessment of doctoral work}

This section attracted considerable response. Five frequently addressed topics emerged from all types of respondents. These were, in order of frequency:

- $\quad$ Training is needed for examiners.

- The students and supervisors should be provided with clear criteria to guide the process. 
- The transfer stage (from Higher degree to PhD status) is extremely important and should be given more attention.

- The process as well as the products should form the basis of assessment.

- The whole current process is too subjective.

Those who subscribed to the last comment varied from considering that it was "inevitably subjective in the end given the complexity and originality of any thesis", through the notion that "any criteria can only ever be guides to examiners", to those demanding a much more detailed framework to guide practice.

What is eminently clear from these data is that, despite all contributors being from the same "academic tribe" (Becher, 1989), and working together over a period of time in relation to doctoral study: The degree of consensus about the criteria for assessment is low; the degree of alternative interpretation of institutional regulations and procedures is relatively wide; the level of insecurity about their knowledge of general standards is high. This confirms the analysis made in the preceding section.

While the data from this research provides a rich resource for in-house workshops and seminars that seek to bring some clarity and a greater degree of understanding to the issue, nevertheless this kind of support for supervisors, examiners and students will still be inadequate while confusion remains rife across the sector, nationally and internationally.

\section{The Future - Can Order Come Out of Chaos?}

In the second section of this chapter the groundswell of concern about doctoral assessment was made evident. This is emerging from students themselves but more importantly from those teachers in Higher Education who have as part of their role the supervision, training and examination of doctoral students. From the compilation of opinion described in the third section, and from the small-scale, focused studies included in the previous section, the requirement for more systematic research is apparent. However, the purpose of such research should also be clarified. From a compilation of all the evidence so far, teachers have made it clear that such research should focus on making transparent the criteria in play. They also emphasised that these criteria should be derived from good practice already extant in the system. Thus the intent should be to clarify, rather than invent, standards, and to provide greater guidance to participants in the process. These teachers are concerned that hidden agendas, tacit rules and covert decision making are detrimental both to building trust and to demonstrating equity and perceived fairness in the system.

Unfortunately, all of this means that more academics than the "activists" need to be brave enough to declare their insecurity and to share the criteria that they use or would think appropriate. We all have to examine our practices and the assumptions, theories and prejudices that inform them. This may be a painful business and is certainly challenging to many egos. It is also threatening for institutions when it seems that "dirty linen" has to be washed in public. However, progress was seldom easily made. 


\section{Section D}

\section{Teacher Development}

Christopher Day provided the Michael Huberman Carfax Memorial Lecture at the Faro conference and his chapter included here "The Challenge to be the Best: Research and the Teacher" summarises its content, which celebrated Huberman's outstanding contribution to knowledge, to the international research community in general and to the work of the membership of ISATT. Day notes Huberman's abiding passion to understand the multiple facets of teachers' learning and to share this knowledge with others. In the chapter, Day seeks to emulate him by putting teachers at the heart of the matter, beginning his treatise by noting the plethora of challenges and dilemmas that face teachers as they strive to be the best they can in their professional careers despite interventionist policy by governments. He draws on Huberman's 1995 work to illustrate his points about teachers having complex and relatively unpredictable development needs at different stages in their careers, following this with consideration of how teachers facing those challenges can be supported by effective, independent research which yet is cognisant of current policy.

His final section addresses the need for those independent researchers and teacher educators in tertiary education to confront and address the challenges inherent in their own educational environment as it too is signified by increasing complexity in a context of social turbulence. Drawing on Schon's analogy of the intellectual high ground compared with the swampy lowland of practice, he addresses the scholarship/ practice divide that concerned Huberman who sought to promote "sustained interactivity" to translate research results into practical applications. Day contends that university researchers need to engage critically both with policy-makers and practitioners, developing new kinds of relationships and expertise in order to do so.

Neil Haigh, too, in his chapter "Tertiary Teacher Development: Connecting Policy, Personal Theory and Practice", addresses the policy/practice divide within tertiary education but specifically investigates the link made between the two entities by personal theory from the perspective of an academic development agent. He begins by examining his own institutional documents for guidance on improving practice for teachers and for facilitators of teacher development. Although he identifies aspects within them in which his work on committees has had an influence, gaps and limitations in policy are also noted. These, he argues, are filled by recourse in his practice to his own personal theories. He summarises the criteria he uses and how these are translated into development activities through reflection and engagement with the scholarship of teaching. Whilst acknowledging differences between disciplines and career stages, he derives a model which moves from a focus on rules, through active reflection in practice to research on practice. He confesses that frustration at having no formal institutional policy to support his own practice has led him to contribute to policy development. He acknowledges that, like any other teacher, he wants his voice to be heard in that arena but thinks that such interventions should be based on scholarship as well as experience.

Lang, Charlier, Saunders, Bomany, Laferrière and Breuleux, in their chapter entitled "Collaboration in Cross-National Networks for Teacher Professional 
Development", note that educators and policy-makers agree on the advantages of collaborative networks in curricular reform but that, while several projects have been initiated to this end, little research has been conducted to evaluate them, particularly how effectively they encourage collaborative reflection. They contend that this cannot be achieved by advanced network technology alone. They go on to provide insights into how this could be achieved, citing examples from cross-national projects. In their conclusion a promising model is presented, itself needing continuing research to exploit its potential that can help provide the scaffolding for such collaborative activities.

In contrast to the technological emphasis of the previous chapters, in "Dilemmas of Democratic Education", Flanagan begins his discussion of engaging pupils in schools through participation and collaboration by comparing the stories they are told with the roles they are expected to play eventually in a democratic society. $\mathrm{He}$ too addresses the role of scaffolding in his argument that teachers have a serious role to play in supporting the development of the child towards responsible citizenship through participation, appropriate to their developmental status, in the social context of the school. He suggests that teachers must learn to balance the dilemmas inherent in such an enterprise, a balance between professional obligation and the promotion of autonomy. This, of course, may make them vulnerable.

In the final chapter in this section, "When the Best Maps Cannot Guide Us" by Susan Lasky, the dearth of research on teacher vulnerability is noted as a prelude to a reflective discussion on how the author developed a theory of vulnerability in the context of large-scale secondary school reform imposed by the government. Like Haigh, Lasky recognises the permeability of the boundaries between professional and personal theory as she describes how her own personal experience had provided insight into a theoretical issue and the methods used to study it through the reflection it engendered. Similar to the ideas expressed in Section One about teacher identity, teacher vulnerability is epitomised as fluid and subject to multiple influences, some with positive outcomes but many with less positive entailments related to response to potential risk. Lasky describes and supports the methodological risks that she felt bound to take in conducting her research in an area which, like much that pervades the swampy ground of educational practice that Schön and Huberman referred to, is uncharted territory. 


\section{Chapter 16}

\section{The Challenge to be the Best: Research and the Teacher}

\section{Christopher Day}

\section{Introduction}

Often, in speaking of the work of former colleagues, we remember them for research in a particular process area - personal construct theory, narrative, action research, cognition - or content area - school effectiveness, teacher voice, classroom interaction, pre- or in-service teacher education. Michael Huberman is the exception to the rule. His long-term interests were in scientific epistemology - how scientific theories are developed and validated - and in adult cognition and knowledge use. His outstanding contributions to knowledge and to the international research community ranged over almost three decades across these areas. His work spoke to practitioners and to policymakers. It was, in his own words, the product of his "reckless curiosity" and "mischievous motivation to check out the connections between policy, research and practice". A brief look at his curriculum vitae reveals significant work and publications in areas fundamental to my own work and, I believe, that of the members of this Association:

1 innovation and change

2 qualitative data analysis

3 teachers' lives

4 teacher learning and development.

On much of this work he collaborated closely with colleagues in Europe and America - Ron Havelock, Matt Miles, Tom Guskey and Roland Vandenberghe to name but a few, and he was one of a rare number of academics who hold posts at more than one university simultaneously - in his case the prestigious Universities of Geneva and Harvard. It is fitting, then, that ISATT should dedicate a lecture to this man for all seasons.

Michael was a scholar. I remember meeting him for the first time in the early 1990s. We talked of his research and his concerns with quality and making a difference. He told me that he aimed for at least one publication in an internationally prestigious journal every three years. To my knowledge, these always added significantly to the knowledge of the field. He did not produce one poor publication in his lifetime - a rare achievement. He had, as do I, an abiding passion to understand teachers' learning, its 
contexts and why they change (or do not change) and to share his knowledge with others. Sadly, his health suffered over a number of years and he was taken from his family and from us in tragic circumstances. I am honoured to give this, the first Michael Huberman Carfax Memorial Lecture.

This lecture will be in three related parts. First, I want, as Michael Huberman did in his work, to place schoolteachers at the heart. As a student myself, I can remember the rare occurrences when a teacher inspired me with their love of literature, cared for me as an individual, or their particular approach to teaching. More often, though, were the seemingly endless, mindless copying from the board, learning without understanding, routinised teaching by teachers whose commitment and vision had withered perhaps in part because no one outside the school (and often no one within the school) was interested in understanding the complexities of their work and providing challenge and support appropriate to their continuing development. I determined that when I became a teacher lessons would be lively, stimulating and filled with opportunities for meaningful learning, though I hadn't quite understood, at that point, the amounts of energy required nor the impossibility of achieving this with every student, every week of every term of every year over the span of a teaching career! Yet if every child and young person is entitled to the best possible learning opportunities, then it follows that teachers need to have the knowledge, skills, capacity and commitment to be able to provide these.

Much emphasis in recent times has been placed by governments upon raising standards through systemic effectiveness and improvement efforts. I will argue that it is the teacher who must be at the centre of change efforts. In company with Michael, I have a passion for understanding the members of this unique profession who, alone, just to do their job, requiring sustained commitment of mind and spirit, of personal and professional selves, of knowledge and skills to be the best they can every day over a 40 -year period in the face of 30 or more children or young people who are obliged to be present and who have a variety of recognised and unrecognised needs, not all of which can possibly be met by teachers. More than this, I believe that research internationally indicates a strong correlation between teachers' emotional and intellectual health and the raising of students' standards of achievement. There are many challenges to being and continuing to be the best teacher over a career. These include personal and professional biography and identity, policy conditions of service, the cultural histories of professionalism and the current cultures and contexts of schools themselves, socialisation, routines, leadership and self-efficacy.

Michael Huberman's research on teachers' lives, networks for learning, professional development and change provides a seminal contribution to conceptualising teacher development as lifelong and emphasises the need for learning with others. In the second part of this lecture, I will draw upon this and other work, in order to consider how the challenge to be the best might be sustained and how researchers may take policy into account whilst maintaining their independence of mind.

As a teacher and then as a schools adviser/inspector, teacher trainer and then university educator and researcher, I have remained curious about how best teachers can continue to learn in changing and challenging circumstances and how higher education can contribute most effectively. An abiding dilemma for universities around the world who wish to connect with the emerging new professionalism of teachers and schools is how to give importance to the legitimate interests and concerns of both the academy and the schools. Whilst organisational strategies of different kinds may be 
applied, e.g. the establishment of research centres in which academic researchers adopt "service" roles in "helping teachers interpret, understand and reflect on their own practice" (Askling and Almen, 1995), the real challenge is in changing the cultures of the pre-service and in-service teacher education tutors themselves. This then will form the third and final part of this lecture.

\section{Placing Teachers at the Heart of the Standards Agenda}

\section{The changing contexts of teaching}

If we want all students to actually learn in the way that new standards suggest and today's complex society demands, we will need to develop teaching that goes far beyond dispensing information, giving a test, and giving a grade. We will need to understand how to teach in ways that respond to students' diverse approaches to learning, that are structured to take advantage of students' unique starting points, and that carefully scaffold work aimed at more proficient performances. We will also need to understand what schools must do to organise themselves to support such teaching and learning. ... 21 st-century schools must shift from a selective mode - "characterized by minimal variation in the conditions for learning" in which "a narrow range of instructional options and a limited number of ways to succeed are available" - to an adaptive mode in which "the educational environment can provide for a range of opportunities for success". (Darling-Hammond, 1996, p. 7)

Teaching now takes place in a world dominated by change, uncertainty and increasing complexity. As a reflection of this, government publications in Europe, North America and the Antipodes stress the technological, economic and social challenges which schools (and therefore teachers) face. They are confronted, it is said, by a number of changes, which lead to contradictory demands.

On the one hand:

- a commitment to education for all;

- an extension of the period of initial schooling;

- recognition of the growing importance of life-long education;

- more emphasis on general education for children and young people which prepares them for life rather than providing vocational skills for specific jobs;

- increasing emphasis on teamwork and co-operation;

- a consensus that general education should include attention to environmental issues, tolerance and mutual understanding.

On the other hand:

- growing inequalities, deepening social differences and a breakdown in social cohesion;

- an increase in alienation among youth and dropping out of school;

- high levels of youth unemployment and charges that young people are ill-equipped to enter the world of work; 
- a resurgence of inter-ethnic tensions, xenophobia and racism, as well as the growing influence of religious sects and problems of drugs and gangs, with associated violence;

- increasing emphasis on competition and material values. (UNESCO, 1996)

Concerned with the need to raise standards of achievement, and improve their positions in the world economic league tables, governments over the last twenty years have intervened more actively and with increasing frequency to improve the system of schooling. Financial self-reliance and ideological compliance have become the twin realities for many of today's schools and their teachers (A. Hargreaves, 1994, p. 5). Externally imposed curriculum, management innovations and monitoring and performance assessment systems have often been poorly implemented; and they have resulted in periods of destabilisation, increased workload, intensification of teachers' work (Day et al., 1996), and a crisis of professional identity for many teachers who perceive a loss of public confidence in their ability to provide a good service. Governments seem not quite to realise the results of research which tell us that: (i) teachers' commitment to their work will increase student commitment (Bryk and Driscoll, 1988; Rosenholtz, 1989); and (ii) enthusiastic teachers (who are knowledgeable and skilled) work harder to make learning more meaningful for students, even those who may be difficult or unmotivated (Guskey and Passaro, 1994).

Whilst governments have introduced changes in different ways at different paces, change is nevertheless not optional. It is, it is said, a part of the "postmodern" condition, which requires political, organisational, economic, social and personal flexibility and responsiveness (Hargreaves, 1994). Little wonder that the post-modern condition for many teachers represents more of a threat than a challenge, or that many are confused by the paradox of decentralised systems, i.e. local decision-making responsibilities, alongside increased public scrutiny and external accountability and the associated bureaucracy.

\section{The new professionalism?}

Interventions which for some are a root and branch attack upon teacher autonomy or teacher professionalism, for others are a change in its nature. At the heart of this paradox lie competing and contested definitions of what it means to be a professional. Some argue that increased bureaucratic control and intensification over the last twenty years have reduced individual teachers' areas of discretion in decision making, and led to "chronic and persisting" overload and have effectively resulted in deskilling (Harris, 1996), and thus, by implication, the likelihood of poorer teaching. The establishment in the UK, for example, of competency-driven, school-based apprenticeship models of preservice teacher training and alongside these systems of in-service teacher development which emphasise short-term training needs related to nationally rather than locally defined priorities, provides evidence in support of a theory of "proletarianisation". In England, the National Curriculum has been described as "a serial killer" in the demands it makes upon teachers (Campbell and Neill, 1994), and there is widespread evidence of increased levels of stress and decreased morale. From these perspectives, teachers are indeed on the way to becoming "technicians" whose job is to meet pre-specified achievement targets and whose room to manoeuvre, to exercise discretion - a hallmark of an autonomous professional - is thus increasingly restricted. 
In a recent book, Eliot Freidson develops a useful model of professionalism based upon a theoretically chosen foundation. Drawing upon Abbott's work, he argues that what we may be witnessing in schools are the first signs of organisational rather than occupational dominance of expertise and that because, "in the everyday practice of teaching, moral and ethical issues assume as much importance as ... technical information" (Halliday, 1987, p. 37), teachers must resist. The major consequence of the ideological attacks on professionalism which have become prominent over the past few decades, he suggests, is:

an atmosphere of distrust that has weakened the credibility of professional claims to an independent moral voice in evaluating social policies. (Freidson, 2001, p. 197)

He goes on to suggest that:

There is, then, still some popular foundation for the professional's claim of license to balance the public good against the needs and demands of the immediate clients or employers. Transcendent values add moral substance to the technical content of disciplines. Professionals claim the moral as well as the technical right to control the uses of their discipline, so they must resist economic and political restrictions that arbitrarily limit its benefits to others. While they should have no right to be the proprietors of the knowledge and technique of their disciplines, they are obliged to be their moral custodians. (Freidson, 2001, p. 222)

Freidson concludes:

What is likely to be the most at risk for the professions is their freedom to set their own agenda for the development of their discipline and to assume responsibility for its use. Thus, the most important problem for the future of professionalism is neither economic nor structural but cultural and ideological. The most important problem is its soul. (Freidson, 2001, pp. 212-13)

There are three conclusions, which may be drawn from these perspectives and the contexts in which they are framed:

a) The impact of the changing economic, social and knowledge contexts upon the education service as a whole has caused a move from the traditional postwar model of the autonomous professional. In particular, what students learn, what they must achieve as the outcome of learning and what standards apply is now explicitly the everyday business of government. Occupational monopoly of expertise is giving way to organisational dominance.

b) The circumstances in which teachers work and the demands made upon them are changing as communication technologies erode the role of teacher as exclusive holder of expert knowledge. As the social fabric of society becomes more fragmented, the educative role of schools and teachers as custodians of the public good becomes more complex. Higher expectations for higher-quality teaching demands teachers who are not only well qualified, highly motivated, knowledgeable, and skilful but also have clear moral and ethical purposes at the point of entry into teaching and throughout their careers. 
c) If standards of student learning and achievement are to be raised and if society's social needs are to be addressed through education, a focus upon teachers' continuing career-long professional development is now not an option, but a key responsibility of governments, schools and teachers themselves. This is so because "behaving as a professional" involves:

Displaying ... degrees of dedication and commitment, working long hours as a matter of course and accepting the open-ended nature of the task involved, which often impinge ... upon home and personal life ... it also entails maximum effort to "do the best you possibly can" and a constant quest for improved performance. At the same time it involves developing appropriate and caring relationships with students, which gives priority to their interests and well being, as well as dealing "professionally" with colleagues, parents and other external agencies where appropriate. Finally, because of the complexities of the task of teaching and the obligation to meet varying individual needs, high levels of skill are necessary to respond intelligently to multiple demands in a complex and changing environment ... (adapted from Helsby, Knight, McCulloch, Saunders and Warburton, 1997, pp. 9-10)

In other words, teaching is more than "just a job".

\section{The relationship between continuing professional development and teaching standards}

Acquiring the qualifications to become a teacher has always been a necessary but insufficient condition to succeed as a professional over a career span. Inevitably, subject knowledge will need to be regularly updated, teaching organisation and methods and skills revisited as, on the one hand, information becomes more accessible through advances in technology, whilst on the other, teaching pupils who are less socially compliant in conditions which are less conducive to promoting learning becomes more challenging. Teachers' voices are an important and still underrepresented part of the debate on the nature, form and content of continuing professional development (CPD). Writing about systemic reform in the province of Ontario, Canada, Ardra Cole suggests that, "perhaps the most persistent and poignant [example] of teacher helplessness is within the context of formalised professional development" (Cole, 1997, p. 16), in which most initiatives are for the most part conceptualised, designed and delivered for teachers, not by them. The current situation internationally is not unlike this. The maintenance of good teaching demands that teachers revisit and review regularly the ways in which they are applying principles of differentiation, coherence, progression and continuity and balance not only in the "what" and the "how" of their teaching but also in the "why" in terms of their core "moral" purposes. To be a professional means a lifelong commitment to inquiring practice. If we want children in schools to become lifelong learners, their teachers must provide the model.

Calls for investment in professional development within the context of institutional development are far from being realised and by and large even the best research, which supports this, is noted but not acted upon. Most teachers still work in isolation from their colleagues for most of the time; opportunities for the development 
of practice based upon observation and critique of that practice remain limited; and, despite the best efforts of many school leaders to promote collegial cultures, these are almost always at the level of planning or talking about teaching rather than at the level of examining practice itself.

Reporting on the findings of a recent Leverhulme-funded study of teachers' perceptions of the provision of CPD, conducted in four LEAs in England, McMahon (1999) found that tensions between the two overall purposes of CPD - to promote school improvement or individual teacher development - had not been resolved. The evidence was that, "teachers are keen to improve their knowledge and skills, although at any one time their learning priorities might differ from those of the school or government" (McMahon, 1999, p. 104). The introduction of site-based school management through which in theory "need" and "relevance" might be more accurately identified had not, the research revealed, proved to be a success. Because resources were more thinly and unevenly spread, choice of CPD mode had diminished (e.g. rural schools had less access to HE, school networking had largely ceased); there were wide variations within schools. Few professional development co-ordinators were allocated time to do their job, commitments of head teachers to CPD varied and the bulk of the CPD budget was used for responding to external demands for curriculum reform and renewal. This meant that, "individual development needs were neglected unless they were in an area that was designated a school priority" (McMahon, 1999, p. 106). The five mandatory non-contact professional development days were often not well used, content and level were judged inappropriate, the quality of training poor and, "little or no attempt was made in any of the case study schools to identify and take account of teachers' preferred learning styles" (McMahon, 1999, p. 107). Finally, most teachers' experience of CPD was of short training courses, which were relevant to the immediate needs of the classroom. Many of these do not fulfil the longer-term motivational and intellectual needs of teachers themselves. They fail to connect with the essential moral purposes that are at the heart of their professionalism or to address directly the emotional commitment of teachers seeking to improve the quality of pupils' learning in changing circumstances. Such emotional commitments are part of teachers' substantive, professional selves (Kelchtermans, 1993), and integral to all teaching. Teacher development must take account of these and the emotional, psychological and social settings which can encourage or discourage learning - for example, the teachers' own personal life histories, their professional learning experiences, expertise and school professional learning cultures which provide the day to day contexts for their work. McMahon concludes that:

It does not appear that the notion of individual teacher entitlement to training and development is being given serious consideration at national level ... so most decisions about who gets access to training will continue to be made at school level and this will disadvantage a number of teachers. (McMahon, 1999, p. 111)

\section{Teachers' development}

Career development is ... a process, not a series of events. For some, this process may be linear, but for others there will be plateaux, regressions, dead ends, spurts, discontinuities. (Huberman, 1989, p. 32) 
We know from research that teachers do not follow a smooth, uninterrupted development trajectory from, for example, novice through to expert (Benner, 1984), that they do not always learn from experience and that experience itself can be limiting to development (Britzman, 1991). We know also that they are influenced by (i) prior beliefs and personal values; (ii) professional experiences; (iii) the school and classroom contexts in which they work; (iv) their personal relationships in and out of school; and (v) other life circumstances, e.g. health, changing educational policy climates, conditions of service (Levin, 2001, p. 22). Because of changes in society (e.g. ICT, policy reform, changes in family circumstances of students) teachers also need to be responsive to external change. Yet under normal circumstances, teachers' learning is limited by the development of routines, "single loop learning" (Argyris and Schön, 1974), and taken for granted assumptions which limit their capacity to engage in the different kinds of reflection necessary for learning and change (Day, 1999). To survive in classrooms, teachers develop routines (Clark and Yinger, 1977) and so are not naturally systematically reflective about their work - partly because of its "busyness" and partly because interrogation of practice and its contexts can be threatening to self-esteem and current practices, especially when organisational cultures are not supportive. That is not to suggest that they do not engage in reflection, but that to engage in systematic reflection of different kinds is not always possible. One of the key recommendations of an American study conducted in 1996 by the National Foundation for the Improvement of Education was that: "finding time to build professional development into the life of the school through flexible scheduling and extended blocks of time when students are on vacation" (Rényi, 1998, p. 71) was the teachers' primary concern. When teachers in England were asked about their professional learning preferences, including INSET (Harland and Kinder, 1997), their responses, too, pointed to the need for time (i) to meet with colleagues from their own and other schools to discuss current issues and concerns; (ii) to engage in curriculum development workshops which embodied the "practicality ethic" (Doyle and Ponder, 1977); and (iii) to learn from outside speakers and "provider-led" higher education programmes. By far the greatest influences on their professional development, however, were their own experiences, beliefs and convictions and those of their colleagues.

I want now to turn to one of Michael Huberman's ground-breaking and lasting contributions to our understandings of teacher development, which remains some fifteen years later without equal. He conducted a preliminary study (1978-9) with 30 and an extended study (1982-5) with 160 secondary level teachers in Geneva and Vaud. Roughly two thirds taught at lower secondary and the rest at upper secondary schools. There were slightly more women than men. Four "experience groups" were chosen:

5-10 years of experience

11-19 years of experience

20-29 years of experience

30-39 years of experience.

Within this sample a random sample was generated, containing teachers of all subject matter areas in equivalent proportions to the population of reference. During a series of five-hour interviews, informants were asked to review their career trajectory and to see whether they could carve it up into phases or stages, each with a theme and identifiable features. 
The career development "process" which Huberman's research revealed has become the touchstone for researchers in this field worldwide. There are few who do not recognise the following.

Years 1-5 Career entry and socialisation - survival and discovery, stabilisation, commitment, easy or painful beginnings, consolidation and refining of teaching repertoires.

Years 5-11 Diversification and change - experimentation, increasing classroom effectiveness, "signing on" for reforms, joining peer networks, strong involvement in school and community, fear of stagnation.

Years 12-19 Stock-taking and interrogations at mid-career-associated with life, career review, self-assessment, stagnation or cynicism, "choosing to make the most of where one is or to leave the profession", plateauing.

Years 19-30 Serenity - reflecting, self-accepting, lessening of involvement, increased professional effectiveness.

Conservatism - more sceptical about attempts at structural reform, increasing levels of rigidity, increased "prudence" or resistance to change.

Years 31-40 Disengagement - serene or bitter.

He discovered that "a large part of development is neither personally programmed nor personally engineered but rather discontinuous ... lacking in continuity and order, and sometimes downright random" (Huberman, 1995, p. 194).

Writing in 1995 about professional careers and professional development, he stated:

The hypothesis is fairly obvious: Teachers have different aims and different dilemmas at various moments in their professional cycle, and their desires to reach out for more information, knowledge, expertise and technical competence will vary accordingly ... A core assumption here is that there will be commonalities among teachers in the sequencing of their professional lives and that one particular form of professional development may be appropriate to these shared sequences ... (Huberman, 1995, p. 193)

He suggested that we "can begin to identify modal profiles of the teaching career and, from these, see what determines more and less 'successful' or 'satisfactory' careers ... identify the conditions under which a particular phase in the career cycle is lived out happily or miserably and, from these, put together an appropriate support structure" (Huberman, 1995, p. 194). However, in a typically self-critical note - a characteristic worthy of the best researchers - he warned of the ways in which ontogenetic, psychological research underestimate, as he had in not accounting in his research for the organisational effects, the importance (and influence) of social and historical factors. There is a need to conduct empirical research on teacher careers in all countries, for, as he acknowledged, his own work was limited by the cultural effect of a homogenous teaching population and did not take place in times of turbulence in teaching.

Huberman's work, alongside that of Ann Lieberman, Milbrey McLaughlin, Judith Warren Little, John Elliott, Judyth Sachs, Peter Woods, Michael Fullan, Andy Hargreaves, and others who champion the complexity of professionals and their 
development, provides an "in principle" critique of prescribed stage theory based professional development programmes such as those favoured by policy makers in the UK looking for a suitable managerial framework for CPD programmes. Linear, "stage" models ignore the complexity and dynamic of classroom life, the discontinuities of learning and the importance of continuing regular opportunities for deliberative reflection "on" and "about" experience as a way of locating and extending understandings of the meaning of experience in broader contexts which research consistently reveals. Teachers will move backwards and forwards between phases during their working lives for all kinds of reasons to do with personal history, psychological and social factors. Taking on a new role, changing schools, teaching a new age group or a new syllabus will almost inevitably result in development disruption, at least temporarily.

There are problems, also, in a changing world, with regarding the acquisition of expertise as the end of the learning journey. Becoming an expert does not mean that learning ends - hence the importance of maintaining the ability to be a lifelong inquirer. Expert teachers are those who retain their ability to be self-conscious about their teaching and are constantly aware of the learning possibilities inherent in each teaching episode and individual interaction.

Huberman's work and the studies of others in areas related to teachers' careers reveal that:

- There are different concerns at different moments in the professional life cycle.

- Few teachers are happy with conventional in-service formats.

- Most learning is done alone - what he calls controversially a "lone wolf" scenario because the architectural and social organisation of schooling make it difficult to do otherwise.

- Where teachers have opportunities to work collaboratively with peers, have assistance and training from experts, access to additional resources, and intensive experimentation on inquiry and development projects, which they approved, they are uniformly enthusiastic.

His work also challenges some of the work of "life history" researchers who do not take account of what Ivor Goodson later called "genealogies of context" (Goodson, 2000).

What is less known is his discovery of three factors which are predictive of professional satisfaction later in the career.

1. Teachers who spontaneously sought some form of role shift [every 4-5 years].

2. The "best years" - specific groups/classes with whom they enjoyed "privileged" relationships.

3. The experience of achieving significant results in the classroom "against the odds".

Finally, as with his collaborations with Matthew Miles, Huberman is not afraid to speak to policy makers directly with the power of his findings:

Minimally, sustaining professional growth seems to require manageable working conditions, opportunities - and sometimes demands to experiment modestly without sanctions if things go awry, periodic shifts in role assignments without a corresponding loss of perquisites, 
regular access to collegial expertise and external stimulation, and a reasonable chance to achieve significant outcomes in the classroom. These are not utopian conditions. It may just be the case, in fact, that they have not been met more universally because policy and administrative personnel have not deliberately attended to them. (op. cit., p. 206)

\section{Teacher burnout}

The findings of the 45th Session of UNESCO's International Conference on Education in 1996 observed a

dissociation between the recognition of the teachers' importance and the absence of any real measure taken in their favour, whether ... from the financial point of view, from that of the level of involvement in management or of the improvement of the limited or in-service training processes (Tedesco, 1997, p. 30)

and provided evidence that structural adjustment policies in many developing countries had led to a decline in expenditure and significant deterioration in the working conditions of teachers:

This deterioration produced, in its turn, a series of well-known phenomena: demoralisation, abandonment of the profession, absenteeism, the search for other occupations and, finally, a negative impact on the quality of education offered. (Tedesco, 1997, p. 24)

In his later years, Huberman focused his work on teachers "playing out their careers in periods of social turbulence ... or in moments of structural reform within their school system [who] are likely to have different trajectories from peers working in different social environments" (Huberman, 1995, pp. 194-5). In a book co-edited with Roland Vandenberghe in 1999, he wrote:

The quality of the relationship between teacher and pupils can be one of the most rewarding aspects of the teaching profession, but it can also be the source of emotionally draining and discouraging experiences. Because burnout has considerable implications for teachers' performance relative to pupils and colleagues - not to speak of teachers' own well being - it is a problem with serious consequences both for the teaching career and, more fundamentally, for the learning outcomes of pupils themselves ... (Huberman and Vandenberghe, 1999 , p. 3)

Burnout is not a new phenomenon, and over the years several studies have identified its effects. We know, for example, that (i) in New York Secondary Schools only 50 percent of the teachers looked forward to each working day in school (RiveraBatiz and Marti, 1995); (ii) burnt-out teachers give less information and praise to students and interact less frequently with them (Mancini et al., 1984); (iii) in the UK, 23 percent of the sample surveyed indicated having significant illness over the last year (Travers and Cooper, 1996).

Although many teachers begin their careers "with a sense that their work is socially meaningful and will yield great satisfactions", this is lost as, 
the inevitable difficulties of teaching ... interact with personal issues and vulnerabilities, as well as social pressure and values, to engender a sense of frustration and force a reassessment of the possibilities of the job and the investment one wants to make in it. (Farber, 1991, p. 36)

- Career development is often accompanied by "a sense of inconsequentiality" (Farber, 1991).

- Many teachers in mid-to-late career become disenchanted or marginalise themselves from learning, no longer holding the good of their pupils as a high priority.

- Low self-esteem, and shame (at not achieving desired results) is directly correlated with less variety of teaching approaches and thus less connection with students' learning needs.

As ever, Huberman points the way forward:

This is not to say that burnout is endemic to the teaching career but rather that there are sources at the individual, institutional, and societal levels that can compromise career satisfaction: meaningfulness, successful execution, enduring commitment, professional growth through increased experience and the learning of new skills, caring relations with peers and pupils, and the balance between work and family life ... (Huberman, 1995, pp. 3-4)

This connection drawn between the centrality of the quality of the teacherlearner relationship and the dire consequences for it when emotional exhaustion, depersonalisation and a sense of reduced personal accomplishment creeps into teachers' working lives is where, I believe, the worldwide governmental concerns for teaching standards and student achievement and, in many countries, problems with recruitment and retention intersect, and where many of us should be placing our emphasis if we are to use our research to influence.

\section{The VITAE Project}

One research project, which explores the theme of variations in teachers and relationships between these and pupil progress and outcomes, is just beginning in England. VITAE is a four-year government funded study of factors contributing to variations in teacher effectiveness. It is collaboration between the Centre for Research on Teacher and School Development at the University of Nottingham and London University Institute of Education. It builds upon and goes beyond Huberman's research on teachers' career cycles and, for the first time, looks systematically over time at what affects teachers' lives and how these effects influence pupils' progress and achievements. The research combines multi-level modelling with extended case studies of cohorts of 300 teachers (drawn from an initial sample of 7500 in 3500 schools) in early, mid and late career in 100 primary and secondary schools with different SES (socio-economic status) in a range of geographical locations. The initial conceptual map on which the work is based is shown in Figure 16.1. 


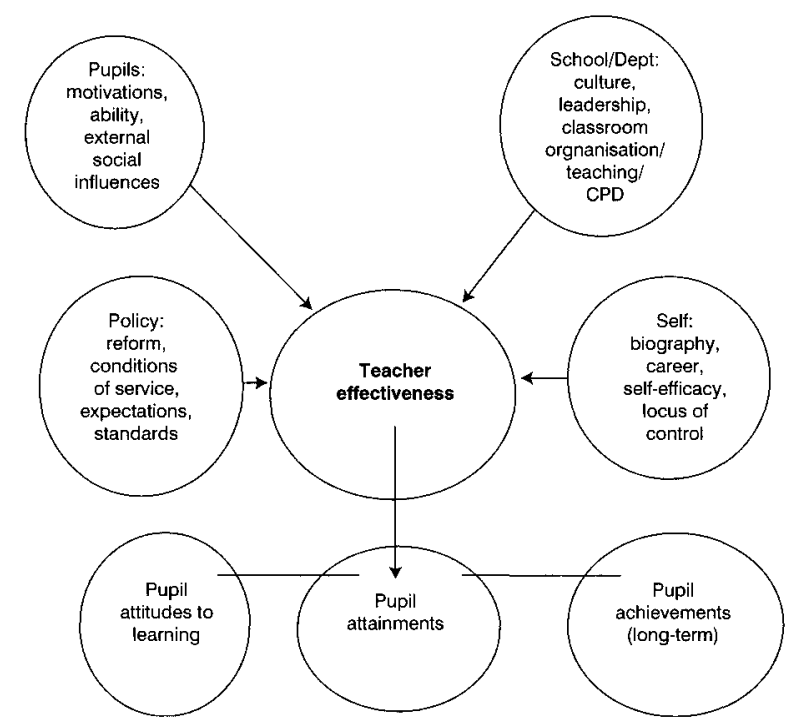

Figure 16.1 A conceptual map of factors affecting teacher effectiveness

The project aims to look at the variables which affect teachers over time in different circumstances - including the influence of teacher biography, identity, policy and school, departmental and pupil cultures. It seeks to tease out connections between these effects and pupil progress and outcomes by creating pupil social, attitudinal and academic assessment data; and, for the first time, we believe, combines and extends previous work on school and teacher effectiveness, teachers' careers and development, relationships between teaching and learning, teacher and learner. In short, our objectives are to provide:

i) an authoritative analysis of factors affecting teachers' effectiveness which will add to knowledge of teachers' careers and occupational satisfaction (or dissatisfaction), commitment (or lack of commitment) and achievements;

ii) empirical data, which will be of use to policy-makers in considering issues of recruitment, retention and quality;

iii) accessible outcomes, which will be of value to teachers and other educational professionals.

\section{The Role of Higher Education in the Standards Agenda}

\section{The nature of educational research}

It is unusual, perhaps, to consider the contributions that educational research may make to the standards raising agendas of governments across the world, for these are normally associated with new centrally imposed governance, results-driven curricula, assessment and management systems designed to increase the contractual accountability of schools and teachers and, through this, raise the educational attainments of students in schools.

Indeed, researchers across the world (e.g. Elliott, 1991; Day, 1991; Zeichner, 1995; Goodson, 1995) have long recognised the divide that often characterises the 
worlds of teacher research and research in the academy and the limits of its influence. In his presidential address to the American Educational Research Association's Annual Conference in Chicago, more than ten years ago, Larry Cuban spoke of the limited usefulness of research as perceived by those outside the academic community and of his own dilemma as one who had "practised" in the schools system, and "researched" as a scholar in higher education. He called for more networking between educational communities of all kinds, and for the establishment of caring communities, which would move beyond what is still for many outside academe the rhetoric of collaboration. In highlighting the scholar-practitioner dilemma he, like others, identified alienation or at best the worldwide scepticism expressed by many teachers about research and researchers which is so unproductive (Day, 1991; Zeichner, 1995).

The same might be said about the divide between policy - in many countries based upon political ideology - and research. Whilst there is not always agreement about priorities and practices, there is a need to assert the unique complementarity of purposes of policy-makers, schools and departments of education in the education of teachers and in seeking the betterment of pupils. There is, however, a tension between the core "service" purposes of departments of education to teachers and schools and their location within the academy. In a historical analysis, Ivor Goodson (1995) claims that schools and departments of education "may have entered a 'devil's bargain' (p. 141) when they became part of universities, with the result that, "their mission changed from being primarily concerned with matters central to the practice of schooling towards issues of status passage through more conventional university scholarship" (p. 141). One consequence of this is that "the relationship between faculties of education and school practitioners constitutes a model of how to talk past each other" (p. 141).

Recently, David Labaree (2000) examined the nature of knowledge produced by educational researchers and considered its status within the academy and impact outside it. Using Tony Becher's distinction between "hard" and "soft", "pure" and "applied" in his seminal book on Academic Tribes and Territories (Becher, 1989), Labaree provides a persuasive explanation of and justification for the kinds of research undertaken by educational researchers. He contrasts disciplines producing "hard" knowledge in which research findings which are claimed to be "verifiable, definitive and cumulative" (p. 57) can be built upon, "pushing the pursuit of knowledge in that field to the next level" (p. 57), with disciplines which produce soft knowledge. Here, as Donald Schön before him identified, the intellectual topography of professional practice is less well defined.

In the varied topography of professional practice, there is a high, hard ground where practitioners can make effective use of researchbased theory and technique, and there is a swampy lowland where situations are confusing "messes" incapable of technical solution. The difficulty is that the problems of the high ground, however great their technical interest, are often relatively unimportant to clients or to the larger society, while in the swamp are the problems of greatest human concern. Shall the practitioner stay on the high ground where he can practice rigorously ... or shall he descend to the swamp where he can engage the most important and challenging problems if he is willing to forsake technical rigour? (Schön, 1983, p. 43) 
It is, Labaree suggests, on such swampy ground that it is "more difficult to establish findings which are reproducible and whose validity can be successfully defended against challenges by others" (p. 57) in work in which producers focus most of their attention on "problems of description and interpretation; how to portray and make sense of the texts or events under study ... [and in which] ... findings are always subject to challenge by researchers who adopt a different interpretive approach. [and so are constantly] ... rebuilding the foundations of their disciplines, as they continually reinterpret the most fundamental issues in their fields" (p. 57).

Educational researchers "cannot build towers on the foundations laid by others because these foundations are always being reconstructed. As a result, research work is spread over a wide area, as individuals and groups continually work at rethinking the most basic issues in the field as they each pursue their own interpretive approaches" (p. 62). Labaree also contrasts disciplines, which produce "pure" knowledge, "oriented around the construction of theory" (p. 59), and those, like education, which produce applied knowledge in order "not to establish general patterns but to solve particular problems" (p. 59). Significantly, he identifies the particular pressure on educational researchers when he writes: "It is not enough to study what is interesting about education; the researcher is under pressure to improve it" (p. 60).

The implications of continuing to draw a line between policy-makers, professional researchers (from the academy) and "other" researchers (in schools) without considering their complementarity and respective development need to be carefully considered, lest separation does a disservice to all. If the evidence still points to a lack of use by teachers of much research where they themselves have not been involved in the research process, by sustaining the notion of a "profession of academic educational research" removed from practitioner communities, we run the risk of perpetuating this.

\section{The influence of educational research on practice}

Huberman and Miles' (1984) up-close study of innovation stressed that success depended on whether or not the change was able to be embedded into the structure through generating a critical mass of committed teachers - a conclusion that provided the cornerstone of all subsequent systemic school improvement models. Huberman's (1993b) later study of dissemination efforts in large-scale national projects of applied research and his paper published in ISATT's own journal on "Networks that alter teaching: conceptualisations, exchanges and experiments" (Huberman, 1995a), like that of Judith Warren Little (1982), Judyth Sachs (2000) and John Elliott (1991), lends empirical support to the twin importance of teachers' and researchers' involvement in the organisational contexts of reform.

Huberman was concerned throughout his life with the ways in which research knowledge becomes practice. Acknowledging the seminal work of Kurt Lewin, Ronald Lippett and Paul Lazarsfeld, he reminded us of two ways in which "researchers" and "users" can interact. The first where researchers generate knowledge in the "scientific" universe, then transfer it to "practitioners", facing the seemingly impossible hurdles of perceived need, relevance and distortions; the second, the action research tradition in which practitioners define the knowledge they require and researchers frame their studies around these needs. In both strands, researchers and practitioners interact, though in different ways.

Huberman's contribution to the debate on researcher/practitioner roles and the theory/practice dimensions is, like his work on teacher development, profound. He 


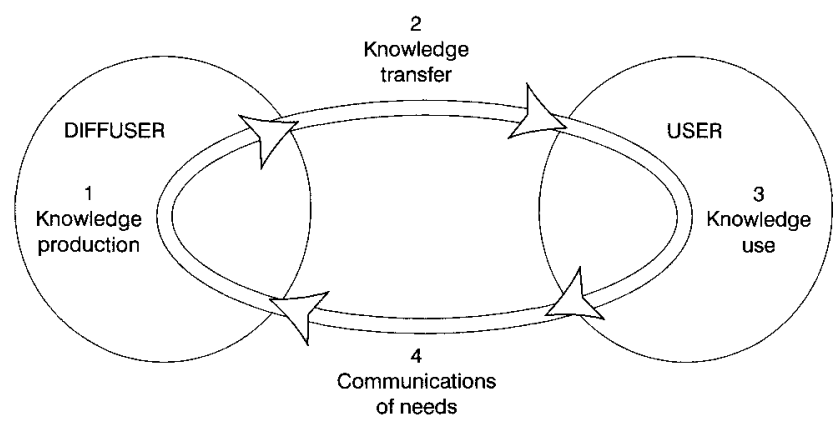

Figure 16.2 Relationship between diffuser and user (Huberman, 1993b, p.36)

was able to draw on both the more traditional researcher role (an inevitable consequence not only of predilection but also of conditions of service which demand a steady flow of publications in learned journals from higher education tutors and a fully timetabled teaching day from school teachers); his knowledge of change and change processes, drawn from his extensive work with David Crandall, Matthew Miles, and Ron Havelock among others; and action research. He coined the term "sustained interactivity" as a means of bridging the gap between knowledge production and knowledge use. Huberman defined it as:

Multiple exchanges between researchers and potential "users" of that research ... prior to, during the conduct of ... and ... during the analysis and write-up phase of a study. (Huberman, 1995, pp. 36-7)

Ten years later this has become central to the work of professional development schools and school improvement networks. Huberman's hypothesis was that such sustained conversations result in measurable shifts in the ways people construe the issues:

The fact of having to reframe one's findings in different ways for different publics, and of having to address counter-examples, qualifications and outright challenges on the part of practitioners testing the research finds against their own experience and local context, appears to trigger a decentring process among researchers. (op. cit., p. 49)

Although he did not embrace fully the emancipatory principles of action research, Huberman concluded that research is more likely to have a strong conceptual influence on practitioners when researchers are active in the contexts where innovations are in process; and that:

If we researchers are interested in changing our minds, we need to take our findings out into the field and observe very carefully how they hold up under duress. (Huberman, in Day et al., 1993, p. 51)

A recent report of a critical review on the impact of educational research in the school sector in Australia (BERA, 2001) demonstrated "the inadequacies of conceiving the relationship between educational research and practice as a 'linear' relationship". Rather, it presented a "multi-layered, unpredictable, interacting process of engagement between the researcher and the educator" (p. 23). Thus: 
The question of "impact" then becomes one of effective and responsive linkages at all levels: within the research community, within the professional community, and between those two communities and the individuals within them. (BERA, 2001, p. 23)

The report also suggested that government-funded programmes, which incorporate strong professional development components, or networks across sectors assist the translation of research into practical applications (op. cit., p. 24). There is a compelling case for reconceptualising the relationship between higher education and the profession.

There remains, then, a pressing need for closer, more sustained relations and joint responsibilities for knowledge creation, development and dissemination, suggesting collaborative research projects, problem-oriented seminars for groups of schools, researchers and mid-career professionals and jointly planned programmes with policy-makers. Yet there are still concerns that (i) the validity of much of the work of educational researchers continues to be questioned from without and within as being either irrelevant, lacking in rigour or simply not generalisable is a continuing concern; and (ii) it is often still researchers, not practitioners, or policy-makers who determine the agenda of educational research. Others have made similar criticisms in the past, though in a different context (Elliott, 1991; Day, 1991; Zeichner, 1995; Goodson, 1995; Hargreaves, 1996); and much research by academics, it seems, does not reach, does not influence, and is not valued by teachers in schools or by policymakers.

\section{Conclusion: The Challenge to Be the Best}

The separation between the school-teaching, policy-making and academic communities that exists partly because of history, partly because of function and partly because of collusion need not continue. Worlds which emphasise the systematic gathering of knowledge, the questioning and challenge of ideology, formal examination of experience, professional criticism and seemingly endless discussion of possibilities rather than solutions, need not necessarily conflict with those dominated by unexamined ideology, action, concrete knowledge and busyness (Day, 1991, p. 537; Cuban, 1992, p. 8). Although it is interesting to observe that as researchers from universities and other agencies seek to work more closely with teachers and schools, the locus of policy formulation becomes more distant, there are examples of growing understandings of the possibilities for their complementarity. Michael Huberman was one who recognised the power of such collaboration despite the possibilities of suppression, distortion, selective inattention and decontextualisation of the results by some for whom the love of politics excludes the application of integrity. Part of higher education's responsibility is to use our "room to manoeuvre", to expose policy masquerading as research, to critique policy where it flies in the face of research, to be rigorous in our own research, whether separate from or in collaboration with teachers; and to communicate rather than colonise the voices of practitioners. In order to do this we need to maintain and develop critical engagement with policy-makers, interest groups and practitioners.

In involving ourselves in the micropolitics of knowledge use (Zeuli, 1996, p. 178) we need appropriate competences: 
The competencies we then need as professionals must include the competence to cross borders, cultures and dialects, the learning and translating of multiple languages (the political, the everyday, the academic) and the courage to transgress when faced with social injustices ... How we practice our authority is then the issue, not what we claim or profess: if we believe in something then we have to practice it. (Walker, 1996, pp. 407-25)

This, perhaps, is the kind of lifelong learning in which, as educational researchers, we must engage. Michael Huberman and his work provide a model to us all. To paraphrase Jaraslav Pelikan (1992), when we are performing at our full potential, we are positioned in a delicate balance between the university and the society, and specifically between the university and the professional constituencies for which the professional schools are responsible. The university protects us from becoming the vassals for the constituency or shaping our courses to what the constituency believes at any particular moment to be needed for a true professional in the field, which may be, and usually is, significantly different from what such a professional will need some years down the line. But the constituency, in turn, protects us from becoming mere satellites of the graduate school of arts and sciences. That delicate balance puts the professional schools into their leadership position in the lifelong education that is reshaping the mission of the university as a whole.

The challenge for university departments of education, then, is to engage in strategic planning for initiation and response through which their capacity to respond to schools' agendas as well as to take forward those of the academy will be increased. In developing new kinds of relationships with schools and teachers they will be demonstrating a service-wide commitment in which traditional expertise (e.g. in research and knowledge production) is combined with new expertise in forms of cooperative and collaborative knowledge creation, development and consultancy which are part of a more diverse portfolio which connects more closely with the needs of the school community at large. Such a portfolio would demonstrate the commitment of university educators to improving teaching and learning in collaboration with schools and teachers through capacity-building partnerships in addition to an ongoing commitment to producing knowledge in, of and about education and generating knowledge for education which could be utilised and tested by the system for which it has been produced, both directly and indirectly. Current perceived problems of credibility; relevance of research and fitness for purpose of programmes of study would thus be minimised (Day, 1998).

The challenge to be the best applies to teachers and researchers in schools and universities. To be the best ourselves requires us to be passionate and disinterested, to be close up and distant to their work, and to reflect critically upon our own work and its impact. Like Michael Huberman, we must always be active in checking out the connections, at all levels, between policy, research and practice; and most of all we should be, become and remain recklessly curious. 


\section{Chapter 17}

\section{Tertiary Teacher Development: Connecting Policy, Personal Theory and Practice}

\section{Neil Haigh}

\section{Introduction}

When I began to think about the conference theme Connecting Policy and Practice and its relevance to my work as a tertiary teacher developer, it immediately occurred to me that while policy is certainly an important influence on my practice, personal theory is at least as influential. Further, personal theory both informs and mediates the policypractice connection. So, with these three interrelated elements in mind, I decided to (a) identify policies and theory that have a major influence on my day-to-day practice; (b) assess the relative "weight" of their influence and the reciprocal interactions that are possible between them; (c) review the extent to which alignment exists between university policies and my theory; and consider associated issues.

Why undertake this exercise? First, as an aspect of on-going reflection on my teaching, I recognise the need to explain my practice - to myself - and to consider the implications of those explanations for future practice (Haigh, 2000a). This is a case study of an attempt to do this. Second, I currently need to explain my practice - to others. The context for this is a review now underway of policies, provisions and practices associated with teacher development in my university. While the review is an institution-wide one, the university's Teaching and Learning Development Unit (TLDU) is a key focal point. As Director of the unit, my own practice and the practice of the unit as a whole, inevitably comes under scrutiny. Undertaking this self-review/reflection is preparation for that scrutiny and my record of the outcomes may be relevant, and of interest, to others preparing for comparable reviews.

\section{Policy}

University policies might be expected to provide views and guidelines concerning the attributes of competent and outstanding teachers, goals for teacher development, the subject matter of teacher development, and priorities for development, strategies for 
teacher development, career-long development requirements and expectations, rewards for teaching development. What are the realities? My university does provide such guidelines in a number of policy documents. These documents include University Strategic Plan, Academic Plan, Course and Teaching Appraisal Policy, Research and Postgraduate Studies Policy, Probation Policy, Promotions Policy and Study Leave Policy. Currently, there is no single policy document concerning academic staff/teaching development or a document that draws together all policies concerning learning and teaching (e.g. a Teaching and Learning Plan). Predictably, there is considerable variation in the specificity of policy statements. In turn, they vary in the extent to which they provide explicit, detailed guidelines for the individual teacher, and those staff who are responsible for facilitating teacher development.

What guidance does existing policy offer? In particular, it indicates explicitly or implicitly some priorities for the subject matter of teaching development. For example, subject matter that can be identified from the University Strategic Plan includes design/delivery of distance learning opportunities; curriculum, learning and teaching approaches for international students; design of e-learning opportunities; the teaching and learning of Maori students. The Research and Postgraduate Studies Policy gives emphasis to scholarship and academic work, the teaching-research nexus and supervision capabilities.

I have had input into the development of some of these policies through my membership of related working parties. In these contexts, my personal theory has influenced policy. An example is a recently developed policy concerning the teaching research nexus. This policy takes into account literature-sourced views about the nexus that I introduced to the working party and illustrations I provided of the way this nexus was expressed in and benefited my own academic work. The policy was developed, in part, because there is a legislative mandate in New Zealand for the interdependence of teaching and research in universities (New Zealand Education Amendment Act, 1990). Prior to the development of this policy, I had introduced a workshop for beginning teachers in which the related topics of the teaching-research nexus and the place of scholarship in academic work were addressed (Haigh, 2000b). This alignment of legislation, policy and personal theory strengthens considerably my ability to make the case for particular teaching practices.

While such policies continue to be developed in my university, some gaps and limitations remain. For example, there are no statements embedded in policy concerning the attributes of competent and outstanding teachers, the goals for teacher development, what development activities are required rather than recommended and career-long development expectations. So, what has been the basis for my practice when university policy cannot inform it? First, I have turned to other "official" policies that offer relevant perspectives. For example, there are documents that prescribe learning goals for university education. These documents include (a) the New Zealand Education Amendment Act (1990) which defines the primary purpose of university education as being "to develop intellectual independence" and (b) definitions of the different levels of university programmes of study (New Zealand Vice Chancellors Committee). Given these learning outcome statements, it is possible to infer:

- The desirable features of students' learning opportunities, experiences and activities, and

- The knowledge, skills and attitudes that teachers would require to arrange and facilitate them and, in turn, construct a teaching development agenda. 
Again, my personal views and the views of those associated with these policies are in alignment, and having a legislative mandate for the intellectual independence goal adds considerable weight to my own view that it merits high status as a tertiary learning goal - and that our teaching methods must "fit" this end (Haigh, 1994).

My second response to gaps and limitations in university policy is to base my practice on personal theory.

\section{Personal Theory}

My personal theory has determined, in particular, the general goals that I have for teaching development and my views about the way in which those goals and associated developmental activities should change as teachers make the journey from novice to expert. What are some of the core concepts and propositions that constitute my personal theory of teaching and teaching development?

Teachers who are best equipped to facilitate their students' learning have the following general attributes:

- A rich repertoire of teaching methods and skills

- Sensitivity to the myriad of factors that make particular ways of teaching more or less appropriate

- Good control of specific skills

- Willingness and capacity to reflect on and research their own teaching

- Awareness that the choices they make concerning teaching and learning objectives and approaches are shaped by their beliefs about the primary purposes of education. They can make those beliefs explicit and teach in ways that "fit" these purposes. In this sense their teaching is "educative" as well as effective (Haigh and Katterns, 1984, pp. 23-7).

An agenda for teaching development based on these criteria includes extending repertoire, increasing sensitivity, gaining control, undertaking reflection and research. When beginning to work with colleagues, I make this agenda, and the assumptions that underpin it, explicit. One of the assumptions is that it is not possible to construct foolproof recipes for effective teaching because a teacher cannot control many of the conditions that ultimately determine whether someone learns.

Effective teachers construct "personal practical knowledge" about teaching through reflection. Three pre-requisites for productive and powerful reflection are belief in the value of reflection, an appreciation of what it would be worthwhile reflecting on and a rich repertoire of reflection skills. If those pre-requisites are to be fulfilled, it is likely that teachers will need to learn what to reflect on and how to reflect. Accordingly, I teach colleagues about reflection and ways of reflecting (Haigh, 2000a) and assist them to engage in reflection on particular learning and teaching situations (Haigh, 1996).

Teachers are more likely to be effective teaching practitioners if they can engage in the "scholarship of teaching" as well as draw on the "scholarship on teaching". Hutchings and Shulman (1999) characterise the scholarship of teaching as "a kind of 'going meta' in which faculty frame and systematically investigate questions related to student learning - the conditions under which it occurs, what it looks like, how to deepen it, and so forth - and to do so with an eye not only to improving their own 
classroom but to advancing practice beyond it" (p. 12). As Shulman observes "we develop a scholarship of teaching when our work becomes public, peer reviewed and critiqued, and exchanged with other members of our professional communities so that they in turn can build on our work" (Shulman, 2000, p. 49). Encouraging and helping colleagues to engage in the scholarship of teaching is one of my key teaching development goals.

Epistemological differences in disciplines give rise to differences in assumptions about valued learning outcomes, conceptions of teaching, views about good learning and teaching practices and ways of engaging in the scholarship of teaching (Huber, 1999; Healey, 2000). I explicitly acknowledge these differences and the constraints that my own discipline background potentially imposes on me as a teaching developer. I also endeavour to help colleagues recognise that standing in the shoes of colleagues who come from disciplines other than their own may provide rewarding new perspective on learning and teaching.

As teachers journey from being a novice to an expert teacher, what they want to learn and need to learn in relation to teaching capabilities changes. The learning and teaching approaches that best assist their learning at each stage of the journey change in turn. Propositions about the novice-expert journey, derived from the widely known Dreyfus and Dreyfus (1986) model of skills acquisition, other literature (e.g. Butler, 1996) as well as my own reflected-on experiences, have a prominent place in my teaching theory. Examples of those propositions include:

Novices need to learn to recognise a limited number of key features of (teaching-learning) situations that will be relevant to certain teaching activities. They also need some context-free/generalisable rules to guide their actions (if these features are present, do this). The agenda for their learning must be relatively modest as their information-handling capabilities will be stretched handling the storage and retrieval of these "getting started" rules. If further information about exceptions to these rules or variations on the rules is offered prematurely, it is likely to overwhelm them. The feedback they will be most responsive to concerns how well they are following the rules (am I doing it right). They need close support, including mentoring, while they practice applying the rules and begin to generate their own experience.

- As novices generate experience, they (can) begin to learn, through reflection on those experiences. Those reflections may include noticing recurrent features of situations (every time this is present, this happens), identifying aspects of situations that should be responded to and recognising the extent to which some rules can be generalised. These reflections are the basis for the beginner constructing their own rules. At this stage, they need to be prompted and assisted to reflect carefully on situations. That assistance includes teaching them what aspects of learning and teaching situations they might reflect on and how to engage effectively in reflection.

- Appropriate development activities for competent teachers may include close analysis of learning and teaching incidents, developing and refining strategies for handling challenging situations, systematically trying out new strategies and skills in real or simulated situations. These activities can provide the basis for teachers engaging in research as an avenue for development (i.e. engaging in the scholarship of teaching). 
- For proficient and expert teachers, techniques such as stream-of-consciousness records, think-aloud protocols and stimulated recall may help them to surface and reflect on the rich set of maxims and rules that they usually draw on unconsciously, using intuition. Confronting them with novel situations may similarly prompt them to engage consciously in analysis and the generation of new rules.

This representation of the novice to expert journey is the foundation for a development agenda in which the focus progressively shifts in emphasis from rules to reflection - then on to research.

How do these elements of my personal theory shape my practice? Here are some examples.

- Introduction to Teaching Workshops for beginning teachers centre on common conceptions of learning and teaching, getting-started rules and an introduction to reflection as a way of developing teaching capabilities.

- As a follow-up to these workshops, participants are encouraged to ask TLDU staff to observe classes and to assist them to reflect on them. This provides the best context for their learning more about the when and how of reflection, as well as for building personal practical knowledge about teaching.

- Further workshops provide an occasion for teachers to share, analyse and discuss case studies (e.g. Top Teachers Talking Teaching, Teachers ... OnLine Teaching). These workshops are targeted to competent teachers from a range of disciplines.

- A variety of strategies (e.g. newsletters) are used to inform colleagues about the sources and products of scholarship on teaching (i.e. the "public general knowledge" about teaching).

Key objectives of a Postgraduate Certificate in Tertiary Teaching programme that is offered to experienced, competent teachers include:

- Developing reflection capabilities

- Extending capacity to access and review critically the scholarship on teaching

- Enhancing ability to engage in the scholarship of teaching.

The similarities and differences, as well as the pros and cons, of these modes of professional development are considered in the programme. Discipline differences in conceptions of teaching and approaches to the scholarship of teaching are acknowledged and examined.

While there is no explicit endorsement in current policy for these elements of my personal theory, there is also no policy that is clearly founded on contrary propositions about teaching. Implicit endorsement for a number of these premises is apparent in the university's approval of the Postgraduate Certificate of Tertiary Teaching programme.

\section{The Policy, Personal Theory and Practice Equation}

When I began this exercise, I "sensed" that I would uncover some instances of fundamental misalignment between university policy and my personal theory. That has not 
eventuated. Perhaps the prediction of misalignment was an artefact of the frustration that I sometimes feel when there is no institutional point of view in place that can lend additional support, credibility and weight to the decisions I must make about my practice. There is also some anxiety that arises from the possibility that decisions that I must now make solely on the basis of personal theory, may one day be considered out of alignment with policy - when present gaps and limitations in policy are ultimately addressed.

Partly in response to that frustration and anxiety, I consider it a priority to proactively contribute to the development of policy on learning and teaching. Two more reasons account for this priority. First, I believe that such policy must take account of the personal theories of university teachers and I consistently advocate for this. As I am a university teacher, as well as a teacher educator, I wish my voice to be heard along with those of my colleagues. Second, I believe that the policy development process should embody scholarship and, in this instance, take account of scholarship on teaching. It is a paradox that the hallmarks of scholarship are often not an obvious feature of policy development in universities. Perhaps a "scholarship of policy development" should be commended as well as the scholarship of teaching. I advocate strongly for both. 


\section{Chapter 18}

\section{Collaboration in Cross-National Networks for Teacher}

Professional Development

\section{Manfred Lang, Bernadette Charlier, Murray Saunders, Joël Bonamy, Thérèse Laferrière and Alain Breuleux}

\section{Chances and Restrictions of Collaboration in Networks}

Educators and policy-makers argue that the development of computer-supported networks should be part of teacher professional development in curricular reform (Terhart, 2000; Dillemans et al., 1998). Reforms are likely to be more successful if teachers develop a professional culture of collaboration in networks rather than of individualism (Riel and Becker, 2000).

As a consequence in different countries a growing number of network projects are initiated as a driving force for teacher education reform. Unfortunately these projects primarily rely on technical aspects of connectivity in networks and neglect practical aspects of collaboration in networked communities. On the one hand, computer technology and the Internet can be regarded as essential facilities of modern schools, and they are frequently suggested as means to improve collaboration. On the other hand, the structure and flexibility of technical means for communication, social interaction and self-organised learning in teacher education are still insufficiently researched and limited, even if multimedia input, management systems and user-friendly graphical interfaces do exist (Schulmeister, 2002).

An important issue is to identify and evaluate conditions and design principles of collaborative networks in a process of professional development. This process requires a school-based environment of collaborative communities that cultivate a disposition of reflection generating dialogue in knowledge building communities of practice and research. Zeichner (1994) calls for a more open commitment of educators and of partisan interests served by educational research that supports teacher reflection and collaborative teaching in a research community. 
Reflective practice is part of teachers' learning process in the classroom context. This is a central position of Schön (1983) generating a fundamental discussion about a valid knowledge base in educational research. But his conception of individual and cognitive teacher thinking is nowadays shifting to a perspective centred on teaching practice in a broad sense that emphasises deliberation, collaboration, scaffolding and distributed expertise in learning communities (Shulman and Shulman, 2004).

Collaborative reflection in a network needs to be specified as part of a discursive process to share meaning with others in an undominated dialogue (Strike and Soltis, 1998). It is in a context of collaborative argumentation during problem solving, reconstruction of a knowledge base and ethical discourse in a process of professional development and curricular innovation. As a consequence this extended system of reflective collaboration will not only result in problem solving for better professional learning but in addition in a higher awareness of values and norms in education or in a production of curricular documents, justified through practical experience and normative acceptance (Lang et al., 2004).

Collaborative networks for professional dialogue have potential to support lifelong and trans-national learning among educators of different subjects and at different stages on the professional development continuum (Laferrière, 2000). But it is a difficult process. Primarily teachers need to meet the challenges of school-based collaboration. The network cannot be an escape, but it must be seen as an instrument for undertaking the necessary re-assessment of one's work through the review and critique of existing practices in an open dialogue extended and enhanced by new digital tools.

Computer technology and the Internet are interactive media that support co-operation in network-enabled communities and that seize opportunities for cultivating local as well as universal knowledge. But tele-collaborative tools alone do not create learning communities. Professional development activities that succeed in engaging participants in networked communities are important in order to lead to educational renewal and improvement. As pointed out in a research study by Little (1993), co-operative professional development in networks of schools, educational institutes and centres is promising but has been an exception.

How can collaboration in teacher education become more manifest? This is not only a question about network technology alone, but also about the successful integration of resources jointly developed, and of ongoing online and face-to-face discourses regarding, for instance, teacher education as a process of the networked classroom. Ways of answering this question should consider teachers as actors in their social and physical work context, but also as participants in local and transnational communities of practice. Research in this area is primarily concerned with the local level. Chaney-Cullen and Duffy (2001) suggest fostering collaboration in a situated learning environment through teachers' participatory activity as facilitators or coaches of students' intentional learning. In a study conducted by Riel and Becker (2000) collaborative use of computers was found to be most effective in a group of teachers identified as teacher leaders. Anderson (1996) points to the necessity of a collaborative work climate with structural features like school-based in-service, encouragement by headmasters, the school administration or financial resources. With these insights in mind, we pursue the question: how can collaborative reflection be effective within and across school-based communities of practice in a process of educational change? 


\section{Insights About Collaboration from Network Projects}

Two European projects EUCISE and LEARN-NETT and a Canadian program, part of TL-NCE, are dedicated to the infusion of information and communication technologies into cross-national educating educators programs. They are developing and exchanging experiences about basic principles of collaboration in various communities of practice for both local and distributed learning.

These approaches use computers and Internet platforms to support networkenabled communities of teacher-as-learners in classroom as well as the professional development process. In the socio-technical designs that are developed, each professional learning community consists of teachers, teacher educators, and educational researchers. Whenever possible, the classroom that they work in at the primary, secondary or post-secondary levels is being reconceptualised as a learning community. But each design has its unique features as it is developed out of a different context with its own local circumstances: one is a collaborative workshop addressing the development of integrated science materials and concepts, one is a university initiative emphasising collaborative action research, and one is a suite of university-school partnerships established at geographically distant sites.

\section{The European Network for Integrated Science Teaching (EUCISE)}

In this Comenius-project a European model is developed for integrated science teacher education through transnational co-operation and professional development, inclusive of in-person meetings and online exchange. Partners of EUCISE are national institutes and schools in Denmark, Germany, Austria, Poland and Rumania.

Part of the EUCISE project is continuous teacher education, developing concepts and materials about content and method of reflective teaching and learning. Materials are mainly adapted from the project PING (Practising Basic Integrated Science Education) for use on a shared workspace and electronic documentation system DoKS, or on a CD-ROM. The materials undergo continuous revision in a collaborative system of school-based planning involving a self-evaluating team of teachers, teacher educators and researchers. Network-based collaboration takes place on two separate levels: on a national level as part of continuous teacher education within the realm of continuous education and on a trans-national level between administrative teams and the EUCISE members of the individual states. To these ends the DoKS platform was developed and is being analysed for the sake of the improvement of collaboration, instructional planning and professional development on integrated science.

A questionnaire about the role of computers and the Internet in collaborative teacher professional development for integrated science education was used to monitor the success of in-service activities organised by EUCISE. Questionnaire data collected from 27 teachers in the second year of the project who participated in in-service seminars on integrated science teaching indicate that they highly rate the improvement of cooperation in school (Table 18.1). However, they rate net-based collaboration and changes in teaching practice for integrated science teaching as less important. However, at the onset of this project, networks do not play a major role. Further analysis is needed. Additional data about changes in collaboration, intended goals and constraints will be collected in a follow-up project about multimedia use for ecological audits in school (SCHAMANE). In an audit, teachers and students are dealing with ecological problems of a school involving specialists of different areas in public discussions. Central to this 
Table 18.1 Answers by teachers on co-operation and use of computers and the Internet

\begin{tabular}{lc}
\hline Improve school work through exchange of experience & $\begin{array}{c}\text { \% of teachers } \\
\text { answering "yes" }\end{array}$ \\
Improve through co-operation with colleagues & 87 \\
Improve through co-operative material development & 69 \\
Computer and Internet for co-operation & 85 \\
Regular co-operation via the Internet & 53 \\
Change of teaching practice through technology & 44 \\
Use of computers and network for student learning & 53 \\
\hline
\end{tabular}

audit process are the establishment of a school agency and the use of a network platform to assist teachers and others to communicate with each other for educational planning and evaluation. Participating schools experience an increasing interest in internal and external collaboration. In a second related project about school-based teacher education across Europe (EUDIST; Lang, 2003) case studies are conducted about a network of collaborative initiatives exchanging experiences and concepts of best practices in educational innovation and its normative implications in a discourse.

\section{Learning Collaboratively in the Learning Network for Trainers and Teachers (LEARN-NETT)}

This European network of ten universities is preparing teachers and trainers to use telematic services for education and training in a collaborative and reflective learning experience.

LEARN-NETT is a two-year SOCRATES-ODL project that allows partners to engage collaboratively in action-research on questions about conditions for collaborative learning, ownership of online collaborative tools for learning purposes and the role of teacher networks for innovation. One result of this project is about the use and effect of "bridging tools", a concept of situated learning theory with the following assumptions: involvement in research or development produces learning through the development of new communities of practice; individuals and groups learn through the adoption of new practices and this process is active, context bound, and essentially reflective. Online vignettes, rehearsals, examples, cases, and accounts are boundary-crossing objects to make the tacit explicit. They provide provisional stability for change. Provisional stability is a term referring to circumstances which allow stability as change occurs. Offering insights into other teachers' transformative experience may support engagement in innovation.

"Bridging tools" built during the LEARN-NETT project are questions guiding cross-cultural collaboration, a virtual campus as a tool to represent and foster a common vision of innovation in the network and a tool to describe, reflect on, and build a common vision about the role of the "on line" facilitator (Bonamy et al., 2001).

\section{The Canadian TeleLearning Network of Centres of Excellence (TL-NCE)}

In Canada, researchers of the TeleLearning Network of Centres of Excellence (TLNCE) are co-designing interconnected learning communities for a process of educating educators. Patterns at local and Pan-Canadian level were conceptualised using Banathy's framework (1991). Patterns of transition between the physical and virtual world 
demonstrate how network-enabled classrooms may operate on different levels when access to tele-collaboration tools is no more a problem. Voluntary participation and collaboration are favoured in order to enable authentic learning. Contrived collaboration is an issue that needs to be addressed on an ongoing basis by facilitators.

A distributed telelearning professional development school (TL-PDS) has been designed with locally grounded and Internet-enabled communities (TL-PDSs) devoted to teacher learning. A number of socio-technical designs for computersupported learning communities have been explored at each of the four pillar sites. Design principles capture the shared understandings as teacher educators extend and enhance their local learning communities to create the TL-PDS, a virtual community of support and communication for learning to teach in the network-enabled classroom. Some of these principles are the following: non-contrived participation in the development of a network, local grounding or site-based teacher learning communities, collaborative learning in network-enabled classrooms, multi-modal (in-person and online) social interactions at a local level, the classroom as a community of learners and diversity.

In a case study in which 120 student teachers participated, data were gathered about their experiences with tele-collaboration tools, from personal documents, interviews, online collaborative activities, Web productions and other artefacts such as digital videos, logs, and interviews.

Student teachers had been introduced over a four-year period to an authentic context that integrated online activities in a school-within-a-school program ( 8 classrooms/communities of learners, 240 junior high and high school students) located in a large secondary school near the university. Each learner in this program owns a laptop, connected to the school intranet and to the Internet, at school and from home. This particular PDS is part of a large network of over 150 associated schools where the 1500 student teachers registered at the higher-education institution do all their clinical experiences. Half of the pre-service teachers went into the technology-enhanced classrooms - for observation periods, participant-observation/ethnographic work, or four-day-a-week student teaching over a fifteen-week period. All 120 student teachers engaged in online pre-action and post-action activities such as individual planning and collaborative journal writing. One teacher educator from the university was present at school as a collaborative inquirer two days per week. The authentic context was the large network of associated schools itself: student teachers engaged in online reflective activities (e.g. collaborative problem-setting and problem-solving). Student teachers could also do virtual visits to the network-enabled classrooms, including the online artefacts created by their peers who were working in those classrooms.

As a result, student teachers preferred collaborative more than individual journal writing, problem setting and problem solving. However, student teachers' supervisors remained preoccupied by issues of privacy, access, and control. In most innovative classrooms, that is those combining pedagogy and technology to do what cannot be attained otherwise in the classroom, student teachers were confronted with their own traditional beliefs and those of their peers as regards teaching and learning "that counts". One instructive event in a related study was that an entire cohort of over 250 third year elementary education student teachers came to the conclusion that projectbased learning could very well be done without computers. When the third year student teachers of the same program were asked in the following year to study the personal, interpersonal, and institutional circumstances of their practicum in order to choose 
between learning projects with or without networked computers, only 15 percent of them chose projects involving ICT. Overall, student teachers who experimented most with networked computers for classroom learning came out of their clinical experiences with a transformed professional identity as teachers-to-be and a sense of belonging to a network-enhanced professional community.

The above case suggests that the design of network-enhanced PDSs allows for: (1) the development of ecologically-valid solutions for integration of information and communication technologies (ICT) into elementary, secondary, and post-secondary schools/institutions and classrooms; (2) a better range of opportunities for sustained dialogue between teachers at different stages of their professional development; (3) boundary-spanning opportunities of courses, practica, graduate seminars, and collaborative research activities within and between institutions.

\section{Interconnected Learning Communities: A System at Work}

Teacher professional development in a cross-national network of open dynamic systems is fundamental for the development of education as global enterprise (Kissock and Kolontai, 1993; Buchberger, 1997). ICT is key to applications of this concept in ways in which teachers engage in collaborative activities and build on ideas of colleagues from other institutional and social-cultural settings.

In the above projects the emphasis for the development of each network differs but there are specific results that point to the effects of design principles to support collaborative group structures and leadership, to negotiate meaning in a group, to relate the physical to the virtual world for net-based collaborative learning in order to provide a public space for cross-national exchange and shared knowledge objects supporting or guiding professional development.

The projects offer experiences, concepts and first data about activities of network-enabled professional development and distributed learning in Europe and Quebec (Canada) beyond a local level in order to integrate information and communication technologies into learning and teaching through the co-design of interconnected learning communities. Promising practices are collaborative reflective teaching and knowledge building carried out in relation to real classroom events and across and beyond school-based professional learning communities. For improvement of cross-national collaboration, project members exchanged materials, resources and research results, gave access to their homepages and visited schools. School-based collaboration in these projects involved small groups in Professional Development Schools' (PDS) situated learning groups or school-based initiatives leading the process. At first, the creative process of producing prototypes and testing them is bound to be small scale - a working group. Ultimately the small group has a curriculum change role to play, which takes its participants beyond the boundaries of their network. New questions arising are the following: How do teachers share innovative ideas amongst themselves? What leadership skills are involved? What resources do they have for this? What are the intentions of this exchange?

In order to relate specific design principles applied on different projects to the common places of the educational situation (Schwab, 1973) a model for educational improvement was adapted (Laferrière et al., 2002; http://www. telelearning-pds. org/ $\mathrm{u}$ /modele.html). This model considers the following dimensions: teaching, content, 


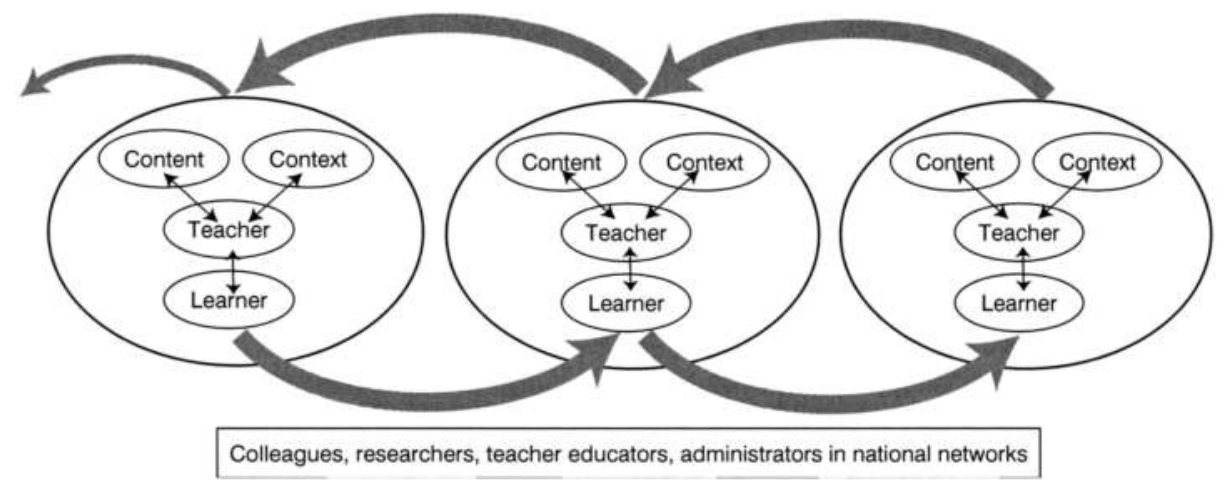

Figure 18.1 A system for cross-national collaborative networks with three units

learning and context. The design principles of each project emphasise only part of these dimensions. EUCISE emphasises content by producing materials and network resources, LEARN-NETT context through bridging tools for situated learning and TL-NCE learning in PDS models. Further iterations to be conducted or experiences in these projects may complete this four-dimensional landscape of the educational situation and validate its use in the search for coherence and integration in cross-national professional development.

At its centre, each network in the system is a teacher leader in a community of learners dedicated to educational improvement through professional development (see Figure 18.1). The model stresses the teacher's interrelation with content, learning and context. This means that a teacher may construct or use pre-organised content, engage in mandatory or self-guided learning and experience a constraining or supportive context. Collaboration between networks in this system is mainly supported by colleagues in school, researchers, teacher educators and administrators, exchanging lesson content, teaching experiences and educational designs.

Up to now the results presented have grown out of a small range of units in the system outlined, because adequate network experiences are time consuming and the selected projects did not, at the onset, involve teachers convinced of the worth of working collaboratively. But first experiences are promising if we look at the dynamic of small groups, teacher leaders and support systems at the local level of the units in open cross-national networks. Further results are needed to complete the model and differentiate the system's applications. 


\title{
Chapter 19
}

\section{Dilemmas of Democratic Education}

\section{Frank M. Flanagan}

\begin{abstract}
A father has only done a third of his duty when he begets children and makes provision for them. To his species he owes men; to society he owes social beings; to the state he owes citizens. Every person who fails to pay this triple debt is blameworthy, even more so if he only pays it in part.
\end{abstract}

Rousseau

\section{Introduction}

In contemporary democratic societies no one is more circumscribed by authority and more dominated by authority figures than the child. Children's hours of waking and sleeping, of working and playing, their eating and drinking, where they go, who they consort with, their amusements and entertainments, what they know, believe, learn, and fear, are all determined by adults, often against the express wishes of the child. Adults who complain that they are being "treated like children" are identifying precisely this aspect of the quotidian experience of the child: absence of liberty, powerlessness, not being taken seriously as a significant individual. (Lodge and Lynch, 2000; Flanagan, 1987) The central problem of childhood is children's perceived and real lack of power reinforced by the absence of adequate programmes of political experience and formation in mainstream schooling.

\section{Parents, Folklore, and Religion}

The child's earliest formative experience of parental power is of omniscient, omnipotent, dominant, unquestionable authorities. The models of power relations to which children are subsequently exposed reinforce this experience.

Many of our most-repeated stories for children begin: "Once upon a time there was ..." and go on to describe, and endorse, a hierarchical polity in which a king, queen, lord, prince, or princess rules over a realm in which the subjects are dependent on the ruler's perception of regal duties or obligations, rather than on the strength of 
their own rights. For in such accounts the latter are subjects, not citizens. A central message of such stories is that there is a class of people, who are, by the colour of their blood (blue), their heredity (noble), the natural refinement of their dispositions (kind and just), the inherited acuity of their moral perceptions ("as good as she was beautiful"), or even the sensitivity of their skin (peas twenty mattresses down) destined to rule over subjects who are expected to be submissive, deferential, and obedient. ${ }^{1}$

The ideological formation promoted by these stories is powerfully reinforced by the accounts we give of the spiritual world as a Transcendental Monarchy supported by an angelic hierarchy in close instrumental relationship (as messengers, defenders, and praise-givers). This Angelic Ascendancy ${ }^{2}$ is closer to, and more in harmony with, Divinity than is humankind with its dulled intellect, its predisposition to evil, and its suspect wilfulness.

Such models of power relations contradict the democratic structures and procedures that we espouse in our social, political, and educational rhetoric; their main message is that the appropriate response to power is subordination and pleading supplication, not equality and rightful justice. These accounts are not only inadequate to prepare children for life in a democracy, but also they are counter-productive: they portray and endorse a model of power relations which is contrary to that espoused by our democratic societies. Assemblies of the people cannot be built on the foundations of palaces.

Modern social or liberal democracies reflect a shift in the emphasis of power from the duties of subjects to the rights of citizens. The definitive viewpoint is no longer that of the sovereign but that of the individual. The relationship between rulers and ruled is defined in terms of the rights of citizens who play an active part in deciding how and by whom they will be ruled (Bobbio, 1996, p. ix): people are no longer dependent subjects.

\section{The School}

We might reasonably expect public schools to be the primary instrument of socialisation into the values and procedures of democratic society. The school is where the transition is made from the protected life of the cherished individual child in the home to the impersonal life of the autonomous, competent adult in an open society. ${ }^{3}$ How individual children experience that transition must have deep and far-reaching consequences for the regulation of communal life.

Daily experience of life in school powerfully affects children's expectations of how life in a community should be lived. Schools are not, themselves, democratic: those over whom the power is exercised do not choose those in power, nor are they directly answerable to them. Early absolutist paradigms of power relations referred to above are reinforced by the authority structures which children experience throughout their lives in school: for school is experienced by pupils as an autocracy presided over by designated, non-elected officials, themselves answerable to authorities who are, in turn, largely undemocratic, and certainly proof against any challenge by those most directly affected, the pupils. The free consent of the governed does not feature: the source, justification and transferral of power is largely invisible to the governed. It might as well be miraculous.

Even in schools where there is provision for pupils to participate in rule formation and implementation, this is often not recognition of a right but a "grace and 
favour" concession, which can be withdrawn if the consequences of pupil participation are unacceptable to those in authority (Jeffs, 1986; Smeyers, 1995). ${ }^{4}$

According to one commentator (Williams, 1998, p. 37), "education which enhances the capacity for considered choice is at odds with the culture of communities whose way of life emphasises the following of tradition and in which obedience to authority autocratically exercised is highly valued". The communities which best typify this description of autocratic control are schools. Schools do not emphasise or promote individual autonomy except, perhaps, in relation to matters which are of purely individual concern such as the selection of subjects to be pursued in a course of study. On the contrary, schools, which emphasise individual and collective autonomy in a real rather than a theoretical sense, are rare and controversial. ${ }^{5}$ In general the culture of school sometimes appears to embody a fear of democracy, a concern on the part of teachers and school administrators that meaningful pupil participation will lead, if not to outright anarchy, then at least to an unacceptable dilution of the schools' proper role (Lodge and Lynch, 2000).

The democratic procedures we claim to value, endorse, and promote are in stark contrast to the autocratic schools and classrooms in which our children are prepared for life in democracies. Power as defined and exercised in schools and classrooms reinforces autocratic power-relations already familiar to children through their early familial experience, stories and inherited ideologies. Teachers and school authorities unilaterally (and often arbitrarily) formulate and impose regulatory imperatives. Resultant rules and power structures do not inculcate appropriate understandings of power for children who will be expected, as adults, to participate in a democratic order. Developmental democratic participation requires mechanisms in our schools which give children a growing (developmental) sense of ownership and a substantive role in the formulation and implementation of the structures of organisation and administration (Sarason, 1997). The choice is not between the authoritarianism of repressive school regimes and licence. Democratic formation will begin in the communities of schools which provide structures that recognise and accommodate the growing moral and political awareness of pupils and their developing capacity to order their own affairs individually and collectively.

Cognitivist approaches to political formation, programmes of civic, social, and political education, which might be necessary to inform pupils about political structures and practices, duties and obligations, are insufficient to prepare them for democratic participation. At best such programmes teach principles of democratic procedures as verbal constructs. If knowledge of democracy goes no further than the transmission of information, it is more likely to induce apathy and passivity rather than a determination to play an active role in the life of the community; verbalism is no substitute for participation. Where the culture of the classroom and the schools are non- or even anti-democratic, verbal lessons are mere empty promises, no more relevant to the real lives of the pupils than dead languages. The competence, confidence, and willingness to become involved in political participation at any level must be acquired by practice: appropriate forms of meaningful participation, not just verbal information, must be available to children. ${ }^{6}$

The aim of democratic education is that the emergent adult will have the capacity to assume full participation in democratic society at appropriate levels (national, regional, community, and neighbourhood). 


\section{Children and Rights}

Rights (for children) divide into what may be called "enabling" rights ("rights of nurturance") and "instrumental" rights ("rights of self-determination") (Rogers and Wrightsman, 1978). The distinction corresponds to rights in respect of which the holder is a passive recipient (the infant's right to nutrition, a right of nurturance) and rights in respect of which the holder is an active participant (the adult's right to freedom of speech, a right of self-determination). Instrumental rights are granted to children conditionally. The conditionality reflects two perceptions of the rights (or the children) in question: the rights may be withdrawn subject to certain contingencies (they are not being exercised responsibly, for example) or, since children have developing moral capacities, the rights will be recognised in institutional practices incrementally and subject to supervision and supportive direction.

So schools have two options: first, children (of whatever age) are considered ignorant and incapable of significant voluntary social participation; their political activities must be constrained, and if necessary terminated, so that damage to themselves or to others (in the judgement of the "authorities" who sanction the participation in the first instance) is minimised. The second option recognises children's evolving capacity to participate in the public sphere in a manner congruent with their interests and abilities (Boulding, 1977, p. 40; Gaden, 1990). This alternative requires an intimate context of care in which the individual capacities of children are known and guided. Given appropriate opportunities children can become competent in specific activities and limited engagements before they assume general responsibility for their own affairs. Schools and educational authorities have traditionally chosen the first option, which does not pose any significant threat to the traditional administration of schools. The second option has major implications for the organisation and administration of schools.

\section{Learning by Participation: Scaffolding}

The higher mental functioning and social competence of adulthood has its origins in social life (Minick, 1996, p. 32). Children's thinking, their "self", is shaped by their interactions with others in social settings (Mead, 1962, Part 3) using "psychological tools", such as language (Minick, 1996; Tappan, 1991), which are also pre-determined in the specific cultural community. The adult community gradually shares knowledge and skill with children in congruence with the child's capacity to benefit from the sharing, in order to advance the child's cognitive and social development.

This is not just social; it is also a moral process: the "cognitive, affective and behavioural qualities which are constitutive of the virtuous self cannot be formed and maintained in isolation" (Punzo, 1996, pp. 19-20). The virtuous self needs a community of other individuals "in and through which moral lives are played out". Others, peers as well as adults, continually clarify and expand the child's moral vision and sense of place in the moral and political order. This can only be done through opportunities for political and moral action and understanding which are relevant and proportionate: relevant to children's position as members of a community of learning and proportionate to their growing capacity to function as members of a community. 
The acquisition and exercise of control should be a developmental process. As children grow, towards and through adolescence, they require supportive understanding and the structures necessary for them to practise their developing competencies in relative safety. The objective of the process is autonomy for the adult that the child will become. Change must be gradual: growing autonomy for the child accompanied by a gradual relaxation of adult restraint (Bigelow et al., 1988).

The role of the educative adult is to bring the child from an existing level of competence to a level of competence slightly beyond that: Vygotsky's "zone of proximal development", the distance between what a child can do with and without help (Daniels, 1996). The zone of proximal development refers to a situation in which children are led beyond their current level of functioning (Minick, 1996, p. 43). The adult supports connections between the child's current competences and the new skills, which are required in order to play her full role in the community. This happens most frequently through an interactive process of sympathetic adult intervention, which reinforces, encourages and (re)directs the child's efforts. The central regulatory concept is competence rather than chronological age or social status. Adults provide supportive contexts, which enable children to develop the skills, which are needed to participate in the culture.

Such a developmental trajectory ought to show gradual but significant change in the competence of the individual over time. In the case of literacy, for example, a child moves from a pre- or non-literate state through intermediate stages of literacy to a competence, which is sophisticated enough to engage unaided with verbal texts of some complexity. Along this developmental trajectory we would expect to see a continuing developmental growth in competence and independence: unless they have been taught more basic mathematics sixteen-year-olds are not expected to solve quadratic equations.

Developmental necessity is recognised in some curricular areas but not always in relation to political development. As in mathematics and reading, political competence must be nurtured through appropriate developmental programmes of theory and practice, which allow the child to test her competence in real situations. Schools must model the structures of participative democracy. This does not mean that the school must be, root and branch, a participative democracy itself but that the exercise of power in the school should not appear arbitrary or random at any level.

If schools are to promote democratic formation they should accord their pupils the right and responsibility to participate in forms of self-determination and selfgovernment appropriate to their age and capacity. Those who inhabit classrooms should feel that they would be governed by rules and procedures which they have helped to formulate and towards which they feel some measure of ownership. The long-term educative goal is not only the immediate formulation of rules and the proper maintenance of order, but learning the complexities of power in a group setting.

\section{Teachers' Task: The Educational Virtues}

But schools must avoid the "disorder and arrogance", which can "threaten the very enterprise of education within schools" (Gutmann, 1987, p. 90). The enterprise of education and the promotion of "participatory virtues" are contingent on the maintenance of the "disciplinary virtues" (imparting knowledge, instilling emotional 
and intellectual virtues), which are at the core of teachers' professional obligations. Democratic participation in schools is necessarily constrained by teachers' professional obligation to teach the disciplinary virtues as well as to promote the participatory ones. This does not deny the democratic ideal. It is not being argued here that schools are, can be, or should be fully functioning democracies. Children are in schools to learn participative democracy through controlled, supervised engagement. A set of balances must be contrived between the pupils' coerced attendance and their freedom to participate, between the demands of equality and freedom on the one hand and the professional obligations of teachers on the other, between the pupils' right to take, and act on, their own decisions and the responsibility of the school for their health, safety, and welfare.

\section{Authority}

Parental sovereignty (and the conferred authority of schools) is morally justified by the dependent status of children and by the moral obligations to protect and nurture which the parents (and the schools as their agents) undertake. Adult sovereignty over children has two objectives: the short-range objective of maintaining order in the family or school (that is, the stability necessary to accomplish the purposes of the family or school) and the long-range objective (to which the former is subordinate) of producing "a self-determining person from a dependent child" (Baumrind, 1978, p. 193). The twin aims of order and emancipation are in constant tension and carers must strike a balance between them. The control will be predominantly either authoritarian or authoritative (Baumrind, 1978, p. 187; Coleman, 1997, p. 46). Authoritarian control places arbitrary limits on the developing child's autonomous strivings, arbitrary because they are static and unrelated either to the child's actual competencies and needs or to the requirements of family living (Baumrind, 1978, p. 187).

Authoritative control will make children feel emotionally secure and attached to society at the same time as they learn practical coping skills (survival skills) and the values necessary to maintain their identity and integrity within the prevailing social order, even if this means challenging the prevailing social order. Authoritative control is positively related to social independence: interventions are firm but not restrictive, children are left with significant opportunities, appropriate to their perceived competence, to make their own decisions, and reasons are given for adult commands. Adults' supervision is balanced against the child's growing capacity to make informed decisions. The function of the authoritative adult is not to prevent children from making mistakes but to protect them from the worst consequences of their mistakes and to structure and encourage a critical and reflective response (Margulies, 1996, p. 1485). In short, this form of control acknowledges and promotes a developmental growth in human autonomy.

\section{Duties and Obligations}

"Taking rights seriously" means that as well as taking our own rights and the rights of others seriously we accept the concomitant responsibilities to the community, which recognises and supports the rights which we claim for ourselves and others. Rights 
must be balanced by the notion of service and obligation to the community which acknowledges and sustains them. Children need to learn that, as well as having rights, they have responsibilities, which go along with these rights whether the rights are welfare rights or freedom rights. ${ }^{7}$ In the first place, the emerging adult has an obligation to respect the rights of others and to intervene actively when they can to protect and promote those rights. This is no less than they come to expect in relation to their own rights. Secondly, they must learn that rights (rights of freedom, instrumental rights) must be exercised responsibly: freedom is not licence. This responsibility is owed to the community and to the individuals who sustain these rights. Thirdly, they must learn that the rights they posses come to them at some cost to others. This is especially true of welfare rights (rights of nurturance) but is also true of freedom rights where the cost to others is their acceptance of limitations on their own freedom.

\section{Conclusion}

The need for rules is not the central issue: all social arrangements require rules. It is the way in which the rules are made and enforced that is most important. What is needed in schools is not simulated democracy, which leaves the traditional authority structures unchallenged (Hart, 1992, p. 43) but participation appropriate to the developmental status of the pupils and recognition by authoritative adults of their capacity to participate responsibly. Children become responsible political agents by practising real political responsibility proportionate to their interests and capacity.

\section{Notes}

1 The images of political power-relations embodied in fairy-tales may have significant psychological utility in resolving parent/child relationships (as illustrated by Greek dramatists as well as argued by Bruno Bettelheim and other neo-Freudians, for example).

2 Aquinas identifies nine orders in the hierarchy: Seraphim, Cherubim, Thrones, Dominations, Virtues, Powers, Principalities, Archangels, and Angels. See http://www.newadvent. org/cathen $/ 01476 \mathrm{~d}$.htm. The point is not that these accounts are true, or even that they are believed, but that they are presented as a model of power relations.

3 Not "open" in the Popperian sense but merely in the sense that the protection of the individual afforded by parental home and school is no longer there.

4 Government of Ireland, Education Act, 1998, Section 27 (5): "The rules for the establishment of a student council shall be drawn up by the board, in accordance with such guidelines as may be issued by the Minister from time to time, and such rules may provide for the election of members and the dissolution of a student council."

5 Schools such as Neill's "Summerhill", Korczak's "Children's Home", Lane's "Little Commonwealth", Flanagan's "Boys Town".

6 It is not irrelevant to invoke Aristotle's dual objective for civic education: the capacity to be ruled and the capacity to rule in one's turn (Aristotle, 1992, Book VII, xiv).

7 Respectively the "enabling" rights ("rights of nurturance") and "instrumental" rights ("rights of self-determination") referred to above. 


\section{Chapter 20}

\section{When the Best Maps Cannot Guide Us: Exploring and Understanding Teacher Vulnerability}

\section{Susan Lasky}

Vulnerability is one of the most fundamental of all human experiences. We hide from it. Flirt with it. Deny that we feel it. And sometimes, feel safe enough to surrender into the opening that allows for deep and sustaining relationships. Being vulnerable, in the sense of being open, is necessary for falling is love, learning, and developing relationships. Yet people can also experience a very different kind of vulnerability when feeling trapped, powerless, or betrayed.

Although vulnerability has been researched in other disciplines, such as psychology, educational researchers have given it little attention (Noam and Fischer, 1996). What vulnerability means to teachers, and how they experience it in their professional lives is largely unknown. In this paper I offer a reflective discussion of how I developed a theory of vulnerability for my dissertation research, and why I chose the particular methods that facilitate understanding it. This is also a story in which the boundaries between the personal and the professional are blurred, in which my own experiences of vulnerability during a critical event in my life informed and enriched how I conceptualised teacher vulnerability.

\section{Starting the Journey}

Several years ago, I decided that my dissertation research would be a study of teacher professional vulnerability in a context of large-scale government-mandated secondary school reform. At this time and over the following several months, I was able to identify that the study of teacher vulnerability was a relatively new area of research, still very much in its formative stages. While I was conducting this part of my work, I saw vulnerability only as an empirical construct to be clarified and operationalised. It was something removed from my personal experience. Although I knew I could not hold an unbiased idea of what it was, I was trying to remain "professional". And although 
there was something missing, I could not identify what it was, other than to say that the theorising by Kelchtermans (1996), and others seemed limited. I knew there was more I wanted to explore, but I did not know what it was.

In trying to understand the term, I went back to its etymological roots. The word vulnerable comes from the Latin vulnerare "to wound". It is defined as a state of being open, or susceptible to injury or attack. This helped, but still did not assuage my frustration with the limited conceptualisations of vulnerability I was reading in the scant empirical literature.

\section{Unexpected Turns}

In January 2000 , I found out that my father had very advanced oesophageal cancer. Dad and I decided that he would stay at home, with the help of the Hospice program, with me as his primary caretaker. From that day on my relationship with vulnerability changed. It was no longer an abstract academic concept to be studied, but rather it was something I experienced fully, deeply, and often uncomfortably in many different ways, in many different situations. Most pertinent to this discussion are the deepening of relationships, and the exponential learning that were at the heart of my experiences over the next several months.

The learning I underwent during those days was not book learning, but rather was from some of the most fundamental life lessons. Dad was going to die soon as the cancer ravaged his body. I felt directly what it was like to know that there was absolutely nothing I could do to change the final outcome. Yet there were things I could do on a daily basis that made a significant difference to my dad and to me. Interdependence took on new meanings as I felt the deepening of relationship that can occur when a person opens herself up to the warmth and compassion of those who offer help, who go the extra mile, who can be emotionally and physically present during times of extreme stress and change, and also the deepening of relationship that can occur when one knows, without a shadow of doubt, that time with a loved one, a parent is limited.

Dad died on 12 July 2000. I came home at the beginning of August, and slowly eased myself back into my studies by taking work down to Lake Ontario. Reading, thinking, dozing, and dreaming in the warm Ontario late summer sun began to bring me back into my own skin. I made the first steps towards making sense of the last few months with my dad while gazing languidly at the shimmering water, being lulled by the sounds of rhythmic lapping waves, steady breezes, and the feel of the balmy air as it skimmed across my skin. A key element in this process was taking my own experiences of vulnerability, and applying them to my intellectual struggles. This integration of personal and professional, experiential and academic was essential to recognising the multifaceted nature of vulnerability, and its importance as a fundamental condition for learning, developing relationships, and growing emotionally and intellectually. I could finally begin naming what I could not articulate in my prior theorising.

As I reflected on that period of my life, and on my experiences with teachers, I could see how teachers involved in professional development and in many other aspects of their teaching, had experienced vulnerability, yet it wasn't necessarily negative. I saw how teachers had leaned on each other when learning new skills and while undergoing changes. I began to ponder the relationship between trust, or the lack there of, and opening one's self to peer critique, taking the risk to "lose control" 
in one's classroom while trying new pedagogy, or new forms of classroom management. I also began to think about the kinds of emotional and material support that might facilitate the risk taking inherent in learning and while undergoing change. I spent as much time as possible discussing my evolving understanding of vulnerability with friends and colleagues. The more I engaged in these conversations, the more clearly I could articulate vulnerability as a multifaceted experience. It was also during these discussions that one of my mentors asked if I considered vulnerability to be an existential human experience, or whether I saw it as an empirical construct. In answering the question, I replied that I saw it as both.

One of the key challenges then became how to take a core human experience, and describe it as an empirical construct. Two primary questions arose: how could I theorise the experience of teacher professional vulnerability as broadly as possible to capture the breadth and depth of their experiences; and what research methods would facilitate understanding vulnerability as complex and multifaceted? Accomplishing these two tasks took months and months of thinking, revisiting literature, writing, and talking.

\section{No Map to Guide Me: Developing the Theory}

Generating my research questions, developing the theory, and designing a conceptual framework were iterative and inseparable processes of clarification, and refinement. I felt frustration with having no road map to guide me. I also felt overwhelmed when I realised that there was no one single way to achieve my goals. There were multiple ways to theorise vulnerability. There were numerous conceptual frameworks that I developed; each one led to different ways of understanding vulnerability. Each had its own inherent value. The tension between constraining the work and creating necessary boundaries was palpable. I came back to one question - what are the core elements of vulnerability?

I came to theorising vulnerability as a multidimensional, multifaceted emotional experience that individuals can feel in an array of contexts. It is a fluid state of being that can be influenced by the way people perceive their present situation as it interacts with their identity, beliefs, values, and sense of competence. It can be theorised as a fluctuating state of mind, with critical incidents acting as triggers to intensify or in other ways change a person's existing state of vulnerability.

It can be an experience of openness and trust, which is necessary for love, experiencing compassion, learning, and relationship building. In these situations, people willingly open themselves to the possibility of embarrassment, loss, or emotional pain because they believe that they, another individual, or a situation will benefit from this openness. A person being open facilitates learning, trust building, and collaboration. In short, a person feels safe in his or her environment to take the risk of losing face and experiencing loss or pain.

Vulnerability can also develop due to feelings of powerlessness, betrayal, or defencelessness in situations of high anxiety or fear. In these situations, people may have no direct control, believe they have no direct control over factors that affect their immediate context, or feel they are being "forced" to act in ways that are inconsistent with their core beliefs and values. Rather than willingly opening themselves up emotionally or physically in such situations, they may in fact withdraw, or close themselves off in a defensive or protective stance. A person being more closed inhibits learning, trust 
building, and collaboration; and may feel political inefficacy, fear, anger, or defensiveness. People do not feel safe in their environment and may take no risks or may take risks that could be harmful to themselves or others.

\section{More Uncharted Territory - Methodological Decisions}

\section{Developing the interview protocols}

I decided a mixed-method case-study approach would best achieve understanding ways the presence or absence of socio-emotional and material support might influence teacher professional vulnerability. Data collection includes distributing a survey to all of the teachers in my research site, interviewing teachers and principals, conducting school observations, and analysing school and ministry documents. I'm thinking that the study will be two staged, first understanding how teachers experience vulnerability, and what it means to them, and then exploring how the current context of large-scale change influences their experiences of professional vulnerability. In this paper I shall discuss only the development of the teacher interview protocol.

Designing the teacher and principal interview protocols was a slow and painstaking process. Several iterations were designed, piloted, and ultimately discarded. One of the primary decisions was whether I should talk directly with teachers about what vulnerability means to them, how they experience it, and how it affects their work. Prior work by Kelchtermans and others was inferential. In conducting analyses of teacher biographies, Kelchtermans found evidence from teachers' stories showing how they had experienced loss of valued work conditions, or had felt unsupported. He had not, however, talked directly with teachers about the ways they experienced vulnerability. Other researchers have discussed the relationship between trust and vulnerability (Toole, 2000; Tschannen-Moran and Hoy, 1998), without defining vulnerability. In short, all published research I have found has relied on inference.

I wanted to think and talk along with teachers to understand the different dimensions of their vulnerability. I also needed a way for teachers to talk about their experiences of vulnerability outside of the present reform context. This is especially important in Ontario where the political tone of government reform is negative, and will very likely affect the ways teachers describe experiencing professional vulnerability. I explored different interviewing approaches, and consistently came back to narrative inquiry, though I ultimately decided not to use a traditional narrative approach.

The study of narratives is the study of the ways humans experience the world (Connelly and Clandinin, 1990), yet I did not necessarily want full biographies, or personal histories. To be consistent with my theorising of vulnerability - that critical events or incidents in one's life can change one's existing state of vulnerability, I needed a way to capture stories of these events. I finally decided on critical event and critical incident methodology for three primary reasons: lack of time to establish trust with teachers before data collection begins; to capture the depth and complexity of situations in which teachers experience vulnerability; and to encourage teachers to talk outside of the present reform context. I drew from Tripp (1993), Woods (1993a, 1993b) and Sykes et al. (1985) to identify how critical incident and critical event methods will be used in this research.

By incorporating both critical incident and critical event methodology into the teacher interviews, I can examine both the flash point and more enduring events in which teachers experience vulnerability. I felt I could capture the key elements of 
teachers' vulnerability by developing an iterative, semi-structured interview protocol in which I probe for things like: what kinds of material and socio-emotional support are present or absent; what is teachers' primary purpose in teaching, can they achieve it in the present reform context; how do teachers develop trusting relationships; what is the role of trust or betrayal of trust; and what power dynamics are present. An integral aspect of the interviews is a reflective component to facilitate thinking along with teachers, to verify the trustworthiness (Angelides, 2001) and validity (Woods, 1993a) of the critical incidents and events, and to ascertain (a) whether teacher views have been represented correctly, and (b) whether I as the researcher have captured the event as they knew it (Woods, 1993a).

The first teacher interview will focus on what risk taking means to teachers, what vulnerability means to them, and an initial discussion of some ways they experience it in their day-to-day work lives. Before the second interview, teachers will be provided with the transcripts from the first interview. They will be asked to discuss if there is anything they would like to amend, or extend, and whether their interview responses begin to capture their experiences of vulnerability. We will go deeper with the themes raised during the first interview, with a focus on support, and conditions that facilitate trust building. The third interview will include the reflective component, questions that extend the prior two interviews will be decided upon based on what has or has not been previously discussed pertaining to teachers' experiences of vulnerability during times of large-scale government-mandated reform. The fourth interview will be reflective, primarily making sure that I have represented the third interview accurately.

\section{The pilot interviews}

While developing the interview questions, I felt the weight of my responsibility as a researcher, probing into sensitive areas of people's experiences. I wondered what right I had to go into teachers' vulnerabilities just for my own research purposes. I struggled with several ethical dilemmas. Several of my mentors and peers encouraged me, and reinforced in me the belief that this was important research; they also reinforced that I had to be very clear what I was looking for. They asked pointed questions: why would teachers want to talk with me about their vulnerabilities; what if they don't talk about it; are you doing research on subjects, or research with people?

I began to feel new kinds of vulnerability as I questioned my own purposes behind conducting this research. One of the key tensions I felt was the realisation that discussing sensitive issues with research participants necessitated trust. It necessitated time to develop relationships. It also necessitated a degree of emotional understanding (Denzin, 1984), and personal involvement with practitioners. Other researchers had also stressed the importance of care and trust (Schultz et al., 1997) because both the researcher and participant live the shared story in an inquiry relationship (Connelly and Clandinin, 1990). Madeline Grumet (1987) stated that:

telling a story requires giving one's self away, then we are obligated to devise a method of receiving stories that mediates the space between the self that tells, the self that is told, and the self that listens: A method that returns the story to the teller that is both hers, and not hers, that contains herself in good company. (p. 323)

When conducting my pilot interviews, what had been academic or theoretical considerations were actually real. The people I talked with could sense right away if I 
was being genuine, nervous, or distant as we moved through the interview. Seemingly little nonverbal cues, like holding a gaze too long or looking away too quickly, pausing too long in forming a probe, or leaning too far into a participant's personal space could stop him or her mid-thought.

I told my participants frankly that teacher professional vulnerability is not something that has been given much research attention, and that I needed them to talk with me about how they experienced it and what it meant to them. I let them know that I would also need them to think along with me by reviewing their transcripts in order to ascertain whether we had captured their words and their experiences accurately. We eased into the discussion of vulnerability by first talking about risk taking. Sometimes there were long pauses as research participants thought about how to frame their words. These people were very willing to disclose both painful and difficult professional stories that were rich and textured. I realised that even though the "data" were strictly from each person's professional life, these were still very personal stories.

I found that in telling and listening to the stories of the critical incidents and events in teachers' professional lives, both the teller and the listener became vulnerable in the sense that each had opened him or herself to the other. As the listener, I felt responsible for relating their stories with fidelity. The storytellers, likewise, trusted me as the listener not to use their words against them. With each person, trust was negotiated in subtle and often intangible ways. There was no road map to guide us through the path that led to trust or to silence.

\section{Discussion}

In choosing to study teacher professional vulnerability, I moved into relatively uncharted research territory. There were no hard and fast rules to follow, nor were there clear guidelines concerning how best to accomplish the task of bringing conceptual clarity refinement to the construct. I felt that I needed the flexibility to renegotiate some of the more traditionally held rules of empirical research in order to capture the depth and complexity of teacher vulnerability.

There are times when conducting research that the boundaries between the personal and professional become blurred. I think that when we choose to conduct research into sensitive topics, or when we go into people's emotional lives, we have a greater responsibility to open ourselves to the phenomenon we are studying. This is not to negate the importance of rigour, or reliability of the data. However contradictory it may seem, it may actually increase the likelihood of developing theory, and methods than can more fully explore and explain the depth of the participants' experiences. We also have a greater responsibility to "care for" those who participate with us in such endeavours. Some research methods are more conducive to renegotiating traditional boundaries between the personal and the professional, and between researcher and participant. A revised form of collaborative narrative research worked for this study because it actually reconsiders the social relations between participants, the place of disclosure for the researcher, and the place that selectivity and silence hold for the texts collected (Denzin, 1984). It allowed me the freedom and the scaffolding to go as deeply into a discussion of vulnerability with each person as we were able to negotiate in the time we had together. 


\section{Section E}

\section{The Theory and Practice of Educational}

\section{Research}

The chapter, "Teacher and Student Identities as Situated Coginitions", combines the research conducted independently by the authors, Lauriala and Kukkonen, in order to discern underlying commonalities other than the focus theme of identity/self-concept. One addresses teachers' views, the other those of pupils through a socio-cognitive perspective. This perspective, along with theories of self-conception, is described briefly at the beginning of the chapter to set the context. The comparison of the two studies highlights clearly: the reciprocal nature of the teachers' and students' influence; the role of memory of similar situations and of stereotyping; and the interplay between ideal and actual self. This leads into a discussion of how this kind of exercise might inform future research. This chapter, in common with the one which follows, exemplifies the role that ISATT members play in developing reflection on the research process and new research ideas, in addition to presenting bounded research results derived from practical issues arising in education.

In the Chapter 22, Oost continues this theme by addressing the title: "On a Pedagogy of Research Problems". He gives his attention to the definition of relevant research problems, an important pre-condition for a satisfactory research process, through exploring intervention programmes for research students in search of an "expert theory". Finding none, he designed an on-line programme for his own students based on a model drawn from a conceptual analysis of theoretical insights from a range of disciplines. He promises a future paper that will provide a more detailed evaluation of the process and results than he is able to present at this stage, in so doing illustrating the role of ISATT as a forum for ongoing research.

The following chapter by Rönnström: "Shared Basic Democratic Values by Means of Education? A Deweyan Perspective on Some Democratic Illusions and Necessities", first describes a politically initiated project implemented in Sweden with the intention of promulgating democratic values. He then examines this enterprise for its relevance to a pluralistic society through the perspective of Dewey's ideas. An outline of the fundaments of Dewey's propositions precedes the analysis, which provides a range of thought-provoking theoretical notions about the role, remit and process of moral education. His analysis indicates that more reflective practice, embodied within and relevant to context, is required within education rather than adherence to a superficial model imposed from outside the system. This echoes several of the themes expressed in earlier chapters in this book and draws them together to indicate the pervasiveness of this concern amongst researching practitioners.

Erkkilä and Mäkelä address a methodological approach: the use of narrative and biographical material, exemplified and recommended in earlier chapters, but from the rarely addressed perspective of the experiences of those conducting the research. In this chapter: "Human Dimensions in Biographical Interviews", examples are provided 
of the difficulties associated with this form of research that are seldom articulated and acknowledged in normal research presentation modes. They are perhaps not always confronted and then addressed by researchers as they conform to the rubric of the method. Thus this chapter encourages us further to analyse and reflect critically on our own research practice, in addition to the practice of our participants - emphasising another theme in the remit of ISATT contributors.

The final chapter in this section and in the book: "Teachers Becoming Researchers: Reflections on Professional Development" by Hayes, weaves several of the recurrent threads of the book together by reflecting on the impact of research practice on trainee teachers and their university tutors. From the learner teachers we are presented, inter alia, with these stimulating thoughts: one says, "Research is education for teachers", and another declares that engagement in research "makes you want to challenge more". These views are mirrored by the responses of the university staff, who find themselves, as a result of reflecting on the course, learning themselves by challenging the stereotypes imposed on their roles and function in the teacher education process. Thus this chapter exemplifies the role and function of our work through ISATT: to explore and challenge our own aspirations and purposes as teacher educators, through our teaching practice and through our research. 


\section{Chapter 21}

\section{Teacher and Student Identities as Situated Cognitions}

\section{Anneli Lauriala and Maria Kukkonen}

This chapter addresses the development and shifts in teacher and pupil identities in different classroom contexts based on the situated cognition approach. Subsequently, contextual and situational features are assumed to influence the construction, actualisation and restructuring of teacher and pupil identities. More generally, social context has been found to have a rather decisive influence on a person's conceptions of his/her self, becoming activated at a given time. According to Banaji and Prentice (1994, p. 324), "how one thinks about oneself at any particular time is strongly influenced by the immediate social context".

The chapter is also based on two originally independent studies of the authors, and on a search for possible common underlying constructs or theoretical explanations of the findings of the studies. The first study focused on the development of teacher's professional identity in a different classroom context (Lauriala, 1997), the other on pupils' academic self-concept in different subject contexts, involving different teacher personalities (Kukkonen, 2000).

\section{Theoretical Guidelines}

\section{Socio-cognitive viewpoint}

Socio-cognitive research, which combines multi-layered elements of personal psychology and social psychology, emphasises cognitions in the context of social interaction and regulation of an individual's action. Cognitions are viewed as "situated", that is, as an inseparable part of the activity, context, and culture in which they are used and generated (cf. Lauriala, 1997, p. 30). Social cognition involves cognitive processes as inherently related to emotion, social relations, and social structure (cf. Andersen et al., 1997, pp. 254-5; Barone et al., 1997, pp. 155-83). Central is the dualistic interaction between personality and social context, in which an individual's self-cognitions are seen as being in a continuous interaction with his/her cognitions of the other participants.

At the heart of socio-cognitive processes lies social perception (cf. e.g. Brehm et al., 1999, p. 125), which involves both personal and contextual factors. How we perceive others is largely related to how we see ourselves. Self-representations are also shown to be linked in the memory system to the representations of significant 
others (Andersen et al., 1997). People interpret their experiences through the self. For instance, a student's self-conception may significantly influence what kinds of scripts are activated in him in each learning situation. In addition, besides oneself and others, individuals have representations of the expected interaction and its nature. We can thus speak of some kind of interaction schemas.

\section{Different Aspects of Self}

The concepts of identity and self-concept can be used as synonyms. When researching teachers, it has become more common to speak about professional identity (e.g. Nias, 1984) while when researching students the interest has more often focused on academic self-concept (e.g. Marsh, 1990). Identity, as well as self-concept can be regarded simultaneously as both stable and changing (e.g. Demo, 1992; Strauman, 1996). Certain core self-conceptions may be chronically active, bringing stability to one's identity, while less central self-conceptions are less chronically accessible, varying across situations. Shifts in identity can be understood both as situational variations and as a more long-lasting reconstruction of identity, associated especially with post-modern cultural perceptions (Banaji and Prentice, 1994, pp. 324-5).

According to Strauman (1996), the most stable aspects of self are mainly related to one's ideal or "ought" self. Ideal self refers to the domain of self-representing one's own and significant others' hopes, wishes or aspirations for him. Ought self refers to the domain of self-representing one's own and significant others' sense of one's duties, obligations or responsibilities. Compared with ideal and ought self, one's actual self - the domain of self-representing the attributes s/he and the significant others believe s/he actually possesses - is seen to be more variable across time and situations (ibid., see also Higgins, 1996). Especially, when describing situational flexibility, the term working self-concept, analogically with working memory, has been used. A working self-concept at any moment includes only a part of all the selfconceptions a person has. It refers to a subset of stored self-knowledge, which is accessible and active in working memory at a given time and in a given context (Andersen et al., 1997, p. 236). It may be seen to be formed by central self-representations linked to the circumstances of a particular situation (Villa and Calvete, 2001). These can also be related to a person's former memory-based experiences, including cultural typifications (cf. Hargreaves, 1977).

The following conceptual model (see Figure 21.1) is based on various theories of self-concept (cf. Higgins, 1996; Strauman, 1996). It will be used here as a heuristic tool for both studying and developing teachers' and pupils' self-concepts.

\section{Research Questions}

The research is based on a cross-analysis of two different studies. Our aim is to outline possible common phenomena and underlying principles in the situational construction of teacher and student identities. Thus the discussion here centres on the question: What communal features and underlying theoretical principles can be found when looking at the situational and reciprocal construction of teachers' and students' identities? 


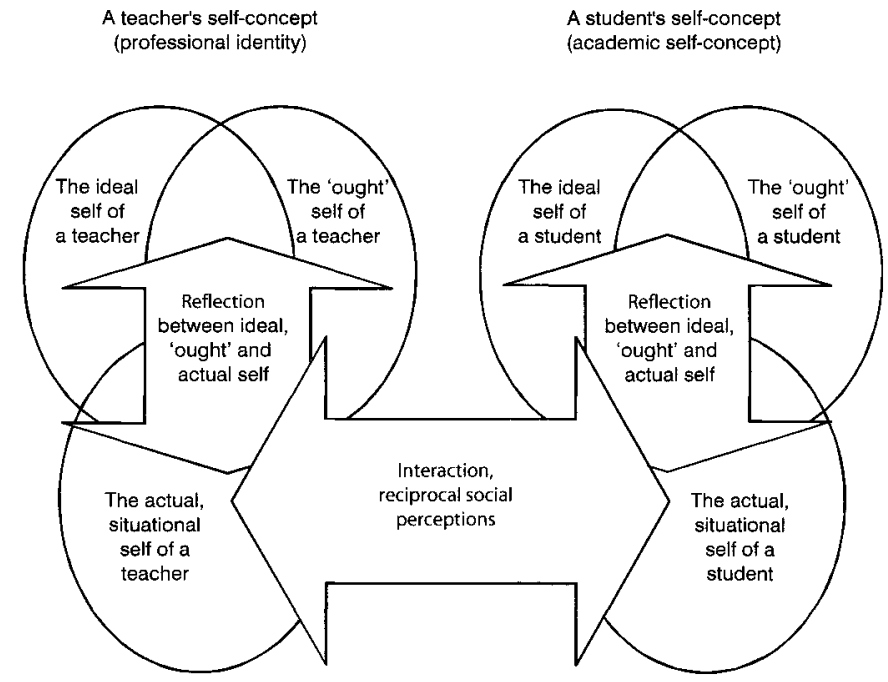

Figure 21.1 The dimensions and dynamics of self-conception formation of teachers and students

\section{Methods}

\section{Methodological background}

When studying the situational formation of teachers' and pupils' identities in the interaction situations of the school, symbolic interactionism is a viable methodological choice, due to its way of defining self as involving two components, the "I" and "Me", and the way it perceives social interaction as a main constructor of the self (Mead, 1973; see also e.g. Harter, 1996).

Symbolic interactionism suggests using research methods in which identities are looked at from the viewpoint of reciprocal interaction processes. Thus, a teacher's or a student's view of him/herself is not seen as separate from the everyday interaction situations at school, but as linked to them and constructed through them, and identities are understood as dynamic processes (ibid.).

In symbolic interactionism, the emphasis is on the meaning of situations. Woods (1992, p. 345) states that "people do not act toward social class or systems; they act toward situations" as they interpret them. As researchers we aimed at looking at the world from the standpoint of the researched and tried to understand how they defined the situations, seeing the subjects in varying situations and moods. For this purpose, repeated and longitudinal data-gathering methods were used to capture the constantly varying nature of interaction. Further, in both studies the researchers acquainted themselves with the cultures of the schools of the subjects (cf. ibid. pp. 348-63).

In symbolic interactionist research, interviewing the persons participating in the situations and participants' telling in general can be regarded as an appropriate mode of inquiry, an approach offered by interpretive interactionism (Denzin, 1992, 1994), and used in both sub-studies. In this study self-theories provided the wide themes within which the data of both studies were analysed and interpreted. 


\section{Data Gathering and Subjects}

\section{Study 1: Development of teacher identities in innovative classrooms}

Subjects of this study consist of: (a) 19 primary school teachers who volunteered to take a one-year in-service course in integrative teaching, involving a three-week practicum in the innovative classrooms carrying out integrative, open education, and (b) 16 student teachers who were doing one of their practica (varying from 2 to 5 weeks) in an open classroom. The practicum classroom contexts were "deviating", involving inquiry-oriented, autonomous approach in learning (Lauriala, 1992, 1995, 1997).

Data gathering was mainly based on individual, repeated interviews, and on narrative inquiry. Interviews involved not directly and only issues pertinent to identity, but teacher cognitions of pupils, learning, teaching and their own role. Interviews were not tightly structured but allowed subjects to freely tell of their experiences gained when doing their teaching practice in the innovative classrooms. Also subjects' written reports and narratives, describing their experiences and development in the classroom, were used as the sources of data.

\section{Study 2: Development of students' identities in different subject contexts}

This study (Kukkonen, 2000) focused on examining the development and dynamics of students' self-concepts in different subject contexts and on describing and understanding relations between students' self-concepts and their expectations for, and experiences of, teacher action. The data were gathered by interviewing four students (named Jaakko, Elina, Tiina and Antti) during a six-week period, using a stimulated recall method based on diary texts. The participants were chosen from 15-year-old students $(\mathrm{N}=$ 101) at one upper secondary school in northern Finland. Each student described weekly and lesson by lesson his/her studying in two subjects. The data, concerning in total 35 lessons, were analysed narratively (Polkinghorne, 1991) by constructing lesson-specific narratives on the basis of diary texts and interviews.

\section{Results and Interpretations}

\section{Situational and contextual influences on identity}

According to symbolic interactionism, the definition of situation is an initial reaction of persons in a new situation (Woods, 1980; cf. Backman, 1988, p. 252). The teachers and student teachers in Study 1 described their experiences in innovative classrooms by comparing these with their earlier experiences in traditional classrooms. They expressed great sensitiveness to the new and deviating contextual features, and described these in detail in their practicum reports. The initial reaction of most participants was surprise, and feelings of anxiety, because they didn't know their own place or how to act there, which also meant a threat to their professional identity. One student teacher's report vividly indicates this:

"The first impressions of the class were confusing: the pupils were working unbelievably quietly and independently at their own work."

It was difficult to adjust to the situation because they worked in such a different way, and deviated from the "norm".

"In the beginning, I felt as though I wasn't myself in that class." 
"Everything was so different - you didn't know your place as a teacher, you didn't know how to act there."

The different physical architecture, and different norms and social structures (e.g. power structure, reciprocal roles of a teacher and pupil), i.e. a different pedagogical culture which the participants confronted in the innovative classrooms, induced or even pressured them to use different action strategies which then affected their situational identities. The evolving strategies involved, for instance, "getting close to the child", understanding the individuality in learning, and developing a more childcentred identity, becoming a facilitator of learning instead of the former role of a transmitter.

"In a class in which pupils move freely, in which no one has a fixed place, and in which a shift from one task to another is done without any outward signal, it doesn't occur to anyone to just sit there. One feels pressured to do something - to at least walk around the class and wonder what is happening."

"This classroom was a working community which as an entity is responsible for its success; the teacher is a facilitator of learning, not an all-knowing transmitter of knowledge."

By far the most influential factor was the children, their peaceful, yet active and concentrated way of working and their well-developed social skills. Through acting in these classrooms it seemed that over time there could be seen changes not only in their situational identities, but also in many cases in their more stable identities as well.

"Now I've received a wonderful confirmation that the teacher needn't be any kind of policeman, that he/she needn't be this one who is the boss and gives orders, and so on. But he/she can really be the pupils' fellow worker."

In the Study 2, the subject context could, in some cases, remarkably influence a student's academic self-concept, as the following examples demonstrate. Tiina's narrative on a German lesson emphasised positive self-descriptions:

"I was the only one with my hand up all the time, so the lesson was actually interaction between me and the teacher. I thought it was cool that I was able to attend all the time, for my studying always is a bit this and that. I was eager and active; I felt I was a success. I felt I was excelling myself that I really could do something and do it so well. The lesson left me with a good impression of studying German, of the teacher and of myself for a long time, and I started directly to look forward to the next German lesson. I was satisfied with my input and in good moods."

However, Tiina's narrative on a religion lesson was almost contradictory:

"The atmosphere was as usual, the teacher talked and tried to make us interested. We were quite somewhere else, it was awfully noisy and boring, and you just were there, thought about everything else and doodled. I was absent-minded ... my thoughts whirled around my personal matters and problems. I was careless, vegetating and apathetic, and I was probably not listening to the teacher at all. I had not read the chapters we had agreed, and I wasn't a bit interested."

Tiina's self-descriptions during these lessons seemed to reflect her attitudes towards these two subjects, and also different teacher personalities and different classroom mates. In their descriptions, students seemed to put a great emphasis on the climate and teachers' dispositions and attitudes, i.e. the socio-affective context, which influenced their goals and motivational orientations in each subject context, and with very different consequences depending on how they defined or experienced these contexts. 
The results of both studies indicate that situational demands and opportunities influence the course of identity formation or negotiation in the situation by prohibiting, requiring or allowing a particular kind of action (cf. Backman, 1988, p. 252; Woods, 1979), and by the kinds of relationships the participants engaged in.

\section{Self-cognitions intertwined with other-cognitions}

After becoming aware of the situational cues, expectations, and norms through social perception, the processes of negotiation and bargaining between individual and situational forces are shown to take place. These forces involve one's own views, ideals and goals on the one hand, and the expectations and behaviour of the partners, or significant others, on the other. For a teacher these are typically pupils and vice versa, denoting reciprocity of teacher and pupil identities.

In the interaction situations of the school, it's also typical for both teachers and students to stereotype cognitions of self as well of the other partners. The influences of stereotypes may, however, be diminished if individuals become motivated to metacognitively regulate and control them (cf. Brehm et al., 1999, pp. 141-142). Becoming aware of cultural stereotypes, and being motivated to re-examine them, may also be brought about by critical, discrepant experiences, as was the case with the teachers in Study 1 . The critical new information gained through social perception in innovative classrooms was unexpected and was apt to break the teachers' old habitual or stereotypical definitions of the pupils.

"The pupils' great ability to express themselves made my teaching harder; I had to develop exercises which suited the level of these pupils."

"I've never seen such independence with which these pupils could work."

"If I compare these with other pupils in the traditional school, this is a kind of dream class. We didn't have to keep control, the pupils followed excellently."

The deviating critical experiences led the teachers and students to reconstruct their pupil conceptions, and at the same, their conceptions of a teacher's role, indicating the interdependency of these two perceptions. Perceptions of students as enthusiastic and inquisitive learners challenged the teacher students also to change their role and action, which in turn affected their situational identities and self-esteem.

"Pupils were awfully inquisitive, and you realised that you can't go into this classroom if you haven't found out about things."

"Pupils' enormous willingness to learn has caught me, too."

"My self-trust was strengthened by the way pupils received us."

The interconnection of the self-cognitions and the other-cognitions could also be clearly seen in Study 2. In many narratives, the student's self-cognitions appeared to be connected with his/her perceptions and conceptions of teacher action. It was typical that a student's positive self-view was linked to his/her positive view of teacher action. Similarly, a student's negative self-concept was, in many occasions, related to a negatively tuned opinion of the teacher action. For example, Elina told about one of her Swedish lessons:

"It was just one of those days when my thoughts were flying somewhere quite else and I could not concentrate at all. The lesson could have passed fairly well, but it finally went all wrong at least to me because the teacher behaved in such an annoying way. Maybe I experienced the teacher's action more personally than the others did. At first he went back on his promises, which made the atmosphere quite tense. The teacher's attitude was that he said what to do and was the boss. His actions 
were reflected at once as anxiety in the pupils. My bad mood got even worse. The teacher taught as quickly as possible: we jumped from one thing to another. It made me nervous and irritable. I was studying quite lazily, I could not keep up with the others nor could I remember anything. I was passive, snappy and irritated."

However, Elina's narrative about another Swedish lesson was quite different from the earlier one:

"The atmosphere was remarkably relaxed. Even the teacher was in a 'humorous' mood, somehow friendlier to the pupils and more relaxed, and there was no tension in the air as there would normally be. It felt quite different, everyone was having a better time and the teacher would join in the fun if one of the pupils joked. He was not scorching at a horrible speed either. I tried hard to keep up. I was quite active and I felt confident about putting up my hand as I had done my homework carefully. I thought that the teacher's working methods were improving, and I hoped it would continue."

As for the students' subject-specific perceptions in Study 2, it can be stated that a student's certain perception of a teacher can lead to a certain role taking and behaviour in relation to the teacher. In other words, a perception of a teacher as understanding and friendly leads to a different kind of student role and behaviour than a perception of a teacher as "arrogant" (cf. case of Elina). A student's behaviour can further stimulate a teacher to have expectations of a certain kind of classroom interaction, which orientates the reconstruction of teacher identity (cf. Andersen et al., 1997; see Higgins's concept of the expectant self, 1996, p. 1068), and shapes his/her action, too.

The above extracts from the data of both studies indicate that teachers and pupils are important definers in each other's situational identities, and that these are developed through reciprocal processes. The affective quality of their perception of each other and mutual relationships seem to influence their roles and situational identities, and their learning motivation as well.

\section{Memory-based Experiences Influencing Identity}

Most socio-cognitive models assume that self-knowledge is stored in memory in ways that make possible both continuity and malleability in the self. Because self and significant-other representations are linked in memory, influencing each in bi-directional ways, a person's former experiences of significant other people, as well as cultural beliefs and stereotypes, may influence his/her present self-conceptions, which are also linked to internal interaction schemes, through which an individual interprets interaction and forms scripts about it (cf. Andersen et al., 1997).

In Study 1, the teachers constructed their pupil conceptions on the basis of a long history, starting from their experiences as a pupil, through their formal teacher education, and especially through their former practicum and work experiences. This implies the deep-rootedness of certain typifications of pupils, and the concomitant difficulty in making changes or transforming these. The new deviating classroom situations in Study 1 seemed to make the participants aware of these kinds of stereotyped and culturally dominant, taken for granted views of the pupil (or teacher).

"I've got a new kind of perspective, so that everything doesn't have to go exactly according to a certain pattern, that there can be different kind of perspectives."

In Study 2 it was noticed, especially in the case of Elina, that memories of earlier studying situations with a certain teacher could have serious consequences on 
the student's perception of herself. These influences might also be associated to the teacher in later, new learning situations. Previous experiences were in the mind of the student in a new situation, although she tried to avoid or get rid of them, to be able to construct a more confident self-conception:

"We had a teacher in the lower secondary school who would start yelling that "you're an idiot, where's your brain", and so on if you did not know how to do something ... It kind of left a horror in me, though we now have quite a nice teacher in the same subject. But whenever he asks me something, a mindless resistance takes over me, and I start snapping at him. He (the previous teacher) left me with such a horror - because whenever he asked something, you would readily sink down begging for forgiveness for not knowing ... I always try to think that - come on - this one is not bad, this is quite a different teacher."

The above description by Elina refers to a transference phenomenon, which means that a new teacher is associated with a formerly known teacher, which caused the actualisation of earlier emotional reactions (Hinkley and Andersen, 1996), although the new teacher didn't resemble the former one, albeit through representing the same subject context. This implies that students not only develop a general stereotypical view of teachers, but also more differentiated views, according, for instance, to the subjects they teach.

\section{The Interplay Between Ideal Self and Actual Self}

Interplay between one's ideal and actual identities, and more stable and situational identities, could be detected in both studies. The most stable elements of identity consist of one's own ideals, goals, needs, and deep-seated hopes concerning oneself as a pupil or teacher (see Higgins, 1996; Strauman, 1996). Furthermore, situational experiences may become meaningful in relation to the ideal self, if they allow actualisation of this.

In Study 1, through their discrepant, positive perceptions of the pupils in the open classroom, the teachers started to critically assess their former cognitions and reconstruct them, leading to a shift in their situational and also in more stable identities. Teachers' personal needs and goals were intertwined with their identity formation.

"This class brought forth that the teacher had this kind of peace and quiet to do the work, somehow this tempted me to become such a teacher."

"I want to be that kind of a teacher that gives more freedom to all. It has been such a nice thing to see that there can really exist such a teacher."

Especially the in-service teachers felt that their own goals, needs and deepseated hopes met a possibility in these new situations. Their ideal identity came to match their actual identity, which was felt to be an empowering and energy-giving experience. A mismatch or incongruence between their ideal and actual identities or roles had in fact made them participate in the course in innovative pedagogies (cf. Lauriala, 1992, 1997). Through their situational experiences in the alternative classroom cultures, they were able to restore a balance between ideal and actual self, and achieve an integration of their different self-systems.

"The open education project has greatly contributed that I've gradually started to find out how to employ my own personality in my own work and that I've dared to do this work on the areas that are my strong points." 
In Study 2, too, the interpretation of the situation as to what aspects of it were estimated as significant seemed to depend on the students' ideals. For instance, one female student (Tiina) who desired encouragement and understanding on the part of the teacher gave a lot of attention to any intercourse where such teacher dispositions were present. She also described the effects of these classroom situations on her later action and attitudes towards school, and through these on her general academic selfconcept. In addition, the interplay between the students' ideal academic self and their actual self could be detected in many learning situations. During interview sessions, students told about their experiences and views concerning the tension between one's ultimate goals and the studying reality. A quotation from Antti's interview data may also be seen to involve tension between ought self and actual self (cf. Strauman, 1996):

"It is a little irritating actually. One should start reading for a test but sometimes one is too tired. One should do more reading for the tests. But one can be too tired or busy."

In Tiina's words:

"It would have been better if my thoughts had changed in a more positive direction [during the course]. If I had learnt more myself and ... [i.e. implying ought self] if going to the class and being there had not been so hard. But they haven't changed. I mean it would be nice if they had changed, but ... if there is no fervour in you, then ... there is not really much you can do about it. ... My thoughts keep wandering too much in other things, I don't know why ... However, I think it is sad I cannot concentrate on school [i.e. actual self], as I know the upper secondary school will take three years and it is quite important, anyway, and I should try and take it seriously right from the start [ought self]."

The students' experiences of the congruence, or the balance, between the ideal self and the actual self seemed to be an important factor influencing their emotions, motivation and well-being in school.

\section{Discussion}

In the studies dealt with above, teacher and pupil identities can be seen to be interactional and dynamic cognitions or interpretations, changing, or transient, over time and situations. These studies indicate that to understand identity formation, teacher and pupil roles should be viewed as interdependent counter-roles affecting each other. The findings also indicate that emotional and affective elements are essentially involved in the construction of teacher and student identities: interaction at school seemed to be associated with strong emotions, which may spring, for instance, from a pupil's or teacher's developmental needs or earlier experiences of success or failure in similar situations. Further, a teacher's certain kind of a conception of self, accompanied by a certain kind of a conception of a student may mean certain, emotionally laden expectations in interaction situations. These teacher's expectations may, on their part, influence a student's academic self-concept.

Of course, self-conceptions shouldn't be regarded as only situationally constructed, in the micro-world of the classroom, but developed within wider cultural contexts of schools, and through individual history. An individual has internalised a repertoire of cultural schemas, as well as personal representations and expectations of significant others. It should be noted that stereotypic conceptions or cultural scripts 
might be a hindrance for teacher/pupil interaction and restrict them from realising their own desires and ideals.

Further, teacher and pupil identities seem to be developed in the dynamic interrelation with their action or action orientations, ${ }^{1}$ which implies also studying identities as part of everyday action in relevant contexts, in other words, in classroom and school situations.

To conclude, teachers and students should be encouraged and supported to rid themselves of unnecessary stereotypes, and develop instead authentic, human interaction, based on dialogue. Research focusing on a school's interaction relations, aimed at clarifying the dynamics of interaction through the identities of the stakeholders, might significantly contribute in this. It seems that restructuring of teacher and pupil identities can be partially attributed to the possibilities of deep processing of the critical and discrepant experiences with others: in the case of teachers with colleagues, and in the case of students with the researcher or study counsellor. This implies the importance of reflective and meta-cognitive skills and dispositions and the strategic role of language as a tool in changes in one's self-concept.

\section{Note}

1 Within interactionist research these coordinated sets of ideas and actions are defined as a perspective. Hence a change or reconstruction of one's identity may be seen as part of perspective transformation (cf. Woods, 1979). 


\section{Chapter 22}

\section{On a Pedagogy of Research Problems}

\section{Heinze Oost}

\section{Introduction}

During the last twenty years, there has been a stream of publications about learning, teaching and supervising research in Higher Education. All along, attention has been drawn to the particular place of problem definition in research processes. Almost unanimously, researchers have pointed out that (ill-timed and ill-defined) research problems are a key factor in explaining the alarming output of degree and post-degree education. ${ }^{1}$ Clearly and quickly defining a relevant research problem seems to be an important precondition for a satisfactory and efficient research process.

\section{Pedagogy of Problem Definition}

Against this background, we looked for successful intervention programs - programs that could help students and their supervisors to develop and formulate (individually or together) a well-defined and relevant problem. We found a lot of examples of programs that work well, at least according to their designers. Programs range from small-scale interventions at course level (e.g. Zuber-Skerritt and Knight, 1986; Higgins et al., 1989; Chakravarti and Tiwari, 1990; Jongepier, 1990) to large-scale projects focusing on the integration of research skills into primary (Riner, 1983), secondary (Smith and Hillocks, 1989) and tertiary education (Hernandez, 1985).

In evaluating these programs, we came up against the difficulty that most designers claim that the proposed interventions (can) work well (under certain conditions and circumstances), but they do not explain why these interventions work well and what exactly the students learn from them (under these conditions and circumstances). Moreover, they do not articulate an underlying expert theory. We expect a scientifically based pedagogy of problem definition to be specified in terms of expertness, acquisition and intervention (Resnick, 1983) - in this order. And subsequently, we expect a scientifically based expert theory of problem definition to elucidate the concept, functions, criteria and procedural structure of research problems - again, in this order (Oost and De Jong, 1996). A systematic ERIC-search did not reveal any sources articulating an expert theory. What's more, we could not even find a simple reference to such a theory. 


\section{Research Program}

Our search led us to the conclusion that, for theoretical as well as for practical reasons, we needed a conceptual analysis of research problems. The aim of such an analysis should be the design of a useful normative model that would elucidate concept, functions and criteria. ${ }^{2} \mathrm{Next}$, we introduced this research mission into a second mission comprising the first: an empirical analysis of research problems. The aim of this empirical analysis should be to investigate the actual quality of research problems. True, output figures are related to the quality of research problems, but how sound is that? As mentioned before, many things have been said and written about the quality of research problems in degree and post-degree inquiry, but a lot of this is opinion and little is fact. And in those cases where research problems have been empirically investigated, data have almost always been collected by means of questionnaires and interviews. Concerning the quality of research problems, very rarely have product analyses been performed.

Building on the results of this conceptual and empirical analysis we developed PreScriptum, a short (on-line) course devised for degree and post-degree students. After a summary of the conceptual and empirical analysis this paper describes the educational format of this course and its educational premises.

\section{Conceptual Analysis}

The conceptual contribution of our study consisted mainly of analysing and structuring theoretical insights from several disciplines (i.e. methodology, philosophy of science, formal logic and linguistics) into a model.

This model, the so-called structure model of the central research problem (Figure 22.1), is an attempt to integrate the main theoretical perspectives, and is based on the definitions, functions and required features of research problems as found in the different disciplines. It presents the central research problem as (1) a question, (2) which is embedded in a disciplinary research context, (3) which derives its raison d'être from an expected contribution to theory, practice or society, and through its linguistic form (4) anticipates an answer, and (5) directs a problem-solving strategy. The relationships between the question and the other structural elements of the model reflect the (six) pivotal criteria:

1 Disciplinary embedding (expressed in the relationship between the question and the disciplinary context)

2 Relevance (expressed in the relationship between the question and the reason)

3 Precision (expressed in the relationship between the question and the answer)

4 Methodical functionality (expressed in the relationship between the question and the general strategy)

5 Consistency (expressed in the mutual above-mentioned relationships)

6 Exposition (expressed in the relationships between all the elements and the text).

\section{Empirical Analysis}

The empirical part of the project has been confined to the formal quality of research problems. By "formal quality", we mean those aspects of the above-mentioned criteria 


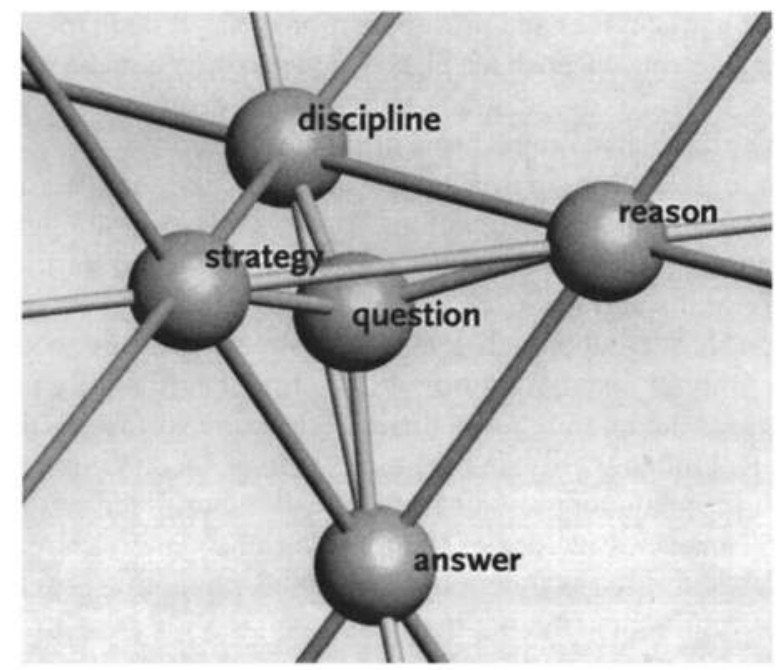

Figure 22.1 Structure model of the central research problem

that can be evaluated without a thorough knowledge of the field. In a surface analysis, the entire collection of (341) dissertations was evaluated. (We first used Cohen's kappa to determine the conditions for a reliable measurement of formal quality aspects on the basis of a surface analysis.) We have applied the criteria benevolently. Nevertheless, 75 percent of the dissertations appeared to be deficient in one or more respects. The separate findings were:

1 Exposition: in about 30 percent of the cases, the central research problem is exposed insufficiently. There are no statistically significant differences between the social sciences, humanities, bio-medical sciences and the natural sciences.

2 Relevance: in about 30 percent of the cases, the justification of the central research problems is insufficient. Again, there are no significant differences between the above-mentioned disciplines.

3 Precision: in about 35 percent of the cases, it is unclear what the central question or hypothesis is. In this respect, dissertations in social sciences lack the required precision ( 55 percent) more often than dissertations in the humanities ( 40 percent), bio-medical sciences ( 30 percent) or natural sciences (25 percent).

4 Methodical functionality: in about 45 percent of the cases it is unclear what the central research function (e.g. describing, explaining) should be. There are significant differences between disciplines: social sciences ( 60 percent), humanities ( 40 percent), bio-medical sciences ( 40 percent) and natural sciences (25 percent).

In a complementary analysis, fourteen selected cases were thoroughly studied. The findings of the deep-level analysis were consistent with the findings of the surface analysis. The main findings of the deep analysis were as follows:

1 Disciplinary embedding: the definition of the research area was sufficient in all fourteen dissertations (1). The same applied to the attention paid to related research (2). On the other hand, minimal attention had been paid to the 
explanation of choices and presuppositions (3), while in most of the dissertations the research had not been placed in the broader context of the discipline(s) concerned (4). No associations between the deep and the surface analysis could be established on the basis of this criterion.

2 Relevance: in a deep approach relevance has been made conditional on an elaborated argument (justification). This was the case in eight dissertations. Six of these eight dissertations had been identified as justified research problems at the surface level.

3 Precision: a deep approach focuses on the relation between question and answer. Only in one dissertation did we find a sufficiently precise question. In five cases the interpretation differed from the surface analysis.

4 Methodical functionality: in nine dissertations, the methodical identity of the research problem could be unambiguously determined with the help of the question-answer structure of the dissertations. The research problems that have been identified as functional questions or hypotheses at the surface level are underrepresented among these nine.

5 Consistency: in seven dissertations the research problem appeared to be sufficiently in line with the other structural elements. For the evaluation of consistency in the other (seven) cases, required information was lacking. Again, no associations between the deep and the surface analysis could be established related to this criterion.

The empirical results provided substantial evidence that the formal quality of research problems in dissertations (recently published in the Netherlands) is rather poor. It supported the assumption that many (post-degree) students have difficulty in properly defining and formulating their research problem. This conclusion suggests that the quality of the present initial academic training and supervision can be seriously questioned.

\section{PreScriptum}

In conformity with this conclusion, we developed a short course for degree and postdegree students. The methodical premise of our educational format is that the quality of a research problem in a scientific text is better when:

1 The position of the research problem in the disciplinary context is clearer (disciplinary embedding).

2 The theoretical or social importance of the desired knowledge is greater (relevance).

3 The linguistic elements of the problem, given its explorative or testable character, are more correctly and clearly stated (precision).

4 The formulation of the statement anticipates a research function more explicitly (methodical functionality).

5 Question, discipline, reason, strategy and answer fit together more logically (consistency).

6 The research problem and the structural relations elaborated are more accessible and consequently easier to judge (exposition). 
Educational premises of the format are derived from student-centred and competency-based learning. We have chosen:

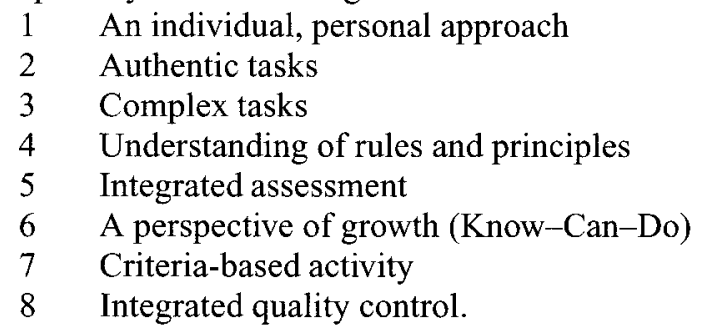

In conformity with the methodical premise, PreScriptum consists of five modules: disciplinary embedding, relevance, precision, methodological functionality and consistency. These modules can be found as buttons on the Homepage of PreScriptum, along with the calendar, bulletin board and e-mail. The non-linear nature of PreScriptum makes it possible for each individual student to decide where to start in the program. It is developed in such a way that each single module can function as a starting module. All modules have the same set-up. We made use of hypertext in such a way that students can decide what to start with in each module; that is, students can start with an exercise (interactivity), first study the theory (information) or do a selftest (interactivity). Depending on the concern of the individual student, he or she can choose the appropriate starting point. In the end, all the students have to complete an assignment and place this on the bulletin board on time.

\section{Evaluation}

The main objectives of the course were to elaborate a well-defined, relevant research problem (real-life task) and to develop skills in defining and constructing research problems (competency). Degree students $(\mathrm{N}=52)$ and post-degree students $(\mathrm{N}=29)$ gave the on-line learning environment a positive evaluation on various aspects, such as output, content, pedagogy and techniques. Moreover, on the basis of independent expert reviews the course was designated as an example of "best practice in the area of ICT and Education in Dutch higher education".

Still, the usual problem arises of measuring the effect of educational change. In conducting a preliminary content analysis of student activities and assignments, certain patterns in product and competency output begin to emerge. Soon we hope to present and discuss both the methods of analysis and the first (promising) findings.

\section{Notes}

1 Compare: Sternberg 1981; Lagerwaard en Mul 1982; Long et al. 1985; Moses 1985; Rudd 1985; Verschuren 1986; Zuber-Skerritt and Knight 1986; Van Hout 1988; Powles 1989; Nightingale 1992; Phillips and Pugh 1994. See for output figures the first chapter in Oost 1999.

2 The fourth element of an (pedagogically oriented) expert theory - the analysis of the procedural structure of the research problem - would then be object of a later study. 


\section{Chapter 23}

\section{Shared Fundamental}

Democratic Values by Means of Education? A Deweyan

\section{Perspective on Some}

Democratic Illusions and

\section{Necessities}

\section{Niclas Rönnström}

In Sweden, a great deal of pedagogical attention has been directed towards a political project to implement fundamental democratic values by means of education. My understanding of the project is as follows: In a culturally pluralistic and socially complex society such as Sweden, fundamental democratic values are needed to bind citizens together. The curriculum for the compulsory school, LPO 94, proposes values like "the inviolability of human life", "individual freedom and integrity", "equality between men and women", "intrinsic value of humans" and "solidarity with the weak and vulnerable". These values are claimed to be a democratic and moral foundation for Swedish society, and are supposed to be in duty "constantly and always" (Swedish National Agency for Education, 1999). All activities in Swedish schools are supposed to be based upon these values, and teachers should embrace the values and make them practical and visible in their teaching. It is not sufficient to impart knowledge of these values. Democratic working methods must be used in accordance with the fundamental values so that, among other things, the pupils' participation in planning, choosing and evaluating their daily education is secured. Teachers embracing the proposed values should be able to represent a clear ethical standpoint with roots in Christian tradition and western humanism, and they should dissociate themselves from anything that conflicts with these values. On these grounds, teachers in the new millennium should themselves be educated to be competent moral agents and democratic educators, so that they can impart, instil and form in pupils the claimed democratic foundation of Swedish society (Swedish National Agency for Education 1994, 1999; SOU 1999). 
In this chapter I will examine conditions for implementation, justification and communication of democratic values in education from the perspective of the American educational thinker John Dewey, and I will particularly refer to the Swedish implementation project mentioned above. One reason why Dewey's classic contribution to democratic education is still relevant today, is because of his analysis of the interdependence between human competence, social organisation, moral agency, education and democracy understood as a way of life. For Dewey, democracy was education in a broad sense, and for him schools played an essential role in developing morality and democracy. With my interpretation of Dewey, I ask myself: what are values, can we justify fundamental values, and particularly the proposed values mentioned above, and, finally, is it possible and desirable to accomplish widespread sharing of particular values in a pluralistic society? These three questions seem to be relevant for teachers assigned to foster respect for fundamental values in any society. I will start with outlining the relevant "Deweyan" interpretative tools, and then I will use them to discuss the questions and conditions mentioned above.

Dewey denied insurmountable barriers between the descriptive sciences and the normative sciences, what is and what ought to be, and between rationality and emotions. In viewing the world from a transactional standpoint, Dewey rejected all philosophical traditions which held the fundamental world order as fixed and stable. For Dewey, all talk about eternal truth or absolutistic and universal theoretical claims was misguiding. In a world constantly changing, all theories and practices are context dependent with regard to their justification, interpretation and application. At the same time, not all things were relative to context. Dewey trusted that human rationality had universal potential but it was not yet well developed, and the best example so far of systematic and impartial rationality was to be found in science. Therefore, Dewey was careful not to confuse universal procedures with the outcome of such procedures. Outcomes were more context dependent than the rational procedures producing the outcomes and the distinction between outcome and rational procedure can be recognised in Dewey's two-level concept of experience (Dewey, 1925a; Hickman and Alexander, 1998).

All human first-order spontaneous or customary experience, like beliefs, likings, smells, frustrations, opinions, feelings, and intuitions, could be made objects of second-order reflective experience. Second-order reflective experience was seen as the rational capacity for ascribing meaning to, theorising about, valuing, or interpreting, first-order experiences, and the results of second-order reflections were to be taken as hypotheses, or theoretical constructions, to be tested, or verified, against first-order experiences. Scientists and laymen had the same rational capacity, but the former group had developed tools in which Dewey put social and moral hope. Human experience was to be guided with better reflective experience, and that implied several consequences (Dewey, 1925a; Murphy, 1990).

First, systematic and impartial scientific methods should be used in moral and social sciences, not only in a descriptive sense, but also in a normative and reconstructive sense. To Dewey, second-order reflection, and especially in its most trustworthy form science, was to be used to make society, education and morality better (Hickman and Alexander, 1998).

Second, first-order experiences like unreflective beliefs and immediate values can be made facts, or real values, if they pass a process of qualified reflection. Facts and values are theoretical constructions to be tested through reflection and verification. 
Facts and values are both results of different reflective procedures, but the difference is not in kind because they are both kinds of valuations. Facts are valued believable, and values are valued valuable. To Dewey, both facts and values refer to something objective in the world, but values are also emotional and motivating. That means that beliefs cannot motivate actions, only values can because they are coloured with emotions, but it also means that there are answers to questions about what is good and what is right. Values refer to intersubjectively accessible states of affairs, in the real world, and that opens the possibility for moral knowledge (Dewey, 1925b). The moral answers cannot be of universal or absolute character, but it is possible to construct objective values in relation to a specific context, action or society (Dewey, 1932). We can never relax thinking we have found the absolute or universal moral norm or value, but we can use our best moral principles and values as tools in reflection, and as guides for action. Dewey encourages us to use traditional moral theories as tools or guides without taking them for granted as right or good. Nothing has value in itself, but things get value through reflection and verification (Hickman and Alexander, 1998).

Third, emotions are necessary, but not sufficient, parts of values. For Dewey, real values and morally good actions were only those that passed a test of reflection. To judge our different pro-attitudes as valuable, and to judge our actions morally wise or justified, was primarily a job for rational capacities, but also for another essential ingredient in his reflective morality:

A person of narrow sympathy is of necessity a person of confined outlook upon the scene of human good. The only truly general thought is generous thought. It is sympathy, which carries thought out beyond the self and which extends its scope till it approaches the universal as its limit. It is sympathy which saves consideration of consequences from degenerating into mere calculation ... to put ourselves in the place of others ... is the surest way to attain objectivity of moral knowledge. (Dewey, 1932, p. 270)

Dewey acknowledges three natural sources for moral justification: rationality, communication and sympathy. Communication is seen as a necessary condition for social life in general, and society existed in communication, according to Dewey (1916). Any sharing of values and traditions were dependent on communication. Thomas $\mathrm{M}$. Alexander understands Deweyan sympathy as "an underlying disposition to care for and be cared for by others ... presupposed in all mature, explicit, self reflective and cognitive endeavours" (Alexander, 1995, p. 133). Dewey's recommendation was to extend human sympathy globally because of the growing internationalisation of interests and relations.

And fourth, old values and habits can be influenced and changed through the process of reflection, but also through inactivity. Dewey saw humans as creatures of habit, and habits are results of individuals interacting, or transacting, as in human communication, with a primarily social environment. Lack of relevant environmental stimuli may cause habits to lose their functionality, and change in environment demands new habits. Dewey distrusted the functionality of old moral norms and values in modern societies with their new problems, relations, and social organisations, and therefore he wanted us to develop more reflective moral habits, called "reflective morality". He was concerned about how his contemporary society actually blocked the road to moral and democratic reflection with its love of power, its capitalistic regime, its hierarchical 
structure, its traditional conventional morals and materialistic biased values. The social conditions necessary to develop reflective morality, were in his own eyes, more or less absent in a hierarchical society where social relations often were characterised by some people's non-sympathetic strategic use of others for their own ends. Moral and democratic competence was dependent on support from social life and organisation (Dewey, 1932, 1916; Gouinlock, 1994).

A Deweyan reflection on the Swedish project to implement fundamental democratic values by means of education reveals problems. Besides the abstract nature of the proposed values it is problematic to implement any set of democratic values in the form of a system imperative within the political administration of schools. They are unpractical if they do not motivate the different actors in schools. It seems plausible that the affected actors should be participating in the formation of values so they can be moved by them, and so that they can be shared. The implementation process might be criticised as un-democratic with respect to the limited participation of those affected, but also because the actual outcome to a great extent was a compromise resulting from strategic political action rather than inclusive cooperative communication among both politicians and those affected. It also seems necessary to reflect on which values will be relevant to a particular context rather than assuming their validity and relevance constantly and always. The internationalisation, or trans-nationalisation, of interests and relations also makes it doubtful to focus on democratic values exclusively within the national state. Of course, education is administrated within the Swedish national state, but from a Deweyan perspective, morality and democracy need to have a wider scope than that.

It also seems necessary that the social organisation stimulate moral reflection and functionality of democratic values. Dewey stressed the importance of a social environment that facilitates certain kinds of reflection, problem solving and communication, if we were to take morality and democracy seriously. For Dewey, it was important to separate moral problem solving, an open situation in which an agent does not know what to do or what to value, from technical problem solving, in which an agent already knows the goal, end, or value in advance, and perhaps even the methods for reaching that end (Dewey, 1932). To foster moral reflection and sympathy in a Deweyan sense, we should therefore reject pedagogical traditions based on one-sided authoritarian or strategic leadership, but also predetermined agendas for students' and teachers' work. In Swedish schools today we can see a development towards effectiveness and productivity in reaching predetermined measurable goals, and Total Quality Management, with roots in business, is introduced as compatible and desirable ways of coordinating and managing schools and their actors (Lagrosen, 1997). From the standpoint of democratic education, where moral problem solving and democratic values are desirable and should be practical, the Swedish development can entail technical schools with limited moral deliberation, reduced fostering of caring relations, and less participation in forming goals and values for pupils and teachers. If the schools succeed, effective production of fulfilled educational goals is secured, but perhaps not morality and democracy.

In Dewey's reflective morality it is valuable that all individuals become wise moral agents through seeking their own values in life, and therefore pluralism and diversity is encouraged because of the creative and enriching potential that differences are supposed to have for individuals and society at large. To Dewey, widespread agreement or convergence upon values was both good and bad. It strengthened a sense 
of community but it could also lead to individual and social stagnation. For my purposes in this chapter I will roughly construct three classes of real values based on my reading of Dewey's reflective morality: individual values, fundamental values, and shared values. The first class refers to those values that pass the test of reflection for an individual. The second class refers to those values necessary to value for upholding and developing democracy, and which also pass the test of critical reflection. The third class refers to those values that participants share by means of communication and intersubjective reflective testing (Dewey, 1932; Gouinlock, 1994).

Values, actions, and goals in general, deserve their justification in terms of probable, or verified, consequences for actions. General justificatory and reflective questions might be: Are they coherent with other values, one's overall life plan, facts and known relations? Are they open for revision in the light of new experiences? Do they lead to a good character in the end or are they just solving problems here and now? Are they socially approvable in relation to others' well-being or the common good? These criteria for reflection can also be translated into language fitting social institutions and societies to judge their moral value, according to Dewey (1932). The moral value of schools was one important aspect to evaluate in Dewey's reconstructive agenda for education (Dewey, 1916).

A morally wise actor is a good chooser of enjoyable ends capable of justifying ends, values and actions in the critical light of reflection. Moral justification was of great importance to Dewey and he stressed the importance of separating reasons for actions and values from their causes. Immediate impulses of anger can cause an individual to kill his child, and needs for economic growth might economically justify cutting down rainforests and cause one to believe it is a good thing to do, and living in a culture where female circumcision is custom might cause one to uncritically believe it is something valuable. None of these examples would probably count as moral reasons for actions, or values, in a Deweyan sense. Moral justification requires qualified reflection, and it is not enough to claim convergence or agreement upon values because it might be a superficial unreflective agreement, or agreement caused by threats, power, manipulation, ignorance, dogmatic beliefs, or custom and convention. Dewey's reflective morality recommends us to be critical about values. The general reflective questions above can be extended with questions like: Why do we, they, value $\mathrm{X}$ ? How did we, they, come to value $\mathrm{X}$ ? Where and when were, are, these values $\mathrm{X}$ functional? Who does valuing X serve? (Gouinlock, 1994)

Hence, Dewey's contextualism does not entail total relativism but a critical morality, but we must remember that female circumcision and exploiting rainforests could possibly be morally justified if they pass critical reflection. A group of people does not really share values if the values do not pass reflection, is the outcome of participation of all affected in the formation and interpretation of them and is a result of open and honest communication. So, consensus or regularity in behaviour is not enough for Dewey, real sharing demands reflective consensus (Dewey, 1932).

Moral education in this critical sense differs radically from obedience to prefixed norms and already established values. From a Deweyan perspective, imparting and instilling values are not sufficient because the distinction between reasons and causes mentioned above is not taken into consideration. Transmission of cultural traditions is inevitably a major part of education (Dewey, 1916), and the crucial question is how learning situations are carried out. We must differentiate between those pedagogical practices that transmit knowledge and values through mere indoctrination, 
or role modelling, with an uncritical attitude, from those that transmit knowledge and values through open communication with a reflective attitude.

Dewey was also aware of the need for more fundamental values. His understanding of fundamental values can be interpreted as those procedural values facilitating and constituting democracy in a broad sense. Democracy for Dewey was not only political government, it was also reflective morality and a social organisation that supported free growth, and search for values, for each individual, but also common welfare or common good. Fundamental values can be seen as only those values that are necessary for upholding democracy as a lifestyle, that is, values anchored in our, for Dewey, natural capacities for sympathy, communication and reflection like: each and every individual participation in the construction of common goals and values, open honest and caring communication of experiences, cooperation rather than competition, active tolerance in that one should encourage criticism and inquiry, equality between all members in society and reflection over experiences to facilitate growth and intelligent action. In other words, fundamental values in Dewey's democratic lifestyle are meant to be procedural in that they aim to regulate the relations, and shape the action orientations, of free individuals seeking their own values while at the same time contributing to the development of the community at large (Dewey, 1932; Gouinlock, 1994).

Fundamental democratic values deserved special criteria for justification because they were constitutive of the idea of democracy as a lifestyle. Fundamental values should be taken as valuable even if any particular individual does not feel for them. This seems contradictory, but Dewey trusted our rational capacities in that they can affect motivation through argumentation and qualified reflection. First, all fundamental values are, if they really can be considered as fundamental, truly valuable in that they facilitate, and protect, all individuals in their seeking personal values, ends and growth. Second, all participants within a certain practice must adapt themselves to the fundamental values, or principles, necessary to uphold that practice. If one accepts the values or principles as necessary for that practice, and if one depends on them, one must also accept them as fundamental, and thereby let them guide one's actions within that practice. One cannot break the rules of chess at the same time as one is accepting to play the very same game. Third, if one enjoys certain rights a principle of reciprocity entails that one must give these rights to others as well. So, in moral language, fundamental "goods" are to be taken as "shoulds" because they can be proved necessary for democratic practice and organisation, or in Dewey's vocabulary, the democratic lifestyle (Dewey, 1932).

Reflecting with Deweyan tools on the claimed fundamental values for Swedish schools, we can see that they probably fail to be both justified and fundamental from a more procedural democratic standpoint. Springing from a variety of traditions they might not pass the test of coherence and context relevance in relation to late modern worldviews. They are claimed to be operative "constantly and always" and they are therefore not revisable and sensitive to context. They might be excluding the interests of democratic citizens from the environmentalist or the animal liberation movement, because of their focus on the value of human life, and equality for all members of the society is more inclusive than equality between men and women. The proposed fundamental values are also not an outcome of cooperation and communication between participants in Swedish schools and citizens. The proposed Swedish fundamental values are hardly fundamental democratic values in that they fail to identify the values, or 
perhaps principles, necessary to uphold, regulate and develop open democratic cooperation, and sharing of experience, within a democratic society. The proposed values have substantial qualities that might disqualify some interests and groups that might be considered democratically valuable and not democratic threats. Therefore, from a Deweyan standpoint, any set of proposed fundamental values in a pluralistic society should be procedural rather than substantial. They should support and regulate human cooperation, reflection and inclusion, rather than explicating what to value in absolute non-revisable and substantial terms. Sympathy, though, is natural, and necessary for any true moral and democratic character, and Dewey recommended us to foster sympathy not only in relation to our neighbours and countrymen, but also in a global sense (Dewey, 1932).

Hence, reflective morality and Deweyan democracy encourages all individuals to seek their own reflective values, but fundamental values, if they are right, are both constraints and facilitators to be accepted as valuable for all members of a democratic society. If individuals in a community reflectively share other values it will be good because it strengthens their sense of community, but only as long as individual and social growth is secured. If processes of sharing lead to stagnation or absolutism, it distorts both the democratic and educational process. The best way of sharing values is to make them practical in our daily lives by letting them explicitly guide our actions, and make them intersubjectively accessible for test, revision and reflection. Remember that Dewey's theory of values entails that there is an objective component in any value because they are referring to states of affairs in the objective world. Dewey (1932) put moral and democratic hope in a more naturalistic moral language, but we have communicative reasons to suspect that reflectively sharing values in any pluralistic society is complex and difficult, and perhaps not even desirable.

Sharing values, fundamental values included, seems to be difficult because of several communicative reasons. Sharing is more than just having pro-attitudes towards the words used for explicating fundamental values. Let us assume that Dewey's reflective morality and democratic ideals were accepted as guidelines among the individuals in a pluralistic community, and in supposing that we will skip any quarrel or arguments about the rightness of Dewey's proceduralism and reflective morality. Would that be a guarantee for reaching agreement in normative questions of norms and values? I do not think so. With Dewey's help we have noticed the interdependent relation between morality and social organisation, and reflective morality seems to need a democratic sound environment, and such an environment is itself dependent on the reflective morality and the participating democratic lifestyle. Reflective morality and democratic social organisation is a mutually supportive, but not an existing condition, so agreeing with Dewey might not be practical. Widespread sharing of values seems to be very difficult to achieve when different habits, practices, traditions, political ideologies and conventions affect the meaning and practicality of values. It is also the case that even if we reach consensus on a particular occasion we might diverge in future applications and valuations.

In our attempts to communicate values, we must also acknowledge that there is always some indeterminacy about what a speaker means by an utterance on a particular occasion, and it is also important to separate communication intents from communication effects. If a hearer understands a speaker's meaning with an utterance it doesn't follow that he agrees with the speaker about what is valuable. Speakers can diverge in valuation even if they converge in understanding the objective reference of the claimed 
value. It is also indeterminate whether someone who is working for equality has moral reasons. His motives might be to impress someone, to increase his status in a group or for a group, or just to feel connected to others, and teachers might refer to values, say, "respect", with the intent of getting the students to obey or just shut up. Communication is complex and we must, perhaps, accept that shared values between all, or most, members of a pluralistic society is impossible in practice, and not even desirable in a democratic community. Even fundamental values seem to be difficult to share between a large numbers of people, if it means that they guide action in all contexts. Fundamental values might be unpractical in societies and institutions governed by money, power and strategic rather than free, cooperative communication (Habermas, 1987). There are more action coordinating mechanisms than democratic values operating in Swedish schools today. It is certainly not easy for teachers to dissociate themselves from strategic coordinating, and success oriented, media like money and power when they are in conflict with democratic values.

Any attempt to implement fundamental values from above seem to be misguided if the intent is to achieve the effect that all affected should embrace the same democratic values, mean roughly the same thing in using them and that teachers should display ethical clarity in the eyes of all students. If we follow Dewey, only procedural fundamental values are really important to share within a democratic community, and even that might be difficult. What makes fundamental values more important to share, and perhaps less difficult than other values, is that all democrats have reason to accept them because of their dependence on them for their own good and their consistency. The fundamental values can never be fixed or absolute. They are also values to be tested and evaluated among the members of a community. Testing, communicating, debating, and reflecting upon values, is perhaps the best we can do in the search for widespread sharing about what is democratically valuable, but only certain kinds of communication will do if we take Dewey seriously (Dewey, 1916, 1927b; Murphy, 1990).

Dewey acknowledged a special problem of communicating values besides the demand for caring qualities, coherence, revision and reflection. We cannot be credible if our communication content, say, the value of respect, opposes our communicative actions, say, never take the hearers' opinions, desires and needs into consideration (Welchman, 1995). We can, with Habermas's (1996) help, talk about performative contradiction whenever content opposes action, or the reverse. If teachers do not live as they teach there might be unwanted learning from a democratic perspective. We can also wonder about teachers' democratic motivation towards students if they are not experiencing and developing democratic habits in their own work life outside their classroom. Democratic values should therefore guide action in all educational contexts on all possible levels between all groups of actors in the school system.

Let me make some concluding remarks about implementation of democratic values by means of education within a Deweyan frame of reference. Participation in forming values through tolerant, critical and caring communication seem necessary for a group of people if they are to reflectively share democratic values, without confusing that with superficial agreement, unreflected custom or convention. Authoritarian social structures, strategic action orientations and one-sided technical problem-solving do not promote democratic values and moral reflection. Therefore, if we take democratic education seriously, it is necessary to develop social environments, and learning situations, in which individuals learn to seek justified values of their own, 
cooperate, reflect, care, communicate, and make values practical in their actions. This is necessary if we want to promote democracy as a lifestyle, and not solely effectiveness and production in education. Democratic societies and schools should value diversity rather than conformity, and it is therefore important that fundamental values do not exclude groups from the democratic community and sharing of experiences. This may be accomplished with a move towards revisable procedural values rather than absolute and substantial fundamental values.

Educational goals and fundamental democratic values are not to be left in the hands of politicians; researchers, teachers and pupils may contribute with their part. I am convinced that Dewey would have enjoyed the Swedish attempt to promote democracy by means of education, but my reflections on Dewey's moral and democratic ideas reveal problems regarding how the attempt is carried out. Dewey did not trust that traditional democratic and moral views were functional in relation to complex social conditions, and he stressed that modern conditions put heavy demands on human creativeness. For Dewey, democratisation was a challenge which he referred to in terms of faith - a faith that could not be reduced to democratic habits and traditions, predetermined educational goals or imparting of fixed values exclusively within the national state:

Democracy is the faith that the process of experience is more important than any special result attained, so that special results achieved are of ultimate value only as they are used to enrich and order the ongoing process. Since the process of experience is capable of being educative, faith in democracy is all one with faith in experience and education ... the task of democracy is forever that of creation of freer and more humane experience in which all share and to which all contribute. (Dewey, 1939, p. 229) 


\section{Chapter 24}

\section{Confronting the Person in Biographical Interviews}

\section{Raija Erkkilä and Maarit Mäkelä}

Biographical methods in social sciences have raised new kinds of issues. In a biographical study a researcher comes very close to his or her informants and thus the feelings and emotions on both sides cannot be neglected. The act of actively listening to another person's life story is a complex phenomenon that seems to warrant more attention than it has been given so far. Narrative and biographical research has frequently touched on the question of what it means to a person to tell his or her own story. The possibility to tell and re-tell one's life story seems to help people to perceive their life as more organised, to assign new meanings to experiences and to undergo an emancipatory process (e.g. McEwan, 1997; Polkinghorne, 1988). Another basic assumption is that human beings have a narrative approach to their lives and therefore tell about things that are important to them (Bruner, 1987).

On the other hand, there is not much research on the experiences of researchers listening to their informants' stories. There are a large number of narrative-biographical research reports as well as methodological handbooks discussing empirical research, but the actual practice of collecting data and, more specifically, the experiences of biographical researchers in doing research are rarely presented and discussed. While doing empirical research, we have become convinced that feelings and emotions are inherently present in each interview situation and shape the discourse produced and, hence, the outcome of the interview. We would like to raise the following question: how should researchers confront their own experiences in interview situations and reflect the meaning they apply to the research process?

\section{Interview Sessions}

We have chosen to conduct a cyclical series of interviews in our research, which focused on describing and analysing the professional growth of student teachers. The repeated interviews took place during 1995-2000, including from three to five interviews with each person. One interview concentrated on a person's general life experiences. The next interviews were stories about study and working years.

Numerous methodological textbooks provide detailed accounts of the technicalities of successful interviews, such as how to prepare for an interview, what equipment is needed, what good questions are like, what should be done after the 
interview, etc. (e.g. Cresswell, 1998; Jovchelovitch and Bauer, 2000; Kvale, 1996). But this was not enough for us as biographical researchers. While doing our actual practice, we needed a wider analytic perspective to the interview situation, including explicit consideration of the influence and personal contribution of the interviewer.

For instance, some of the student teachers started to tell about their previous life more intensively than expected. Also, it became evident during the research process that personal life and professional growth are so strongly intertwined as to be inseparable. Thus, reflecting back on these research episodes, we may easily claim that it was these repeated interview sessions that convinced us of the relevance of the biographical viewpoint. Through repeated interviews, the interviewer really becomes interested in her informant's personality and choices as well as confronting her feelings and emotions. The interviewee similarly begins to feel that the researcher is genuinely interested in his or her life, and in an optimal case, the repeated meetings with the researcher result in a confidential relationship.

Kelchtermans (1994) describes in detail this cyclical way of doing biographical interviews. He highlights the benefit of analysing the data after every interview. Each analysis provides topics for the next interview, and the interviews thus constitute cumulative sources of data. Also, the "information gaps" and unclear passages of the first interview can be filled in during the later sessions. Each resumption of a topic elaborates the story, and the repetitive instances of narration may shed new light on the interrelations of events, not only for the researcher but also for the narrator. It was these guidelines that oriented our work of doing biographical interviews.

\section{Unexpected Situations and Feelings Faced by the Researcher}

An interview may sometimes turn out to be thoroughly frustrating, and the interviewer may end up trying to find a way out of the situation. For some reason, no relationship develops or the initially established relationship fails to develop further. Kelchtermans (1994, p. 100) noted in his own research that the development of a confidential relationship required a balanced give-and-take relationship. Collecting biographical data should not be "one-way-traffic", but trustfulness is enhanced by mutual reciprocity. Goodson (2000, p. 20) also talks about giving and taking in biographical interviews. There are two participants in the research, who see the world through different prisms of practice and thought. Such a valuable difference may provide the outsider, i.e. the researcher, with a possibility to give back goods in "the trade". The insider offers data and insights; the outsider, in pursuing glimpses of structure in different ways, may also contribute data and insights. That is, according to Goodson, why the terms of trade look favourable.

We believe that many researchers have experiences of both successful and unsuccessful interviews. According to our experience, interviews are always situationspecific. Different roles inevitably evolve in a given situation. They are not merely something adopted by the researcher, nor does the interviewee decide about these roles in advance. It is the act of telling and re-organising their life-story that generates a need, to which the researcher is expected to respond through the role assigned to her. It is precisely this intimacy with another person's life that is characteristic of biographical interviews and ties the researcher to the interviewee more closely than any other kind of interview. 
The repeated interviews may allow the informant to resume themes at a more profound level and even bring up sensitive topics. The biographical approach may even have the consequence that the researcher finds that the interviewee expects her to be, apart from a researcher and a listener, also a friend and even a therapist (cf. Connelly and Clandinin, 1995). Still, as far as we can see, the therapist's role is not good for the researcher. Researchers have not been educated to work as therapists, nor does research aim to be therapeutic. According to Kvale (1996, p. 125), too, the researcher should try to keep the interview from turning into a therapeutic session. A good interview, however, may resemble therapy in that the interviewee finds the very act of telling relieving without expecting the interviewer to contribute a solution to their problems. The interviewee finds the interviewer to be a listener who is like a reliable friend they can confide in.

While conducting biographical interviews, both of us have also come across another researcher's role, which may be the most common expectation applied to the interviewer. This resembles the "traditional" role of a researcher (see Gudmundsdottir, 1996; Jovchelovitch and Bauer, 2000). In those situations, we felt that we were expected to ask direct questions, to which the interviewee tried to provide as "good" answers as possible. The interviewee may also subjectively assume what things the interviewer wants to hear and what she already knows. Differences in background and culture between the interviewer and the interviewee may also result in a situation where the interviewee only tries to give the kind of answers they expect the interviewer to want.

What makes the researcher especially interested in certain stories? Time and again, the biographical researcher is faced by the question of both her own motives for doing this kind of research and her informant's motives in telling about their life. Our own motives derive from the theoretical and methodological premises of narrativebiographical research. That is why part of the stories always gets less attention. We are convinced that a narrative-biographical interview is a relatively new and unfamiliar situation to both the interviewee and the interviewer, which always requires some negotiation of roles. Although it may resemble informal conversation, it differs from ordinary conversation in being goal-oriented.

\section{The Researcher and her own Life-story}

The commitment to work on the life experiences and biographies of other people makes the researcher face a number of questions about her own identity, biography and personal experiences. The researcher can never be a completely neutral outsider. Our own life experiences orient our interpretations, and the life-story to be interpreted orients our life, even if only by evoking minor memories and past incidents. The need to listen to other people's life-stories awakens a desire to consider one's own biography.

But where are researcher biographies? This topic has not been discussed much in the guidebooks for researchers. Yet, there are clear signs to indicate that researcher biographies should also be told, and public discussion concerning this has already begun. There are also some examples of stories told by researchers or supplementing research reports (e.g. Elbaz-Luwisch, 1995).

Brannigan and Merrens (1995) also point out that studies aiming at objectivity lack the human voice. Research reports lack a narrator who would go beyond the phenomenal level of research and describe the context in which the researcher's interest 
in this specific topic was aroused. Researcher's voice and personal signature are always manifested in the style and form of the research report. Traditionally, research reports have been stories of what aspects of a given phenomenon have been studied and how. Why and by whom a certain phenomenon has been studied are questions that have not been answered in the course of research, nor have they even been asked explicitly. Elbaz-Luwisch and Pritzker (2001, p. 17) consider the norms of the academic world to be a major problem. These norms underrate the need to expose feelings or even experiences of failure. Therefore we agree with their conviction that acknowledgement of one's own feelings helps the researcher to understand both herself and the object of her research. Therefore, the researcher should not try to completely separate the emotional and cognitive aspects of her work.

The basic assumption of narrative research is that the story continues to evolve upon being told and reported. For instance, we began to analyse our own experiences as researchers, but soon realised that it was not so simple to capture them on paper as we had thought. Writing about oneself was really quite different from reading and analysing the life-stories of other people. Writing about own emotions and feelings during a research process or even publishing them, demands something that is not common in academic life. Still, one should try, because emotions are present, whether discussed openly or not.

\section{Why Carry out Biographical Interviews?}

Our aim throughout this article has been to underline the researcher's contribution to biographical interviews and to highlight the relationships implicit in them. According to our experience, the narrative-biographical interview is a special kind of interview. It is demanding and time-consuming both to the interviewee and interviewer. It is always situation-specific and unpredictable, and the researcher often ends up in novel and unexpected situations while collecting data. We found this astonishing, as our own education in the 1980s prepared us for different researchers' roles. According to this alleged role, the researcher should remain distant from her informants and maintain a neutral attitude towards them. Our recent experiences of research, however, have shown that we are living, very concretely, at a "narrative turn" (see Chamberlayne et al., 2000). This has also caused us, as researchers, to undergo a kind of paradigm change, though only practical work shows how well one has been able to internalise new ideas and how functional they are.

The researcher is seldom prepared to encounter the variety of roles and emotions that may emerge in the course of an interview. Therefore, it has even been claimed that all factors contributing to the process of narrative research should be critically evaluated. It is not enough to present the content of the story, but we should also ask how we, as researchers, have contributed to the process of research (McEwan, 1997). An interviewer doing research is always present in the interview as her own self. She always affects the storytelling: what is said and how and the way in which the narrator mirrors her personal characteristics. The interview is like "a two-way mirror" (Elbaz-Luwisch and Pritzker, 2001). Who does the narrator feel they are telling their story to? Hence, the researcher does not merely represent her own personality to the teller, but may also represent the larger audience to whom the story is addressed (Wortham, 2001). 
It is also important to consider the question, how is the researcher's voice heard and seen in the research process more generally? The researcher's voice can be manifested in different ways. Both while listening to a story and when analysing the material, the researcher may, intuitively and spontaneously, fill in gaps. This may result in two stories: the researcher's story and the interviewee's story. It is also a known fact that different researchers see different things in the same story. Apart from being guided by her personal view, the researcher is always also guided by theoretical knowledge. The researcher always views things through her own lenses and may even be blind to certain aspects of her own research. 


\title{
Chapter 25
}

\section{Teachers Becoming \\ Researchers: Reflections on Professional Development ${ }^{1}$}

\author{
Helen E. Hayes
}

\section{Introduction}

As Loughran (1999) reflects, "[t]he tension between the nature of teachers' work and the time, energy and expertise necessary to inform practice through research ... is a constant dilemma for teachers" (p. 1). Compounding this dilemma is the pressure from authorities for teachers to become more publicly accountable, to effect change in their curriculum practice, and to embrace innovation.

The University of Ballarat offers a Master of Education program, which incorporates a yearlong research component. Students in this program work in small research teams to design and carry out research on some aspect of their practice. The university staff (two of them) act to provide challenge and support throughout this experience.

Reflections of the lecturers and more importantly of the students reveal a powerful learning process in operation. The students see the research as something that is owned by them, something that "empowers you with your own knowledge and learning" (transcript, November 1998). They recognise that they have developed habits of looking, noticing, and questioning as a result of being involved in the research: "It's become part of us ... We've become little researchers" (transcript, November 2000).

This chapter will reflect on teachers' professional learning by presenting themes that have emerged from analysis of the students' reflections, and will also consider aspects of the pedagogical role of the university lecturers involved in the program.

Becoming a university lecturer after many years of classroom teaching felt at first like a challenge to become an "elder", to ready myself to pass on the wisdom of the tribe. My misconception was that wisdom is passed on in abstraction and principle, in "inert" forms (to quote Alfred North Whitehead); I discovered (what most "elders" already know) that wisdom is embedded in story. And the story is not of things long past, but of the here and now where we university people attend in dialogue to the 
stories of teachers, now constructed as knowers and agents (Cochran-Smith and Lytle, 1999 b, p. 16). We may then interrogate the story of our own journey from classroom to university: How did we learn what we now know? What gave us the freedom to question ourselves as teachers? How (and why) did we adopt the strictures of the academy? Was there a price to pay for that? What have we lost by embracing "totalised and decontextualised approaches" before we developed a "renewed interest in what is conceived of as situated knowledge and embodied knowledge ... [and] in what are called "multiple realities"' (Greene, 1994, p. 426)? How can we reconceptualise our pedagogic relationship to teachers as they explore and validate their own knowledge and develop confidence in their own agency?

This chapter recounts what might be framed as a case study of teacher "inquiry communities" engaged in the generation of "knowledge-of-practice". I borrow these terms from Cochran-Smith and Lytle (1999a) who define knowledgeof-practice as the knowledge that is generated "when teachers treat their own classrooms as sites for intentional investigation at the same time that they treat knowledge and theory produced by others as generative material for interrogation and interpretation. In this sense, teachers learn when they generate local knowledge of practice by working within the context of inquiry communities to theorize and construct their work and to connect it to larger, social, cultural, and political issues" (p. 250, italics in the original).

My case study is set within an academic institution in a regional area of Australia. The University of Ballarat is situated in a provincial city with a population of about 80,000 . Its students are largely drawn from the rural areas to the west of the city, the schools in that region provide the practice sites for our student-teachers, and many of our graduates return there to find teaching positions. As well as courses for the preparation of teachers, the University's School of Education has been offering courses at the graduate level for about 15 years, and a small but steady stream of teachers continues to enrol in these courses.

From the beginning, the Master of Education program comprised a mix of coursework and research. Student evaluation suggested that the research component, originally placed towards the end of the program, should become its starting point. From 1998, therefore, a new, yearlong course entitled Researching issues in education was offered as the mandatory entrée into the program. Students ${ }^{2}$ in this course work in small teams to design and carry out research on some aspect of their practice. The university staff (two of them) offer challenge and support throughout this experience.

The case study provides the basis for the reflections in this chapter. It has already spanned almost four years, during which the course has been offered to three different groups of students. There are several sources of data: personal observation, reflective conversations between the two lecturers following meetings with the students, and evaluative discussion with students at the end of the year when their research is completed.

This chapter will do two things. It will first of all reflect on teachers' professional learning by presenting themes that have emerged from analysis of the students' reflections. It will do this by drawing on the final evaluation discussion in 2000 . Secondly, it will consider aspects of the pedagogical role of the university lecturers involved in the program. For this part of the chapter, I will draw on a series of discussions held between the two lecturers over the years we have been teaching this course. 


\section{Teachers' Professional Learning}

It was almost midday on a Sunday in late November 2000 . The previous day and a half had been given over to presentation of the research projects that the Masters students had conducted over the course of the year. In various ways, they had shared their stories and discussed what had emerged from their research. I framed the evaluation session in the following terms: "What we're interested in [is] what's been significant in your learning throughout the year." It was suggested that they consider what had been for them an important milestone in their learning.

They needed no further prompting, and spoke in strong terms about their coming to "look for things and notice things", about learning to make sense of theory and research in their own terms and thus to "[understand] a lot more about what we're actually doing in the classroom", and their feeling of wonder that their research "might be of use or interesting to someone else".

Several themes emerge from a re-reading of the transcript of this discussion. I will call these themes: teachers as learners; learning in a community of inquiry; and (borrowing again from Cochran-Smith and Lytle, 1999a) "knowledge-of-practice". What also emerges, but is difficult to convey here, is a sense of the teachers' enthusiasm, confidence and community.

\section{Teachers as Learners}

Uppermost in the minds of the teachers appeared to be what they had learnt to be, namely (to quote the words of one of them), "little researchers". "It's become part of us," she explained. "You sort of look for things and notice things ... a habitual thing now." They acknowledged that they had come to understand research practices, not just for their own use, but to enable them to read research and critique the findings of others. As another student said: "To have a clear understanding of what [research] means makes a lot more sense of what others are doing."

Doing research had meant learning to read in a new way, not in the way of "reading a few books and then writing the essay", as one said. He expounded his distinction in this way: "You could sit down and read [books] over three or four days, allow a couple of days for the ideas to gel and then write the essay ... The lead-in time with this stuff is a lot longer ...". The motivation and starting-point for the reading also made a difference; as one said: "Getting into a book from the information and ideas meant that you wanted to look for more, and I got really voracious about looking for information and new ideas and ..." (her final words were lost in a chorus of exclamations of agreement).

The experience of researching enabled the students to become more questioning. "I always thought that research was kind of absolutes," said one, "and the good thing after you've read for a while is you realise that it's not ... there's all this enormous divergence." Another chimed in: "It's sort of like ... where's your evidence? We're becoming very critical and saying: Well, where's your data?"

Two of the group summarised quite succinctly what this learning experience had been for them. One expressed it thus: "I guess what we're doing is making sense of our world." For the other, the insight was that "the research is education for teachers". 


\section{Learning in a Community of Inquiry}

The course within which this research was conducted, Researching issues in education, is conceptualised within a framework of collaborative learning (Hayes, 1999). The research, which is the central task of the course, is to be conducted in small groups. These groups form themselves at the first meeting of the course, usually around shared interest in a common topic or issue. In 2000, these issues were the schooling of young adolescents, concerns over boys and literacy, the educational impact of information and communication technologies, and professional development within schools and systems. The small groups also form part of the whole group, and meetings of this larger group provide opportunities for sharing across groups and broadening their understanding of a range of issues, not just their own.

In discussing the concept of "discourse communities for teachers" within a broader theory of distributed cognition, Putnam and Borko (2000) suggest that "when diverse groups of teachers with different types of knowledge and expertise come together in discourse communities, community members can draw upon and incorporate each other's expertise to create rich conversations and new insights into teaching and learning" (p. 8). The students in the 2000 Researching issues course represented a range of knowledge, expertise and experience. There were teachers from primary, secondary and tertiary levels of education, as well as two ex-teachers now working in business and consultancy. There were early-career teachers and teachers with many years of experience. Some exercised roles of administration or professional development within their institutions. Some worked in large institutions in the city, others in small schools in rural towns. Most of them had not met previously.

Clearly, the process of creating "rich conversations" in the groups had challenges as well as rewards. For one person, whose avowed preference was for working independently, the challenge was deeply felt. She acknowledged, however, that it was a "very valuable experience in that I think the information that we got was very rich and I probably wouldn't have been able to get that depth of information if I'd just been by myself". This feeling was reflected by another person recalling how "you bounce off each other", and noting the way different personalities complement each other and keep the group's focus on the task. Another person, still in the early years of his teaching career, found that belonging to the small group provided a safe environment in which he could express his views: "I feel like it's been a good way for me to have a say in education in some way."

Another challenge of working in groups is the practical one of getting together. The meeting of the whole group at the university took place about every six weeks. In between, the small groups needed to keep in touch and move their project along. Most groups consisted of people who were somewhat scattered, living and working in different towns in western Victoria. One aspect that is perhaps "a sign of the times" was the effect of email on the group's working. "Actually," commented one, "that's one notion, one significant difference between what we're doing now and what we maybe would have done ten years ago, ... email ... You know, I'll do this draft, send it off, comments back ... The email made things just so easy." Of course, there was across the group a range of sophistication in the use of information technology and for some it was a potential rather than an actual benefit.

Cochran-Smith and Lytle (1999a) argue that "what is needed in professional development ... are opportunities for teachers to explore their own and others' 
interpretations" (p. 278). An added strength of the program being discussed here was the relationship of the small research teams to the larger group. As one student wrote to me months after the course had finished: "We all felt involved in each other's research so that at the end of the year we could celebrate where we had got to - knowing so much about the journey each group had taken."

\section{Knowledge-of-practice}

According to Cochran-Smith and Lytle (1999a), "implicit in the idea of knowledgeof-practice is the assumption that, through inquiry, teachers across the professional life span ... make problematic their own knowledge and practice as well as the knowledge and practice of others and thus stand in a different relationship to knowledge" (pp. 272-3). Citing Noffke (1997), they go on to state that "the goal of inquiry [is not] taken to be production of 'findings' but rather the raising of fundamental questions about curriculum, teachers' roles, and the ends as well as the means of schooling" (p. 274). These notions were echoed by one of our students: "It gives you a much broader perspective to your teaching than if you just go into the classroom and teach away. You're empowered to know more about what goes on in this profession."

The connection to practice and the "making problematic" was evident in the way the students talked about their work and how "we could put what we'd been researching into practice and think about, reflect on it as we were doing the research ...". However, they also felt that in some ways this new urge to research and reflect marked them off from certain colleagues in their institutions, those "that resist change and go in the other direction". This led one student to "wonder if there's a bridge that can be built, or if it's just going to stay that way, and what do you do about that ...". "I think," she said later, "this course makes you want to challenge more."

A question that arises at this juncture is the role of the university. In the situation that provides the context for this case study, the university lecturers were guiding and supporting the students, but were not direct participants in the projects and were, for the most part, unfamiliar with the particular contexts in which the research was taking place. The next section of this chapter raises some questions regarding a pedagogy for teacher learning in the light of this case study.

\section{A Pedagogy for Teacher Professional Learning}

Over the three and half years that the Researching issues course has been running, the two lecturers involved have been engaging in regular reflective sessions. Usually, these sessions follow a weekend seminar with the students, and pursue issues that have arisen for us during the seminar. We have recorded these conversations and attempted at intervals to make sense of them. Each of us has drawn on our readings to give shape to our analysis. Each of us has also attempted to put down in writing some of our thoughts. I wrote this at one of the reflective points in our ongoing dialogue:

Our project is a reflection on pedagogy, so I begin with a simple question: What does it mean to teach?

Teaching implies, in essence, a relationship. Within the literature, this relationship has been conceptualised in philosophically divergent ways. In the "modern" 
way of thinking, with its emphasis on harmony, unity and clarity, the concept of teaching is situated within a "language of an Other that is always engendered, devalued, disciplined ... in the infinite search for a more tractable and ordered world" (White, 1991 , p. 20). Thus, teaching may be seen to have, by its very nature, inequalities of control and shaping. It becomes something done "to" rather than "with" learners. It embodies a notion of authority - being "in authority", managing, disciplining.

This idea of teaching suggests meticulous pre-planning by the teacher and insistence on adherence to a set of steps towards pre-defined goals. Writers on instructional design (e.g. Ausubel) have shown how to break down content into "logical" steps in order to have students learn it in an "orderly" manner. Such a procedure embodies a view of knowledge as structured, finite and transmissible.

There are two main questions that arise from this. The first has to do with the roles of teacher and learner. It appears that the knowledge is the teacher's, so how does it become the student's? Second, learning in such a framework would seem to be a matter for the thinking mind alone. Metaphors of possession, such as "grasping", abound in these discussions. Belief in the finitude of knowledge supports arbitrary and artificial definitions of what it means to know and concepts of pedagogy as transmission. But as Goble and Porter observed as long ago as 1977:

Significant change in the role of the teacher begins when the rate of accumulated data forces upon us the realization that real knowledge is infinite and cannot be possessed; that the forms in which the human senses grasp it and the human mind codifies it are tentative and arbitrary, not absolute, and are validated only when knowledge is successfully applied to current needs; that symbolic communication has to be continuously enlarged and enriched, and even created, to accommodate new perceptions; and that skills and mythologies alike are subject to continuous modification. (p. 54)

White (1991) offers an idea similar to this when his reading of Foucault leads him to posit what he calls the "presence of dissonance in our lives": "Dissonance ... is allowed to show itself to us, an experience that has an unsettling effect on our modern, deep-rooted quest for harmony and unity, for a world of problems finally solved" ( $\mathrm{p}$. 20).

All of this raises the question of how the practice of "teaching" relates to learning. If the two concepts are not to be seen in some sort of symmetry, as some would claim they should be, how does learning proceed? How may the teaching relationship embody an "ability to stimulate the creativity of the other" (Freire), and support the emotional engagement needed for deep and powerful learning? How may the teacher confront the expectations of the learner that the teacher will be responsible for the learner's growth of knowledge? What of the learner's culturally encouraged belief that the teacher is the one who "knows"?

Or may teaching be seen as co-learning? Such a shift of position means that we have to be aware of what each party brings to the relationship, so that we can learn together in "conversation". It is an abandonment of power without an abrogation of responsibility. We need to explore what, in this different conception of pedagogy, is the responsibility of the teacher.

An idea that seems to me to hold the essence of the pedagogical relationship is that of dialogue (Bakhtin; Freire). But "dialogue" is much more than a casual chat; 
it implies attentiveness. The teacher engages in dialogue with students within a particular context of space and time, aware of and responsive to the concerns of the learners. Such attentiveness may be the essence of the teacher's responsibility (Elbaz, 1991). White (1991) distinguishes "responsibility to act" with its inherent danger of "closing off sources of possible insight and treating people as alike for the purpose of making consistent and defensible decisions ..." (p. 21) from "responsibility to otherness". It is this concept of "responsibility to otherness" that I would like to explore within my reflections on pedagogy. In this exploration, I hope to articulate some thoughts regarding what some (e.g. Simon, 1992) have called "a pedagogy of possibility".

\section{Embracing the Dilemmas}

Within our conversations there emerged for the two of us lecturers a series of dilemmas that are reflected in the above passage. What was our role in the Researching issues course: to present an authoritative voice on research or to encourage deep questioning? Should we prescribe formulaic methodologies or allow more creative design? Was there merit in insisting on induction into the discourse, or was it preferable to allow the emergence of more teacher-friendly language? We grappled strongly in our reflective conversations with questions of voice and language, of directiveness and control, of explicitness and how far to go with this. In the seminars, we found ourselves needing to dispel preconceptions (e.g. beliefs in the need for "objectivity" and in the superiority of quantitative approaches) and to urge students to be creative and to find their own voice (see Coulter, 1999, for a fascinating exploration of "research as dialogue").

Responsibility to otherness means attentiveness to student expectation, even if we think they should expect otherwise. In the evaluation session in November 2000, the students discussed their preferences for structure (even, perhaps, for "the authoritative voice"). Some valued the freedom to follow their interests and explore different perspectives, using their "freedom to move". Others would have liked more lecturing, while some in the middle would have liked "a bit more about the types of research". For another, the question of timing was significant: "[The lecturer] spent a bit of time in the first session talking about methodologies, and it didn't hit me, it didn't kind of enter my consciousness until I started reading ... It was when I needed it. I think maybe it's a good idea to have something there as a backdrop earlier on, but you only take in information when it's really relevant ... time for you, the time thing as well. Maybe it's hard to know when the time is right for different people, too."

Probing more deeply, however, I find that the request was not necessarily for more "authoritative" knowledge and more "formulaic" guidance, but for more inspiration, for an opening up of the realms of possibility: "We may have missed someone who would have been fascinating to look at." Our dilemma was to know if, in being less prescriptive, we were really communicating our belief that "no meta-narrative can offer guarantees" and that "education is ... a matter of beginnings and possibilities" (Greene, 1994, p. 459).

Encouragement of innovation means that we also have to become more open to the form in which the research is presented. Dadds and Hart (2001) discuss several examples of "doing practitioner research differently". They explore three kinds of influences that enable or constrain innovation in research: the personal, the academic, and the professional (pp. 154-7). One might ask whether, in practitioner research, the 
"academic" should be the dominant influence, or whether the personal and professional are not, in fact, more appropriate discourses for sharing the knowledge-of-practice.

\section{Where To From Here?}

There are many frameworks that suggest themselves as we consider the ongoing research possibilities within this program. Some examples are the "dialogism" proposed by Coulter (1999), or the ways in which teacher knowledge is shaped by "landscape", as discussed by Whelan et al. (2001), or issues of ownership and communication (see, for example, Cochran-Smith and Lytle, 1999b, p. 22). There is also the issue raised by one of our students, wondering, "if there's a bridge that can be built" between teacherresearchers and those of their colleagues who resist questioning and change.

Doing this initial piece of research with the teachers in our Masters program has been exciting, challenging, and constantly thought-provoking. I would like to echo the words of one of the 2000 group: "This is the best learning I've ever done in my life."

\section{Notes}

1 I am grateful for the help and advice provided by my colleagues, Maryann Brown and Richard Lea, who read and commented on earlier drafts of this chapter.

2 Throughout this chapter, "students" refers to the teachers who participate in the Masters course. I am conscious of an irony in thus describing them and so suggesting an unequal balance of knowledge and authority. I am also conscious that the students of the teachers are absent parties in the research discussed in this chapter. 


\section{References}

Aarsæther, F. (1997) '1990-åras danskfag, norskfag og svenskfag. Tre nordiske læreplaner' ('The 1990s' subject in Danish, Norwegian and Swedish. Three Nordic syllabuses'), Nordisk pedagogik, 17: 43-55.

Achinstein, B. (in press) The Ties that Blind: Community, Diversity, and Conflict Among Schoolteachers, New York: Teachers College Press.

Ackrill, J.L. (transl.) (1985) Aristotle's Categories and De Interpretatione, Oxford: Clarendon Press.

Aguirre, J. (2001) 'Teaching high school mathematics in a climate of standards-based reform: The influence and interaction of teacher beliefs and department culture on instructional decision-making and practice', $\mathrm{PhD}$ dissertation, University of California, Berkeley.

Alexander, T.M. (1995) 'John Dewey and the roots of democratic imagination', in L. Langsdorf and A. Smith (eds) Recovering Pragmatism's Voice. The Classical Tradition, Rorty and the Philosophy of Communication (pp. 131-54), Albany, NY: State University of New York Press.

Almeida, L.S. (1998) 'Questionário de Vivências Académicas para jovens universitários: estudos de construção e de validação', Revista Galego-Portuguesa de Psicoloxía e Educación, 2(3): 113-30.

Almeida, L.S., Soares, A.P. and Ferreira, J.A. (1999) Adaptação, rendimento e desenvolvimento dos estudantes do Ensino Superior: Construção/validação do Questionário de Vivências Académicas, Braga: Universidade do Minho, Centro de Estudos em Educação e Psicologia.

Andersen, S.M., Reznik, I. and Chen, S. (1997) 'The self in relation to others: motivational and cognitive underpinnings', in J. Snodgrass and R. Thompson (eds) The Self Across Psychology. Annals of the New York Academy of Sciences, 818.

Anderson, R.E. (1996) 'The United States context of computer education', in T. Plomp, R.E. Anderson and G. Kontogiannapoulou-Polydores (eds) Cross-national Policies and Practices on Computers in Education (pp. 445-68), Dordrecht: Kluwer.

Angelides, P. (2001) 'The development of an efficient technique for collecting and analyzing qualitative data: the analysis of critical events', Qualitative Studies in Education, 14: 429-42.

Apple, M. and Beane, J. (1999) Democratic Schools: Lessons from the Chalkface, Buckingham: Open University Press.

Arias, A., Cabanach, R.G., Perez, J.C., Riveiro, J.M., Aguin, I.P. and Martinez, S.R. (2000) 'Approaches to learning in university students', Psicothema, 12(3): $368-75$.

Argyris, C. and Schon, D.A. (1974) Theory in Practice: Increasing Professional Effectiveness, New York: Jossey-Bass.

Aristotle (1984) The Nicomachean Ethics (trans. D. Ross), New York: Oxford University Press.

Aristotle (1992) Politic (trans. T.A. Sinclair, revised and re-presented by T.J. Saunders), London: Penguin Books. 
Armstrong, D., Calnan, M. and Grace, J. (1990) Research Methods for General Practitioners, Oxford: Oxford University Press.

Askling, B. and Almen, E. (1995) 'The reflective turn in teacher education: possibilities and limitations of an implementation in teacher education and for forming 'reflective practitioners', Paper presented at AERA Annual Meeting, 18-22 April, San Francisco.

Association of University Teachers (1999) Your Guide to Intellectual Property Rights. London: Association of University Teachers.

Atkinson, E. (2000) 'In defence of ideas, or what works is not enough', British Journal of Sociology of Education, 21(3): 318-30.

Audi, R. (1989) Practical Reasoning, New York: Routledge. Available: http://www.ed. gov/pubs/EdReformStudies/SysReforms/little1.html. NCREST Reprint.

Avalos, B. (1996) 'Moving towards the XXI century. Teachers and teaching processes in Latin America and the Caribbean region', UNESCO, The Major Project of Education in Latin America and the Caribbean, Bulletin 41, December: 7-43.

Avalos, B. (2000) 'Policies for teacher education in developing countries', International Journal of Educational Research, 33: 457-74.

Azcárate, P. (1999) 'Metodología de enseñanza', Cuadernos de Pedagogía, 276: 72-8.

Backman, C.W. (1988) 'The self: a dialectical approach', in L. Berkowitz (ed.) Advances in Experimental Social Psychology, 21: 229-60, London: Academic Press.

Baggen, P. (1996) 'Academische vorming op weg naar een nieuw tijdperk: kanttekeningen bij Hoger Onderwijs in Fasen', Comenius: Wetenschappelijk Forum voor Opvoeding, Onderwijs en Cultuur, 16: 86-95.

Baggen, P. and Weijers, I. (1985) De Toekomst van de Universiteit, Amsterdam: Amsterdam University Press.

Baker, R., McNeil, O. and Siryk, B. (1985) 'Expectations and reality in freshman adjustment to college', Journal of Counseling Psychology, 32(1): 94-103.

Bakhtin, M.M. (1981) The Dialogic Imagination (ed. M. Holquist, trans. C. Emerson and M. Holquist), Austin, TX: University of Texas Press.

Bakhtin, M.M. (1986) Speech Genre and other Late Essays (eds C. Emerson and M. Holquist) Austin, TX: University of Texas Press.

Ball, D.L. and Cohen, D.K. (1999) 'Developing practice, developing practitioners: Toward a practice-based theory of professional education', in L. DarlingHammond and G. Sykes (eds), Teaching as the Learning Profession: Handbook of Policy and Practice (pp. 3-32), San Francisco, CA: Jossey-Bass.

Ball, S. (1994) Educational Reform: A Critical Post Structural Approach, Buckingham: Open University Press.

Banaji, M. and Prentice, D. (1994) 'The self in social contexts', Annual Review of Psychology, 45: 297--332.

Banathy, B.H. (1991) Systems Design of Education: A Journey to Create the Future, Englewood Cliffs, NJ: Educational Technology Publications.

Barker, S.F. (1964) Philosophy of Mathematics, Englewood Cliff, NJ: Prentice-Hall.

Barley, S.R. and Orr, J.E. (eds) (1997) Between Craft and Science: Technical Work in US Settings, Ithaca, NY: Cornell University Press.

Baron, J. (1988) Thinking and Deciding, Cambridge: Cambridge University Press.

Barone, D.F., Maddux, J.E. and Snyder, C.R. (1997) Social Cognitive Psychology: History and Current Domains, New York: Plenum Press. 
Baumrind, D. (1978) 'Reciprocal rights and responsibilities in parent/child relations', Journal of Social Issues, 34(2): 179-96.

Beane, J. and Apple, M. (1995) 'The case for democratic schools', in M. Apple and J. Beane (eds) Democratic Schools, Alexandria, VA: Association for Supervision and Curriculum Development.

Beattie, M. (1997) 'Fostering reflective practice in teacher education: inquiry as a framework for the construction of a professional knowledge in teaching', AsiaPacific Journal of Teacher Education, 25(2): 111-28.

Becher, T. (1989) Academic Tribes and Territories: Intellectual Enquiry and the Culture of Disciplines, Buckingham: Open University Press.

Becker, H.A. (1979) Sociale methodologie: inleiding tot de werkwijze van de sociale wetenschappen, Amsterdam: Boom.

Bell, B.C. (1982) 'Research guides in English', College English, 44: 390-404.

Bell, J. (1987) Doing your Research Project, Milton Keynes: Open University Press.

Belnap, N.D. and Steel, T.B. (1976) The Logic of Questions and Answers, New Haven, CT: Yale University Press.

Bengtsson, J. (1988) Sammanflätningar. Fenomenologi från Husserl till Merleau Ponty, Göteborg: Daidalos.

Benner, P. (1984) From Novice to Expert: Excellence and Power in Clinical Nursing Practice, San Francisco, CA: Addison-Wesley.

Ben-Peretz, M. (1995) 'Book review of "making sense of teaching", Teaching and Teacher Education, 11(1): 103-6.

Ben-Peretz, M. and Schonmann, S. (2000) Behind Closed Doors: Teachers and the Role of the Teachers' Lounge, Albany, NY: SUNY Press.

Benson, L.K. (1987) 'How to pluck an albatross: the research paper without tears', English Journal, 76: 54-60.

Bigelow, J., Campbell, J., Dodds, S., Pargetter, R., Prior, E. and Young, R. (1988) 'Parental autonomy', Journal of Applied Philosophy, 5(2): 183-96.

Biggs, J. (1993) 'What do inventories of students learning-processes really measure: a theoretical review and clarification', British Journal of Educational Psychology, 63(1): 3-19.

Biggs, J. (1999) Teaching for Quality Learning at University, Buckingham: SRHE and Open University Press.

Biggs, J.B. (1985) 'The role of mental learning in study processes', British Journal of Educational Psychology, 55: 185-212.

Biggs, J.B. (1994) 'Approaches to learning: nature and measurement', International Encyclopedia of Education, 1: 319-22. Oxford: Pergamon Press (2nd edn).

Biggs, J.B. and Collins, K.F. (1989) Evaluating the Quality of learning: The SOLO Taxonomy. New York: Academic Press.

Bimmel, P. (1999) Training en transfer van leesstrategieën. Training in de moedertaal en transfer naar een vreemde taal, een effectstudie bij leerlingen in het voortgezet onderwijs, Den Bosch: Malmberg.

Black, E., Hill, T. and Acker, S. (1994) 'Thesis supervision in the social sciences: managed or negotiated?', Higher Education, 28(4): 483-98.

Blackmon, M. (1984) 'Real research for student writers', Exercise Exchange, 29: 31-3.

Bloom, B.S., Krathwohl, D.R. and Masia, P. (1960) Taxonomy of Educational Objectives I: Cognitive Domain, New York: McKay.

Bobbio, N. (1996) The Age of Rights (trans. Allan Cameron), Cambridge: Polity Press. 
Boice, R. (1987) 'A programme for facilitating scholarly writing', Higher Education Research and Development, 6: 9-20.

Bonamy, J., Charlier, B. and Saunders, M. (2001) "Bridging tools" for change: evaluating a collaborative learning network', Journal of Computer Assisted Learning, 17(3): 295.

Boulding, E. (1977) 'Children's rights', Society, 15(1): 39-43.

Bowker, G.C. and Star, S.L. (1999) Sorting Things out: Classification and its Consequences, Cambridge, MA: MIT Press.

Brameld, T. (1950) Patterns of Educational Philosophy. A Democratic Interpretation, New York: World Book Company.

Brameld, T. (1956) Towards a Reconstructed Philosophy of Education. New York: Drysden Press.

Brandes, G.M. and Seixas, P. (1996) 'Subjects and disciplines: Epistemological negotiation in a collaborative curriculum development project', Paper presented at the annual meeting of the American Educational Research Association, New York.

Brannigan, G.C. and Merrens, M.R. (eds) (1995) The social Psychologists Research Adventures, New York: McGraw-Hill.

Brehm, S., Kassin, S. and Fein, S. (1999) Social Psychology, Boston, MA: Houghton Mifflin.

Brinke, S. ten (1994) Samen Kennis Maken, Utrecht: Universiteit Utrecht, afscheidscollege.

British Educational Research Association (2001) 'The impact of educational research (in Australia)', Research Intelligence (British Educational Research Association Newsletter), 76: 17-25.

Britzman, D.P. (1991) Practice Makes Practice: A Critical Study of Learning to Teach, Albany, NY: State University of New York Press.

Brookfield, S.D. (1991) Developing Critical Thinkers, Oxford: Oxford University Press.

Brown, L.M., Depold, E., Tappan, M. and Gilligan, C. (1991) 'Reading narratives of conflict and choice for self and moral voices: a relational method', in W.M. Kurtines and J.L. Gewirtz (eds) Handbook of Moral Behavior and Development. Volume 2: Research (pp. 25-61), Hillsdale, NJ: Lawrence Earlbaum.

Brown, S., Fauvel, J. and Finnegan, R. (eds) (1981) Concepts of Inquiry, London: Methuen and the Open University Press.

Brugman, G.M. (1989) 'Problem finding: a conceptual analysis', Pedagogische studieën, 66: $23-36$.

Bruner, J. (1985) 'Vygotsky: a historical and conceptual perspective', in J. Wertsch (ed.) Culture, Communication and Cognition: Vygotskian Perspectives (pp. 21-34), Cambridge, MA: Cambridge University Press.

Bruner, J. (1987) 'Life as narrative', Social Research, 54(1): 11-32.

Bruner, J. (1990) Acts of Meaning, Cambridge, MA: Harvard University Press.

Bryk, S. and Driscoll, M.E. (1988) 'The high school as community: contextual influences and consequences for students and teachers' Office of Educational Research and Improvement, 1 November 1988 (Washington, DC): 78.

Buchberger, F. (1997) 'Anmerkungen zur curricularen Gestaltung von Lehrerbildung in Europa' ('Remarks about curricular development of teacher eduation in Europe'), in M. Bayer, U. Carl and J. Wild (eds) Brennpunkt Lehrerbildung (pp. 219-36), Opladen: Leske und Budrich. 
Bullough, R.V. and Gitlin, A. (1995) Becoming a Student of Teaching: Methodologies for Exploring Self and School Contents, Vol. 2, New York: Garland.

Bunge, M. (1967) Scientific Research I. The Search for System, Dordrecht: Reidel.

Butler, J. (1996) 'Professional development: practice as test, reflection as process, and self as locus', Australian Journal of Education, 40(3): 265-83.

Butt, R. (1984) 'Arguments for using biography in understanding teacher thinking', in R. Halkes and J.K. Olson (eds) Teacher Thinking: A New Perspective on Persisting Problems in Education (pp. 95-102), Lisse: Swets \& Zeitlinger.

Campbell, J., Smith, D., Boulton-Lewis, G., Brownlee, J., Burnett, P. C., Carrington, S. and Purdie, N. (2001) 'Students' perceptions of teaching and learning: the influence of students' approaches to learning and teachers' approaches to teaching', Teachers and Teaching: Theory and Practice, 7(2): 173-88.

Campbell, R. and Neill, S. (1994) Secondary Teachers at Work, London: Routledge.

Canadian Association of University Teachers (CAUT) (1999) CAUT Commentary on the Final Report on the Commercialization of University Research, Ottawa, Ontario: CAUT.

Canadian Intellectual Property Group (2000) A Guide to Protecting Intellectual Property, Montreal: Canadian Intellectual Property Group.

Casey, C. (1995) Work, Self and Society: After Industrialism, London: Routledge.

Castells, M. (1997) The Power of Identity, Oxford: Basil Blackwell.

Chakravarti, A.K. and Tiwari, R.C. (1990) 'A basic research paradigm in geography', Journal of Geography, 89: 53-7.

Chamberlayne, P., Bornat, J. and Wengraf, T. (eds) (2000) The Turn to Biographical Methods in Social Science. Comparative Issues and Examples, London and New York: Routledge.

Chemers, M.M., Hu, L.T. and Garcia, B.F. (2001) 'Academic self-efficacy and firstyear student performance and adjustment', Journal of Educational Psychology, 93(1): 55-64.

Cheung, K.C. and Taylor, R. (1991) 'Towards a humanistic constructivist model of science learning: changing perspectives and research implications', Journal of Curriculum Studies, 23: 21-40.

Claesson, S. (1999) "Hur tänker du då?" Empiriska studier om relationen mellan forskning om elevuppfattningar och lärares undervisning, Sweden: Göteborg Studies in Educational Sciences, 130.

Clark, C.M. (ed.) (2001) Talking Shop: Authentic Conversation and Teacher Learning, New York: Teachers College Press.

Clark, C.M. and Yinger, R.J. (1977) 'Research on teacher thinking', Curriculum Inquiry, 7(4), 279-305.

Cochran-Smith, M. and Lytle, S.L. (1999a) 'Relationships of knowledge and practice: teacher learning in communities', in A. Iran-Nejad and P.D. Pearson (eds), Review of Research in Education 24 (pp. 249-305), Washington, DC: American Educational Research Association.

Cochran-Smith, M. and Lytle, S.L. (1999b) 'The teacher research movement: a decade later', Educational Researcher, 28(7): 15-25.

Cohen, M.J. (1996) 'Over studeerbaarheid, vouchers en academische vorming', Openings speech ter gelegenheid van de twintigste dies van de Rijksuniversiteit Limburg, Maastricht. 
Cole, A.L. (1997) 'Impediments to reflective practice', Teachers and Teaching: Theory and Practice, 3(1): 7-27.

Cole, A.L. and Knowles, J.G. (1993) 'Shattered images: understanding expectations and realities of field experience', Teaching and Teacher Education, 9(5/6): 457-71.

Cole, M. (1996) Cultural Psychology: A Once and Future Discipline, Cambridge, MA: Cambridge University Press.

Coleman, J.C. (1997) 'The parenting of adolescents in Britain today', Children and Society, 11: 43-51.

Connelly, F.M. and Clandinin, D.J. (1990) 'Stories of experience and narrative inquiry', Educational Researcher, 19, 2-14.

Connelly, F.M. and Clandinin, D.J. (1995) 'Narrative and education', Teachers and Teaching: Theory and Practice, 1(1): 73-86.

Corte, E. de (1991) 'Recent onderzoek over leren en instructie: een selectief overzicht', Tijdschrift voor Hoger Onderwijs, 9: 2-17.

Coulter, D. (1999) 'The epic and the novel: dialogism and teacher research', Educational Researcher, 28(3): 4-13.

Coulthard, A.R. (1983) 'A case for the research theme', Freshman English News, 11: 19-20.

Cresswell, J.W. (1998) Qualitative Inquiry and Research Design. Choosing Among Five Traditions, Thousand Oaks, CA: Sage Publications.

Cryer, P. (1996) The Research Student's Guide to Success, Buckingham: SRHE/Open University Press.

Cuban, L. (1992) 'Managing dilemmas while building professional communities', Educational Researcher, 211:4-11.

Czarniawska, B. (1997) Narrating the Organization, Chicago, IL: University of Chicago Press.

Dadds, M. and Hart, S. (2001) Doing Practitioner Research Differently, London: RoutledgeFalmer.

Damrosch, S.P. (1987) 'Research preparation for undergraduates', Nursing Outlook, 35: $288-9$.

Daniels, H. (1996) 'Introduction: psychology in a social world', in H. Daniels (ed.) An Introduction to Vygotsky (pp. 1-27), London: Routledge,

Darling-Hammond, L. (1996) 'The quiet revolution: rethinking teacher development', Educational Leadership, 53 (6): 4-10.

Day, C. (1991) 'Roles and relationships in qualitative research', Teaching and Teacher Education, 7: 537-47.

Day, C. (1993) 'The importance of learning biography in supporting teacher development: an empirical study', in C.Day, J. Calderhead and P. Denicolo (eds) Research on Teacher Thinking: Understanding Professional Development, London: Falmer Press.

Day, C. (1998) 'Re-thinking school-university partnerships: a Swedish case study', Teaching and Teacher Education, 14 (8): 807-19.

Day, C. (1999) 'Researching teaching through reflective practice', in J. Loughran (ed.) Researching Teaching: Methodologies and Practices for Understanding Pedagogy (pp. 215-32), London: Falmer Press.

Day, C., Tolley, H., Hadfield, M., Watling, R. and Parkins, E. (1996) Class Size Research and the Quality of Education: A Critical Survey of the Literature, Haywards Heath: National Association of Headteachers. 
Deem, R. and Brehony, K.J. (2000) 'Doctoral students' access to research cultures - are some more unequal than others?', Studies in Higher Education, 25(2): 14965.

Delamont, S., Atkinson and Parry, O. (1997) Supervising the PhD, Buckingham: SRHE/ Open University Press.

Dellinger, D.G. (1989) 'Alternatives to clip and stitch: real research and writing in the classroom', English Journal, 78(5): 31-8.

Demo, D. (1992) 'The self-concept over time: research issues and directions', Annual Review of Sociology, 18: 303-326.

Denicolo, P.M. (1999) Transforming teaching and learning in HE: one perspective from inside the chrysalis', Research and Development in HE, 21: 1-13.

Denicolo, P.M. and Pope, M.L. (1999) 'Supervision and the overseas student', in Y. Ryan and O. Zuber-Skerrit (eds) Supervising Students from Non-English Speaking Backgrounds, Buckingham: SRHE/Open University Press.

Denicolo, P.M., Boulter, C.J. and Fuller, M. (1999) 'The higher degree viva - a case of constructive alternativism', in J.M. Fisher and D.J. Savage (eds) Beyond Experimentation into Meaning (pp. 43-52), Preston: EPCA Publications.

Denzin, N. (1984) On Understanding Emotion, San Francisco, CA: Jossey-Bass.

Denzin, N. (1992) Symbolic Interactionism and Cultural Studies, Cambridge: Basil Blackwell.

Denzin, N. (1994) 'The art and politics of interpretation', in N. Denzin and Y. Lincoln (eds) Handbook of Qualitative Research (pp. 500-15), London: Sage Publications.

Dewey, J. (1916/66) Democracy and Education: An Introduction to the Philosophy of Education, New York: Free Press.

Dewey, J. (1925a) 'Experience and nature', in J.A. Boydston (ed.) (1981) The Later Works of John Dewey, 1925-1953. Volume 1: 1925 (pp. 3-412), Carbondale, IL: Southern Illinois University Press.

Dewey, J. (1925b) 'Value, objective reference and criticism', in J.A. Boydston (ed.) (1984) The Later Works of John Dewey, 1925-1953, Volume 2: 1925-1927 (pp. 78-97), Carbondale, IL: Southern Illinois University Press.

Dewey, J. (1927) 'The public and its problems', in J.A. Boydston (ed.) (1984) The Later Works of John Dewey, 1925-1953. Volume 2: 1925-1927 (pp. 235-431), Carbondale, IL: Southern Illinois University Press.

Dewey, J. (1932) 'Ethics', in J.A. Boydston (ed.) (1984) The Later Works of John Dewey, 1925-1953, Volume 7: 1932. Carbondale, IL Southern Illinois University Press.

Dewey, J. (1966) Logic. The Theory of Inquiry, New York: Holt, Rinehart and Winston. Dewey, J. (1997) The Public and its Problems, Athens, OH: Swallow Press.

Dillemans, R., Lowyck, J., van der Perre, G., Claeys, C. and Elen, J. (1998) New Technologies for Learning: Contribution of ICT to Innovation in Education, Leuven: Leuven University Press.

DiPardo, A. (1999) Teaching in Common: Challenges to Joint Work in Classrooms and Schools, New York: Teachers College Press.

Dolk, M., Korthagen, F.A.J. and Wubbels, T. (1995) 'What makes teachers teach the way they teach? Instruments to investigate aspects of teachers' gestalts', Paper presented at the 6th European Conference for Research on Learning and Instruction, Nijmegen, The Netherlands. 
Doyle, W. and Ponder, G. (1977) 'The practicality ethic and teacher decision making', Interchange, 8: 1-12.

Drew, P. and Heritage, J. (eds) (1992) Talk at Work: Interaction in Institutional Settings, Cambridge: Cambridge University Press.

Dreyfus, H.L. and Dreyfus, S.E. (1986) Mind our Machine: The Power of Human Intuition and Expertise in the Era of the Computer, New York: Free Press.

Drop, W. and de Rooij, M.J. (1985) Schrijven van Probleemstellingen (Cursus schrijven voor 1e jaars studenten Algemene Letteren), Utrecht: Universiteit Utrecht.

Drop, W. and de Vries, J.H.L. (1977) Taalbeheersing. Handboek voor Taalhantering, Groningen: Wolters-Noordhoff.

du Gay, P. (1996) Consumption and Identity at Work, London: Sage.

Dunne, J. (1993) Back to the Rough Ground: Practical Judgment and the Lure of Technique, Notre Dame, IN: University of Notre Dame Press.

Elbaz, F. (1991) 'Hope, attentiveness and caring for gifference: the moral voice in teaching', Paper presented at the Fifth Conference of the International Study Association on Teacher Thinking, University of Surrey, Guildford, UK.

Elbaz-Luwisch, F. (1995) 'Teachers as immigrants. Stories of self and place', Paper presented at the ISATT Conference at Brock University, Canada.

Elbaz-Luwisch, F. and Pritzker, D. (2001) 'Autobiographical texts as transformations', Paper presented in annual meeting of AERA, Seattle, USA.

Elling, M.G.M. (1984) De techniek van het schriftelijk rapporteren, Groningen: WoltersNoordhoff.

Elliott, J. (1991) Action Research for Educational Change, Buckingham: Open University Press.

Elliott, J. (2000) Towards a synoptic view of educational change in advanced industrial societies', in H. Altrichter and J. Elliott (eds) Images of Educational Change, Buckingham: Open University Press.

Elshout-Mohr, M. (1984) Dikke boeken weinig tijd, Muiderberg: Coutinho.

Engelsen, B.U. (1994) 'Ny læreplan for skoleverket' ('A new curriculum for the educational system'), Norsk pedagogisk tidskrift, 4: 244-53.

Engestrom, Y. and Middleton, D. (eds) (1998) Cognition and Communication at Work, Cambridge: Cambridge University Press.

Englund, T. (1991) 'Didaktisk kompetens', Didactica Minima, 18-19: 8-17.

Englund, T. (2001) 'Rethinking democracy and education: towards an education of deliberative citizens', Journal of Curriculum Studies, 32: 305-13.

Entwistle, N.J. and Ramsden, P. (1983) Understanding Student Learning, London: Croom-Helm.

Epstein, A. (1978) Ethos and Identity, London: Tavistock.

Ethell, R.G. (1997) 'Reconciling propositional and procedural knowledge: beginning teachers' knowledge in action', unpublished doctoral thesis, Griffith University, Brisbane, Australia.

Ethell, R.G. (2000) 'Teacher education or teacher training? Challenges of a changing educational context', Paper presented at the Teacher Education Forum of Aotearoa New Zealand, Christchurch, New Zealand.

Ewing, R. and Smith, D. (1999) 'Preparing Australia's teachers for the 21 st century: the master of teaching experience', AERA Annual Conference, Montreal.

Farber, B. (1991) Crisis in Education, San Francisco, CA: Jossey-Bass. 
Farber, E.I. (1984) 'Alternatives to the term paper', New Directions for Teaching and Learning, 18: 45-53.

Featherstone, D., Munby, H. and Russell, T. (1997) Learning to teach: the learning is in the experience', in D. Featherstone, H. Munby and T. Russell (eds), Finding a Voice While Learning to Teach (pp. 7-14), London: Falmer Press.

Feibleman, J.K. (1972) Scientific Method. The Hypothetico-Experimental Laboratory Procedure of the Physical Sciences, The Hague: Martinus Nijhoff.

Fennema, E., Carpenter, T.P., Franke, M.L., Levi, L., Jacobs, V.R. and Empson, S.B. (1996) 'A longitudinal study of learning to use children's thinking in mathematics instruction', Journal for Research in Mathematics Education, 27: 403-34.

Fenstermacher, G.D. (1994)' The knower and the known: the nature of knowledge in research on teaching', Review of Research in Education, 20: 3-56.

Fergusson, R. (1994) Managerialism and education', in J. Clarke, A. Cochrane and E. McLaughlin (eds) Managing Social Policy, London: Sage Publications.

Flanagan, F.M. (1987) Survey of former students of high schools in the Palm Beach County school district, Boca Raton, Florida Atlantic University.

Florio-Ruane, S. and Raphael, T.E. (2001) 'Reading lives: learning about culture and literacy in teacher study groups', in C.M. Clark (ed.) Talking Shop: Authentic Conversation and Teacher Learning (pp. 64-81), New York: Teachers College Press.

Ford, J.E. and Perry, D.R. (1982) 'Research paper instruction in the undergraduate writing programme', College English, 44: 825-31.

Fraassen, B.C. van (1980) The Scientific Image, Oxford: Clarendon Press.

Franke, M.L., Carpenter, T., Fennema, E., Ansell, E. and Behrend, J. (1998) 'Understanding teachers' self-sustaining, generative change in the context of professional development', Teaching and Teacher Education, 14(1): 67-80.

Freidson, E. (2001) Professionalism: The Third Logic, Oxford: Policy Press

Freire, P. (1970) Pedagogy of the Oppressed, New York: Seabury Press.

Freire, P. (1983) Pedagogy of the Oppressed, New York: Continuum.

Fuchs, J.G. (1987) 'Making history something to think about', Learning, 16: 80-2.

Fullan, M. (1982) The Meaning of Educational Change, Toronto: Ontario Institute for Studies in Education Press.

Fullan, M. (1993) Change Forces, London: Falmer Press.

Fullan, M. (2000) 'The return of large-scale reform', Journal of Educational Change, 1: 5-28

Furlong, J., Barton, L., Miles, S., Whiting, C. and Whitty, G. (2000) Teacher Education in Transition, Buckingham: Open University Press.

Gabrielli, D.L. (1981) 'The importance of research and legal writing in the law school education', Albany Law Review, 46: 1-5.

Gaden, G. (1990) 'Rehabilitating responsibility', Journal of Philosophy of Education, 24(1): 27-38.

García Díaz, J.E. (1999) 'Las ideas de los alumnos', Cuadernos de Pedagogía, 276: 58-64.

Garcia, M.E. (1988) 'A system of thesis and dissertation supervision: helping graduate students succeed', Teaching of Psychology, 15: 186-91.

Garrison, J.W. (1988) 'Hintikka, Laudan and Newton: an interrogative model of scientific inquiry', Synthese, 74: 145-71. 
Gearhart, M. and Wolf, S.A. (1994) 'Engaging teachers in assessment of their students' writing: the role of subject matter knowledge', Assessing Writing, 1: 67-90.

Geerligs, T. (1991) 'Scriptiebeoordeling', Onderzoek van Onderwijs, 20: 35-38.

Geertz, C. (1973) The Interpretation of Cultures, New York: Basic Books.

Geertz, C. (1983) Local Knowledge, New York: Basic Books.

Gephart, W.J. and Ingle, R.B. (eds) (1968) Educational Research. Selected Readings, Columbus, OH: Charles E. Merrill.

Gerdes, H. and Mallinckrodt, B. (1994) 'Emotional, social, and academic adjustment of college-students: a longitudinal study of retention', Journal of Counselling and Development, 72(3): 281-8.

Gergen, K. and Gergen, M. (1988) 'Narrative and the self as relationship', in L. Berkowitz (ed.) Advances in Experimental Social Psychology, 21, New York: Academic Press.

Geurts, J.P.M. (1978) Feit en theorie. Kernproblemen in de wetenschapsleer, Assen: Van Gorcum.

Geurts, P.A.T.M. (1999) Van probleem naar onderzoek. Een praktische handleiding met COO-cursus, Bussum: Coutinho.

Gibson, J.J. (1977) 'The concept of affordances', in R. Shaw and J. Bransford (eds) Perceiving, Acting, and Knowing (pp. 67-82), Hillsdale, NJ: Lawrence Erlbaum.

Goble, N.M. and Porter, J.F. (1977) The Changing Role of the Teacher: International Perspectives, Paris: UNESCO.

Goldman, A.I. (1986) Epistemology and Cognition, Cambridge: Harvard University Press.

Gonçalves, F.R. (2000) Movimentação das expectativas dos alunos durante o decurso do seu primeiro ano na Universidade', in Transição para o Ensino Superior (pp. 111-17), Braga: Universidade do Minho.

Gonzalez Pienda, J.A., Perez, J.C, Gonzalez Pumariega, S. and Garcia, M.S. (1997) 'Self-concept, self-esteem and school learning', Psicothema, 9(2): 271-89.

Goodlad, J. (1991) 'Why we need a complete redesign of teacher education', Educational Leadership, 49(3): 4-6.

Goodlad, J. (1994) Educational Renewal, San Francisco, CA: Jossey-Bass.

Goodlad, J. (1999) 'Whither schools of education?', Journal of Teacher Education, 50(5): 325-38.

Goodson, I. (1995) 'Education as a practical matter: some issues and concerns', Cambridge Journal of Education, 25: 137-48.

Goodson, I. (2000) 'Professional knowledge and the teacher's life and work', in C. Day, A. Fernandez, T.E. Hauge and J. Möller (eds) The Life and Work of Teachers', International Perspectives in Changing Times, London and New York: Falmer Press.

Gouinlock, J. (ed.) (1994) The Moral Writings of John Dewey. Amherst, NY: Prometheus Books.

Gratch, B. (1985) ‘Toward a methodology for evaluating research paper bibliographies', Research Strategies, 3: 170-7.

Greene, M. (1994) 'Epistemology and educational research: the influence of recent approaches to knowledge', in L. Darling-Hammond (ed.) Review of Research in Education, 20: 423-64, Washington, DC: American Educational Research Association. 
Greenfield, T.B. (1984) 'Notes from graduate seminar on research methods', Ontario Institute for Studies in Education, University of Toronto, Canada.

Greeno, J.G. (1978) 'Natures of problem-solving abilities', in W.K. Estes (ed.) Handbook of Learning and Cognitive Processes. Volume 5: Human Information Processing (pp. 239-69), Hillsdale, NJ: Prentice-Hall.

Greeno, J.G. (1998) 'The situativity of knowing, learning, and research', American Psychologist, 52(12): 5-26.

Groot, A.D. de (1981) Methodologie. Grondslagen van onderzoek en denken in de gedragswetenschappen, The Hague: Mouton.

Grossman, P., Wineburg, S. and Woolworth, S. (2001) 'Toward a theory of teacher community', Teacher College Record, 103(6): 942-1012.

Grumet, M. (1987) 'The politics of personal knowledge', Curriculum Inquiry, 17: 31929.

Gudmundsdottir, S. (1996) 'The teller, the tale, and the one being told: the narrative nature of the research interview', Curriculum Inquiry, 23(3): 293-306.

Gudmundsdottir, S. (2001) Narrative research on school practice', in V. Richardson (ed.) Handbook of Research on Teaching (pp. 226-240), Washington, DC: American Educational Research Association.

Gumperz, J. and Hymes, D. (eds) (1972) Directons in Sociolinguistics: The Ethnography of Communication, New York: Holt, Rinehart and Winston.

Gusfield, J. (1975) Community: A Critical Response, Oxford: Basil Blackwell.

Guskey, T.R. and Passaro, P.D. (1994) 'Teacher efficacy: a study of construct dimensions', American Educational Research Journal, 31(3): 627-43.

Gustavsson, B. (1996) Bildning $i$ vår tid (Learning and Education in our Time), Borås: Wahlström and Widstrand.

Gutierrez, R. (1996) 'Practices, beliefs and cultures of high school mathematics departments: understanding their influence on student advancement', Journal of Curriculum Studies, 28(5): 495-529.

Gutmann, A. (1987) Democratic Education, Princeton, NJ: Princeton University Press.

Habermas, J. (1987) The Theory of Communicative Action, Volume Two. Lifeworld and System: A Critique of Functionalist Reason (transl. Thomas McCarthy), Boston, MA: Beacon Press.

Habermas, J. (1996) Moral Consciousness and Communicative Action, Boston, MA: MIT Press.

Haigh, N. (1994) 'Promoting intellectual independence: a legislative catalyst', Proceedings of the Annual Conference of the Higher Education Research and Development Society of Australasia, Canberra, Australia.

Haigh, N. (1996) 'Tell me what I am doing right. Tell me what I am doing wrong', Proceedings of the Annual Conference of the Higher Education Research and Development Society of Australasia, Perth, Australia.

Haigh, N. (2000a) 'Teaching teachers about reflection and ways of reflecting', Waikato Journal of Education, 6: 87-98.

Haigh, N. (2000b) 'Everyday academic life as an expression of scholarship: a staff development perspective on Ernest Boyer's views', Paper presented to the Conference of the International Consortium of Educational Developers in Higher Education, Bielefeld, Germany.

Haigh, N. and Katterns, R. (1984) 'Teacher effectiveness: problem or goal for teacher education', Journal of Teacher Education, 33(5): 23-7. 
Halliburton, D. 1997 'John Dewey: a voice that still speaks to us', Change (Washington, DC), Jan/Feb: 24-9.

Halliday, T.C. (1987) Beyond Monopoly: Lawyers, State Crises and Professional Empowerment, Chicago: University of Chicago Press.

Hamilton, D. (2001) 'In Schwabian fields. A review essay of teaching as reflective practice: the German didactic tradition', in I. Westbury, S. Hopmann and K. Riquarts (eds) Pedagogy, Culture and Society, 9: 119-28.

Hammersley, M. (1984) 'Staffroom news', in A. Hargreaves and P. Woods (eds) Classrooms and Staffrooms: The Sociology of Teachers and Teaching (pp. 20314), Milton Keynes: Open University Press.

Hargreaves, A. (1992) 'The cultures of teaching', in A. Hargreaves and M. Fullan (eds) Understanding Teacher Development, New York: Teachers College Press.

Hargreaves, A. (1994) Changing Teachers, Changing Times: Teachers' Work and Culture in the Postmodern Age, New York: Teachers College Press.

Hargreaves, A. and Fullan, M.G. (eds) (1992) Understanding Teacher Development, New York: Teachers College Press.

Hargreaves, D. (1994) 'The new professionalism: the synthesis of professional and institutional development', Teaching and Teacher Education, 10(4): 423-38.

Hargreaves, D. (1996) 'Teaching as a research-based profession: possibilities and prospects', Teacher Training Agency Annual Lecture, mimeo.

Hargreaves, D.H. (1977) 'The process of typification in classroom interaction: models and methods', British Journal of Educational Psychology, 47: 274-84.

Harland, J. and Kinder, K. (1997) 'Teachers' continuing professional development: framing a model of outcomes', Journal of In-service Education, 23(1): 71-84.

Harris, A. (1996) 'Teaching as a profession: response to Eric Hoyle', in K. Watson, C. Modgil and S. Modgil (eds) Teachers, Teacher Education and Training (pp. 55-7), London: Cassell.

Hart, R.A. (1992) 'Children's participation: from tokenism to citizenship', Innocenti Essays, 4: 43. Florence: UNICEF.

Harter, S. (1996) 'Historical roots of contemporary issues involving self-concept', in B. Bracken (ed.) Handbook of Self-concept: Developmental, Social and Clinical Considerations (pp. 1-37), New York: John Wiley.

Hartley, J. (2000) 'Nineteen ways to have a viva', PsyPAG Quarterly Newsletter, 35(June): $16-20$.

Hartley, J. and Jory, S. (2000) 'Lifting the veil on the viva: the experience of psychology PhD candidates in the UK', Psychology Teacher Review, 9(2): 76-90

Hativa, N. and Birenbaum, M. (2000) 'Who prefers what? Disciplinary differences in students' preferred approaches to teaching and learning styles', Research in Higher Education, 41(2): 209-36.

Have, P. and Psathas, G. (eds) (1995) Situated Order: Studies in the Social Organization of Talk and Embodied Activities, Washington, DC: International Institute for Ethnomethodology and Conversation Analysis and University Press of America.

Hayes, H.E. (1999) 'Learning to live together: some implications for teacher education', Paper presented at the Fifth UNESCO-ACEID Conference, Bangkok, Thailand, December.

Hayes, K., King, E. and Richardson, J. (1997) 'Mature students in higher education. Approaches to studying in access students', Studies in Higher Education, 22(1): 19-31. 
Hayward, G., Childs, A., Kurina, L. and Black, A. (1999) 'A science curriculum for twenty-first century: throwing the baby out with the bath water?', Paper presented at 9th Biennial Conference International Study Association on Teachers and Teaching (ISATT) in Dublin, July.

Hazeu, C.A. (1990) 'Universitaire onderzoekscholen', Tijdschrift voor Hoger Onderwijs, $8: 142-9$.

Healey, M. (2000) 'Developing the scholarship of teaching in higher education: a discipline-based approach', Higher Education Research and Development, 19(2): 169-89.

Heathcote, D. (1984) 'Collected writings on education and drama', in L. Johnson and C. O’Neill (eds), London and Melbourne: Hutchinson.

Helsby, G., Knight, P., McCullouch, G., Saunders, M. and Warburton, T. (1997) Professionalism in Crisis, A report to participants on the professional cultures of teachers research project, Lancaster University, January.

Hempel, C.G. (1966) Filosofie van de Natuurwetenschappen, Utrecht: Spectrum (Aula). Hernandez, N. (1985) 'The fourth, composite "R" for graduate students: research', research paper, University of Wyoming.

Heus, P. de, van der Leeden, R. and Gazendam, B. (1995) Toegepaste data-analyse. Technieken voor niet-experimenteel onderzoek in de sociale wetenschappen, Utrecht: Lemma.

Hickman, L.A. and Alexander, T.M. (1998) The Essential Dewey, Volume 2: Ethics, Logic, Psychology, Indianapolis: Indiana University Press.

Higgins, E. (1996) 'The "self-digest": self-knowledge serving self-regulatory functions', Journal of Personality and Social Psychology, 71(6): 1062-83.

Higgins, J.S., Maitland, G.C., Perkins, J.D., Richardson, S.M. and Warren Piper, D. (1989) 'Identifying and solving problems in engineering design', Studies in Higher Education, 14: 169-81.

Hill, B.C. (1989) 'Written research: an endangered species?', Journal of Teaching Writing, 8: 67-75.

Hillocks, G. (1982) 'Inquiry and the composition process: theory and research', College English, 44: 659-73.

Hillway, T. (1969) Handbook of Educational Research. A Guide to Methods and Materials, Boston, MA: Houghton Mifflin.

Hindmarsh, J. and Heath, C. (1998) Video and the analysis of objects in action. Communication and Cognition, 31(2/3): 111-30.

Hinkley, K. and Andersen, S. (1996) 'The working self-concept in transference: significant-other activation and self change', Journal of Personality and Social Psychology, 71(6): 1279-95.

Hintikka, J. (1981) 'On the logic of an interrogative model of scientific inquiry', Synthese, 47:69-83.

Hockey, J. (1995) 'Change and the social science PhD: supervisors' responses', Oxford Review of Education, 21(2): 195-206.

Hofstee, W.B.K. (1980) De empirische discussie. Theorie van het sociaalwetenschappelijk onderzoek, Meppel: Boom.

Holleman, W., Berg, I. van den, Oost, H., Tholen, B. and Admiraal, W. (1998) 'Vijf definities van academische vorming', Tijdschrift voor Hoger Onderwijs and Management, 5: 4-9.

Holquist, M. (1990) Dialogism: Bakhtin and his World, London: Routledge. 
hooks, b. (1994) Teaching to Transgress: Education as a Practice of Freedom, New York: Routledge.

Horn, I.S. (2001) 'Fast kids, slow kids, lazy kids: conceptions of students and subject matter in two high school math departments', Paper presented at the annual meeting of the American Educational Research Association, Seattle.

Hout, J.F.M.J. van (1988) Onderzoekers in opleiding. Een verklaringsmodel voor problemen van promotie-assistenten en assistenten in opleiding, Nijmegen: IOWO.

Hout, J.F.M.J. van, Hulshof, M.J.F. and Jurgens, H.J.H. (1991) De opleiding van onderzoekers: Een evaluatie-onderzoek naar het functioneren van het AiOstelsel, Nijmegen: IOWO.

Huber, M. (1999) 'Disciplinary styles in the scholarship of teaching: reflections on the Carnegie Academy for the Scholarship of Teaching and Learning', Paper presented at the Seventh International Improving Student Learning Symposium, University of York, UK.

Huber, R.M. (1992) How Professors Play the Cat Guarding the Cream, Fairfax, VA: George Mason University Press.

Huberman, M. (1989) 'The professional life cycle of teachers', Teachers College Record, 91(1): 31-56.

Huberman, M. (1992) 'Teacher development and instructional mastery', in A. Hargreaves and M. Fullan (eds) Understanding Teacher Development, London: Cassell.

Huberman, M. (1993a) 'Changing minds: the dissemination of research and its effects on practice and theory', in C. Day, J. Calderhead and P. Denicolo (eds), Research on Teacher Thinking: Understanding Professional Development (pp. 34-52), London: Falmer Press.

Huberman, M. (1993b) 'The model of the independent artisan in teachers' professional relations', in J.W. Little and M.W. McLaughlin (eds) Teachers' Work: Individuals, Colleagues and Contexts (pp. 11-50), New York: Teachers College Press.

Huberman, M. (1995a) 'Networks that alter teaching: conceptualisations, exchanges and experiments', Teachers and Teaching: Theory and Practice, 1(2): 193221.

Huberman, M. (1995b) The Lives of Teachers, London: Cassell.

Huberman, M. and Miles, M. (1984) Innovation up Close, New York: Plenum.

Huberman, M. and Vandenberghe, R. (eds) (1999) Understanding and Preventing Teacher Burnout: A Sourcebook of International Research and Practice, Cambridge: Cambridge University Press.

Husserl, E. (1970) The Crisis of European Sciences, Evanston, IL: Northwestern University Press.

Husu, J. (2001) 'Teachers at cross-purposes: a case-report approach to study the ethical dilemmas in teaching', Journal of Curriculum and Supervision, 17: 67-89.

Hutchins, E. (1996) 'Learning to navigate', in S. Chaiklin and J. Lave (eds), Understanding Practice: Perspectives on Activity and Context (pp. 35-63), Cambridge: Cambridge University Press.

Huthching, P. and Shulman, L. (1999) 'The scholarship of teaching: new elaborations and new developments', Change, 31(5): 10-15.

Jackson, P.W. (1992) 'The enactment of the moral in what teachers do', Curriculum Inquiry, 22: 401-7. 
Janssens, J.M.M. (1988) Ogen doen onderzoek. Een inleiding in de methoden van sociaalwetenschappelijk onderzoek, Lisse: Swets and Zeitlinger.

Jeffs, T. (1986) 'Children's rights at school', in B. Franklin (ed.), The Rights of Children, London: Basil Blackwell.

Jones, M., Carter, G. and Rua, M. (1999) 'Children's concepts: tools for transforming science teachers' knowledge', Science Education, 83: 545-57.

Jong, A.J.M. (1986) 'Kennis en het oplossen van vakinhoudelijke problemen (Een voorbeeld uit een natuurkundig domein)', dissertation, Technische Hogeschool Eindhoven, Eindhoven.

Jongepier, P. (1990) 'Scriptieproblemen voorkomen', Onderzoek van Onderwijs, November: 62-3.

Joram, E. and Gabriele, A. (1998) Preservice teachers' prior beliefs: transforming obstacles into opportunities. Teaching and Teacher Education, 14(2): 175-91.

Jovchelovitch, S. and Bauer, M. (2000) 'Narrative interviewing', in M.W. Bauer and G. Gaskell (eds) Qualitative Researching with Text, Image and Sound. A Practical Handbook (pp. 58-74), London: Sage Publications.

Joyce, B. and Weil, M. with Showers, B. (1992) Models of Teaching, Boston, MA: Allyn and Bacon.

Kagan, D.M. (1992a) 'Implications of research on teacher belief', Educational Psychologist, 27(1): 65-90.

Kagan, D.M. (1992b) 'Professional growth among preservice and beginning teachers', Review of Educational Research, 62(2): 129-69.

Kaldeway, J. (in press) 'Kunst en kunde van het studeren', in: J. Kaldeway (ed.) Leren leren in het hoger onderwijs, Leuven: Acco.

Kaplan, A. (1964) The Conduct of Inquiry, New York: Chandler.

Kelchtermans, G. (1993) 'Getting the story, understanding the lives: from career stories to teachers' professional development', Teaching and Teacher Education, 9(5/6): 443-56.

Kelchtermans, G. (1994) 'Biographical methods in the study of teachers' professional development', in I. Carlgren, G. Handal and S. Vaage (eds) Teachers' Minds and Actions: Research on Teachers' Thinking and Practice (pp. 93-108), London: Falmer Press

Kelchtermans, G. (1996) 'Teacher vulnerability: understanding its moral and political roots', Cambridge Journal of Education, 26: 307-23.

Kelly, G.A. (1955) The Psychology of Personal Constructs, 1 and 2, New York: Norton.

Kember, D. and Gow, L. (1994) 'Orientations to teaching and their effect on the quality of student learning', Journal of Higher Education, 65(1): 58-74.

Kember, D. and Leung, D. (1999) 'The dimensionality of approaches to learning: An investigation with confirmatory factor analysis on the structure of the SPQ and LPQ', British Journal of Educational Psychology, 68: 395-407.

Kevelson, R. (1988) 'Hows of whys and whys of hows: relation of method and cause in inquiry', Synthese, 74: 91-106.

Kissock C. and Kolontai, Z. (1993) 'A network of international teacher education centers', European Journal of Teacher Education, 16(1): 61-8.

Kjolseth, R. (1972) 'Making sense: natural language and shared knowledge in understanding', in J. Fishman (ed.) Advances in the Sociology of Language, Vol. 2 (pp. 50-76), The Hague: Mouton. 
Kleiner, S.A. (1981) 'Problem solving and discovery in the growth of Darwin's theories of evolution', Synthese, 47: 119-62.

Kleiner, S.A. (1988) 'Erotetic logic and scientific inquiry', Synthese, 74: 19-46.

Kline, R.R. (1989) 'Teaching advanced level students to hypothesize: proceeding one step at a time', Foreign Language Annals, 22: 255-62.

Knowles, M.S. (1990) The Adult Learner: A Neglected Species, 4th edn, Houston, TX: Gulf Publishing.

Kohlberg, L. (1981) Essays on Moral Development, San Francisco, CA: Harper and Row.

Kompf, M. and Neufeld, J. (1997) 'The person the professor is', Paper presented to the Eighth Biennial meeting of the International Study Association on Teachers and Teaching, Kiel, Germany, October.

Kondo, D. (1990) Crafting Selves, Chicago, IL: University of Chicago Press.

Korthagen, F. (2001) Linking Practice and Theory: The Pedagogy of Realistic Teacher Education, Mahwah, NJ: Lawrence Erlbaum Associates.

Korthagen, F. and Kessels, J. (1999) 'Linking theory and practice: changing the pedagogy of teacher education', Educational Researcher, 28(4): 4-17.

Korthagen, F. and Lagerwerf, B. (1994) 'Levels in learning about teaching, towards a theory on teacher knowledge', Paper from SITE Colloquium, Simon Fraser University, Canada.

Korthagen, F., Kessels, J. and Lagerwerf, B. (1997) 'Towards a new paradigm in teacher education: A new way of relating teacher cognition and teacher behavior', Paper presented at EARLI Conference, Athens, Greece.

Krapp, J.V. (1988) 'Teaching research skills: a critical-thinking approach', School Library Journal, 34(5): 32-5.

Kruijer, G.J. (1958) Observeren en redeneren. Een inleiding tot de kennisvorming in de sociologie, Meppel: Boom.

Kuhn, T.S. (1970) The Structure of Scientific Revolutions, Chicago: University of Chicago Press.

Kuhn, T.S. (1976) De structuur van wetenschappelijke revoluties (B. Willink, transl.), Meppel: Boom.

Kukkonen, M. (2000) 'High school students' working self-concepts and expectations for teacher action: A contextual approach', a poster presentation in Seventh Workshop on Achievement and Task Motivation and Earli SIG: Motivation and Emotion, May 12-15.

Kuypers, G. (1986) ABC van een onderzoeksopzet, Muiderberg: Coutinho.

Kvale, S. (1996) InterViews. An Introduction to Qualitative Research Interviewing, Thousand Oaks, CA: Sage Publications.

Labaree, D. (2000) 'Educational researchers: living with a lesser form of knowledge', in C. Day, A. Fernandez, T.E. Hauge and J. Moller (eds) The Life and Work of Teachers: International Perspectives in Changing Times, London: Falmer Press.

Laferrière, T. (2000) 'In-service education through face-to-face and on-line interaction in learning communities', Paper presentation at the ATEE conference, Barcelona. On-line. Available: http://www.telelearning-pds.org/tlpds/atee.pdf.

Laferrière, T., Breuleux, A., Erickson, G. and Lang, M. (2002) 'Network-supported PDSs: teacher preparation and professional development for the knowledge age', Paper presentation at the AERA Conference, New Orleans. 
Lagerwaard, H. and Mul, J. (1982) Scripties onderzocht. Een analyse van de kwaliteit van doctoraalscripties in de culturele antropologie, de politicologie en de sociologie en de tijd, die het schrijven ervan kost. Met aanbevelingen ter verbetering, Leiden: Rijksuniversiteit Leiden, Centrum voor Onderzoek van Maatschappelijke Tegenstellingen.

Lagerweij, N.A.F. (1992) 'Naar een onderwijsconcept voor de academische vorming', Utrecht: Universiteit Utrecht, Vakgroep Onderwijskunde, internal memo.

Lagrosen, S. (1997) 'Kvalitetsstyrning i skolans? En analys av TQM:s tillämpbarhet inom den svenska grundskolan sett från en företagsekonomisk utgångspunkt', Doktorsavhandling vid Företagsekonomiska institutionen, Stockholm University.

Lakatos, I. and Musgrave, A. (eds) (1984) Criticism and the Growth of Knowledge. Proceedings of the International Colloquium in the Philosophy of Science, London, 1965, Volume 4, Cambridge: Cambridge University Press.

Lamers, H.A.J.M. (1986) Hoe schrijf ik een wetenschappelijke tekst, Muiderberg: Coutinho.

Lampert, M. (2000) 'Issues in the representation of teaching practice: Difficulties and opportunities in multimedia archives', Paper presented at the annual meeting of the American Educational Research Association, for the Symposium on Issues in the Representation of Teaching Practice, New Orleans.

Lang, M. (2003) Crossing Boundaries of Science Subjects: A Collaborative Perspective for Teacher Education. On-line. Available: http://www.leeds.ac.uk/educol/ beia.htm.

Lang, M., Drake, S. and Olson, J. (in press) 'Discourse and the new didactics of scientific literacy', Journal of Curriculum Studies.

Laudan, L. (1977) Progress and Its Problems, Berkeley, CA: University of California Press.

Lauriala, A. (1992) 'The impact of innovative pedagogy on teacher thinking and action: a case study of an in-service course for teachers in integrated teaching', Teaching and Teacher Education, 8(5/6): 523-36.

Lauriala, A. (1995) Student Teaching in a Different Environment. Examining the Development of Students ' Craft Knowledge in the Framework of Interactionist Approach to Teacher Socialisation (Report No. 96), Oulu, Finland: University of Oulu, Faculty of Education.

Lauriala, A. (1997) Development and Change of Professional Cognitions and Action Orientations of Finnish Teachers, Oulu, Finland: Acta Universitatis Ouluensis. Scientiae Rerum Socialium E 27.

Lave, J. (1996) 'The practice of learning', in S. Chaiklin and J. Lave (eds) Understanding Practice: Perspectives on Activity and Context (pp. 3-32), Cambridge: Cambridge University Press.

Lave, J. and Wenger, E. (1991) Situated Learning: Legitimate Peripheral Participation, Cambridge: Cambridge University Press.

Lawson, A.E. (1990) 'Use of reasoning to a contradiction in grades three to college', Journal of Research in Science Teaching, 27: 541-51.

Levin, B. (2001) 'Reflections on factors that influence the personal and professional lives of teachers', Paper presented to the American Educational Research Association, Seattle. 
Levin, B.B. (1995) 'Using the case method in teacher education: the role of discussion and experience in teachers' thinking about cases', Teaching and Teacher Education, 11(1): 63-70.

Ley, H. de (trans1.) (1977) Aristoteles. Metafysica A (Introduction, pp. 9-50), Baarn: Het Wereldvenster Dixit.

Lieberman, A. and Wood, D. (2001) 'When teachers write: of networks and learning', in A. Lieberman and L. Miller (eds) Teachers Caught in the Action: Professional Development that Matters (pp. 174-87), New York: Teachers College Press.

Liston, D. and Zeichner, K. (1991) Teacher Education and the Social Conditions of Schooling, London and New York: Routledge.

Little, J.W. (1982) 'Norms of collegiality and experimentation: workplace conditions of school success', American Educational Research Journal, 19: 325-40.

Little, J.W. (1987) 'Teachers as colleagues', in V. Richardson-Koehler (ed.) Educators' Handbook: A Research Perspective (pp. 491-518), New York: Longman.

Little, J.W. (1990) 'The persistence of privacy: autonomy and initiative in teachers' professional relations', Teachers College Record, 91(4): 509-36.

Little, J.W. (1999) Teachers' professional development in the context of secondary school reform: findings from a three-year study of restructuring schools', Paper presented at the annual meeting of the American Educational Research Association, Montreal.

Little, J.W. (2001) 'Locating learning in teachers' communities of practice', Paper presented at the annual meeting of the American Educational Research Association, Seattle.

Lodge, A. and Lynch, K., (2000) 'Power: a central educational relationship', Irish Educational Studies, 19: 46-67.

Long, T.J., Convey, J.J. and Chwalek, A.R. (1985) Competing Dissertations in the Behavioral Sciences and Education, San Francisco, CA: Jossey-Bass.

Lortie, D. (1975) Schoolteacher, Chicago, IL: University of Chicago Press.

Loughran, J. (ed.) (1999) Researching Teaching: Methodologies and Practices for Understanding Pedagogy, London: Falmer Press.

Loughran, J., Brown, J. and Doeke, B. (2001) 'Continuities and discontinuities: the transition from pre-service to first-year teaching', Teachers and Teaching: Theory and Practice, 7(1): 7-25.

Louis, K.S. and Kruse, S.D. (1995) Professionalism and Community: Perspectives on Reforming Urban Schools, Thousand Oaks, CA: Corwin Press.

Lovlie, L. (1997) 'Utdanningsreformens paradoxer' ('The paradoxes of the educational reform'), Norsk pedagogisk tidskrift, 6: 350-61.

Lowijck, J. (1991) 'Vaardigheden: inleiding op een thema', Tijdschrift voor Hoger Onderwijs, 9: 70-6.

MacDonald, S.P. (1987) 'Problem definition in academic writing', College English, 49: 315-31.

Mahony, P. and Hextall, I. (2000) Reconstructing Teaching: Standards, Performance and Accountability, London: RoutledgeFalmer.

Malin, M. (1999) 'I'm rather tired of hearing about it ... challenges in constructing an effective anti-racism teacher education program', Curriculum Perspectives, 19(1): 1-11.

Maltha, D.J. (1979) Literatuuronderzoek en schriftelijk rapporteren, Wageningen: Centrum voor Landbouwpublikaties en Landbouwdocumentatie. 
Mancini, V., Wuest, D., Vantine, K. and Clark, E. (1984) 'Use of instruction in interaction analysis on burned out teachers: its effects on teaching behaviours, level of burnout and academic learning time', Journal of Teachers in Physical Education, 3(2): 29-46.

Marginson, S. (1997) Markets in Education, Sydney: Allen and Unwin.

Margulies, P. (1996) 'The lawyer as caregiver: child client's competence in context', Fordham Law Review, 64: 1473-504.

Marsh, H.W. (1990) 'The structure of academic self-concept: the Marsh/Shavelson model', Journal of Educational Psychology, 82(4): 623-36.

Martín del Pozo, R. and Rivero, A. (2001) 'Construyendo un conocimiento profesionalizado para enseñar ciencias en la Educación Secundaria: los ámbitos de investigación profesional en la formación inicial del profesorado', Revista Interuniversitaria de Formación del Profesorado, 40: 63-79.

Marton, F. (1995) 'Cognosco ergo sum. Reflections on reflections', Nordiskpedagogik, 15(2): 72-84.

Marton, F. and Booth, S. (1996) 'The learner's experience of learning', in D. Olson and N. Torrance (eds) The Handbook of Education and Human Development. New Models of Learning, Teaching and Schooling (pp. 534-64), Cambridge: Blackwell.

Marton, F. and Booth, S. (1997) Learning and Awareness, Mahwah, NJ: Lawrence Erlbaum Associates.

Marton, F. and Tsui, A. (2004) Classroom Discourse of Learning. Mahwah, NJ: Lawrence Erlbaum.

Marton, F., Watkins, D. and Tang, C. (1997) 'Discontinuities and continuities in the experience of learning: an interview study of high-school students in Hong Kong', Learning and Instruction, 7 (1): 21-48.

McEwan, H. (1997) 'The functions of narrative and research on teaching', Teaching and Teacher Education, 13(1): 85-92.

McLaughlin, M.W. and Talbert, J.E. (2001) Professional Communities and the Work of High School Teaching, Chicago: University of Chicago Press.

McMahon, A. (1999) 'Promoting continual professional development for teachers: An achievable target for school leaders?', in T.L. Bush, R. Bell, R. Bolam, R. Glatter and P. Ribbens (eds) Educational Management: Redefining Theory, Policy and Practice, London: Paul Chapman.

Mead, G.H. (1962) Mind Self and Society from the Standpoint of a Social Behaviorist (ed. C.W. Morris), Chicago, IL: University of Chicago Press.

Mead, G.H. (1973) Geist, Identität und Gesellschaft, Baden-Baden: Suhrkamp.

Medawar, P. (1991) The Threat and the Glory, D. Pyke (ed.), Oxford: Oxford University Press.

Meerling (1981) Methoden en technieken van psychologisch onderzoek, Part I, Meppel: Boom.

Mehan, H. (1996) 'Beneath the skin and between the ears: a case study in the politics of representation', in S. Chaiklin and J. Lave (eds) Understanding Practice: Perspectives on Activity and Context (pp. 241-68), Cambridge: Cambridge University Press.

Melucci, A. (1996) The Playing self. Person and Meaning in the Planetary Society, Cambridge: Cambridge University Press. 
Menter, I., Muschamp, Y., Nicholls, P., Ozga, J. and Pollard, A. (1997) Work and Identity in the Primary School, Buckingham: Open University Press.

Merleau-Ponty, M. (1962) Phenomenology of Perception, New York: Routledge and Kegan Paul.

Merriam, S.B. (1994) Fallstudien som forskningsmetod, Lund: Studentlitteratur.

Meyer, M. (1988) 'The revival of questioning in the twentieth century', Synthese, 74: 5-18.

Middleton, D. (1998) 'Talking work: argument, common knowledge, and improvisation in teamwork', in Y. Engestrom and D. Middleton (eds) Cognition and Communication at Work (pp. 233-56), Cambridge: Cambridge University Press.

Miles, M.B. and Huberman, A.M. (1994) Qualitative Data Analysis, Thousand Oaks, CA: Sage Publications.

Minick, N. (1996) 'The development of Vygotsky's thought: An introduction to thinking and speech', in D. Harry (ed.) An Introduction to Vygotsky (pp. 28-52), London: Routledge.

Mirande, M.J.A. and Wardenaar, E. (1983) Scriptieproblemen, Utrecht: Spectrum Aula.

Moerman, M. (1988) Talking Culture: Ethnography and Conversation Analysis, Philadelphia, PA: University of Pennsylvania Press.

Moses, I. (1985) Supervising Postgraduates, Kensington: Higher Education Research and Development Society of Australia.

Mulders, W. (1995) 'Wetenschappelijk onderwijs moet vaker werken met echte problemen', Tijdschrift voor Hoger Onderwijs en Management, 3: 8-11.

Murphy, J.P. (1990) Pragmatism: From Peirce to Davidson, Boulder, CO: Westview Press.

Myers, G. (1986) 'Writing research and the sociology of scientific knowledge: a review of three new books', College English, 48: 595-610.

Nash, R. (1996) "Real World" Ethics. Frameworks for Educators and Human Service Professionals, New York: Teachers College Press.

Neale, J.M. and Liebert, R.M. (1973) Science and Behavior. An Introduction to Methods of Research, Englewood Cliffs, NJ: Prentice-Hall.

Necka, E. (1989) 'Stimulating curiosity', Gifted Education International, 6: 25-7.

Nederhoed, P. (1985) Helder rapporteren, Deventer: Van Loghum Slaterus.

Nias, J. (1984) 'Definition and maintenance of self in primary education', British Journal of Sociology of Education, 53: 267-80.

Nias, J., Southworth, G. and Yeomans, R. (1989) Staff Relations in the Primary School, London: Cassell.

Nickles, T. (1981) 'What is a problem that we may solve it?', Synthese, 47: 85-118.

Niemi, H. (1997) 'Active learning by teachers', in D. Stern and G.L. Huber (eds) Active Learning for Students and Teachers, Reports from Eight Countries OECD. Frankfurt am Main: Peter Lang.

Nightingale, P. (1992) 'Understanding processes and problems in student writing', Studies in Higher Education, 13: 263-83.

Noam, G.G. and Fischer, K.W. (eds) (1996) Development and Vulnerability in Close Relationships, Mahwah, NJ: Erlbaum.

Noddings, N. 1998 'Thoughts on John Dewey's 'ethical principals underlying education', The Elementary School Journal (Chicago, IL), 98(5): 479-88.

Noel, J. (1999) 'On the varieties of phronesis', Educational Philosophy and Theory, 31: $273-289$. 
Noffke, S. (1997) 'Professional, personal, and political dimensions of action research', in M. Apple (ed.) Review of Research in Education, 22: 305-43. Washington, DC: American Educational Research Association.

Norton, L.S. and Crowley, C.M. (1995) 'Can students be helped to learn how to learn an evaluation of an approaches to learning program for first year degree students', Higher Education, 29(3): 307-28.

Nunnally, J.C. (1978) Psychometric Theory, New York: McGraw-Hill.

Ogden, T. (2001) Sosial kompetanse og problematferd i skolen (Social Competence and Problem Behavior in School), Oslo: Gyldendal Norsk Forlag.

Oost, H. (1991a) 'Inperken I', Los-contact, 22: 5-8.

Oost, H. (1991b) 'Inperken II', Los-contact, 23: 6-10.

Oost, H. (1995) Hoe schriff ik een betere scriptie. Een nieuwe methode voor het schrijven van scripties en andere teksten, Amsterdam: Contact.

Oost, H. (1999) 'De kwaliteit van probleemstellingen in dissertaties. Een evaluatie van de wijze waarop vormtechnische aspecten van probleemstelllingen worden uitgewerkt', dissertation, Utrecht: W.C.C.

Oost, H. and Jong, J. de (1996) 'Cursus scriptie schrijven', in J. Kaldeway, J. Haenen, $\mathrm{S}$. Wils and G. Westhoff (eds) Leren leren in didactisch perspectief, Groningen: Wolters-Noordhoff.

Oost, H. and Jong, J. de (1997) Scripties en verslagen ontwerpen, Utrecht: Universiteit Utrecht (IVLOS, reader).

Oost, H., Holleman, W., Berg, I. van den, Thoolen, B. and Milius, J. (1998) Naar een interpretatie van academische vorming, Utrecht: Universiteit Utrecht, IVLOS, Mededeling No. 60.

Orlenius, K. (1999) Förståelsens pradox. Yrkeserfarenhetens betydelse när föreskollärare blir grundskollärare (The paradox of understanding. The meaning and value of professional experience when pre-school teachers become compulsory school teachers), Göteborg: Acta Universitatis Gothoburgensis.

Orlenius, K. (2001) Värdegrunden - finns den? (The value foundation - does it exist?), Malmö: Runa.

Orr, J.E. (1996) Talking about Machines: An Ethnography of a Modern Job, Ithaca, NY: Cornell University Press.

Overduin, B. (1990) Rapporteren. Het schrijven van rapporten, notas, scripties en artikelen, Utrecht: Spectrum Aula.

Palmer, P. (1998) The Courage to Teach: Exploring the Inner Landscape of a Teacher's Life, San Francisco, CA: Jossey-Bass.

Pascarella, E.T. and Terenzini, P. (1991) How College Affects Students: Findings and Insights from Twenty Years of Research, San Francisco, CA: Jossey-Bass.

Pearson, M. (1996) 'Professionalising the PhD: education to enhance the quality of the students' experience', Higher Education, 32(3): 303-20.

Pelikan, J. (1992) The Idea of the University: A Reexamination, New Haven, CT: Yale University Press.

Pendlebury, S. (1990) 'Practical arguments and situational apperception in teaching', Educational Theory, 40: 171-9.

Perrin, R. (1987) 'Myths about research', English Journal, 76: 50-3.

Peterson, R. and Treagust, D. (1998) 'Learning to teach primary science through problembased learning', Science Education, 82: 215-37. 
Pettersson, T. and Postholm, M.B. (eds) (2003) Klasseledelse (Classroom Management) Oslo: Universitetsforlaget.

Pettersson, T., Gudmundsdottir, S., Flem, A. and "Tina" (2000) "Det levende ordet." $i$ en krevende klasse ("The living word" in a Demanding Class), Trondheim: Tapir Akademisk Forlag.

Pfeiffer, L.C. and Featherstone, H.J. (1996) “Toto, I don't think we're in Kansas anymore": Entering the Land of Public Disagreement in Learning to Teach, East Lansing: National Center for Research on Teacher Learning, Michigan State University.

Pfundt, H. and Duit, R. (1991) Student's Alternative Frameworks and Science Education. Biography, Tyskland: Institute for Science Education (Institut für die Pädagogik der Naturwissenschaften).

Phillips, E.M. and Pugh, D.S. (1987) How to Get a PhD: Managing the Peaks and Troughs of Research, Milton Keynes: Open University Press.

Pinch, T., Collins, H.M. and Carbone, L. (1997) 'Cutting up skills: Estimating difficulty as an element of surgical and other abilities', in S.R. Barley and J.E. Orr (eds) Between Craft and Science: Technical Work in US Settings (pp. 101-12), Ithaca, NY: Cornell University Press.

Polkinghorne, D.E. (1988) Narrative Knowing and the Human Sciences, Albany, NY: State University of New York Press.

Polkinghorne, D.E. (1991) 'Narrative and self-concept', Journal of Narrative and Life History, 1(2/3): 135-53.

Popkewitz, T.S. (1991) A Political Sociology of Educational Reform: Power/knowledge in Teaching, Teacher Education, and Research, New York: Teachers College Press.

Popper, K.R. (1965) Conjectures and Refutations: The Growth of Scientific Knowledge, New York: Harper and Row.

Popper, K.R. (1968) The Logic of Scientific Discovery (1935), London: Hutchinson.

Porlán, R. (1999) ‘Formulación de los contenidos escolares', Cuadernos de Pedagogía, 276: 65-70.

Porlán, R. and Rivero, A. (1998) El conocimiento de los profesores. Sevilla: Díada.

Porlán, R., Rivero, A. and Martín del Pozo, R. (1997) 'Conocimiento profesional y epistemología de los profesores I: Teoría, métodos e instrumentos', Enseñanza de las Ciencias, 15(2): 155-71.

Porlán, R., Rivero, A. and Martín del Pozo, R. (1998) 'Conocimiento profesional y epistemología de los profesores II: Estudios empíricos y conclusiones', Enseñanza de las Ciencias, 16(2): 271-89.

Posch, P. and Mair, M.G. (1997) 'Dynamic networking and community collaboration: the cultural scope of education action research', in S. Hollingsworth (ed.) International Action Research: A Casebookfor Educational Reform (pp. 26174), London: Falmer Press.

Post-primary Teachers Association (2000) 'Summary paper of PPTA concerns', Presented to the Teacher Education Liaison Day, Christchurch College of Education, Christchurch, New Zealand, August.

Powell, S.D. and McCauley, C. (2002) 'Research degree examining: common principles and divergent practices', Quality Assurance in Education (special edition 'Standards and the Doctoral Award'), 10(2): 104-16. 
Pramling, I. (1994) Kunnandets grunder, Prövning av en fenomenografisk ansats til/att utveckla barns sätt att uppfatta sin omvärld (Göteborg Studies in Educational Sciences, 46), Göteborg: Acta Universitatis Gothoburgensis.

Prawat, R.S. (1992) 'Teachers' beliefs about teaching and learning: a constructivist perspective', American Journal of Education, May: 354-95.

Pressley, M. and Ahmad, M. (1986) 'Transfer of imagery based mnemonics by adult learners', Contemporary Educational Psychology, 11(2): 150-60.

Prosser, M. and Trigwell, K. (1999) Understanding Learning and Teaching: The Experience in Higher Education, Buckingham: SRHE and Open University Press.

Punzo, V.A. (1996) 'After Kohlberg: virtue ethics and the recovery of the moral self', Philosophical Psychology, 9(1): 7-23.

Putnam, R.T. and Borko, H. (2000) 'What do new ideas of knowledge and thinking have to say about research on teacher learning?', Educational Researcher, 29(1): 4-15.

Quality Assurance Agency for Higher Education (1999) Code of Practice for the Assurance of Academic Quality and Standards in Higher Education: Postgraduate Research Programmes, Gloucester: Quality Assurance Agency for Higher Education.

Quality Assurance Agency for Higher Education (2000) Framework for Awards in Higher Education, Gloucester: Quality Assurance Agency for Higher Education.

Rappaport, L., Baumgardner, S. and Boone, G. (1999) 'Postmodern culture and the plural self', in J. Rowan and M. Cooper (eds) The Plural Self: Multiplicity in the Everyday Life (pp. 93-106), London: Sage Publications.

Reid, A., McCallum, F. and Dobbins, R. (1998) 'Teachers as political actors', Asia Pacific Journal of Teacher Education, 26(3): 247-59.

Reimers, F. (1994) 'Education and structural adjustment in Latin America and subSaharan Africa', International Journal of Educational Development, 14(2): 119-29.

Reiser, R.A. (1982) 'Improving the research skills of instructional designers', Educational Technology, 22: 19-21.

Renkema, J. (1980) Schrijfwijzer. Handboek voor duidelijk taalgebruik. The Hague: Staatsdrukkerij.

Rényi, J. (1998) 'Building learning into the teaching job', Educational Leadership, 55(5), February: 70-4.

Resnick, L.B. (1983) 'Toward a cognitive theory of instruction', in S.G. Paris, G.M. Olson and H.W. Stevenson (eds) Learning and Motivation in the Classroom, Hillsdale, NJ: Prentice-Hall.

Richards, R.T. (1988) 'Thesis/dissertation writing for EFL students: an ESP course design', English for Specific Purposes, 7: 171-80.

Richardson, J.T. (1995) 'Mature students in higher education. An investigation of approaches to studying and academic performance', Studies in Higher Education, 20(1): 5-17.

Riel, M. and Becker, H. (2000) 'The beliefs, practices and computer use of teacher leaders', Paper presented at the AERA, New Orleans, 26 April. On-line. Available: http://www.crito.uci.edu/TLC.

Riner, P.S. (1983) 'Establishing scientific methodology with elementary gifted children through field biology', GCT, 28: 46-9. 
Rivera-Batiz, F.L. and Marti, L. (1995) A School System at Risk: A Study of the Consequences of Overcrowding in New York City Schools, New York: Institute for Urban and Minority Education Research Report No. 95-1.

Robertsson Hörberg, C. (1997) Lärares kunskapsutnyttjande i praktiken. Ett personligt och kontextuellt perspektiv på vardagskunskap och forskning (Linköping Studies in Education and Psychology, 53), Linköping: Linköping University, Department of Education and Psychology.

Rogers, C.M. and Wrightsman, L.S. (1978) 'Attitudes towards children's rights: nurturance or self-determination', Journal of Social Issues, 34(2): 59-69.

Rosebery, A.S. and Warren, B. (1998) 'Interanimation among discourses: one approach to studying learning in teacher research communities', Paper presented at the annual meeting of the American Educational Research Association, San Diego, CA.

Rosenholtz, S. (1989) Teachers' Workplace: The Social Organisation of Schools, New York: Longman.

Rovie-Johansson, A. (1999) Being Good at Teaching. Exploring Different Ways of Handling the Same Subject in Higher Education, Sweden: Göteborg Studies in Educational Sciences, 140.

Rudd, E. (1985) A New Look at Postgraduate Failure, Guilford: SRHE and NFERNelson.

Russell, T. (1999) The challenge of change in teaching and teacher education', in J.R. Baird (ed.) Reflecting, Teaching, Learning. Perspectives on Educational Improvement (pp. 219-38), Cheltenham, VIC: Hawker Brownlow Education.

Russell, T. (2001) 'Radical programme change in preservice teacher education: What and how we learn from personal and institutional experience', Paper presented at the American Education Research Association, Seattle.

Russell, T. and McPherson, S. (2001) 'Indicators of success in teacher education: A review and analysis of recent research', Paper presented at the Pan-Canadian Education Research Agenda (PCERA) Symposium on Teacher Education/ Educator Training, Quebec, Canada.

Sachs, J. (2000) 'Rethinking the practice of teacher professionalism', in C. Day, A. Fernandez, T.E. Hauge and J. Moller (eds) The Life and Work of Teachers, London: Falmer Press.

Sacks, H., Schegloff, E.A. and Jefferson, G. (1974) 'A simplest semantics for organization of turn-taking in conversation', Language, 50: 696-735.

Sagadin, J. (1991) 'Kvalitativno empirièno pedagoško raziskovanje', Sodobna pedagogika, 40(7-8): 343-55.

Sarason, S.B. (1993) The Case for Change: Rethinking the Preparation of Educators, San Francisco, CA: Jossey-Bass.

Sarason, S.B. (1997) How Schools Might be Governed and Why, New York: Teachers College Press.

Satchell, S. and Booth, A. (1996) 'British PhD completion rates: some evidence from the 1980s', Higher Education Review, 28(2): 48-56.

Scenters-Zapico, J.T. (1987) 'From oral communication skills to research skills', English Journal, 76: 69-70.

Schegloff, E.A. (1992) On talk and its institutional occasions', in P. Drew and J. Heritage (eds) Talk at Work (pp. 101-34), Cambridge: Cambridge University Press. 
Schellekens, H. (1995) Academische vaardigheden. Vormgeving en toetsing, Tilburg: Katholieke Universiteit Brabant.

Schön, D. (1983) The Reflective Practitioner: How Professionals Think in Action, New York: Basic Books.

Schön, D. (1995) 'Knowing-in-action: the new scholarship requires a new epistemology', Change, November/December: 27-35.

Schulmeister, R. (2002) Lernplattformen für das virtuelle Lernen. Evaluation und Didaktik (Learning Platforms for Virtual Learning. Evaluation and Didactics) Munich: Oldenbourg.

Schultz, R., Schroeder, D. and Brody, C. (1997) 'Collaborative inquiry: fidelity and the ethics of caring in teacher research', Qualitative Studies in Education, 10: 473-85.

Schutz A. (1967) The Phenomenology of the Social World, Evanston, IL: Northwestern University Press.

Schwab, J.J. (1973) 'The practical 3: translation into curriculum', Elementary School Journal, August: $501-22$.

Schwegler, R.A. and Shamoon, L.K. (1982) 'The aims and process of the research paper', College English, 44: 817-24.

Seixas, P. (1993) 'The community of inquiry as a basis for knowledge and learning: the case of history', American Educational Research Journal, 30(2): 305-24.

Shamoon, L. and Schwegler, R.A. (1982) 'Teaching the research paper: a new approach to an old problem', Freshman English News, 11: 14-17.

Sherman, N. (1989) The Fabric of Character: Aristotle's Theory of Virtue, Oxford: Clarendon Press.

Shotter, J. (1993) Conversational Realities: Constructing Life Through Language. London: Sage.

Shuell, T. (1986) 'Cognitive conceptions of learning', Review of Educational Research, 56(4): 411-36.

Shulman, L. (2000) 'From Minsk to Pinsk: why a scholarship of teaching and learning', The Journal of Scholarship of Teaching and Learning, 1(1): 48-52.

Shulman, L.S. (1987) 'Knowledge and teaching: foundations of the new reform', Harvard Educational Review, 57(1): 1-22.

Shulman, L.S. and Shulman, J.H. (2004) 'How and what teachers learn: a shifting perspective', Journal of Curriculum Studies, 36(2): 257-71.

Siegel, S. and Castellan, N.J. (1988) Nonparametric Statistics for the Behavioral Sciences, New York: McGraw-Hill.

Simon, R.I. (1992) Teaching Against the Grain: Texts for a Pedagogy of Possibility, Westport, CT: Greenwood.

Skolverket (1999) Ständigt Alltid (Constantly Always), Stockholm: Liber Distribution.

Smeyers, P. (1995) 'On the unavoidability of power in child-rearing: is the language of rights educationally appropriate?', Studies in Philosophy and Education, 14 (1): 9-21.

Smith, G.H. (1999) 'Paulo Friere: lessons in transformative praxis', in P. Roberts (ed.) Paulo Friere, Politics and Pedagogy: Reflections from Aotearoa-New Zealand (pp. 35-42), Palmerston North, New Zealand: Dunmore Press.

Smith, M.W. and Hillocks, G. (1989) 'What inquiring writers need to know', English Journal, 78(2): 58-63. 
Smith, R. (2000) 'The future of teacher education: principles and prospects', Asia Pacific Journal of Teacher Education, 28(1): 7-28.

Smithrim, K. (2000) 'Who will teach?', in R. Upitis (ed.) Who Will Teach? A Case Study of Teacher Education Reform (pp. 13-25), San Francisco, CA: Caddo Gap Press.

Smyth, J., Dow, A., Hattam, R., Reid, A. and Schacklock, G. (2000) Teachers' Work in a Globalizing Economy, London: Falmer Press.

Snowman, J. (1986) 'Learning tactics and strategies', in C.D. Phye and T. Andre (eds) Cognitive Classroom Learning: Understanding Thinking and Problem Solving (pp. 243-75), New York: Academic Press.

Soares, A.P. (1998) 'Desenvolvimento de jovens adultos: a exploração, a indecisão e o ajustamento vocacional em estudantes universitários', Braga: Universidade do Minho (Dissertação de Mestrado).

Sørlie, M.A. (1998) Liv og leven i skolen. NOVA Rapport 12b/1998 (Life and commotion in school: NOVA's report 12b/98) Oslo: Norsk institutt for forskning om oppvekst, velferd og aldring (The Norwegian Institute of Growth, Welfare, and Aging).

Statens Offentliga Utredningar (SOU) 1999:63 (1999) Att lära och leda: En lärarutbildning för samverkan och utveckling, Stockholm: Utbildningsdepartementet.

Statistics Canada (1999) The Survey of Intellectual Property Commercialization in the Higher Education Sector. CAT. No. 88F0006XIB-0001, Ottawa, Canada: Statistics Canada.

Steehouder, M.F., Jansen, C., Maat K., van der Staak, J. and Woudstra, E. (1992) Leren Communiceren. Procedures voor Mondelinge en Schriftelijke Communicatie, Groningen: Wolters-Noordhoff.

Šteh Kure, B. (2000) 'Kakovost uèenja in pouèevanja v okviru gimnazijskega programa', doctoral dissertation. Ljubljana: University in Ljubljana, Faculty of Arts, Department of Psychology.

Šteh Kure, B. and Marentiè Požarnik, B. (1998) "Portraits" of secondary school teachers - their mental models of teaching and perception of context', Paper presented at the European Conference on Education Research (ECER), Ljubljana, Slovenia.

Stein, M.K., Silver, E.A. and Smith, M.S. (1998) 'Mathematics reform and teacher development: a community of practice perspective', in J. Greeno and S. Goldman (eds) Thinking Practices, Hillsdale, NJ: Lawrence Erlbaum.

Sternberg, D. (1981) How to Complete and Survive a Doctoral Dissertation, New York: St Martins Press.

Stoan, S.K. (1984) 'Research and library skills: an analysis and interpretation', Collegeand-Research-Libraries, 45: 99-109.

Stokes, L. (2001) 'Lessons from an inquiring school: Forms of inquiry and conditions for teacher learning', in A. Lieberman and L. Miller (eds) Teachers Caught in the Action: Professional Development that Matters (pp. 141-58), New York: Teachers College Press.

Stoll, L. and Fink, D. (1996) Changing our Schools: Linking School-effectiveness and School Improvement, Buckingham: Open University Press.

Stone, E. (1992) Quality Teaching: A Sample of Cases, London: Routledge. 
Strauman, T. (1996) 'Stability within the self: a longitudinal study of the structural implications of self-discrepancy theory', Journal of Personality and Social Psychology, 71(6): 1142-53.

Strike, K. and Soltis, J.F. (1998) The Ethics of Teaching, New York: Teachers College, Columbia University.

Strike, K.A. (1996) 'The moral responsibilities of educators', in J. Sikola, T.J. Buttery and E. Guyton (eds) Handbook of Research on Teacher Education, 2nd edn, New York: Macmillan.

Swanborn, P.G. (1972) Aspecten van sociologisch onderzoek, Meppel: Boom.

Swanborn, P.G. (1981) Methoden van sociaal-wetenschappelijk onderzoek. Inleiding in ontwerpstrategieën, Meppel: Boom.

Swanborn, P.G. (1987) 'Vormen van verklaren', Sociologische Gids, 34: 408-19.

Swanborn, P.G. (1989) Kleine catechismus van de probleemstelling, Leiden: PAOS/ Utrecht: Rijksuniversiteit Utrecht/Groningen: Rijksuniversiteit Groningen.

Swanborn, P.G. (1990) 'De probleemstelling, in het bijzonder bij interpretatief onderzoek', Sociologische Gids, 107-23.

Swanborn, P.G. (1991) Basisboek sociaal onderzoek, Meppel: Boom.

Swanborn, P.G. and Zijl, P.J.M. (1984) 'Interactionists do it only symbolically', Mens en Maatschappij, 59: 142-64.

Swedish National Agency of Education (SNAE) (1999) Constantly. Always! (Ständigt. Alltid!) Stockholm: Liber Distribution.

Sykes, P., Measor, L. and Woods, P. (1985) Teacher Careers, Crises, and Continuities, London: Falmer Press.

Talbert, J. (1995) 'Boundaries of teachers' professional communities in US high schools: power and precariousness of the subject department', in L.S. Siskin and J.W. Little (eds) The Subjects in Question: Departmental Organization and the High School (pp. 68-94), New York: Teachers College Press.

Tappan, M.B. (1991) 'Narrative, language, and moral experience', Journal of Moral Education, 20(3): 243-56.

Tavares, J., Santiago, R.A., Taveira, M.C., Lencastre, L. and Gonçalves, F.R. (2000) Transição para o ensino superior, Braga: Universidade do Minho.

Tedesco, J.C. (1997) 'Enhancing the role of teachers', in C. Day, D. van Veen and S. Wong-Kooi (eds) Teachers and Teaching: International Perspectives on School Reform and Teacher Education, Leuven/Apeldoorn: Garant.

Telhaug, A.O. (1995) Reform 97-planen om 10-årig grunnskole i samtidshistorisk belysning (Reform-97-proposal of the 10 years' compulsory school in contemporary historical elucidation), Norsk pedagogisk tidskrift, 6: 279-95.

Terhart, E. (2000) Perspektiven der Lehrerbildung in Deutschland. Abschlußbericht der von der Kultusministerkonferenz eingesetzten Kommission (Perspectives of Teacher Education in Germany), Final Report of the Commission of the Conference of Ministries for Culture, Weinheim: Beltz.

Tilanus, C.B. (1978) Een scriptie/rapport/artikel schrijven, Utrecht: Spectrum Aula.

Tinkler, P. and Jackson, C. (2000) 'Examining the doctorate: Institutional policy and the $\mathrm{PhD}$ examination process in the UK', Studies in Higher Education, 25(2): $167-80$.

Todd, S. (2001) “"Bringing more than I contain": Ethics, curriculum and the pedagogical demand for altered egos', Journal of Curriculum Studies, 33: 431-50. 
Toole, J. (2000) 'Framing the role of trust in school reform: Case studies of service learning', Paper presented at the annual meeting of the American Educational Research Association, New Orleans, April.

Toulmin, S. (1972) Human Understanding: The Collective Use and Evolution of Concepts, Princeton, NJ: Princeton University Press.

Transcript (1993) Een onderzoeksplan schrijven, Bussum: Coutinho.

Travers, C.J. and Cooper, C.L. (1996) Teachers under Pressure: Stress in the Teaching Profession, London: Routledge.

Trigwell, K., Prosser, M. and Waterhouse, F. (1999) 'Relations between teachers' approaches to teaching and students' approaches to learning', Higher Education, 37(1): $57-70$.

Tschannen-Moran, M. and Hoy, W. (1998) 'Trust in schools: a conceptual and empirical analysis', Journal of Educational Administration, 36: 334-52.

Tumblin, A. and Gholson, B. (1981) 'Hypothesis theory and the development of conceptual learning', Psychological Bulletin, 90: 102-24.

Ultee, W.C. (1977) 'Groei van kennis en stagnatie in de sociologie. Een aantal regels van de methode en een kritische doorlichting van enkele sociologische tradities, dissertation, Rijksuniversiteit Utrecht.

Undervisningsministeriet (1995) Act on the Folkskole. The Danish Primary and Lower Secondary School. On-line. Available: http://www.uvm.dk/eng/publications/ laws/actonthe.htm.

UNESCO (1996) Enhancing the Role of Teachers in a Changing World. ED/BIE/ CONFINTED 45/Info 10, International Conference on Education, 45th session, Geneva 30 Sept-5 October.

Valadas, S. (2001) 'Students learning approaches and academic achievement at the University of Algarve', unpublished master dissertation, University of Algarve, Faro, Portugal.

van Maanen, J. and Barley, S.R. (1984) 'Occupational communities: culture and control in organizations', Research in Organisational Behavior, 6: 287-365.

van Manen, M. (1990) Researching Lived Experience, Human Science for an Action Sensitive Pedagogy, New York: The University of New York.

van Manen, M. and Li, S. (2002) 'The pathic principle of pedagogical language', Teaching and Teacher Education, 18: 215-24.

Vanderlocht, M. and Damme, J. van (1989) 'Probleemaanpak en het oplossen van natuurkundige problemen', Pedagogische Studiën, 66: 97-106.

Vanderlocht, M. and Damme, J. van (1990) 'Kennis en het oplossen van natuurkundige problemen. Enkele aandachtspunten voor de onderwijspraktijk', Pedagogische Studiën, 67: 70-81.

Vavrus, M. (in press)' Successful teacher education programs in the era of reform: an essay review of studies in excellence in teacher education', Teacher and Teacher Education.

Verschuren, P.J.M. (1986) De probleemstelling voor een onderzoek, Utrecht: Spectrum Aula.

Vestager, M. (2000) Values in Practice On-line. Available: http://www.uvm.dk/pub. Undervisningsministeriet.

Villa, A. and Calvete, E. (2001) 'Development of the teacher self-concept evaluation scale and its relation to burnout', Studies in Educational Evaluation, 27: 23955. 
von Glasersfeld, E. (1995) ‘A constructivist approach to teaching', in L.P. Steffe and J. Gale (eds) Constructivism in Education (pp. 3-15), Hillsdale, NJ: Erlbaum.

Vries, G. de (1985) De ontwikkeling van wetenschap. Een inleiding in de wetenschapsfilosofie, Groningen: Wolters-Noordhoff.

Vught, F.A. van (1997) 'Academische vorming: over experts en intellectuelen', Liberaal Reveil, 38, 254-8.

Vygotsky, L.S. (1978) Mind in society. The development of higher psychological processes. Cambridge, MA: Harvard University Press.

Walker, K. (1998) 'Jurisprudential and ethical perspectives on "the best interests of children", Interchange, 29: 287-308.

Walker, M. (1996) "'Subaltern" professionals: acting in pursuit of social justice', Educational Action Research, 4: 407-28.

Weinstein, C.E. and Mayer, R.E. (1986) 'The teaching of learning strategies', in M.C. Wittrock (ed.) Handbook of Research on Teaching, New York: Macmillan.

Welchman, J. (1995) Dewey's Ethical Thought, Ithaca, NY: Cornell University Press.

Wenger, E. (1998) Communities of Practice: Learning, Meaning and Identity, Cambridge: Cambridge University Press.

Wertsch, J.V. (1984) 'The zone of proximal development: some conceptual issues', in B. Rogoff and J.V. Wertsch (eds) Children's Learning in the "Zone of Proximal Development" (pp. 7-18), San Francisco, CA: Jossey-Bass.

Wertsch, J.V. (1991) Voices of the Mind. A Sociocultural Approach to Mediated Action, Cambridge, MA: Harvard University Press.

Wertsch, J.V. (1998) Mind as Action, New York: Oxford University Press.

Westheimer, J. (1998) Among Schoolteachers: Community, Autonomy and Ideology in Teachers' Work, New York: Teachers College Press.

Wetenschappelijke Raad voor het Regeringsbeleid (WRR) (1995) Hoger Onderwijs in Fasen, Report 1995-47 of the Wetenschappelijke Raad voor het Regeringsbeleid (WRR), The Hague: Sdu-uitgeverij.

Whelan, K.K., Huber, J., Rose, C., Davies, A. and Clandinin, D.J. (2001) 'Telling and retelling our stories on the professional knowledge landscape', Teachers and Teaching: Theory and Practice, 7(2): 143-56.

White, S.K. (1991) Political Theory and Postmodernism, Cambridge: Cambridge University Press.

Williams, K. (1998) 'Education and human diversity: the ethics of separate schooling revisited', British Journal of Educational Studies, 46(1): 26-39.

Willman, A. (2001) 'The conflicting discourses of collaboration: a discourse analysis approach to teachers' interpretations of team work', Paper presented at the biannual conference of the International Study Association on Teachers and Teaching (ISATT), Faro, Portugal.

Wilson, M. (1994) 'Community of judgment: a teacher-centered approach to educational accountability', in Office of Technology Assessment (eds) Issues in Educational Accountability, Washington, DC: Office of Technology Assessment, United States Congress.

Wilson, S.M. and Berne, J. (1999) 'Teacher learning and the acquisition of professional knowledge: an examination of research on contemporary professional development', Review of Research in Education, 24: 173-209.

Wood, D., Bruner, J.S. and Ross, G. (1976) 'The role of tutoring in problem solving', Journal of Child Psychology and Psychiatry, 17: 89-100. 
Woods, P. (1979) The Divided School, London: Routledge and Kegan Paul.

Woods, P. (1980) 'Strategies in teaching and learning', in P. Woods (ed.) Teacher Strategies: Explorations in the Sociology of the School (pp. 18-33), London: Croom Helm.

Woods, P. (1984) 'Staffroom humour', in A. Hargreaves and P. Woods (eds) Classrooms and Staffrooms: The Sociology of Teachers and Teaching (pp. 190-202), Milton Keynes: Open University Press.

Woods, P. (1992) 'Symbolic interactionism: theory and method', in: M. LeCompte, M. Millroy and J. Preissle (eds) The Handbook of Qualitative Research in Education (pp. 337-404), San Diego, CA: Harcourt Brace.

Woods, P. (1993a) Critical Events in Teaching and Learning, London: Falmer Press.

Woods, P. (1993b) 'Critical events in education', British Journal of Sociology, 14: 35573.

Wortham, S. (2001) Narratives in Action. A Strategy for Research and Analysis, New York and London: Teachers College Press, Columbia University.

Wragg, E.C. (1994) An Introduction to Classroom Observation, London and New York: Routledge.

Wubbels, T. (1992) 'Taking account of student teachers' preconceptions', Teaching and Teacher Education, 8(2): 137-49.

Zackari, G. and Modigh, F. (2000) Värdegrundsboken-Om samtal för demokrati (The Book of the Value Foundation -- Dialogue for Democracy), Stockholm: Utbildningsdepartementet.

Zeichner, K.M. (1995) 'Beyond the divide of teacher research and academic research', Teachers and Teaching, 1: 153-72.

Zeuli, J.S. (1996) 'Using research as a substitute for practical judgement: response to John Eisenberg's', The Limits of Educational Research, Curriculum Inquiry, 26: 175-9.

Zimmerman, B.J. and Martinez-Pons, M. (1986) 'Development of a structured interview for assessing student use of self-regulated learning strategies', American Educational Research Journal, 73: 614-28.

Zimmerman, B.J. and Martinez-Pons, M. (1990) 'Student differences in self-regulated learning: Related grade, sex, and giftedness to self-efficacy and strategy use', Journal of Educational Psychology, 82: 51-9.

Zuckerman, J. (1999) 'Student science teachers constructing practical knowledge from inservice science supervisors' stories', Journal of Science Teacher Education, 10(3): $235-45$. 


\section{Index}

Aarsæther, F. 79

abandonment 119, 163, 233

abstraction 44, 80, 84, 90, 128, 192, 217, 228

academic motivation $109,114,118-19$

acceptance 178,190

accountability 20,83, 126, 129, 132, 134, $143,156,165$

Achinstein, B. 51

Acker, S. 143

action research $17,18,40,153,167,168$, 179,180

actualisation 199, 206

adaptation 109-10, 189

affordance 53, 57, 61

Aguin, I.P. 111

Aguirre, J. 52, 73

Ahmad, M. 110

Alexander, T.M. 215-16

alienation 155,166

Almeida, L.S. 118

Almen, E. 155

Anderson, R.E. 178

Anderson, S. 206

Angelides, P. 195

Ansell, E. 57

Apple, M. 12, 13, 15

apprenticeship 26-7, 55, 70, 135-7, 143, 156

Argyris, C. 160

Arias, A. 111

Aristotle 81, 84-5, 190

Askling, B. 155

assimilation 77

Atkinson, E. 17

attribution: of academic failure 109, 114-15

Audi, R. 84

authenticity $34,46,100,141,145,181,208$

auto/biography see narrative

autonomy $11,17,156,186,188-9$

Avalos, B. 39

Azcárate, P. 33

Backman, C.W. 202, 204

Baker, R. 109, 118

Bakhtin, M.M. 94-97, 233

Ball, D.L. 53

Ball, S. 10

Banaji, M. 199-200
Barley, S.R. 53, 55

Barone, D.F. 199

Barton, L. 18-20

basic values $75-7,79-81$

Bauer, M. 224-5

Baumgardner, S. 100

Baumrind, D. 189

Beane, J. 12, 13, 15

Beattie, M. 135, 137

Becher, T. 150, 166

Becker, H.A. 177-8

behavioural symptoms 109, 113

Behrend, J. 57

Bengtsson, J. 24

Benner, P. 160

Ben-Peretz, M. 53, 134

Berne, J. 52

Bigelow, J. 188

Biggs, J.B. 29, 99, 110-11, 119

Birenbaum, M. 110

Black, A. 100

Black, E. 143

Bloom, B.S. 29

Bobbio, N. 185

Bonamy, J. 180

Boone, G. 100

Booth, A. 143

Booth, S. 23, 28, 110

Borko, H. 231

Bornat, J. 226

Boulding, E. 187

Boulton-Lewis, G. 103

Bowker, G.C. 56

Brameld, T. 82

Brandes, G.M. 57

Brannigan, G.C. 225

Brehm, S. 199, 204

Brehony, K.J. 146

Breuleux, A. 182

Britt Postholm, M. 95

Britzman, D.P. 134,160

Brody, C. 195

Brown, J. 134, 135

Brown, L.M. 87

Brownlee, J. 103

Bruner, J. 94, 95, 223

Bryk, S. 156 
Buchberger, F. 182

Bullough, R.V. 134,137,141

Burnett, P.C. 103

burnout 7, 163

Butler, J. 174

Cabanach, R.G. 111

Calvete, E. 200

Campbell, J. 103, 188

Campbell, R. 156

Carbone, L. 55-6

Carpenter, T.P. 57

Carrington, S. 103

Carter, G. 34

Casey, C. 10

Castells, M. 8

Chakravarti, A.K. 209

Chamberlayne, P. 226

Chemers, M.M. 110

Childs, A. 100

Chwalek, A.R. 213

citizenship 33, 35, 79, 184, 185, 214, 219

Claesson, S. 22, 24

Claeys, C. 177

Clark, E.M. 57, 160

Clandinin, D.J. 194, 196, 225, 235

Clark, E. 163

co-construction $62,64,72,122,127$

Cochran-Smith, M. 209, 229-32, 235

Cohen, D.K. 53

Cole, A.L. 134, 158

Cole, M. 98

Coleman, J.C. 189

collective capacity 13,51

Collins, H.M. 55-6

Collins, K.F. 29

complexity 150, 155; of academic success

110 , of identity $9,13,15,161$; of teaching/learning 162, 188, 194, 196

commodification of education 126,130 , 132-3

communitarianism $75,78-9$

conceptualisation 40,52, 167, 192

Connelly, F.M. 194, 196, 225

consistency 62, 210; conceptual analysis

210, 212-3; departmental 59-60;

institutional 143; as shared value of

democracy 221

constructivism $22-9$

control 20, 189, 193, 204, 233; authoritarian

189; autocratic 186; bureaucratic 156 ;

managerial 10-11, quality $40-1,43,213$ copyright 121,130

Cooper, C.L. 163

co-operation $105,179,219,220$

corporatisation, of universities 125, 132

counsel 101, 132, 208

Coulter, D. $234-5$

Convey, J.J. 213

creativity 60,233

Cresswell, J.W. 224

critical theory perspective 133

Crowley, C.M. 111

Cryer, P. 143

Cuban, L. 166, 169

curricular reform 99,187

Czarniawska, B. 15

Dadds, M. 234

Daniels, H. 188

Darling-Hammond, L. 155

Davies, A. 235

Day, C. $156,160,165-6,168-70$

De Jong, J. 209

decontextualisation $70,71,169,229$

Deem, R. 146

Delamont, S. 143

Demo, D. 200

democracy $76-80$; in education $12-15,21$, $182-4,186$; in university 129

democratic structure 12,185 ; values 214-22

Denicolo, P.M. 143

Denzin, N. 195, 196, 201

Dewey, J. 12, 80, 26, 136-8, 215-22

Depold, E. 87

dichotomy $31,86,122,134$

dignity 13,78

Dillemans, R. 177

discovery $131,132,147,161,162$

dissonance 89,233

divergence $220,230,232$

diversity $31,42,77,144-9,181,217,222$

Dobbins, R. 17

Dodds, S. 188

Doeke, B. 134, 135

Dolk, M. 106

doorkeeping see gatekeeping

Dow, A. 10

Doyle, W. 160

Drew, P. 55

Dreyfus, H.L. 174

Dreyfus, S.E. 174

Driscoll, M.E. 156 
Du Gay, P. 10

Duit, R. 22

Dunne, J. 86

educational bureaucracy $10,11,129$

Elbaz-Luwisch, F. 225-6, 234

Elbaz, F. see also Elbaz-Luwisch, F.

Elen, J. 177

Elliott, J. 42, 161, 165, 167, 169

emancipation 13, 14, 46, 78-9, 168, 189, 223

empowerment 44, 86, 121, 206, 228, 232

Empson, S.B. 57

Engelsen, B.U. 78

Engestrom, Y. 55

Englund, T. 28, 82

enthusiasm 88, 133, 140, 145, 230

Epstein, A. 9

Erickson, G. 182

essentialism 80,81

Ethell, R.G. 134, 135, 137

ethnography 52,181

ethnomethodology 74

Ewing, R. 18

expert $11,157,160,162,173-5$; theory 209 , 213

Farber, B. 164

Fauvel, J. 134

Featherstone, D. 138

Featherstone, H.J. 52

Fein, S. 199, 204

Fennema, E. 57

Fenstermacher, G.D. 85-6

Fergusson, R. 11

Ferreira, J.A. 118

Finnegan, R. 134

Fischer, K.W. 191

Flanagan, F. M. 184

Flem, A. 92, 93, 98

flexibility $85,110,119,156,177,196,200$

Florio-Ruane, S. 57

frameworks 41, 193, 235

Franke, M.L. 57

freedom: academic 121, 127-8, 157; of choice 29; as ideal 75-6, 78, 132, 187, 190,196

Freidson, E. 157

Freire, P. 137-8, 234

Fullan, M. 43, 134, 161

Furlong, J. 18-20

Gabriele, A. 34
Gaden, G. 187

Garcia, B.F. 110

Garcia, M.S. 110

García Díaz, J.E. 32

gatekeeping 127, 131, 145, 176

Gearhart, M. 57, 73

Geertz, C. 95

Gerdes, H. 110

Gergen, K. 14

Gergen, M. 14

Gibson, J.J. 57

Gilligan, C. 87

Gitlin, A. 134,137,141

Goble, N.M 223

Gonçalves, F.R. 109, 110, 118

Gonzalez Pienda, J.A. 110

Gonzalez Pumariega, S. 110

Goodlad, J. 134

Goodson, I. 162, 165-6, 169, 224

Gouinlock, J. 217-19

Gow, L. 100

Green, H. 145, 146

Greene, M. 229, 234

Greenfield, T. 126

Greeno, J.G. 57

Grossman, P. 51, 57

Grumet, M. 195

Gudmundsdottir, S. 92, 93, 95, 98, 225

Gumperz, J. 74

Gusfield, J. 54

Guskey, T.R. 154, 156

Gustavsson, B. 78

Gutierrez, R. 51

Gutmann, A. 188

Habermas, J. 221

Haigh, N. 171-3

Halliburton, D. 138

Halliday, T.C. 157

Hamilton, D. 83

Hammersley, M. 53

Hargreaves, A. 12, 156, 161

Hargreaves, D. 169, 200

Harland, J. 160

Harris, A. 156

Hart, R.A. 190

Hart, S. 234

Harter, S. 201

Hartley, J. 147, 148

Hativa, N. 110

Hattam, R. 10

Have, P. 74 
Hayes, H.E. 231

Hayward, G. 100

Healey, M. 174

Heath, C. 55

Heathcote, D. 98

Helsby, G. 158

Heritage, J. 55

Hernandez, N. 209

heuristics 53, 57, 200

Hextall, I. 16

Hickman, L.A. 215-16

Higgins, E. 200, 206

Higgins, J.S. 209

Hill, T. 143

Hillocks, G. 209

Hindmarsh, J. 55

Hinkley, K. 206

Hockey, J. 143

holism 29, 30, 101

Holquist, M. 95

hooks, b. 137-8

Horn, I.S. 56, 73

Hoy, W. 194

Hu, L.T. 110

Huber, J. 235

Huber, M. 174

Huber, R.M. 122, 123

Huberman, M. 73, 101, 127-8, 131-2, $153-4,159-64,169-70$

Husserl, E. 24

Husu, J. 83

Hutchings, P. 173

Hutchins, E. 55, 74

Hymes, D. 74

ICT (information communication technology) $42,125,160,182,213$

individualism 12,177

intellectual property $120-124,130$

interactivity $44,99,104,168,177,188,213$

interplay 43, 73, 94-7, 110, 206, 207

interrelations 84, 183, 208, 224

intersubjectivity $94,96,127$

IT (information technology) see ICT

Jackson, C.144 6

Jackson, P.W. 87

Jacobs, V.R. 57

Jefferson, G. 74

Jeffs, T. 186

Jones, M. 34

Jongepier, P. 209
Joram, E. 34

Jory, S. 148

Jovchelovitch, S. 244-5

Joyce, B. 27

Kagan, D.M. 134, 137

Kassin, S. 199, 204

Katterns, R. 173

Kelchtermans, G. 159, 192, 194, 224

Kember, D. 100, 110, 111

Kessels, J. 23, 134

Kissock, C. 182

Kinder, K. 160

Kjolseth, R. 74

Knight, P. 158

knowledge: experiential 18, 31, 34; formal 31,86 ; personal practical 173,175 ; practical $32,147,174-5$; professional 17 , 19, 31-5, 38, 41, 87; prepositional 86; scientific $35-8$; society 79

Knowles, J.G. 134

Knowles, M.S. 143

Kohlberg, L. 128

Kolontai, Z. 182

Kompf, M. 127

Kondo, D. 9

Korthagen, F.A.J. 23, 106, 134, 137

Krathwohl, D.R. 29

Kruse, S.D. 51, 52, 72

Kuhn, T. 126

Kukkonen, M. 199, 202

Kurina, L. 100

Kvale, S. 224, 225

Labaree, D. 166-7

Laferrière, T. 178, 182

Lagerwaard, H. 213

Lagerwerf, B. 23, 106

Lagrosen, S. 218

Lampert, M. 74

Lang, M. 178, 180, 182

Lauriala, A. 199, 202, 206

Lave, J. 23, 54-6, 70

learning community $54,58,61,64,66,179$

learning trajectory, 9

Lencastre, L. 110, 119

Leung, D. 110, 111

Levi, L. 57

Levin, B. 134, 160

Li, S. 24, 29

liberal universalism $75,78,79$

Lieberman, A. 57, 161 
Liston, D. 16-17

Little, J.W. 51, 52, 55, 57, 71, 72, 156, 161, 167,178

Lodge, A. 184, 186

Long, T.J. 213

Lortie, D. 135

Loughran, J. 134, 135, 228

Louis, K.S. 51, 52, 72

Løvilie, L. 78

Lowyck, J. 177

Lynch, K. 184, 186

Lytle, S.L. 209, 229-32, 235

Maddux, J.E. 199

Mahony, P. 16

Maitland, G.C. 209

Malin, M. 137-9

Mallinckrodt, B. 110

managerialism 10-13, 15, 21, 162

Mancini, V. 163

Marginson, S. 11

Margulies, P. 179

Marsh, H.W. 200

Marti, L. 163

Martín del Pozo, R. 31, 32, 34

Martinez, S.R. 111

Martinez-Pons, M. 110, 119

Marton, F. 23-4, 27-8, 110-111

Masia, P. 29

Mayer, R.E. 110,119

McCauley, C. 145, 146

McCallum, F. 17

McCullouch, G. 128

McEwan, H. 223, 226

McLaughlin, M.W. 52, 54, 72, 161

McNeil, O. 109, 118

McPherson, S. 134, 135, 137

Mead, G.H. 187, 201

Measor, L. 194

mediation 43, 90, 92, 94, 98

Mehan, H. 56-7

Melucci, A. 9

Menter, I. 10-11

Merleau-Ponty, M. 24

Merrens, M.R. 225

Merriam, S.B. 24

meta-narrative 234

Middleton, D. 55

Miles, M.B. 101, 153, 162, 167, 168

Miles, S. 18-20

Minick, N. 187-8

Modigh, F. 77
Moerman, M. 74

moral code development 75,128 ; moral character $84,85,87,90$; rational 84,87 , 89 ; situational $84,85,87,89$

Moses, I. 213

Mul, J. 213

Munby, H. 138

Murphy, J.P. 215, 221

Muschamp, Y. 10-11

narrative $11,14,45-6,48,154,165,223$, $225-6$

Nash, R. 84

negotiated experience 9

Neo-Pragmatism 82

Neufeld, J. 127

Nias, J. 19, 200

Nicholls, P. 10-11

Niemi, H. 106

Nightingale, P. 213

Noam, G.G. 191

Noddings, N. 138

Noel, J. 84

Noffke, S. 232

Norton, L.S. 111

novice $55,63,160,173-5$

objectivity $216,225,234$

obligations: institutional 89 ; moral 189 ; professional $89,90,189$

Ogden, T. 93

Oost, H. 209, 213

Orlenius, K. 79, 81

Orr, J.E. 55, 74

Ozga, J. 10-11

Palmer, P. 137

Pascarella, E.T. 109, 118

Pargetter, R. 188

Parry, O. 143

Passaro, P.D. 156

Pearson, M. 143

pedagogical ethics $83,84,86,91,125$

Pelikan, J. 170

Pendlebury, S. 85

perennialism 80,81

Perez, J.C. 110, 111

performance of students 61 ; of teachers 110

Perkins, J.D. 209

personal theory 171-6

Peterson, R. 34

Pettersson, T. 92, 93, 98 
Pfeiffer, L.C. 57

Pfund, , H. 22

phenomenography 23-9

phenomenology 24, 29

Phillips, E.M. 213

phronesis 84-6

Pinch, T. 55-6

Polkinghorne, D.E. 202, 223

Pollard, A. 10-11

polyphony 94,97

Ponder, G. 160

Pope, M. 143

Popkewitz, T.S. 54

Porlán, R. 31, 32, 34

Porter, J.F. 223

Postholm, M.B. 98

Powell, S.D. 145, 146

Po•arnik, M. 100

Pramling, I. 23, 27

Prawat, R.S. 137

Prentice, D. 199-200

pre-service programs $134,137,155$; teachers 44-8, 181

Pressley, M. 110

Prior, E. 188

productivity 83,217

professional identity $8-21,139,156,182$, 199-202; activist 15-18, 20, 150; entrepreneurial $8,10,12,14$; orthodox use of 8 professional community 51-2, 54-5, 57, 70, $73,86,169,182$; optimistic premise of 51 professional research $34,35,38$

progressivism 81,82

Prosser, M. 100, 110

Psathas, G. 74

Pugh, D.S. 213

Punzo, V.A. 187

Purdie, N. 103

Putnam, R.T. 231

qualifications $40,143,158,168$

quality assurance 134, 142,144

Raphael, T.E. 57

Rappaport, L. 100

real-life situations 56, 90, 102-4, 213

realities $70,90,156,172,229$

reciprocity $204,220,224$

Reconstructivism 80, 81, 82

reflection, ethical 84,86

reflective practice $83,136,178$; teaching 40 , 179,182
Reid, A. 10, 17

Reimers, F. 39

Rényi, J. 160

Resnick, L.B. 209

Richardson, J.T. 118

Richardson, S.M. 209

Riel, M. 177, 178

Riner, P.S. 209

Riveiro, J.M. 111

Rivera-Batiz, F.L. 163

Rivero, A. 31, 32, 34

Robertsson Hörberg, C. 23

Rogers, C.M. 187

Rose, C. 235

Rosebery, A.S. 57

Rosenholtz, S. 156

Ross, G. 94

Rovie-Johansson, A. 23, 28

Rua, M. 34

Rudd, E. 213

Russell, B. 36

Russell, T. 134, 135, 137, 138, 141

Sachs, J. 20, 21, 161, 167

Sacks, H. 74

Sagadin, J. 100

Santiago, R.A. 110, 119

Sarason, S.B. 134, 186

Satchel, S. 143

satisfaction $38,110,162,164,165$

Saunders, M. 158

scaffolding: conceptual $8,16,178,196$; cultural 92-97

Schacklock, G. 10

Schegloff, E.A. 55, 74

Schön, D.A. 134, 136, 160, 166, 178

Schonmann, S. 53

Schroeder, D. 195

Schulmeister, R. 177

Schultz, R. 195

Schutz, A. 24

Schwab, J.J. 182

self-concept 102; importance 110; language 208; student 199-204, 207; teacher 201

self-determinism 187-90

semiotic mediation 94

Sexias, P. 57

Shaw, M. 145, 146

Sherman, N. 85

Shotter, J. 91

Showers, B. 27

Shuell, T. 111 
Shulman, J.H. 178

Shulman, L. 173, 174

Shulman, L.S. 134,178

Silver, E.A. 57

Simon, R.I. 83, 234

simultaneity 74

Siryk, B. 109, 118

Skolverket 81

Smeyers, P. 186

Smith, D. 18, 103

Smith, G.H. 137-8

Smith, M.S. 57

Smith, M.W. 209

Smith, R. 20

Smithrim, K. 137-8

Smyth, J. 10

Snowman, J. 111

Snyder, C.R. 199

Soares, A.P. 209, 118

socialisation and democracy 185 ; in Norway

93; teacher $11,53,54,132,135,154,161$

socio-culture contexts $23,24,26-9$; theory

92-3

solidarity $11,52,76,214$

Soltis, J.F. 178

Southworth, G. 19

Star, S.L. 56

Statistics Canada 123-4

Steh Kure, B. 100

Stein, M.K. 57

Sternberg, D. 213

Stokes, L. 52, 57

storytelling see narrative

Strauman, T. 200, 206, 207

Strike, K.A. 78,178

survival: organisational 126 , professional

$126,131,132,135,137,161$; skills 189

Sykes, P. 194

symbolic interactionism 200, 201

Talbert, J.E. 52, 54, 72, 161

Tappan, M.B. 187

Tang, C. 111

Taveira, M.C. 110,119

Tavares, J. 110,119

technician, teacher as $7,15,74,134,156$

Tedesco, J.C. 163

Telhaug, E. 77

tenure $125,127,131$

Terenzini, P. 109, 118

Terhart, E. 177

Theory of Variation $22-3,28-30$
Tinkler, P. 144-6

Tiwari, R.C. 209

Todd, S. 84

Toole, J. 194

transformative attitude 13; experience 181; perspective of identity 208 ; praxis 38,54 , $73,127,138$

transparency $55,58,71,142$

Travers, C.J. 163

Treagust, D. 34

Trigwell, K. 100, 110

Tschannen-Moran, M. 194

Tsui, A. 28

UNESCO (United Nations Educational, Scientific and Cultural Organization) 156, 163

Valadas, S. 109, 118

Van Der Perre, G. 177

Van Hout, J.F.M.J. 213

Van Maanen, J. 53

Van Manen, M. 24, 29, 83

Vantine, K. 163

värdegrunden (value foundation) 76

Vavrus, M. 135

Verschuren, P.J.M. 213

Vestager, M. 78

Villa, A. 200

Von Glasersfeld, E. 22

Vygotsky, L.S. 22, 27, 92, 95-7

Walker, K. 85, 86

Walker, M. 170

Warburton, T. 158

Warren, B. 57

Warren Piper, D. 209

Waterhouse, F. 110

Watkins, D. 111

Weinstein, C.E. 110, 119

Welchman, J. 222

Wenger, E. 23, 54-6, 70

Wengraf, T. 226

Wertsch, J.V. 94-7

Westheimer, J. 52, 72

Whelan, K.K. 235

White, S.K. 233-4

Whiting, C. 18-20

Whitty, G. 18-20

Wiel, M. 27

Williams, K. 186

Willman, A. 52 
Wilson, M. 57

Wilson, S.M. 52

Wineburg, S. 51, 57

Wolf, S.A. 57

Wood, D. 57, 94

Woods, P. 53, 161, 194-5, 201-2, 204, 208

Woolworth, S. 51, 57

Wortham, S. 226

Wragg, E.C. 101

Wrightsman, L.S. 187

Wubbels, T. 106, 137
Wuest, D. 163

Yeomans, R. 19

Yinger, R.J. 160

Young, R. 188

Zackari, G. 77

Zeichner, K.M. 16-17, 165, 166, 169, 177

Zeuli, J.S. 169

Zimmerman, B.J. 110, 119

zone of proximal development $23,93,188$ 
